\title{
Kinematics of the central Alpine Fault mylonite zone, Tatare Stream, South Island, New Zealand.
}

Benjamin G. Gillam

\author{
A thesis submitted to \\ Victoria University of Wellington \\ in partial fulfillment of the requirements for the degree of
}

\author{
Master of Science \\ in Geology
}

School of Geography, Environment and Earth Sciences

Victoria University of Wellington 


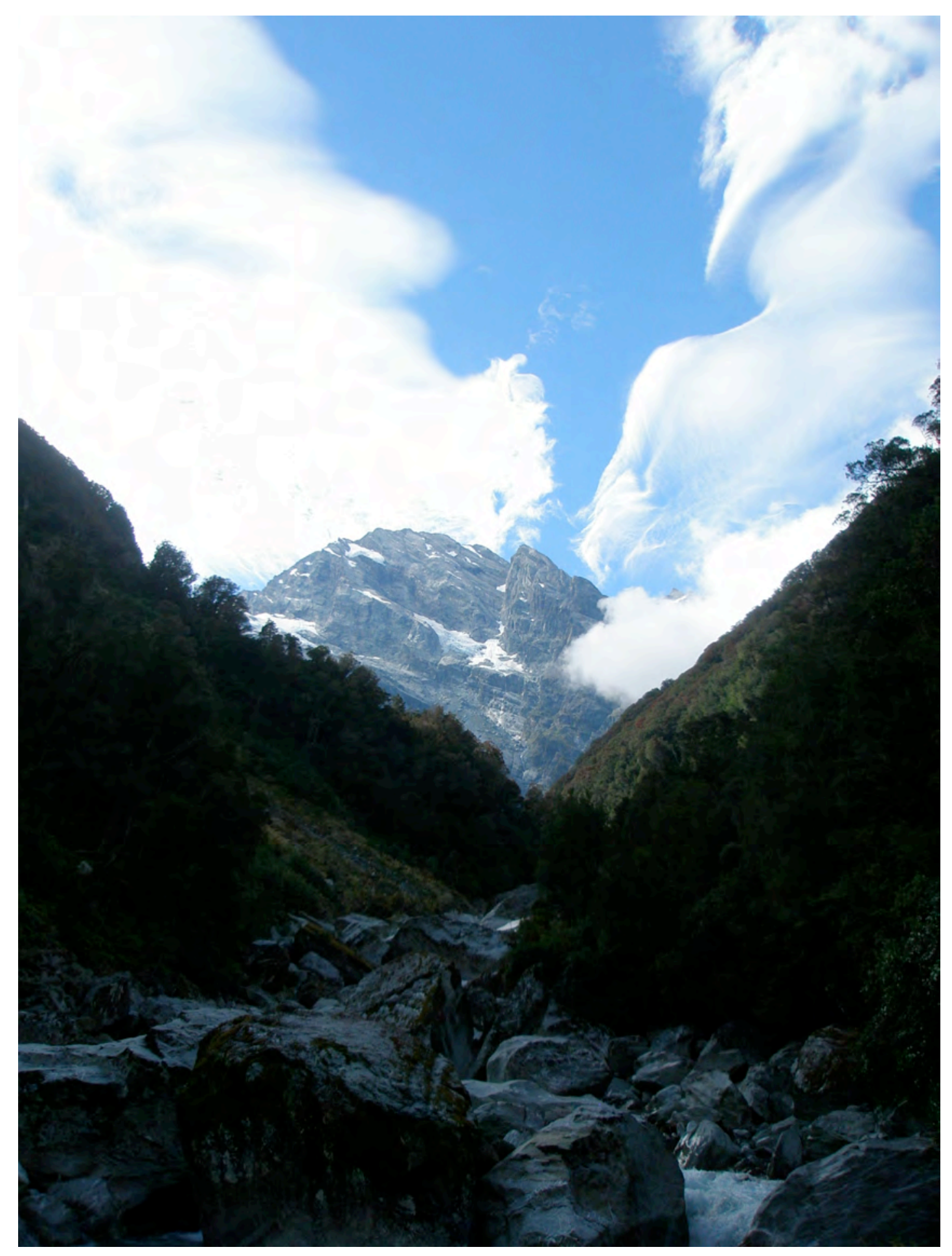

Frontispiece: Typical postcard cloud development looking up the Butler River at Mt Loughman (2590 $\mathrm{m})$. The weather gods were with me for two extensive field seasons on the West Coast. Twenty six days of fine sunny weather an unheard phenomena for a structural geologist on the West Coast of New Zealand's South Island. 
To Heather, Garth, and Aimee

"He displayed a large homemade geological map (about 3 x 6 feet in my recollection, mounted on a easel) of the South Island, and then, after talking for a while, suddenly proceeded to slide southern Westland 300 miles along the Alpine Fault to match up the strata near Nelson"

"Wellman recalled that the idea had come to him on a wet Sunday afternoon when he was sitting at the dining room table in Greymouth"

Harold Wellman 1909 - 1999 


\section{THESIS ABSTRACT.}

The hanging wall of the Alpine Fault (AF) near Franz Josef Glacier has been exhumed during the past $\sim 3 \mathrm{~m}$. y. providing a sample of the ductilely deformed middle crust via obliquereverse slip on the AF. The former middle crust of the Pacific Plate occurs as an eastward-tilted slab that has been upramped from depths of $\sim 25-35 \mathrm{~km}$. A mylonitic high strain zone abuts the eastern edge of the AF in Tatare Stream. This ductile shear zone is locally $\sim 2 \mathrm{~km}$ thick. The Tatare Stream locality is remarkable along the AF in the Central Southern Alps for the apparent lack of near surface segmentation of the fault there; instead its mylonitic shear zone appears uniformly inclined by $\sim 63^{\circ}$ to the SE. I infer this foliation is parallel to the shear zone boundary (SZB). In the distal part of the mylonite zone in extensional $\mathrm{C}^{\prime}$ shear bands cross-cut the older non-mylonitic Alpine foliation $\left(\mathrm{S}_{3}\right)$, and deflect that pre-existing fabric in a dextral-reverse sense. Based on the attitude of these shears the ductile shearing direction in the Alpine mylonite zone (AMZ) during extensional shear band activity is inferred to have trended $090 \pm 6^{\circ}(2 \sigma)$, which is $\sim 20^{\circ}$ clockwise of sea floor spreading based estimates for the azimuth of the Pacific Plate motion. This indicates that slip on this central part of the AF is not fully "unpartitioned".

Measurements of the mean spacing, per-shear offset, C' orientation, and per-shear thickness on $>1000$ extensional C' shears provides perhaps the largest field-based data set of extensional shear band geometrical parameters so far compiled for a natural shear zone. The mean spacing between $\mathrm{C}^{\prime}$ shears decreases towards the AF from $\sim 6 \mathrm{~cm}$ to $\sim 0.2 \mathrm{~cm}$. The per-shear offsets $(8.2$ $\pm 5 \mathrm{~mm} 1 \sigma)$ and thickness $(128 \pm 201 \sigma)$ of the extensional shears remains consistent despite a finite shear strain gradient. Using shear offset data I calculate a bulk finite shear strain accommodated by slip on C' shears of $0.4 \pm 0.3(1 \sigma)$, and a mean intra-shear band (C' local) finite shear strain of $12.6 \pm 5.4(1 \sigma)$. Consistency in the intra-shear band finite shear strain throughout the mylonite zone, together with increased C' density implies that the quartzose rocks have behaved with a strain hardening rheology as the shears evolved. The dominant C' (synthetic) extensional shears are disposed at a mean dihedral angle of $30^{\circ} \pm 2.2(2 \sigma)$, whereas the C', (antithetic) shears are $135 \pm 3^{\circ}(2 \sigma)$ to the foliation (SZB). The C' and C', shears appear to lie approximately parallel to planes of maximum instantaneous shear strain rate from which I obtain an estimate for $\mathrm{W}_{\mathrm{k}}$ of 0.5 for the AMZ.

I have measured the geometrical orientation of Mesozoic Alpine Schist garnet inclusion trails and tracked these pre-mylonitic age porphyroblastic garnets through the distal and main mylonite zones to determine their rotational response to late Cenozoic shearing. Electron microprobe analysis indicates that all the garnets examined in Tatare Stream are prograde from the regional $\left(\mathrm{M}_{2}\right)$ Barrovian metamorphism. The mean inclusion trail orientations in the distal 
mylonite zone have been forward rotated by $35^{\circ}$ relative to their equivalent orientation in the adjacent, less deformed non-mylonitic Alpine Schist. This rotation is synthetic to the dextralreverse shear of the AF zone. The rotation of approximately spherical shaped garnet porphyroblasts in the distal mylonite implies a finite shear strain of 1.2 in that zone. In the main part of the mylonite zone an additional forward rotation of $46^{\circ}$ implies a finite shear strain there of 2.8. The inclusion trail rotational axis measured trends approximately perpendicular to the shear direction and parallel to the inferred late Cenozoic vorticity vector of ductile shearing. Using GhoshFlow, a program for simulating rotation of rigid passive objects in plane strain general shear a new kinematic vorticity number $\left(\mathrm{W}_{\mathrm{n}}\right)$ estimate of $0.5-0.7$ is established for the AMZ.

The transition zone between the distal mylonite and the main mylonite zone, though little described in the literature, is well exposed in Tatare Stream. A distinct quartz rodding lineation, inherited from the non-mylonitic schist as an object into the mylonite zone, is distorted in the plane of the foliation across the transition from SW plunges to NE plunges. Because the foliation plane is here parallel to the SZB and by special reference to strongly curved lineation traces I have been able to isolate the pure shear component of deformation considering a simple $2 \mathrm{D}$ deformation on that slip plane; by modeling the distortional reorientation of inherited lineations in that plane. The direction of maximum finite elongation that I calculate in this plane trends 89 $\pm 3.8^{\circ}(2 \sigma)$. I believe this records the finite strain related to the co-axial component only. The parallelism of the previously calculated mylonitic ductile shearing direction to this stretching direction (also trending 090) indicates that the late Cenozoic ductile flow path in the central AMZ has been approximately monoclinic. I estimate a $\mathrm{W}_{\mathrm{n}}$ of $0.8 \pm 0.06(2 \sigma)$ based on the observed finite shearing in the mylonite zone (garnet rotation) and on the co-axial strain observed deforming the inherited lineations. 


\section{ACKNOWLEDGMENTS.}

My greatest thanks go to my supervisor, Tim Little, for all his knowledge, advice, support, and endless proof reading of chapters. This thesis would have suffered greatly had it not been for Tim's guidance, vision and reviews. I have enjoyed working with and learning from Tim, and have benefited immensely from exposure to his style of presentation and teaching. Thank you Tim and best wishes for you and your family for the future.

I would like to thank Euan Smith, Julie Vry and Virginia Toy. Euan has provided expert guidance and knowledge with several trips to his office discussing lineation and shear band attitudes; putting up with my constant question "can we get errors on this". Julie's expertise and knowledge in petrology and Alpine Schist garnets has benefited this thesis immensely. Thank you Virginia for your guided visit to Gaunt Creek and the use of your data and knowledge of the central Alpine mylonite zone. Without the addition of this material this thesis would have suffered. Thank you to you all.

This research was funded by a science faculty research grant. With this support I have been able to become a more confident structural field geologist. I would like to pay special thanks to Megan Korchinski. Megan and I have progressed through the entire university "system" together. Megan has provided help on ideas, eating habits, sun awareness, and endless proof reading of edits. Without Megan this thesis would not be where it is today. I thank Megan for all her patience and I have made a friend for a lifetime.

Thank you Dave Murphy for all the discussions on fabric development and garnet growth in the Alpine Schist. Dave also helped in the field as a fantastic assistant, which has helped to develop ideas within this thesis. I would like to thank all my office buddies, past and present, Dee, Megan, Gemma, Rachel, Susanne for all your support. I would like to thank all of my fellow postgraduate buddies, Chris, George, Matt, Boots, Aidan, John, Ramona, Katy, Rookie, Tim, Sam, Kim, Holly, Zara, Kathi and anyone else that I may have missed. We all helped each other through this and I thank you all. My Flatties Matthew, Paul, Reeves (aka Matt), and Garry I thank you all for the hard work you have put in over the years. You all really knew how to get me into another "gear" to get this completed.

My final thanks go to Alyshia, my parents Garth and Heather, and my sister Aimee for their keen interest and support throughout the duration of this thesis. This thesis would have not been possible without your unrelenting patience, love and support. Thank you Mum and Dad for the opportunity to pursue this dream and supporting me along the way. It has been a long road that has been filled with ups and downs. I would be lost without your help and my sincerest thanks go to you both. 


\section{CONTENTS.}

Frontispiece

Thesis Abstract IV

$\begin{array}{lll}\text { Acknowledgements } & \text { VI }\end{array}$

Contents $\quad$ VII

1. Introduction 1

2. Shear band development on the outer margin of the Alpine mylonite zone, Tatare Stream, Southern Alps, New Zealand

3. Porphyroblast rotation: tracking garnet porphyroblasts through the central Alpine mylonite zone, Southern Alps, New Zealand

4. Flow kinematics in the central part of the Alpine Fault mylonite zone, Tatare Stream, Southern Alps, New Zealand

5. Thesis Conclusions

List of figures

List of Tables

XIV

1.

1.1 Thesis organization

1.2 Thesis outline 


\section{Shear band development on the outer margin of the Alpine - mylonite zone, Tatare Stream, Southern Alps, New Zealand.}

2.1 Introduction

2.2 Synthetic shear bands and shear band boudins: models for their origin and evolution

2.2.1 Synthetic shear bands (C')

2.2.2 Shear band boudins

2.2.3 Limitations in current understanding of extensional $C$ ' shears

2.3 Tectonic setting and structural framework

2.3.1 Alpine Fault and Southern Alps

2.3.2 Tatare Stream structural geology

2.4 Analytical methods of extensional C'shear geometries in Tatare Stream

2.4.1 Macroscopic outcrop extensional C' shears

2.4.2 Outcrop scale extensional C' apparent offset and spacing correction

2.4.3 Microscopic observation of extensional C' shears

2.4.4 Extensional C' shear band orientation

\subsection{Results}

2.5.1 Determination of the shear zone boundary in Tatare Stream

2.5.2 Orientations of synthetic C' and antithetic C'" shears

2.5.3 Direction of Ductile Shearing in the Alpine Mylonite Zone

2.5.4 Dihedral angle $(\delta)$ between the shear zone boundary and the $C$ ' and $C$ ', shears 28

2.5.5 Variance in $C^{\prime}$ spacing as a function of mechanical layer and proximity to the Alpine Fault

2.5.6 Variance in $C^{\prime}$ offset as a function of mechanical layer and proximity to the Alpine Fault

2.5.7 Variance in bulk C'strain accommodated by slip parallel to $C^{\prime}$ shears as a function of proximity to the Alpine Fault

2.6.1 C' shear band variables (spacing, offset, thickness and $\gamma$ ) as a function of increasing finite strain

2.6.3 Estimation of bulk vorticity using synthetic ( $C$ ') and antithetic ( $C$ ') shear band geometries 


\section{Porphyroblast rotation: tracking garnet porphyroblasts 3. through the central Alpine mylonite zone, Southern Alps, New Zealand.}

3.2 Rotational and non-rotational models for porphyroblasts

3.3 Tectonic setting and structural framework

3.3.1 Alpine Fault and Southern Alps $\quad 52$

3.3.2 Tatare Stream structural geology 56

3.4 Measuring porphyroblast inclusion trail orientations relative to the Alpine Fault shear zone boundary in Tatare Stream

3.4.1 Garnet porphyroblasts in Tatare Stream

3.4.2 Garnets in the pre-shearing Mesozoic non-mylonitic Alpine Schist

3.4.3 Garnet porphyroblast aspect ratio $(R)$

3.4.4 Angle $\beta$ between long axis of garnets $(R=1-1.5)$ and the shear zone boundary boundary

3.4.5 Garnet porphyroblasts internal inclusion angle ( $\alpha$ ) for garnets with R-values

$$
1-1.2
$$

3.4.6 Estimation of bulk finite shear strain from porphyroblast rotation

3.4.7 3D orientation of internal inclusions in garnet porphyroblasts $(R=1-1.5) \quad 73$

3.5 Discussion

3.5.1 Evidence for porphyroblast rotation

3.5.2 Vorticity modeling of rigid garnet porphyroblasts in Tatare Stream

3.5.3 Estimation of bulk finite shear strains and flow kinematics in the Alpine mylonite zone 


\section{Flow kinematics in the central part of the Alpine Fault}

4.1 Introduction

86

4.2 Geological setting and structural framework

4.2.1 Alpine Fault and Southern Alps

4.2.2 Tatare Stream structural geology

4.3 Tatare Stream mylonite zone: the transitional zone

4.4 Shear zone boundary orientation: attitude of the Alpine shear zone at depth

4.5 Direction of ductile shearing in the Alpine mylonite zone

4.6 Lineation deformation in the transition zone between the distal and main mylonite zone

4.6.1 Co-axial finite stretching direction parallel to the SZB of the Alpine mylonite zone.

4.6.2 Finite magnitude of co-axial stretching and thinning

4.7 Discussion

111

4.7.1 Transitional zone foliation development and deformed lineation patterns 
5. Thesis Conclusions

References

Appendix outline

Appendix A

- Structural Data, Tatare Stream and Gaunt Creek

Appendix $B$

- Extensional shear band data

- Macroscopic (outcrop)

- Microscopic (thinsection)

Appendix $C$

- Garnet porphyroblast rotation data

- Alpine Schist garnet classification chart

- Electron microprobe analytical data

Appendix D

- Lineation orientation data in the transitional zone

- Matlab lineation modeling

Appendix E

- Plate 1: Geological map of Tatare Stream: Sample locations

- Plate 2: Geological map of Tatare Stream: Structure

- Plate 3: Geological cross-section of Tatare Stream

Appendix $F$

Rear Cover

- CD containing SBOC and READ ME file 


\section{LIST OF FIGURES.}

\section{Introduction}

Fig. 1.1 Regional tectonic setting of the South Island, New Zealand

2.

Shear band development on the outer margin of the Alpine mylonite zone, Tatare Stream, Southern Alps, New Zealand.

Fig. 2.1

Schematic diagram of extensional C' shear bands

Fig. $2.2 \mathrm{a}-\mathrm{d}$

Extensional shear band models

Fig. 2.3

Schematic features of shear band boudins

Fig. 2.4

Regional tectonic setting of the South Island, New Zealand

Fig. $2.5 \mathrm{a}-\mathrm{c}$

Bedrock structural geology of the Alpine Schist at Tatare Stream

Fig. $2.6 \mathrm{a}-\mathrm{e}$

Photomicrographs and outcrop photos of the Alpine mylonite zone

Fig. 2.7

Fig. $2.8 \mathrm{a}-\mathrm{b}$

Ductile slip vector in the Alpine mylonite zone, Tatare Stream

Fig. $2.9 \mathrm{a}-\mathrm{c} \quad$ Scatter plots of mean C' dihedral angles

Fig. $2.10 \mathrm{a}-\mathrm{c} \quad$ Scatter plots of extensional C' attributes (spacing, thickness) 33

Fig. $2.11 \mathrm{a}-\mathrm{b} \quad$ Outcrop S and C' geometries (schematic) 37

Fig. $2.12 \quad$ Scatter plot of C' spacing relative to layer thickness 38

Fig. 2.13 Rose diagram of C' and C' 'shear orientations 42

Fig. 2.14 Schematic ramping of the Pacific Plate's hanging wall 46

3. Porphyroblast rotation: tracking garnet porphyroblasts through the central Alpine mylonite zone, Southern Alps, New Zealand.

Fig. 3.1 Regional tectonic setting of the South Island, New Zealand 53

Fig. $3.2 \mathrm{a}-\mathrm{c} \quad$ Bedrock structural geology of the Alpine Schist at Tatare Stream $\quad 57$

Fig. $3.3 \mathrm{a}-\mathrm{d} \quad$ Photomicrographs of typical garnets in Tatare Stream $\quad 61$

Fig. 3.4 a - b Compositional zoning profile of garnet porphyroblasts, Tatare Stream 63

Fig. $3.5 \mathrm{a}-\mathrm{b} \quad$ Key parameters for garnet porphyroblast characterization $\quad 66$ 
Fig. 3.6

Histogram of garnet aspect ratios in Tatare Stream

Fig. $3.7 \mathrm{a}-\mathrm{h} \quad$ Long axis and inclusion orientation scatter plots $\quad 68$

Fig. $3.8 \mathrm{a}-\mathrm{c} \quad$ Rose plots of internal inclusion orientations $\quad 70$

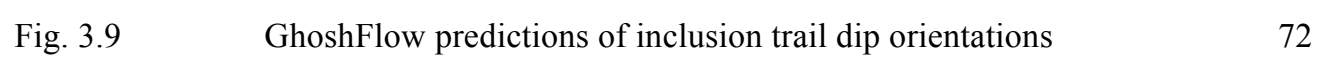

Fig. 3.10 a $-\mathrm{c} \quad$ Stereographic plots of mean inclusion attitudes $\quad 74$

Fig. 3.11 Stereographic plot of deflected inclusion planes and rotational axis 75

$\begin{array}{lll}\text { Fig. } 3.12 \mathrm{a}-\mathrm{d} \quad \text { GhoshFlow long axis versus Si plots } & 78\end{array}$

Fig. $3.13 \mathrm{a}-\mathrm{b} \quad$ GhoshFlow long axis versus Si plots $\quad 80$

Fig. $3.14 \mathrm{a}-\mathrm{c} \quad$ GhoshFlow long axis versus Si plots $\quad 81$

Fig. $3.15 \mathrm{a}-$ c. $\quad$ GhoshFlow long axis versus Si plots $\quad 83$

\section{Flow kinematics in the central part of the Alpine Fault mylonite zone, Tatare Stream, Southern Alps, New Zealand.}

Fig. 4.1 Regional tectonic setting of the South Island, New Zealand

Fig. $4.2 \mathrm{a}-\mathrm{c} \quad$ Bedrock structural geology of the Alpine Schist at Tatare Stream 93

Fig. $4.3 \mathrm{a}-\mathrm{e} \quad$ Structural field observations in Tatare Stream 96

Fig. 4.4 Outcrop photo of the entire transitional zone $\quad 97$

Fig. $4.5 \mathrm{a}-\mathrm{b} \quad$ Deflected and distorted quartz rodding lineations 99

$\begin{array}{lll}\text { Fig. } 4.6 & \text { Ductile slip direction in the Alpine mylonite zone } & 102\end{array}$

Fig. $4.7 \mathrm{a}-\mathrm{d} \quad$ Stereographic plots of quartz rodding lineation attitudes $\quad 104$

Fig. $4.8 \quad$ Scatter plot of the deflected lineations in Tatare Stream 106

Fig. $4.9 \mathrm{a}-\mathrm{c} \quad$ Retrodeformed lineation patterns $\quad 110$

Fig. $4.10 \mathrm{a}-\mathrm{b} \quad$ Transitional zone foliation development 113

Fig. $4.11 \quad$ Monoclinic stretching shear zone model for the Alpine mylonite zone 117 


\section{LIST OF TABLES.}

2. Shear band development on the outer margin of the Alpine mylonite zone, Tatare Stream, Southern Alps, New Zealand.

Table 2.1. Calculated shear band geometries using the SBOC

Table 2.2. Outcrop scale extensional shear band measurements

Table 2.3. Thin-section extensional shear band measurements 


\section{Introduction}

The Alpine Fault, South Island, New Zealand is one of the best global examples of a deeply exhumed but active crustal-scale oblique-reverse fault (Fig. 1). The ductile kinematics of this natural shear zone is a topic of some interest as it may influence seismic behaviour on the Alpine Fault and it has controlled uplift of the Southern Alps on its hanging wall.

Flows in natural materials are likely to be inhomogeneous and to vary spatially. One of the most commonly seen types of inhomogeneous deformation is a planarsided shear zone that localizes displacement between their walls. Shear zones can occur on a range of scales and usually contain a rotational (non-coaxial or vertical) component of flow that accompanies (and accommodates) displacement of the shear zone walls with respect to each other (Passchier \& Trouw, 2005). In addition, there may be an irrotational (co-axial) component so that the flow is three-dimensional and deviates from simple shear. The fabrics that develop in a shear zone will reflect the flow type (and its steadiness), the sense of motion, and associated P-T conditions that accompanied its evolution and exhumation. Many zones are thought to be largely formed by progressive simple shear between relatively rigid wall rocks; however, shear zones with deformation histories that deviate from simple shear are probably common in nature where deformation is likely to be three-dimensional involving combinations of stretching and shortening parallel and perpendicular to the shear zone boundary (SZB).

The hanging wall of the Alpine Fault near Franz Josef Glacier has been exhumed and eastward-tilted from depths of $\sim 25-30 \mathrm{~km}$ during the past $\sim 3 \mathrm{~m}$. y. via oblique-slip on the Alpine Fault. This has exposed a section of the ductilely deformed middle crust at the surface (Grapes, 1995; Little et al., 2002a) including a $\sim 2 \mathrm{~km}$ thick mylonite zone (Sibson et al., 1979; Little et al., 2002a; Toy, 2007; Toy et al., 2008). A near-complete exposure through this latter ductile shear zone is expressed in Tatare Stream, near Franz Josef (Figs. 1 \& Plate 1). The trace of the Alpine Fault in its central section is segmented at the surface along strike into a series of oblique-reverse and vertical strike-slip sections (Norris \& Cooper, 2007). The Tatare Stream locality is remarkable, however, for the simple and apparently 


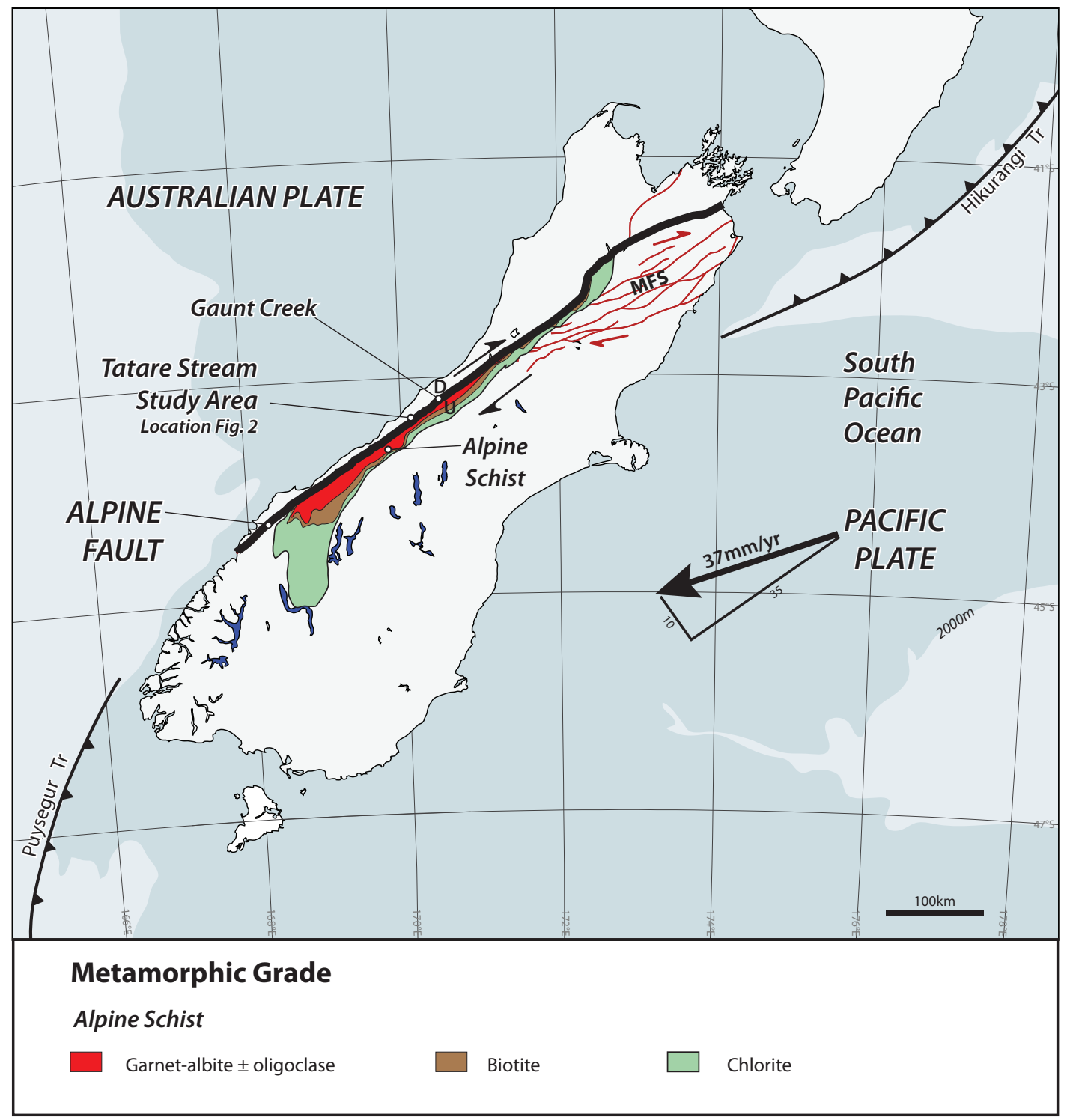

Fig. 1. Regional tectonic setting of the South Island of New Zealand showing the moden rate of plate motion between the Pacific Plate to the Australian Plate (using Nuvel 1A angular velocities from DeMets, et al. (1994), and the Alpine Fault Trace at Tatare Stream as a reference point), with normal and parallel motion with respect to the Alpine Fault. MFS - Marlborough Fault System. $2000 \mathrm{~m}$ - bathymetric contour. Map also showing metamorphic grade of Alpine Schist. Data from N.Z. Geological Survey map (1979); Mortimer (2000); Murphy (2010). 
planar unsegmented nature of the SE inclined Alpine Fault there, and for its excellent stream washed outcrops. In this thesis I evaluate structural field data collected in this well-exposed, natural oblique-slip mylonitic shear zone. I aim to measure and quantify macroscopic structures and microstructures developed across the strain gradient between the non-mylonitic wall rocks and the Alpine mylonite zone. These data are evaluated in terms of the late Cenozoic ductile flow in the Alpine shear zone and its relationship to the well-known Pacific-Australian Plate motions that have been in part accommodated by slip through that zone.

\subsection{Thesis organisation}

This thesis consists of 5 chapters where chapters 2,3 , have been written as selfcontained papers designed to be submitted; an original structure that has led to some repetition of material. In particular, there is some repetition of content in the introductions, tectonic setting/structural framework sections, references, and some figures. Moreover, the sections pertaining to the shear zone boundary orientation and the calculated ductile shearing direction are relevant to each chapter so some repetition is inevitable. Contributions to this thesis by others (supervisors and collaborators) of the individual chapters are cited below.

Chapter 2, entitled "Shear band development on the outer margin of the Alpine mylonite zone, Tatare Stream, Southern Alps, New Zealand" has contributions from Associate Professor Timothy A. Little, Professor Euan Smith, and Dr Virginia G. Toy. Tim Little is my primary supervisor for this thesis. He accompanied me in the field, advised me on the research strategy and techniques to use, and undertook proofreading of earlier drafts. Euan Smith developed the code (SBOC) for calculating shear band attitudes from sectional observations using the Matlab ${ }^{\circledR}$ program. The Matlab ${ }^{\circledR}$ code can be found in Appendix B. Professor Smith also contributed corresponding explanatory text to the section entitled "Extensional shear band orientation", which explains this computational algorithm. Virginia Toy accompanied me in the field to Gaunt Creek on a memorable rainy West Coast day and has supplied new sample material and structural data/interpretation from that locality (Fig. 2) which has extended the sample density into the main mylonite and ultra-mylonite zone. Virginia did not see or review any part of this thesis prior to submission. 
Chapter 3, entitled "Porphyroblast rotation: tracking garnet porphyroblasts through the central Alpine mylonite zone, Southern Alps, New Zealand" is entirely my own work except for Tim Little's supervisory guidance and proofreading.

Chapter 4 is entitled "Flow kinematics in the central part of the Alpine Fault mylonite zone, Tatare Stream, Southern Alps, New Zealand”. Tim Little contributed supervisory advice regarding data analysis and interpretation, while also reviewing and proof reading earlier versions of the chapter. Euan Smith developed a Matlab ${ }^{\circledR}$ code to apply Wettstein's formula towards forward modelling the distribution of lineations in 2D in the plane of the Alpine Schist foliation. The model results can be found in Appendix D.

Chapter 5 concisely concludes the marcostructures, microstructures, and kinematics of the Alpine Fault mylonite zone exposed in Tatare Stream.

\subsection{Thesis outline}

In Chapter 2, I present a detailed structural and microstructural study on pervasively developed extensional (C') shear bands that occur in the distal mylonite and mylonite zones of the Alpine Schist in Tatare Stream, central Southern Alps. Extensional shear bands are common globally and may provide valuable information on the kinematics of shear zones; however, despite their widespread occurrence in nature their dynamic and kinematic interpretation remains a controversial topic in the structural geological literature. In this chapter I present numerous quantitative measurements of extensional C' shear spacing, per-shear offset, per-shear thickness, and shear band attitude. A new way to measure best-fit orientations of planar features from sectional data (Matlab ${ }^{\circledR}$ code by Euan Smith) is presented in this chapter. The chapter investigates how the attitude, spacing, per-shear slip and thickness of these extensional shears may (or may not) vary as a function of increasing distance into the Alpine mylonite zone and increasing finite shear strain. Moreover, the direction of ductile shearing in the Alpine mylonite zone is calculated. The data are interpreted in terms of nucleation angle of the C' shears, the non-simple shear flow kinematics of the zone, and the rheological evolution of the Alpine Schist subsequent to C' shear development. 
In chapter 3, I examine the rotational behaviour of pre-existing garnet porphyroblasts in the Alpine Schist as they have been subjected to late Cenozoic shearing in the Alpine mylonite zone. Over the past 25 years curved inclusion trails in porphyroblasts have been interpreted to record a relative rotation between the porphyroblast and external foliation outside them; however, the nature of any rotation relative to geographic coordinates is less certain. In this chapter I evaluate the effect of late Cenozoic ductile flow on the pre-mylonitized garnet porphyroblasts while measuring their inclusion trail orientation relative to the SZB of the Alpine mylonite zone and changes in that attitude relative to their "original" orientations in the non-mylonitic Alpine Schist. I evaluate the effect of an increasing finite strain on these inclusion trail attitudes in $2 \mathrm{D}$ and to a degree in 3D. Tracking the inclusion trail attitudes through the distal mylonite and into the main part of the mylonite zone in Tatare Stream, while relating them to the SZB reference direction, allows me to infer how much rotation, if any the garnets have experienced as a result of the late Cenozoic shearing, and clearly supports a "rotational" model for porphyroblasts, at least in shear zones. After making several simplifying assumptions I use the GhoshFlow program developed by R Holcombe to estimate the kinematic vorticity number (proportion of pure to simple shear during deformation) and finite shear strain during late Cenozoic ductile flow in the Alpine mylonite zone and compare these to previous estimates based on different types of data.

In chapter 4, I compile various lines of field data derived from this thesis in an effect to quantify the nature and symmetry of ductile flow in the Alpine mylonite zone. Previous workers have suggested that the Alpine mylonite zone has been subject to predominantly simple shear or to complex three-dimensional triclinic symmetries of flow that deviate from simple shear (Jiang et al., 2001; Toy et al., 2011 in review). My contribution is to examine the pattern of deformational reorientation of pre-mylonitic, inherited object (rodding) lineations as they are swept into the main mylonite zone in Tatare Stream. By focusing first in 2D on the slip plane itself, which in Tatare Stream is exactly parallel to the foliation, I use the distribution of the lineations to estimate the co-axial ( $S_{2}$ parallel and perpendicular) and irrotational component of ductile stretching and thinning of the zone. I infer that a significant SZB parallel stretch has been recorded by distortion of these lineations into sub-parallelism with the independently known ductile shear direction, and by 
other boudinage structures in the schist from which I infer that the late Cenozoic Alpine mylonite zone is a stretching and thinning general shear zone of monoclinic symmetry.

Appendix A tabulates structural field data that was collected in both Tatare Stream and Gaunt Creek during the 2009 and 2010 field seasons. It also lists sample information. Appendix B presents transect-derived data on the spacing of and offsets on extensional C'. Appendix $\mathrm{C}$ tabulates data on inclusion trail attitudes and presents a garnet classification chart that I used for distinguishing between different inclusion trail geometries. It also tabulates Electron microprobe compositional analysis of garnets in the main mylonite zone. Appendix D contains a transect of detailed lineation orientation data that was collected in the field in the transitional zone between the distal and main mylonite zones and the Matlab ${ }^{\circledR}$ model using Wettstein's formula. Appendix E contains A3 plates of Tatare Stream sample locations, structural data, and a NW - SE cross section. Appendix F is a CD located at the back of the thesis that contains the SBOC. This Matlab $\mathbb{R}$ code is used to determine bestfit C' attitudes and errors. Code requires an input file and outputs an excel file and figures. Also on the $\mathrm{CD}$ is a readme file for using the code. 


\section{Shear band development on the outer margin of the 2. Alpine mylonite zone, Tatare Stream, Southern Alps, New Zealand.}

\subsection{Introduction}

Quantitative structural field data on pervasively developed extensional C' shear bands may provide valuable information on the kinematics of ductile shear zones; however, kinematic and dynamic interpretation of such shear bands remains a controversial topic in geological literature despite their widespread occurrence in nature (Platt \& Vissers, 1980; Simpson \& De Paor, 1993; Little et al., 2002a; Blenkinsop \& Treloar, 1995; Kruz \& Northrup, 2008). Extensional shear bands may be defined by a mylonitic foliation (S) truncated at a small angle by sets (mm-cmscale) of inclined ductile shear zones (White, 1979) (Fig. 1). Extensional shear bands are also known as C' (of an S-C' fabric) or extensional crenulation cleavages (ECC) (e.g., Platt \& Vissers, 1980). Conjugate sets of extensional shear bands are not uncommon, but remain imperfectly understood, particularly with respect to what orientations they may have during initiation and subsequent deformation in the flow field of a shear zone. It has been suggested they may nucleate on planes of maximum instantaneous shear strain rate (Platt \& Vissers 1980; Simpson \& De Paor, 1993; Kurz \& Northrup, 2008); on planes that parallel the contractional eigenvector of flow (Bobyarchick, 1986); on plans that coincide with an idealized Coulomb failure surface (Blenkinsop \& Treloar, 1995); or on planes parallel to directions of maximum finite shear strain (Ramsay \& Lisle, 2000) (Fig. 2). The Alpine Fault, South Island, New Zealand is one of the best global examples of a deeply exhumed plate boundary-scale oblique-reverse fault. Here, rapid uplift and erosion of the hanging wall of the Alpine Fault has exposed a neotectonic example of a mylonitic ductile shear zone that formed at mid to lower crustal depths within the last few million years. This shear zone has external plate motion directions that are well constrained from seafloor spreading data (DeMets et al., 1994; Walcott, 1998). In this study we will take advantage of this natural laboratory context of the Alpine mylonite shear zone to better understand the evolution of extensional shear bands in ductile shear zones. 


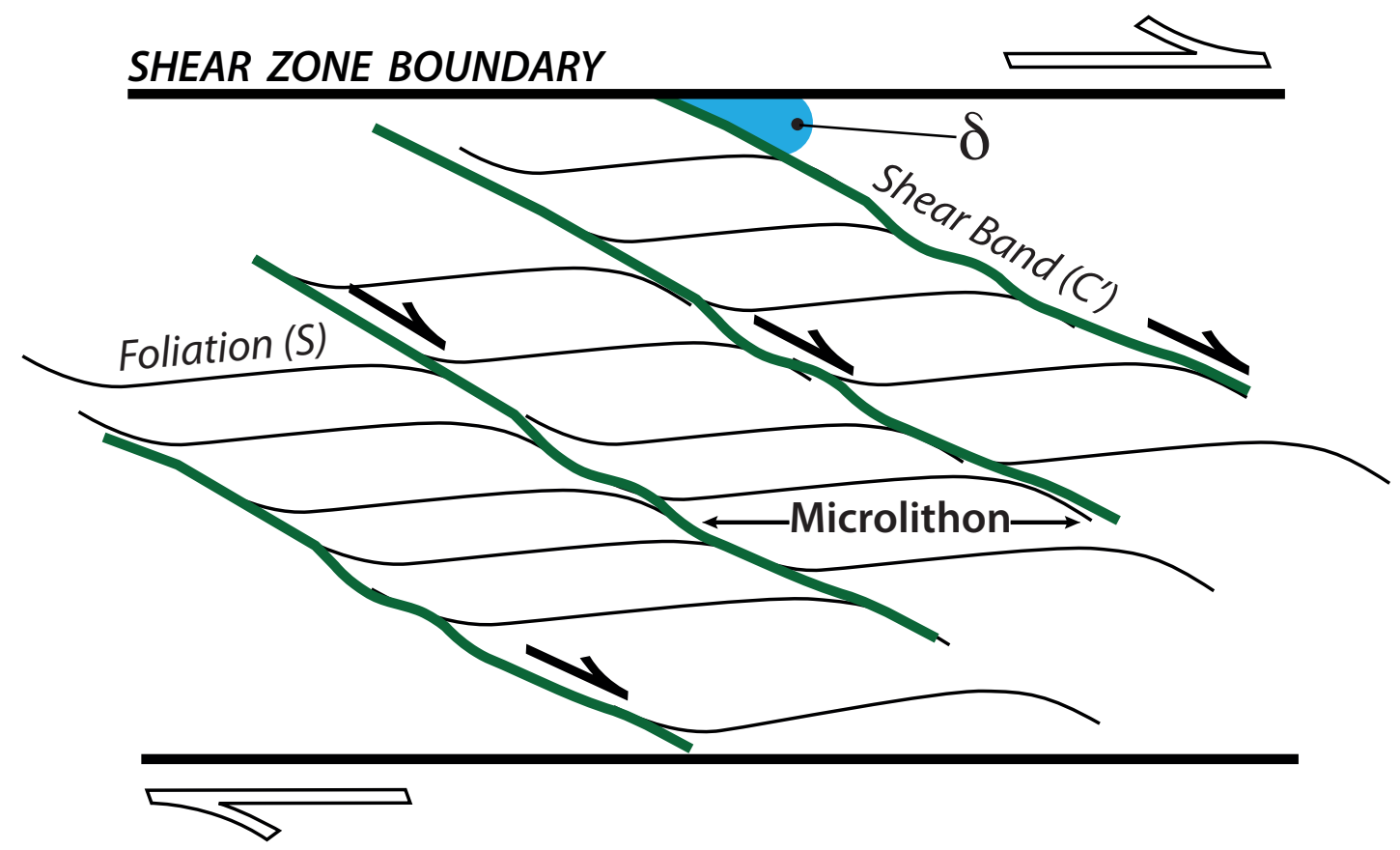

Fig.1. Schematic diagram of extensional $C^{\prime}$ shear bands. $S$ is the older foliation, deflected in a dextral sense and $C^{\prime}$ are shear bands, inclined relative to the shear zone boundary. Microlithons are the tabular zones between $C^{\prime}$ shears. $\delta$ (dihedral angle) is the angle between the inclined $C^{\prime}$ shears and the shear zone boundary. 
Extensional shear band development has been simulated in some laboratory deformation studies on analogue materials (e.g., Williams \& Price, 1990; Ji et al., 2004). In these studies the mean C' shear spacing decreases with increasing bulk shear strain and strain is partitioned into the oblique C' shears (Ji et al., 2004). Different geometric constraints have been argued (e.g., Dennis \& Secor, 1987; Passchier, 1991) for the partitioning of bulk simple shear in extensional shear banded mylonites. Shearing may occur parallel to an oblique foliation and parallel to a set of inclined C' shears (Dennis \& Secor, 1987). Whilst an apposing model argues that the C' shear bands and adjacent microlithons (between shears) shorten to compensate for oblique shearing in a zone dominated by bulk simple shear (Passchier, 1991).

In this paper we present detailed and qualitative measurements of C' shear spacing, per-shear offset, per-shear thickness, and orientation in a particularly wellexposed part of the Alpine mylonite zone in the central Southern Alps. These data will be used to gain insight into the kinematics of the Alpine Fault shear zone and to gain new insight into extensional shear band evolution. Apparent stretching lineations measured in Alpine mylonite zone have variable attitudes (Sibson et al., 1979; Little et al 2002a; Toy, 2007), consequently, there is some controversy regarding the interpretation of their relationship to the kinematics of the shear zone. By contrast, fewer direct measurements of the direction of ductile shear have been made. In-depth analysis of the geometrical configuration of the C' shears to the Alpine mylonite shear zone's boundary (SZB) will allow the calculation of the ductile shearing direction in the exhumed part of the Alpine mylonite zone, thus sidestepping the issue of how these lineations may or may not have been inherited from the precursor schist, or how they relate to the late Cenozoic shear direction. In addition, detailed structural work on the offsets across these shears will allow us to evaluate the bulk finite strain accommodated by slip on these shears.

It is first necessary to identify the orientation of the SZB in the central Alpine Fault mylonite zone. We show that a constant foliation attitude exposed in the mylonitic rocks provides a robust estimate for the dip of the SZB at depth. Secondly, we will statistically analyze the orientation of C' shears relative to the SZB and the Alpine Fault plane. Thirdly, we determine the ductile shearing direction, interpreted to lie normal to the intersection of S and C' planes within the plane of the SZB. From these data we argue that the directions of ductile shearing in the Alpine mylonite 
zone pitches significantly more down-dip in the plane of the Alpine Fault than does the Pacific Plate motion vector, in contrast to earlier suggestions that these direction are essentially parallel to one another (e.g. Sibson et al., 1981; Wightman, 2000; Little et al., 2002a; Toy, 2007). Fourth, we describe how offsets, spacing and attitude of the C' shears vary across an observed strain gradient between non-mylonitic schist precursor to incipiently mylonitized rock to thoroughly mylonitized rocks in the main mylonite zone. Detailed measurements of offset will allow us to calculate bulk shear strains accommodated by slip along these extensional shears in the Alpine mylonite zone, and also estimate the mean finite shear strain that is accommodated internally within a given shear and determine how this may or may not vary across the strain gradient. Lastly, this comprehensive C' data set we will be able to support a hypotheses about the development of extensional C' shear bands with respect to the direction of the flow field and the strain path (early vs late), and about the shear bands' subsequent rotation as a function of increasing strain. Using this model we will analyze the dihedral angle $(\delta)$ between the synthetic $\left(C^{\prime}\right)$ and antithetic $\left(C^{\prime}\right.$ ') extensional shear bands to determine the kinematic vorticity of the Alpine mylonite zone.

\subsection{Synthetic shear bands and shear band boudins: models for their origin and evolution}

\subsubsection{Synthetic shear bands ( $\left.C^{\prime}\right)$}

The origin of shear bands in relation to the kinematics and rheology of ductile flow is not well resolved in the current literature. Platt \& Vissers (1980) proposed that extensional shear bands propagate parallel to the planar directions of maximum shear stress and maximum shear strain rate (Hill, 1950) (Fig. 2a). Sets of extensional shears are commonly oblique to the SZB. Platt (1984) argued that this maybe because the flow field commonly departs from overall simple shear due to flow partitioning. The bulk simple shear flow could be partitioned into three components: slip along discrete surfaces parallel to the foliation $\mathrm{S}$, coaxial stretching of the whole system parallel to S, and rotation (spin) of the surfaces relative to the SZB. Platt's (1984) model predicts that conjugate sets of extensional shear bands should develop at $45^{\circ}$ to the foliation, which accords with the shear bands observed by Platt $\&$ Vissers (1980) (Fig. 2a). Passchier (1991) developed a kinematic model for 
a.

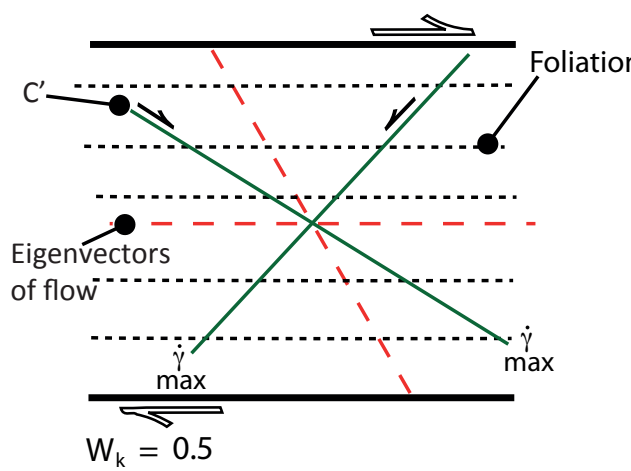

Simpson \& De Paor (1993) after Platt \& Vissers (1980)

C.

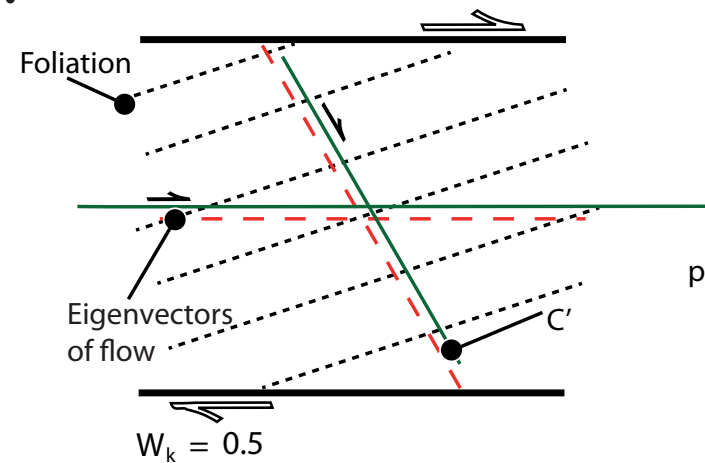

Bobyarchick (1986)

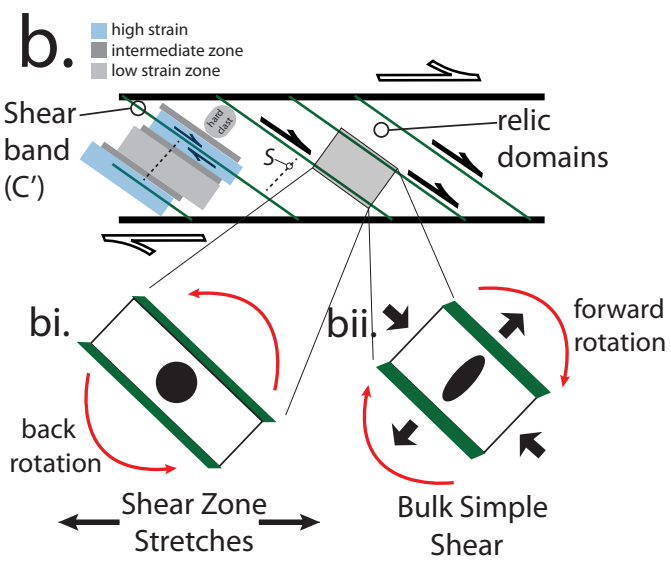

Passchier (1991) and Holyoke \& Tullis (2006)

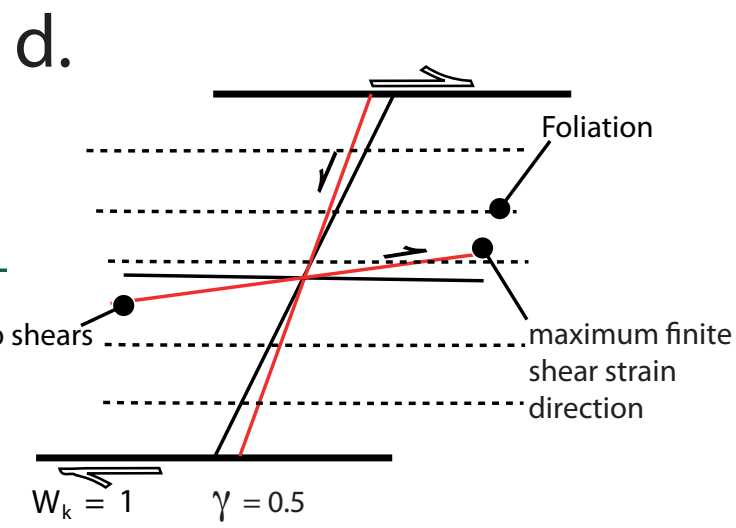

Ramsay \& Lisle (2000)

Fig. 2. Schematic diagrams depicting different possible orientations of extensional $C^{\prime}$ shear bands described in geological literature. $W_{k}$ is the kinematic vorticity number (proportion of pure to simple shear). (a) Orientations of conjugate $C^{\prime}$ shears forming parallel to the acute (AB) and obtuse (OB) bisectors of the flow eigenvectors during general shear (Simpson \& De Paor, 1993 after Platter \& Vissers 1980). (b) Passchier's (1991) model of shear band development. Divided into two domains; shear bands and relic domains (microlithons). (bi) Predicted back rotation of the $\mathrm{C}^{\prime}$ shear band and relic domain in a shear zone that is stretching. No internal deformation occurs to the inclined $C^{\prime}$ shear and relic domain. (bii) Predicted forward rotation of the $C^{\prime}$ shear band and relic domain in a shear zone with bulk simple shear. To maintain a bulk simple shear flow with slip on inclined $C^{\prime}$ shears the shear bands and relic domains must internally deform (stretch and thin). Further depicted is Holyoke \& Tullis (2006) schematic diagram for strain partitioning in a thinning shear zone with localized shear in the $C^{\prime}$ bands accommodating both thinning and shear strain. (c) $C^{\prime}$ shear bands forming parallel to the eigenvectors of flow, parallel to the extensional and contractional eigenvectors during general shear (Bobyarchick, 1986). (d) Orientations of conjugate C' shears forming parallel to the maximum finite shear strain directions (Ramsay \& Lisle, 2000). 
extensional shear band development where the shear zone is envisioned to consist of two domains: extensional shear bands and the relic domains (microlithons) that the former bound (Fig. 2b). To accommodate bulk simple shear by slip on inclined extensional shear bands, the microlithons and the shear bands must shorten and for the shear bands rotate in the same direction as the bulk sense of shear. This type of extensional shear band development is uncommon in nature (Passchier, 1991). Passchier (1991) argued that the relic domains remain undeformed, and all deformation is concentrated in the shear bands. In this case, the shear zone must stretch, the angle between the shear bands at the SZB must decrease, and the shear bands must rotate in an opposite direction to the bulk shear sense (Fig. 2b).

Simpson \& De Paor (1993) and recently Kurz \& Northrup (2008) suggested that extensional shear bands initiate on planes of maximum shear strain rate, rather than parallel to the eigenvectors of flow as argued by Bobyarchick (1986) (Fig. 2a). Blenkinsop \& Treloar (1995) undertook a comprehensive field study of an extensional shear band fabric and proposed that C' surfaces form in the orientation of a Coulomb failure surface at an angle of less than $45^{\circ}$ to the maximum principal stress. Ramsay \& Lisle (2000) argue that shear bands occur in conjugate sets that coincide with planes of maximum finite shear strain within the shear zone (Fig. 2d). However, conjugate extensional shear bands of this latter type have been rarely described in the literature.

\subsubsection{Shear band boudins}

Shear band boudins have a long, curved lenticular shape, and large relative displacement/synthetic drag on an inter-boudin surface $\left(\mathrm{S}_{\mathrm{ib}}\right)$ that is gently inclined to the external foliation (Goscombe \& Passchier, 2003; Passchier \& Trouw, 2005). This inter-boudin surface can be in the form of: (1) shear bands, (2) veins, or (3) fractures (Cloos, 1947; Rast, 1956; Uemura, 1965; Gosconbe \& Passchier, 2003) (Fig. 3). In some cases shear band boudin structures can be used as shear sense indicators (Goscombe \& Passchier, 2003). These tend to have a high mean aspect ratio (L/W) of 3 - 4 (Goscombe \& Passchier, 2003) (Fig. 3). When extension along the foliation is high complete isolation of adjacent boudins can occur via slip on the inter-boudin surface, which places shear band boudins in a boudin train structure (Goscombe \& Passchier, 2003). 


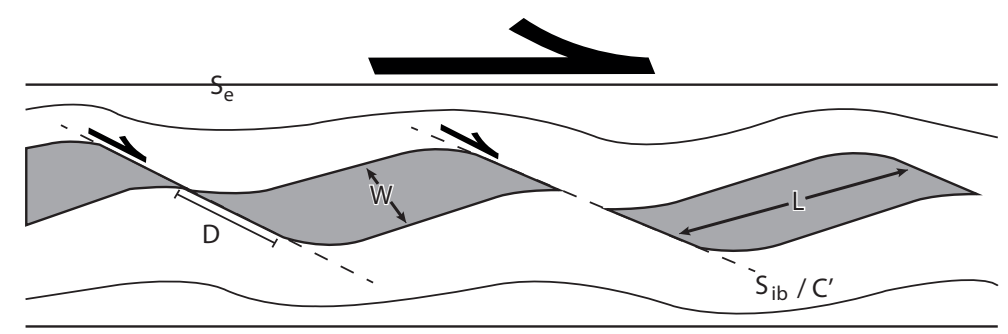

Fig. 3. Sketch illustrating the features of shear band boudins. This describes the nomenclature and symbols used. Explanation in text. Figure simplified from Goscombe \& Passchier (2003).

\subsubsection{Limitations in current understanding of extensional C' shears}

To date, detailed studies that document the spacing, slip and orientation of extensional shear bands as a function of bulk shear strain in relation to a kinematically well understood shear zone, are rare. A pervasive development of extensional shear bands in the central Southern Alps, including excellent exposures in Tatare Stream provides a rare opportunity to undertake such a study. In this study we measure precise attitudes of the extensional shear band planes relative to the SZB in the Alpine shear zone and we track changes in this attitude, spacing and offset as a function of distance from the Alpine Fault across a marked strain gradient. We ask the questions: Do the attitudes of extensional shears change with increasing finite shear strain? Did the shears nucleate parallel to the directions of maximum shear strain rate? What is the relationship between pervasively developed extensional shears and shear band boudins? Did the Alpine mylonite extensional shear bands develop in a simple shear zone or a stretching and thinning one? No investigation has been made to measure relative offsets and thickness of shear bands in natural shear zones, a gap that this paper will attempt to close.. Finally, understanding how shear bands may relate to the kinematics of general shear zones will allow them to be used more reliably for distinguishing between different types of shear zones (i.e., kinematic vorticity).

\subsection{Tectonic setting and structural framework}

\subsubsection{Alpine Fault and Southern Alps}

In the South Island, New Zealand, the dextral-reverse Alpine Fault $(\sim 25 \mathrm{Ma})$ (Sutherland et al., 2000) is the chief plate boundary fit between the Australian and Pacific Plates (Fig. 4). In the central Southern Alps this fault has an average strike of 
$053 \pm 2^{\circ}(2 \sigma)$ and it dips SE (Gillam et al., 2011 chapter 4 this thesis). In detail, its trace in that region is segmented in the near surface into a series of oblique-reverse and vertical strike-slip sections (Norris \& Cooper, 2007). The Nuvel-1 A plate motion model, which incorporates the last $\sim 3 \mathrm{~m}$.y. of global seafloor spreading data, infers a plate motion vector of $37 \mathrm{~mm} \mathrm{yr}^{-1}$ on an azimuth of $71 \pm 2^{\circ}(2 \sigma)$ in the region of the central Southern Alps (DeMets et al., 1994). This plate motion vector trends $\sim 20^{\circ}$ anticlockwise of the strike of the Alpine Fault and is expressed by oblique convergence across the Southern Alps. Surface geological (e.g., Sibson et al., 1979; Norris \& Cooper, 2007) and seismic reflection data (e.g., Davey et al., 1995; Kleffman et al., 1998) have been used to infer the mean dip of the Alpine Fault at the surface to mid-crustal depths is typically $40-50^{\circ}$ to the SE. Neotectonic studies indicate that the Alpine Fault has a dextral strike-slip rate of $27 \pm 5 \mathrm{~mm} / \mathrm{yr}$, accommodating about $70-75 \%$ of the margin-parallel component of the PacificAustralia Plate motion (Norris \& Cooper, 2000). The rate of late Quaternary dip-slip on the Alpine Fault is quite variable along strike reaching a maximum of $\sim 12 \mathrm{~mm} / \mathrm{yr}$ in the especially mountainous central Southern Alps (Norris \& Cooper, 2000).

Rapid erosional exhumation and associated uplift of the Alpine Schist, as it is brought to the surface by oblique-reverse slip on the SE-dipping Alpine Fault, has exposed a SE-tilted section of the Pacific Plates lower to middle crust (Fig. 4). Rocks that abut the eastern edge of the Alpine Fault have been exhumed from crustal depths of $\sim 20$ - $30 \mathrm{~km}$ (Grapes, 1995) over the last $\sim 3-5$ m.y to expose ductile fabrics from deep crustal levels of the active transpressive origin, at the surface (Little et al. 2002a). In the central part of the Southern Alps (near Franz Josef Glacier) a $\sim 1-2$ $\mathrm{km}$ thick zone of back-shears at a structural distance $7 \pm 1 \mathrm{~km}$ above the Alpine Fault are exposed (Little et al., 2002a). These back-shears strike sub-parallel to the Alpine Fault, and are inferred to been activated, in an escalator-like fashion, to accommodate tilting of the Pacific Plate rocks onto the Alpine Fault ramp (Little, 2004). The Alpine mylonite zone forms the structural base of this tilted crustal section and occurs as a strongly deformed zone, $\sim 1-2 \mathrm{~km}$ thick that is bounded to the west by the Alpine Fault (Sibson et al., 1979).

The Alpine Schist is a $\sim 20 \mathrm{~km}$ wide strip of east tilted Barrovian metamorphic rocks ( $\sim 86 \mathrm{Ma}$ ) (Vry et al., 2004) that constitutes the immediate hanging wall of the Alpine Fault. Across this strip the metamorphic grade decreases eastward and strictly 


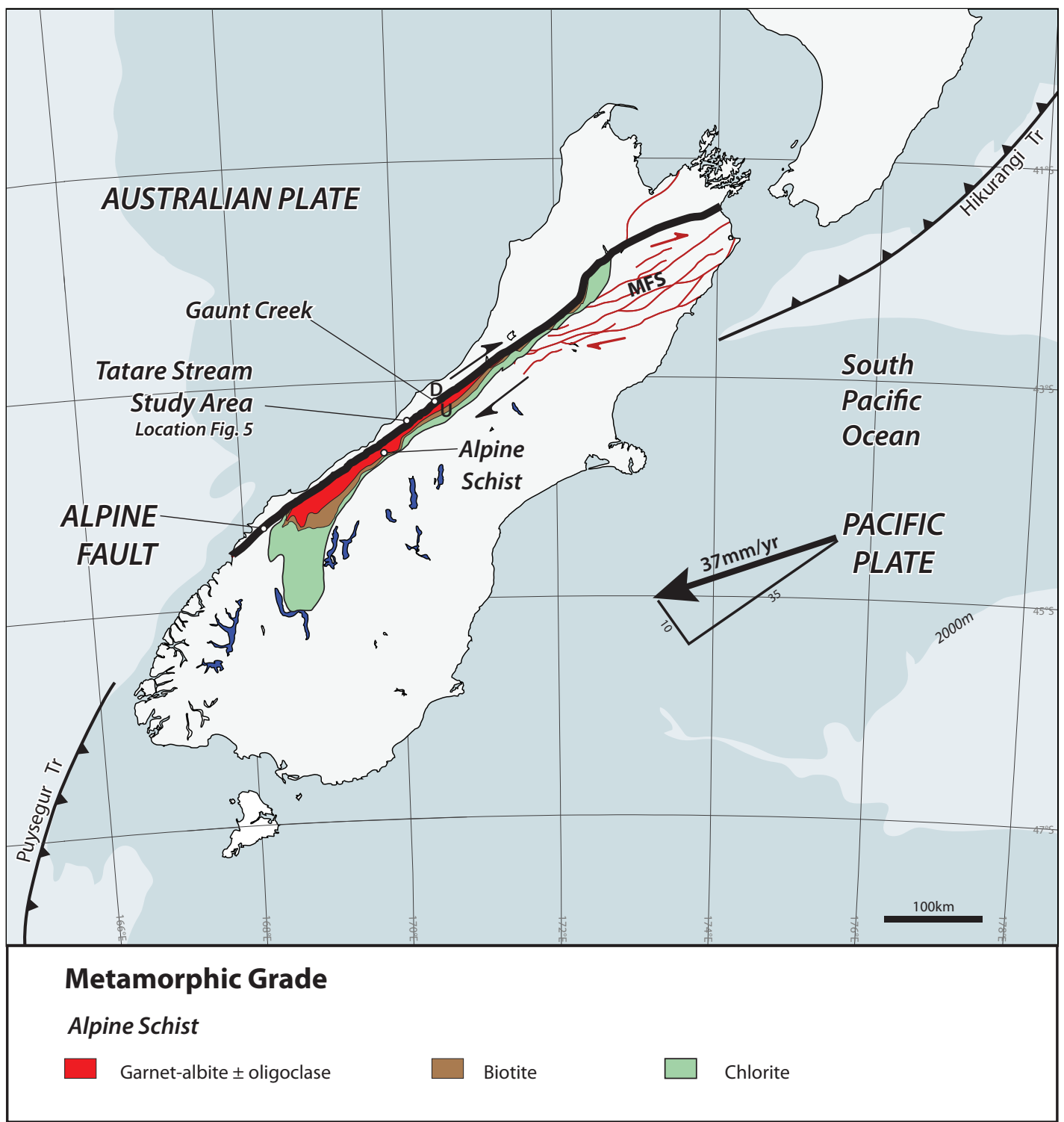

Fig. 4. Regional tectonic setting of the South Island of New Zealand showing the moden rate of plate motion between the Pacific Plate to the Australian Plate (using Nuvel 1A angular velocities from DeMets, et al. (1994), and the Alpine Fault Trace at Tatare Stream as a reference point), with normal and parallel motion with respect to the Alpine Fault. MFS - Marlborough Fault System. 2000m - bathymetric contour. Map also showing metamorphic grade of Alpine Schist. Data from N.Z. Geological Survey map (1979); Mortimer (2000); Murphy (2010). 
upward from garnet-oligoclase zone (amphibolite-facies) in the mylonitic rocks adjacent to the Alpine Fault, to chlorite zone (greenschist-facies) in the east (Fig. 4). The mylonite zone and its non-mylonitic hanging wall consist chiefly of metagreywacke derived greyschist, with subordinate pelitic and mafic units (Little et al., 2002a; Toy et al., 2008). Along its SE margin the mylonite zone is bordered by a 0.4-0.7 km thick zone of protomylonitic schist (we will further refer to this as the distal mylonite zone) (Sibson et al., 1979; Toy et al., 2008). In this zone, preservation of crenulation structures inherited from the (Mesozoic) non-mylonitic Alpine Schist such as SW-pitching fold and crenulation hinges $\left(\mathrm{L}_{2 \times 3}\right)$ is widespread and characteristic; however, the rocks are also pervaded by younger, late Cenozoic extensional C' shear bands. In the main (central) part of the mylonite zone, farther to the NW, the dominant lineation in the schist is a quartz rodding lineation that has been inherited from its non-mylonitic precursor; however, it has been strongly deformed in the dextral-reverse shear zone and now it plunges NE (Sibson et al., 1979; Little et al., 2002a; Toy, 2007).

Finite shear strains in the mylonite zone have been estimated in parts of the Southern Alps (Norris \& Cooper, 2003). These estimates were based on a statistical analysis of deformational thinning of pre-shearing pegmatite dikes in the Alpine Schist that were later deformed in the Alpine mylonite zone (Norris \& Cooper, 2003). Depending on what type of flow is assumed for the Alpine mylonite zone (e.g., simple shear, or sub-simple shear that includes a pure shear thinning factor of up to 3) these thickness variations can be used to model the finite shear strain parallel to the Alpine Fault across the diffuse zones in the Alpine mylonite zone. For assumed simple shear (thinning factor of 1.0) and general shear (thinning factor of 3.0) shear strain estimates between 12 to 32 were modeled for the distal mylonites (lower estimates correspond to general shear with a thinning factor of 3, higher estimates to simple shear) and 100 to 200 in the central mylonite zone (Norris \& Cooper, 2003).

\subsubsection{Tatare Stream structural geology}

Tatare Stream (Fig. 4) exposes an excellent structural section from the garnet zone non-mylonitic Alpine Schist, to the SE; through the shear-banded part of the distal mylonite zone, further to the NW; and including the upper part of the main 
Alpine mylonite zone in the most NW outcrops (Fig. 5a). The ultra-mylonite zone and the Alpine Fault are covered by alluvium. In Tatare Stream the dominant foliation in the non-mylonitic Alpine Schist (see insert in Fig. 5b) $\left(\mathrm{S}_{3}\right)$ strikes $053 \pm$ $2^{\circ}(2 \sigma)$ and dips $63 \pm 2^{\circ} \mathrm{SE}(2 \sigma)$ (for fabric nomenclature see Little et al., 2002a). Vergence changes relative to $\mathrm{S}_{3}$ have been able to be used to map several $\mathrm{km}$-scale $\mathrm{F}_{3}$ folds of $\mathrm{S}_{2}$ (Fig. 5a). The dominant lineation in the non-mylonitic Alpine Schist is a crenulation lineation parallel to the intersection of the $S_{2}$ and $S_{3}$. This distinct lineation is typically expressed by a strong quartz rodding at the outcrop scale caused by the intersection of the $S_{2}$ quartz laminae with the $S_{3}$ plane. The $L_{2 \times 3}$ intersection lineations and hinges of the $\mathrm{km}$-scale $\mathrm{F}_{3}$ folds plunge $\sim 20^{\circ} \mathrm{SW}$ in Tatare Stream (Little et al., 2002a; Gillam et al., 2011 chapter 4 this thesis) (Fig. 5a arrow symbols).

A gradational contact is observed between the non-mylonitic Alpine Schist and the distal part of the Alpine mylonite zone (Fig. 5a). The latter is defined by the appearance of ubiquitous extensional C' shear bands that pervade the rock at $\mathrm{mm}$ to cm-scale and that cut and offset the older, yet still distinct $S_{3}$ foliation (Fig. 6a). The distal mylonite zone is $\sim 600 \mathrm{~m}$ thick in Tatare Stream. There, the lower boundary of the main mylonite zone against the ultra-mylonites does not outcrop (for a field description of the ultra-mylonites see Toy et al., 2008); however from the known mylonitic outcrop and Alpine Fault trace a total thickness of $800 \mathrm{~m}$ is estimated for the Alpine mylonite zone (including the unexposed ultra-mylonites). With increasing proximity to the Alpine Fault, further to the NW, the $\mathrm{S}_{3}$ fabric becomes increasingly planar and finely quartz laminated as a result of a progressive increase in the intensity of the late Cenozoic mylonitic overprint. This overprint is also expressed by an increased oppression of the $F_{3}$ crenulation micro-folds of $S_{2}$ and transposition of the $\mathrm{S}_{2}$ planar remnants so that they become indistinguishable from $\mathrm{S}_{3}$. The distal mylonite zone preserves the characteristically SW-pitching $\mathrm{L}_{2 \times 3}$ intersection/quartzrodding lineation inherited from the non-mylonitic Alpine Schist. This lineation retains the SW plunge despite the way that deformation in the distal mylonite zone has been strongly localized into shear bands. The distal mylonite zone has informally been referred to as the "curly schist" (Reed, 1964); a term that relates to the sigmoidal deflection of the $\mathrm{S}_{3}$ foliation between adjacent bounding $\mathrm{C}^{\prime}$ shears on either side of the microlithon. The sense of deflection of $\mathrm{S}_{3}$ across the $\mathrm{C}^{\prime}$ shear bands 


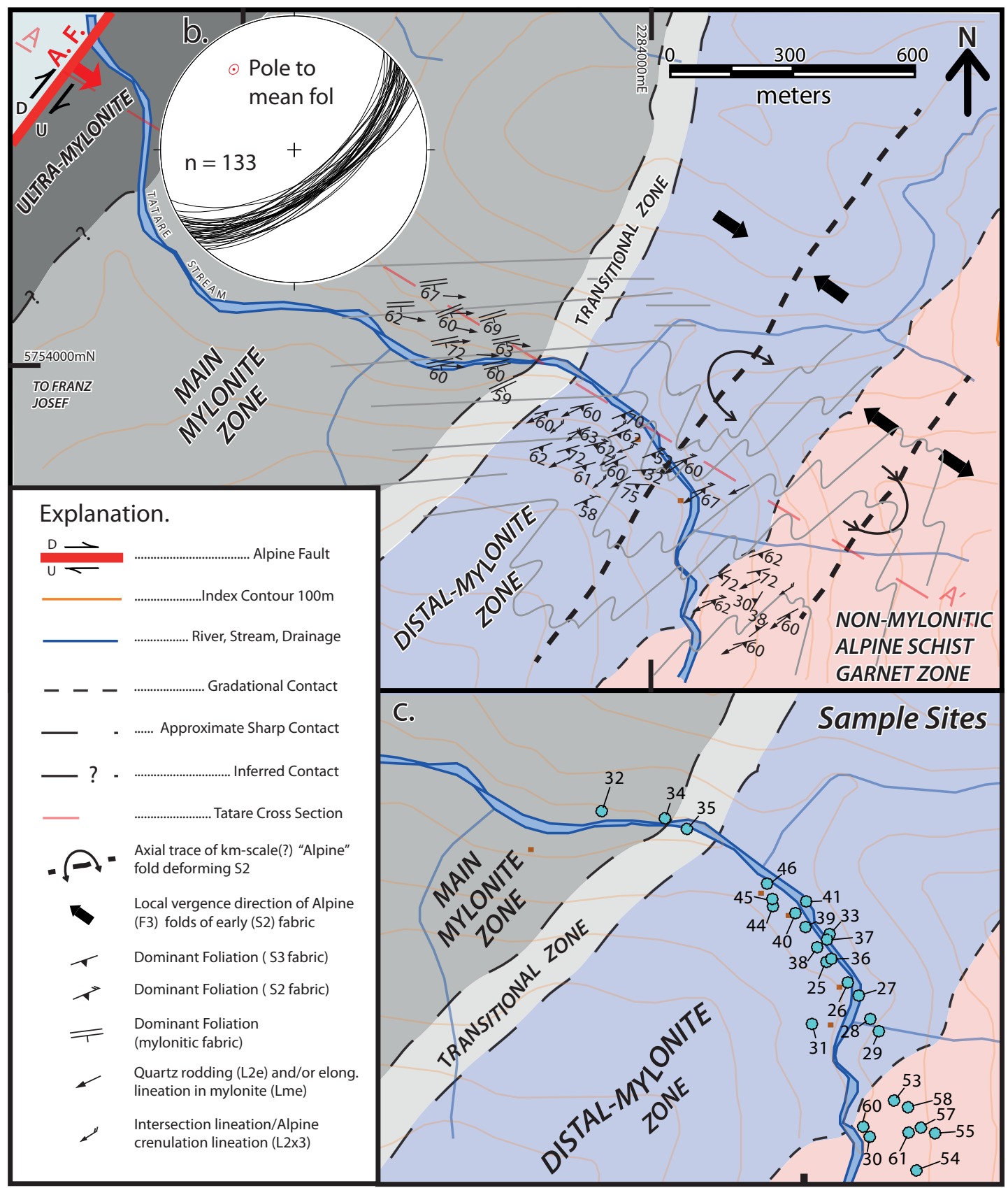

Fig. 5. (a) Bedrock structural geology of the Alpine Schist at Tatare Stream near Franz Josef Glacier. Trace of Alpine Fault is from Norris and Cooper (1995). Position of ultra-mylonite is approximated from the thickness distributions in Gaunt Creek to the north from Toy et al., (2008). (b) Stereographic projection of 133 non-mylonitic, protomylonitic, and mylonitic foliations attitudes in Tatare Stream with a mean foliation pole 323/27 and 95\% confidence ellipse on mean pole. (c) Sample localities in Tatare Stream for thin-section analysis. 
is everywhere consistent with dextral-reverse shearing that is synthetic with the Alpine Fault.

In Tatare Stream the distal mylonite zone and mylonite zone are separated by an $\sim 50 \mathrm{~m}$ wide, transitional zone (Fig. 5a). Across this transitional zone the SWpitching $\mathrm{L}_{2 \times 3}$ lineation (quartz rods) changes pitch gradually by $\sim 140^{\circ}$ in an anticlockwise sense to achieve the gently NE-pitching orientation typical of the main mylonite zone. In detail, the transitional zone is not gradational but occurs in a more punctuated fashion so there are m-scale domains in which both NE and SW lineation plunges are observed.

The uppermost $\sim 250 \mathrm{~m}$ of structural section of the main mylonite zone is exposed in Tatare Stream (Fig. 5a). There, the mylonite fabric includes the same strong quartz rodding lineation, which we infer to be inherited from the adjacent non-mylonitic Alpine Schist, but which has been reoriented to a NE plunge during deformation (see also Toy, 2007; Toy et al., 2011 in review; Gillam, 2011 chapter 4 this thesis). In Tatare Stream the lineation in the main part of the mylonite zone plunges NE at an average angle of $17^{\circ}$. The main mylonite zone, like the distal mylonite zone to the SE, contains mm-spaced extensional C' shears that cut and deflect the mylonitic foliation $\left(\mathrm{S}_{\mathrm{m}}\right)$. A remarkable feature of the Tatare Stream section is that across the entire finite strain gradient related to the transition between non-mylonitic to mylonitic rocks the attitude of the foliation (variably non-mylonitic, distal mylonite, and mylonitic) remains consistent at 053/63SE.

In the mylonitic and protomylonitic zones at Tatare Stream the dominant quartzofeldspathic (metagreywacke) protolith is locally interlayered with $\sim 1-2 \mathrm{~m}$ thick zones of micaceous pelitic schist and amphibolite mafic schist. The distal and main mylonite zones consist chiefly of quartzofeldspathic greyschist that includes $\sim 2.5 \mathrm{~mm}$ thick quartz laminae that are foliation parallel and lesser lenticular concordant quartz veins up to $4 \mathrm{~cm}$ thick. Both are cut and offset by the C' shear bands. Mafic amphibolite and pelitic-rich schist are interlayered with greyschist in lenses $1-2$ m thick. In Tatare Stream, the main part of the mylonite zone contains a slightly greater abundance of micaceous pelitic schist than does the distal mylonite zone adjacent to it to the SE, which is more uniformly psammitic in composition. 
Various different styles of boudinage are present in mylonite zone in Tatare Stream. Symmetrical foliation boudins occur in the strongly foliated quartz laminated schist (Platt \& Vissers, 1980; Arslan et al., 2008). These most commonly include small-scale pull-apart structures filled with diamond or lozenge deformed veins consisting of quartz or calcite. The foliation around these veins has been pinched inwards so that the structures superficially resemble layer boudins. These structures differ from classical boudins in that they do not occur in trains and are not associated with any obvious layer parallel compositional contrasts. The thicker foliation parallel quartz veins and the mafic amphibolite units display shear band boudinage indicating that the thick quartz layers and the mafic rocks were both stiffer than the more common mixed quartz-feldspar-mica lithologies during mylonitic deformation (Fig 6b). These shear band boudins are synthetic in shear sense to that of the bulk shear zone and have elongate and curved, lenticular shapes with back rotation against the sense of shear (see also Goscombe \& Passchier, 2003). Complete isolation of boudins commonly occurred, so that the boudin elements occur in trains separated by the inter-boudin shear surface (either $\mathrm{S}_{\mathrm{ib}}$ or C'). Lastly, where interlayering occurs the more classical type of layer boudinage is observed (Fig. 6c). Foliation parallel quartz veins apparently behave as stiff layers as they have been boudinaged between surrounding pelitic-rich schist zones. In this example, more typical quartz laminated greyschist underwent foliation boudinage to form a foliation lens that is $20-30 \mathrm{~cm}$-thick by $\sim 1 \mathrm{~m}$ long. Such boudins resemble a teardrop shape aligned parallel to the foliation and separated from one another by a dilative cavity. All these types of boudinage observed in Tatare Stream indicate that there has been finite extension parallel to the dominant foliation and at right angles to the $\mathrm{S} / \mathrm{C}^{\prime}$ intersection line.

\subsection{Analytical methods of extensional C' shear geometries in Tatare Stream}

\subsubsection{Macroscopic outcrop extensional C' shears}

At the outcrop scale the following geometrical properties of the extensional shear bands were measured: (1) the spacing between consecutive C' shears, (2) the amount of slip on each shear band, and (3) the thickness of the layers of different lithology (e.g. quartz-feldspar vs. mica) that define the foliation (S) deflected by the C' shears. Three different foliation parallel lithologies were observed: (1) quartz laminated 

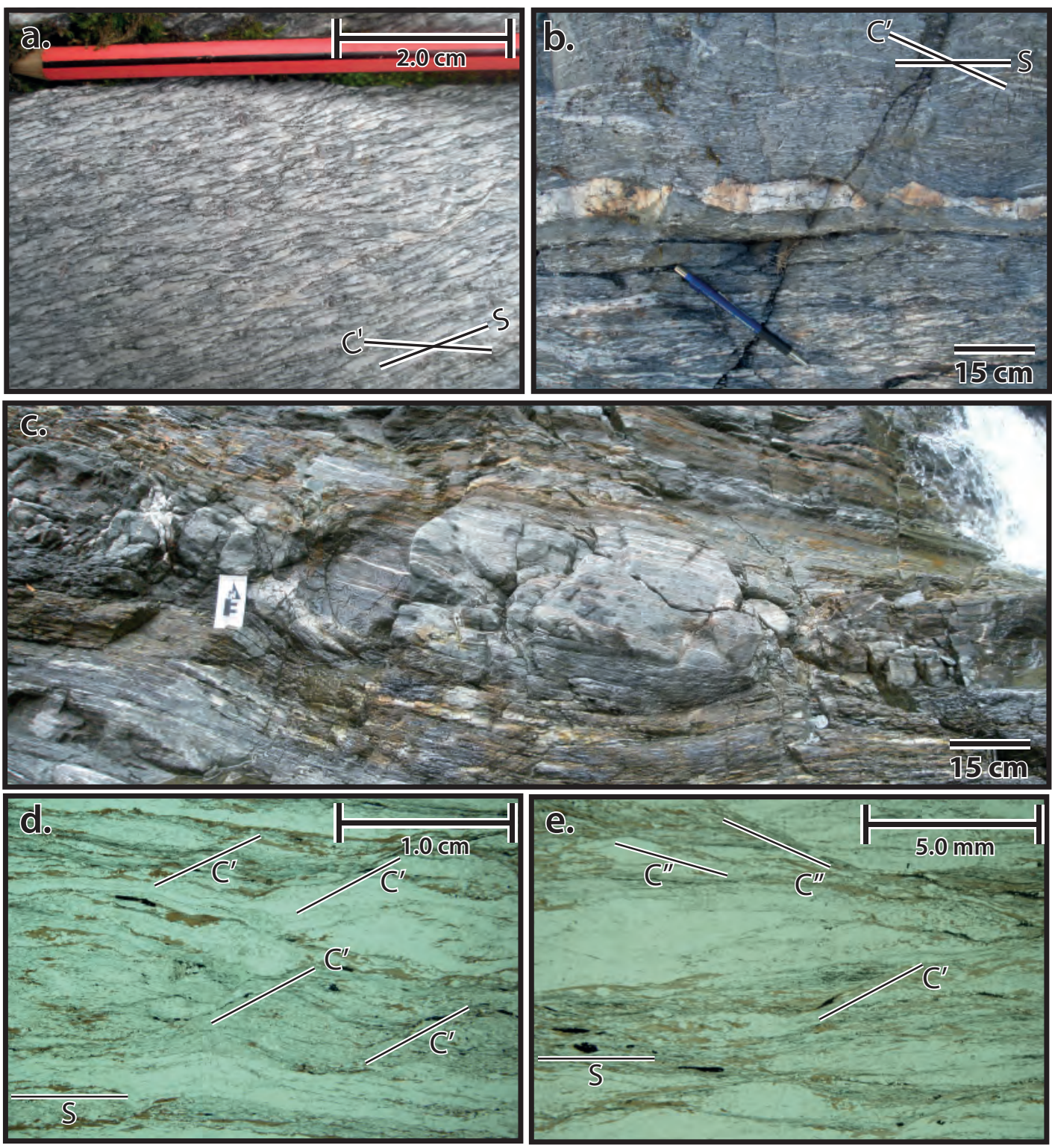

Fig. 6. Photomicrographs and outcrop photos of the central Alpine mylonite zone in Tatare Stream. Scale bar is positioned in the down-dip direction for the photomicrographs. (a) Outcrop photo of the mylonite zone with $\mathrm{mm}$-scale quartz laminations and pervasive extensional $\mathrm{C}^{\prime}$ shears. (b) Outcrop photo in the distal mylonite zone of shear band boudins. (c) Outcrop photo of layer boudinage in a mafic lithology, distal mylonite zone. (d) Photomicrograph (plane light) of $C^{\prime}$ shears (arrows). Sense of shear is top up-dip (dextral-reverse). (e) Photomicrograph of $C^{\prime}$ and $C^{\prime \prime}$ structures. 
schist (here grouped for convenience into two categories; with layer thicknesses of either $0-10 \mathrm{~mm}$, or $>10 \mathrm{~mm})$, (2) mafic amphibolite $(<\sim 1 \mathrm{~m})$, and (3) micaceous garnet-rich pelitic schist. Measurements were made using a tape and $500 \mu \mathrm{m}$ increment ruler draped across outcrop faces in order to construct structural transects through arrays of shears bands. Outcrops were selected for this analysis if there were large clean faces that lay close to the M-plane orientation (identification of this will be discussed later). A measuring tape was extended across the outcrop approximately perpendicular to the Alpine Fault strike, and perpendicular to the $C^{\prime}$ traces on that face. The 4 variables (shear spacing, per-shear thickness, lithology type and thickness and per-shear offset of the (S) foliation fabric) were measured as a function of distance along this tape. At each outcrop site the attitude of the outcrop face, the foliation (S), and the shear bands (C') were all measured. Wherever possible the latter was calculated from multiple observations of apparent dips of the shears on different orientated faces not only on the main outcrop face but also on other nearby faces that were not parallel to it. Apparent offsets of the $S$ foliation across the trace of the shear bands on the outcrop face were also measured (Fig. 7).

\subsubsection{Outcrop scale extensional C' apparent offset and spacing correction}

Once these data were collected on a given outcrop face a correction was made to convert the apparent spacing and offsets to that of the actual movement plane (Mplane). The M-plane was determined by finding the plane that was normal to both the foliation (S) and the C' plane using the program GeoCalculator@ 4.9.3. (Holcombe, 1999). Knowing the orientation of the M-plane and the orientation of the outcrop face allowed the sectional observations to be converted trigonometrically from apparent offsets and spacings on the outcrop surfaces to actual distances in the direction of shear (Fig. 7).

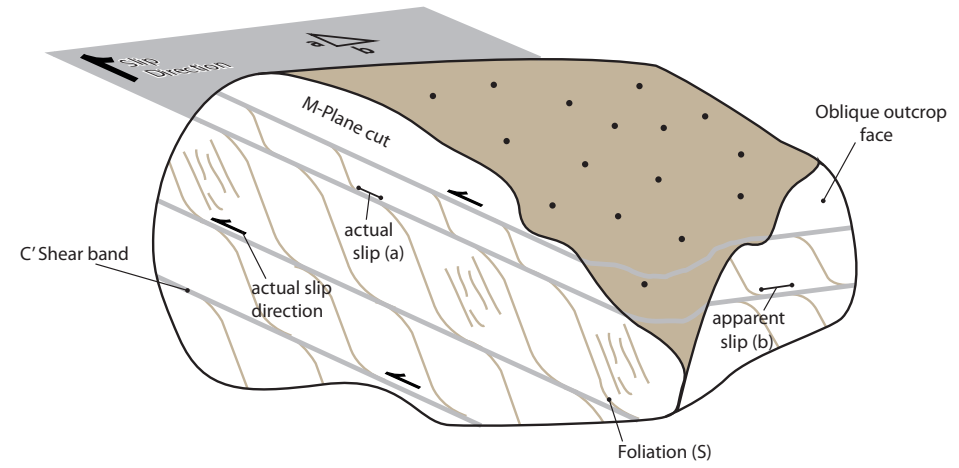


Fig. 7. Previous page. Schematic diagram depicting movement plane (M-plane) $C^{\prime}$ shear band offsets versus apparent offsets on obliquely orientated outcrop faces.

\subsubsection{Microscopic observation of extensional C' shears}

Synthetic C' shear bands are oblique $\left(\sim 30^{\circ}\right)$ to the SZB and to the older foliation $\left(\mathrm{S}_{3}\right)$ in the Alpine mylonite zone, where they are most obvious in more strongly foliated micaceous lithologies (Fig. 6d). At the microscopic scale synthetic C' shear bands are discontinuous. In other words, they are typically only $\sim 2-3 \mathrm{~cm}$ long. The relative grain size of mica in the microlithons is $200-300 \mu \mathrm{m}$. This is reduced to less than $\sim 50 \mu \mathrm{m}$ locally in the C' shears (Fig. 6d). The synthetic C' shears are typically lined with biotite and chlorite, which is preferentially aligned parallel to the C' traces. At the C' boundaries, mica grains either curve into or are cut off by the C' shears and the quartz grains are truncated. The microlithons between C' shears are defined by parallel quartz and micaceous materials with a strong grain shape preferred orientation. The quartz grains are $200-300 \mu \mathrm{m}$ in diameter and are interleaved with $>500 \mu \mathrm{m}$ thick planar micaceous domains. If there had been planar slip parallel to these micaceous and quartz domains, one would expect step like offsets in the C' shears; these are not observed. Commonly, only one low angle set of $\mathrm{C}^{\prime}$ is developed with dextral-reverse kinematics synthetic to the Alpine fault, however in a few samples a second steeper set (C',) with antithetic slip directions may be present; in which case it is conjugate to the more dominant low angle synthetic C' (Fig. 6e).

In thin-section cuts parallel to the M-plane microscopic extensional C' thickness, spacing and offsets were measured with the aid of digital imaging software (AnalySIS TM). For obliquely cut sections true offsets and spacing were calculated trigonometrically from the apparent offsets and spacing on $2-3$ different thinsection cuts at each sample locality (Fig. 5c). As mentioned, the shear bands at the microscopic scale are discontinuous so my approach was to find a part on that section that had five or more shears pervasively developed in succession deflecting the $\mathrm{S}$ planes.

\subsubsection{Extensional C' shear band orientation}

We have developed an extensional shear band orientation code (SBOC) to determine precise C' attitudes from apparent C' dip lines in variably oriented outcrop 
faces and thin-section cuts. Trend and plunge data for the foliation pole and apparent extensional C' dip lines (trend and plunge) are converted to unit vector representations. For each sample location (either outcrop or thin-section cut) the trend and plunge data are classified into subsets with similar trend and plunge values, as follows. The subsets for C' laboratory thin section data are specified in advance as extensional C' dip lines are confined to pre-determined thin-section cuts (e.g., ductile shearing direction) and not randomly oriented outcrop faces. The pairwise Euclidean distances between C' vectors for outcrop data are calculated using the MatLab "pdist" routine, and then the MatLab routines "linkage" follow by 'cluster' return the subsets within a maximum of 22.5 degrees of each other. The subsets are used in the error assessment. The best fitting pole for the extensional C' plane is calculated by finding the vector (eigenvector) that gives the smallest scatter of the $C^{\prime}$ trend/plunge vectors about any plane. The method is identical to that of GEOrient(C), ver 9. 4. 4 (Holcombe, 1999).

Random sample sets of 500 are drawn from the C' data of size equal to the number of data per outcrop/thin-section in such a way that every subset has the same number of random samples as the original subset. The sampling is done with replacement; that is, having selected a data point, it remains available for reselection. In this way a reasonable range of values is maintained for C' pole calculation. A C' pole is then calculated for each random sample, giving a spread of C' poles that represent the uncertainty in the original best C' pole. This process of resampling the original data, with replacement, is called "bootstrap sampling" (see e.g., Efron \& Tibshirani 1994; Varian 2005). For each C' bootstrap pole, a transport direction (vector) is calculated using the measured and inputted foliation pole. A plot is produced displaying the besting fitting C' plane (red), best C' pole and bootstrap poles (blue) and foliation pole and transport directions (black) (see appendix B this thesis).

\subsection{Results}

\subsubsection{Determination of the shear zone boundary in Tatare Stream}

In a deforming zone undergoing a progressive, non-coaxial deformation, passive material lines and planes will rotate towards the fabric attractor (Passicher, 1997). This plane contains the extensional eigenvector of flow and for a shear zone will be 
coincident with the SZB (Passchier \& Trouw, 2005). The dominant foliation in all parts of the Alpine Schist in Tatare Stream has a remarkably consistent attitude (Fig. $5 b)$. This is equally true for the non-mylonitic Alpine Schist $\left(\mathrm{S}_{3}\right)$; the distal mylonite zone $\left(\mathrm{S}_{3}\right.$ cut by extensional shear bands) and the main mylonite zone $\left(\mathrm{S}_{\mathrm{m}}\right)$. The mean attitude of the foliation inside and outside the Alpine mylonite zone is 053/63SE (Fig. 5b). On this basis of this observation, we infer that the Alpine Fault SZB is parallel to that mean foliation attitude because only planes that are disposed parallel to the SZB will remain in a single stable orientation throughout an intense superposition of shearing across a strain gradient. The Alpine Fault SZB can be confidently identified as striking 053 and dipping $63^{\circ} \mathrm{SE}$.

\subsubsection{Orientations of synthetic $C$ ' and antithetic $C$ "' shears.}

Precise outcrop and thin-section shear band orientations were determined by finding the best fitting, site specific, average plane for the range of apparent dips observed in different thin-sections and on different outcrop faces, using the Matlab script (SBOC) described earlier. Inputting apparent dip-line orientations from variously orientated thin-section cuts into the SBOC leads to that program calculating a "best-fit" synthetic C' or antithetic C", attitude and error. Within the results, there are no statistically significant changes in C' shear attitude over the 700 $\mathrm{m}$ of outcrop towards the Alpine Fault in Tatare Stream. This invariance of shear band attitude is typical of all parts of the shear zone deformed in the late Cenozoic. Three hundred and sixty two apparent synthetic C' dips and 188 antithetic C', apparent dips allowed calculation of forty eight site averaged C' extensional shear bands that have an average $C^{\prime}$ strike of $064 \pm 3.7^{\circ}(2 \sigma)$, and an average dip of $38 \pm$ $3.1^{\circ} \mathrm{SE}(2 \sigma)$ (Table. 1). The average antithetic C', strike is $205 \pm 12.15^{\circ}(1 \sigma)$, and the average dip is $79 \pm 0.85^{\circ} \mathrm{NW}(1 \sigma)$. The obtuse angle between the two conjugate mean shear planes $\left(C^{\prime}\right.$ and $\left.C^{\prime \prime}\right)$ is $109 \pm 18^{\circ}(1 \sigma)$ (Table. 1).

\subsubsection{Direction of Ductile Shearing in the Alpine Mylonite Zone}

Based on the above data on site specific C' orientations plus foliation attitude data we calculated the attitude of the $\mathrm{S}$ and $\mathrm{C}^{\prime}$ intersection line at 25 outcrops in the distal mylonite and mylonite zones. The plane perpendicular to this line was taken to coincide with the local movement (M) plane; and to be parallel to the direction of ductile shearing; in contrast to interpretations of shear sense based on a kinematic 
Table 1. Calculated shear band geometries using the SBOC; combination of both outcrop and thin-section observations.

Number of shear bands used $=48$ (site averaged)

Number of foliation measurements $=133$

\begin{tabular}{|c|c|}
\hline Attribute & Calculated Data \\
\hline Mean attitude of foliation (S) & $053 / 63^{\circ} \mathrm{SE}$ \\
\hline Mean Attitude of C' plane & $064 / 38^{\circ} \mathrm{SE}$ \\
\hline Mean attitude of C" plane & $205 / 79^{\circ} \mathrm{NW}$ \\
\hline Dihedral angle $C^{\prime}(2 \sigma)$ & $30 \pm 2.2^{\circ}$ \\
\hline Dihedral angle C" (2 $\sigma)$ & $135 \pm 3^{\circ}$ \\
\hline $\begin{array}{l}\text { Mean dihedral angle } \\
\text { between C'and C'shears }\end{array}$ & $109^{\circ}$ \\
\hline $\begin{array}{l}\text { Calculated ductile shear } \\
\text { azimuth based on } C^{\prime}(2 \sigma)\end{array}$ & $90 \pm 6^{\circ}$ \\
\hline $\begin{array}{l}\text { Calculated ductile shear } \\
\text { azimuth based on C" }(2 \sigma)\end{array}$ & $090 \pm 14^{\circ}$ \\
\hline $\begin{array}{l}\text { Mean width of } C^{\prime} \text { shears } \\
\text { in thin-section } \mu \mathrm{m}(1 \sigma)\end{array}$ & $128 \pm 20$ \\
\hline $\begin{array}{c}\text { Mean intra-shear band } \\
\text { finite } \gamma \text { (distal mylonite at } 1 \sigma)\end{array}$ & $15.5 \pm 5.4$ \\
\hline $\begin{array}{c}\text { Mean intra-shear band } \\
\text { finite } \gamma \text { (mylonite zone at } 1 \sigma)\end{array}$ & $9.8 \pm 0.8$ \\
\hline
\end{tabular}



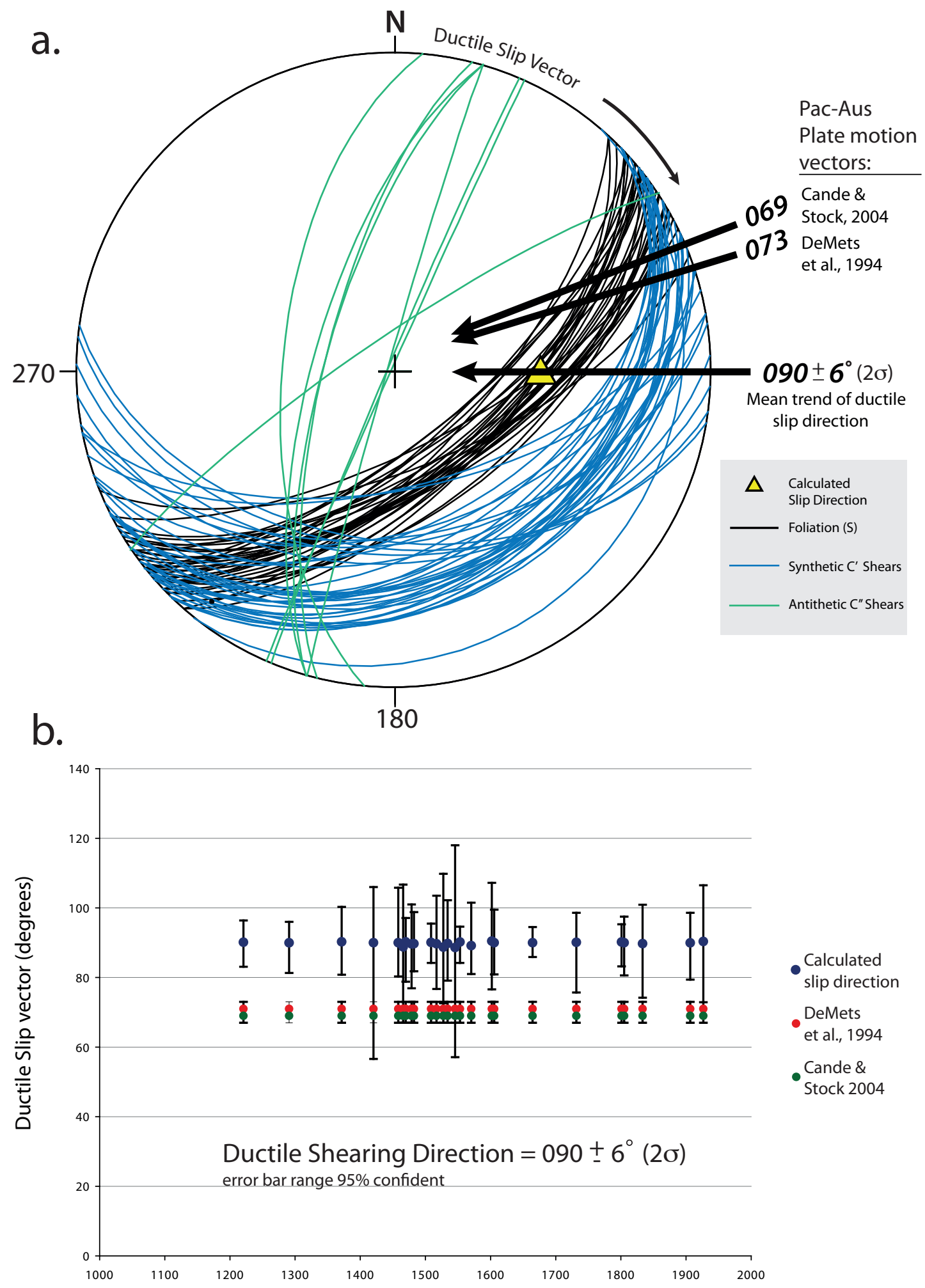

Structural distance above Alpine Fault (m)

Fig. 8. (a) Attitude of extensional synthetic $\left(C^{\prime}\right)$ and antithetic $\left(C^{\prime \prime}\right)$ shears at Tatare Stream. The ductile slip vector was calculated as the perpendicular to the intersection lineation of the $S$ and $C^{\prime}$ planes that lies in the mylonitic foliation plane (parallel to the Alpine Fault). (b) Scatter plot showing the calculated ductile slip vector at specific outcrop localities (Fig. 5c) in Tatare Stream. Error bars denote a $95 \%$ confidence interval in the ductile slip direction. 
interpretation of lineations in the Alpine mylonite zone of which are obviously inherited from the non-mylonitic precursor schist (Sibson et al., 1979). The kinematic analysis is based on $\mathrm{S}$ and $\mathrm{C}$ ' intersections and does not require any assumptions about the origin of the lineations or the flow kinematics in the mylonite zone, such as an assumption of bulk simple shearing across the zone (e.g., Sibson et al., 1981). Above, we inferred that the foliation plane is parallel to the SZB. We use the intersection of mean foliation plane with the extensional C' shear band attitudes to calculate mean slip vector trend in the Alpine mylonite zone. This is $090 \pm 6^{\circ}(2 \sigma)$ (Fig. 8a) or pitches $56 \pm 6^{\circ}(2 \sigma)$ and is inferred to lie in a shear zone plane that has a strike and dip of 053/63SE (i.e., Alpine Fault is the reference plane). Previous estimates for the trend and plunge of the ductile slip direction using a similar $\mathrm{S}$ and C' intersection method on much smaller data sets and without the fitting of apparent dips from multiple faces/sections, range from $072 \pm 6^{\circ}$ to $078 \pm 6^{\circ}(2 \sigma)$ (Wightman, 2000; Little et al., 2002; Toy, 2007). By a similar method but using the intersection of the antithetic C" shears with the SZB, we can define a slip vector trend of $090 \pm$ $14^{\circ}(2 \sigma)$ (Table. 1). The results suggest that the direction of ductile shearing, at least at the time the shear bands were forming, throughout the mylonite and distal mylonite in Tatare Stream varies only by $2-3^{\circ}$ over the entire $700 \mathrm{~m}$ despite the large inferred finite strain gradient between the mylonite and distal mylonite zones (Fig. 8b). Moreover, this direction pitches significantly down-dip relative to the pitch of the Pac-Aus Plate motion vector (here, $38 \pm 2^{\circ}$ at $1 \sigma$, DeMets et al., 1994) in the reference plane of the Alpine Fault.

\subsubsection{Dihedral angle $(\delta)$ between the shear zone boundary and $C$ ' and $C$ " shears}

Across the distal mylonite and mylonite zone the site-specific mean attitude of C' shear bands was determined at 39 different outcrops. At these sites the mean dihedral angle between the $(\mathrm{S})$ foliation and $\mathrm{C}^{\prime}$ shear plane is $30 \pm 2.2^{\circ}(2 \sigma)$ (Table 1) regardless of which part of the mylonite zone is sampled; that is, regardless of the magnitude of the inferred late Cenozoic shear strain. A similar mean dihedral angle of $32 \pm 7^{\circ}(1 \sigma)$ from the attitudes of 63 pairs of S and C' planes was determined by Little et al., (2002) for a single outcrop in Tatare Stream. The average dihedral angle at each outcrop is plotted against its proximity to the Alpine Fault. Viewing the entire data set, no systematic change in the mean dihedral angle is evident between the mylonite and distal mylonite zones despite the inferred contrasts in finite shear 
a.

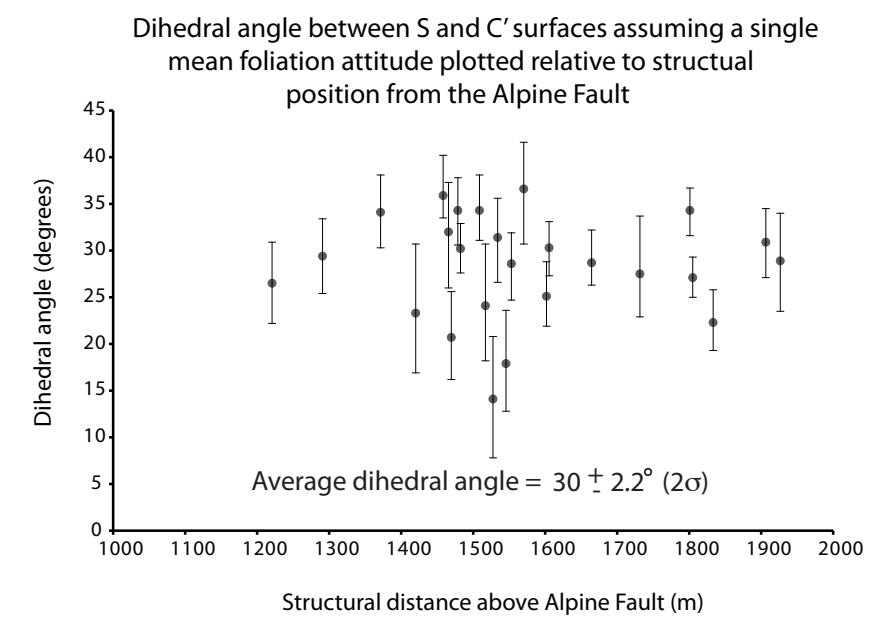

b.

Dihedral angle between $S$ and $C^{\prime}$ surfaces assuming a single mean foliation attitude

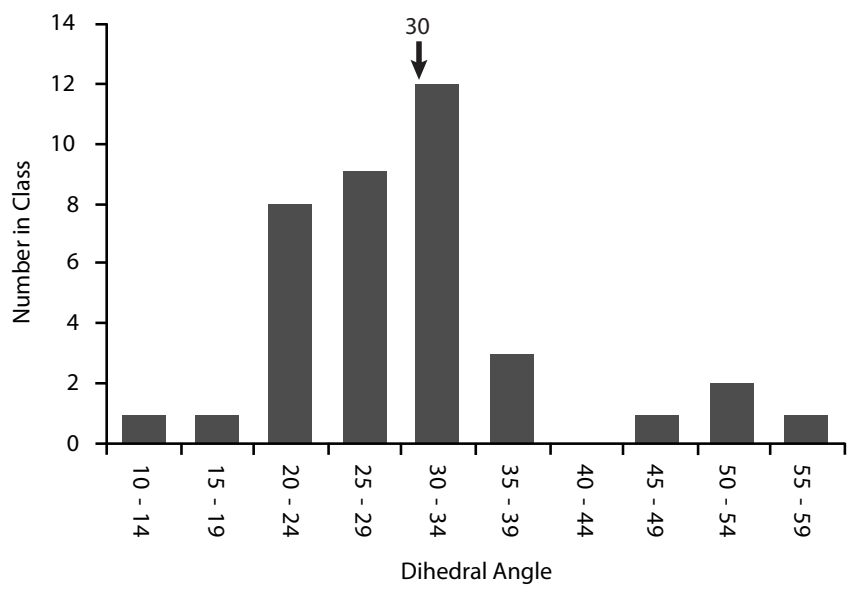

C.

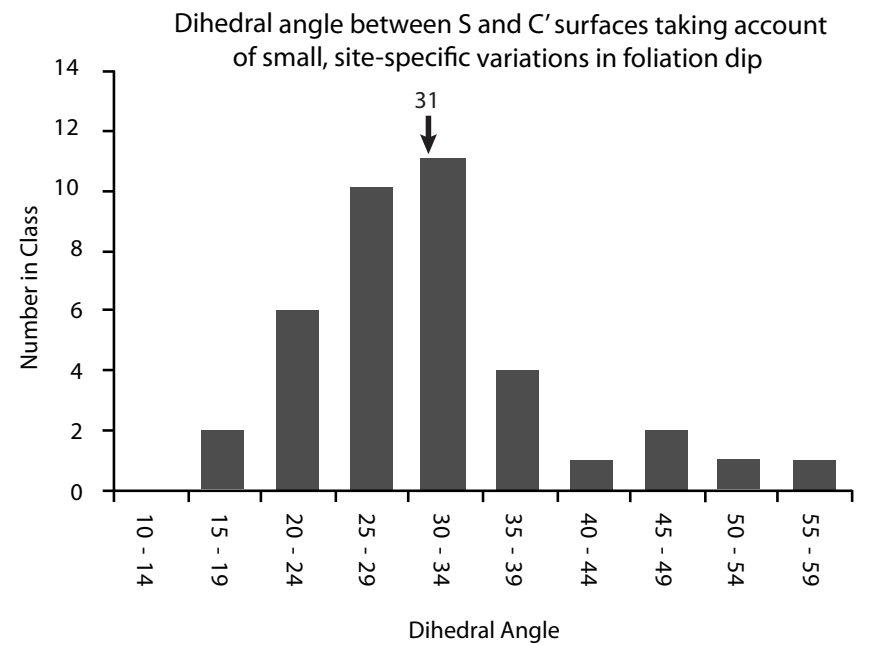

Fig. 9. (a) Scatter plot of mean dihedral angles (Fig. 1.) at specific outcrop sites (Fig. 5c) in Tatare Stream. Error bar range depicts a $95 \%$ confidence. (b) Histogram of the distribution of dihedral angles between $\mathrm{C}^{\prime}$ shears and a single mean foliation attitude. (c) Histogram of the distribution of dihedral angles between $C^{\prime}$ taking account of small, site-specific variations in foliation dip. 
Table 2. Geometric parameters of extensional shears measured at the outcrop scale, Tatare Stream. Number of shear bands used $=\mathbf{5 8 0}$

\begin{tabular}{|c|c|c|c|c|c|c|}
\hline Layer Type & $\begin{array}{c}\text { Total distance } \\
\text { measured }(\mathbf{m m})^{*}\end{array}$ & $\begin{array}{c}\text { Number of } \\
\text { shears }\end{array}$ & $\begin{array}{c}\text { Average offset } \\
(\mathrm{mm})(1 \sigma)\end{array}$ & $\begin{array}{c}\text { Average } \\
\text { spacing }(\mathbf{m m})\end{array}$ & Total offset $(\mathrm{mm})$ & Bulk $\gamma(1 \sigma)$ \\
\hline Quartz (0-10mm) & 7310 & 316 & $4.72+/-2.8$ & 23.13 & 1491.52 & $0.20+/-0.12$ \\
\hline Quartz (>10mm) & 1481 & 43 & $8.12+/-3.2$ & 34.44 & 349.16 & $0.24+/-0.08$ \\
\hline Mafic & 910 & 38 & $15.1+/-7.3$ & 23.95 & 573.8 & $0.63+/-0.31$ \\
\hline Garnet Schist & 2624 & 183 & $4.7+/-3.14$ & 14.34 & 860.1 & $0.33+/-0.21$ \\
\hline Total & 12325 & 580 & $8.16+/-4.9$ & 23.97 & 4732.8 & $0.38+/-0.3$ \\
\hline
\end{tabular}

* Total distance is the cumulative distance along the outcrop perpendicular to the strike of the $C^{\prime}$ shear bands

Table 3. Geometric parameters of extensional shears measured at the thin-section scale, Tatare Stream. Number of shear bands used $=100$

\begin{tabular}{|l|r|r|r|r|r|r|}
\hline Zonal Domain & $\begin{array}{c}\text { Total distance } \\
\text { measured }(\mathbf{m m})^{*}\end{array}$ & $\begin{array}{c}\text { Number of } \\
\text { shears }\end{array}$ & $\begin{array}{c}\text { Average offset } \\
(\mathbf{m m}) \mathbf{( 1 )}\end{array}$ & $\begin{array}{c}\text { Average } \\
\text { spacing (mm) }\end{array}$ & Total offset (mm) & Bulk $\gamma(\mathbf{1 \sigma})$ \\
\hline & & & & & & \\
\hline Distal mylonite & 329 & 91 & $1.98+/-0.7$ & 3.62 & 180.18 & $0.55+/-0.19$ \\
\hline mylonite & 15 & 9 & $1.25+/-0.2$ & 1.60 & 11.25 & $0.75+/-0.09$ \\
\hline Ultra Mylonite & $\mathrm{N} / \mathrm{A}$ & $\mathrm{N} / \mathrm{A}$ & $\mathrm{N} / \mathrm{A}$ & $\mathrm{N} / \mathrm{A}$ & $\mathrm{N} / \mathrm{A}$ & $\mathrm{N} / \mathrm{A}$ \\
\hline
\end{tabular}


strain (Fig. 9a). Using the SBOC, dihedral angles could be investigated in 2 different ways. First, a single fixed attitude of the foliation plane attitude was used; in other words, only the C' shear band attitude was considered as a variable in determining the intersection line. Based on this, the dihedral angle distribution follows a normal distribution with an average angle of $30 \pm 9.4^{\circ}(1 \sigma)$ (Fig 9b). Alternatively, C' attitudes were intersected with site-specific estimates of foliation attitude. Using this method, that acknowledges the minor warping in the attitude from foliation boudinage and deflection within an instable orientation in the flow field, the resulting distribution of dihedral angles is statistically no different to that calculated using a fixed S-plane, yielding an average dihedral angle of $31 \pm 8.7^{\circ}(1 \sigma)$ (Fig. 9c). The dihedral angle between nine antithetic C" shears, determined using the SBOC, relative to a fixed mean foliation, could also be investigated with proximal distance to the Alpine Fault. The mean $C^{\prime \prime}$ dihedral angle is $139 \pm 18^{\circ}(1 \sigma)$, anticlockwise from the SZB with no significant change in this angle across the distal mylonite and mylonite zones.

\subsubsection{Variance in $C^{\prime}$ spacing as a function of mechanical layer and proximity to} Alpine Fault.

The extensional C' shear bands show differences in spacing as a function of lithology and proximity to the Alpine Fault (Table 2). At the outcrop scale, 80\% ( $\mathrm{n}=$ 316) of the observed shear bands truncate schist in which the foliation (S) is defined by quartz laminates that are $0-10 \mathrm{~mm}$ thick. These $\mathrm{C}$ ' shears are spaced at an average width of $23 \mathrm{~mm}$ (Table 2). In general, thick quartz layers $(>10 \mathrm{~mm})$ are cut by $C^{\prime}$ shears $(n=43)$ that are more widely spaced (mean spacing $34 \mathrm{~mm}$ ) and are associated with shear band boudinage. The C' shears $(n=38)$ that cut the mafic amphibolite layers have a similar mean C' spacing as the thin quartz laminated schist (mean spacing $23 \mathrm{~mm}$ ). The thinly laminated pelitic-rich micaceous schist is cut by C' shears $(\mathrm{n}=183)$ with a closer mean spacing of $14 \mathrm{~mm}$ (Table 2). At the microscopic scale, C' shear show differences in mean spacing that correlate with spatial proximity to the Alpine Fault; in other words, to inferred degree of late Cenozoic finite strain (Table 3). The mean spacing of C' shears $(n=91)$ at the thinsection scale in the distal mylonite zone is $3.6 \mathrm{~mm}$ (Table 3). In the mylonite zone the C' shears $(n=9)$ have a mean spacing of $1.6 \mathrm{~mm}$ (Fig 10a). 
2.5.6 Variance in C' offset as a function of mechanical layer and proximity to Alpine Fault.

At the outcrop scale, corrected in the M-plane, offsets measured on the extensional C' shears remain consistent through different lithologies and are invariant across the all zones of the Alpine mylonites. C' shears that cut the schist in which the foliation (S) is defined by quartz laminates have an average per-shear offset of $4.72 \pm 2.8 \mathrm{~mm}(1 \sigma)$ (Table 2). Schist that contains foliation parallel quartz laminae $>10 \mathrm{~mm}$ thick has mean per-shear offsets of $8.12 \pm 3.2 \mathrm{~mm}(1 \sigma)$. Shear bands cutting the amphibolite mafic lithology have the largest mean per-shear offsets of $15.1 \pm 7.3 \mathrm{~mm}(1 \sigma)$. The pelitic-rich micaceous schist had similar mean per-shear offsets to that of the thinly laminated quartz $(4.7 \pm 3.14 \mathrm{~mm}$ at $1 \sigma)$. Similar results were measured at thin-section scale but are more precisely resolved. C' shears cutting the distal mylonite have a mean per-shear offset of $1.98 \pm 0.7 \mathrm{~mm}(1 \sigma)$. Shear bands cutting the mylonite zone have a similar mean offset of $1.25 \pm 0.2 \mathrm{~mm}(1 \sigma)$ (Table. 3).

2.5.7 Variance in bulk C'strain accommodated by slip parallel to $C^{\prime}$ shear and subsequent rotation of $C^{\prime}$ as a function of proximity to the Alpine Fault.

Bulk finite shear strains accommodated by slip parallel to the extensional shear bands can be calculated in distal mylonite zone outcrops by dividing total per-shear offsets as a function of lithology by the total distance orthogonal to the C' shears across which measurements were taken. Bulk finite shear strains increase with increasing proximity to the Alpine Fault, chiefly as a result of decreased shear band spacing in that direction rather than as a result of the change in the per-shear mean offsets. The C' shears that cut quartz laminated schist $(<10 \mathrm{~mm})$ had a total cumulative offset of $\sim 1.5 \mathrm{~m}$ implying a bulk finite shear strain accommodated by slip on the C' shears of $0.20 \pm 0.12(1 \sigma)$ (Table 2). In a similar way, a statistically indistinguishable bulk finite shear strain of $0.24 \pm 0.08(1 \sigma)$ was measured for C' shears that cut the schist with $>10 \mathrm{~mm}$ quartz laminae. The C' shears that cut the mafic amphibolite had a total cumulative offset $573.8 \mathrm{~mm}$ over a total C' orthogonal distance of $910 \mathrm{~mm}$ implying a bulk finite shear strain $0.63 \pm 0.31(1 \sigma)$. This increased bulk finite shear strain in the mafic unit can be attributed to a sampling bias. In other words, few C' shears were measured and where measured they had 
a.

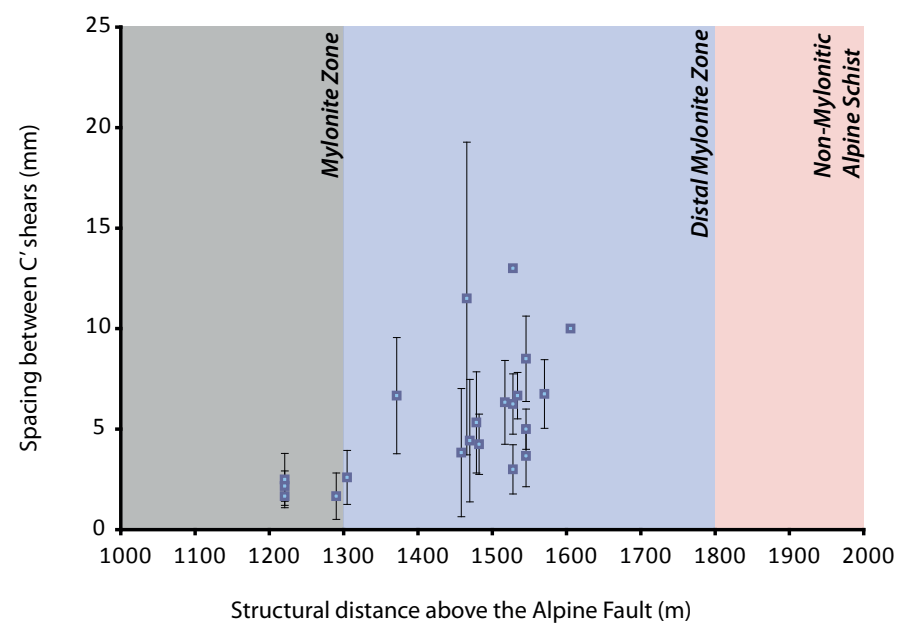

b.

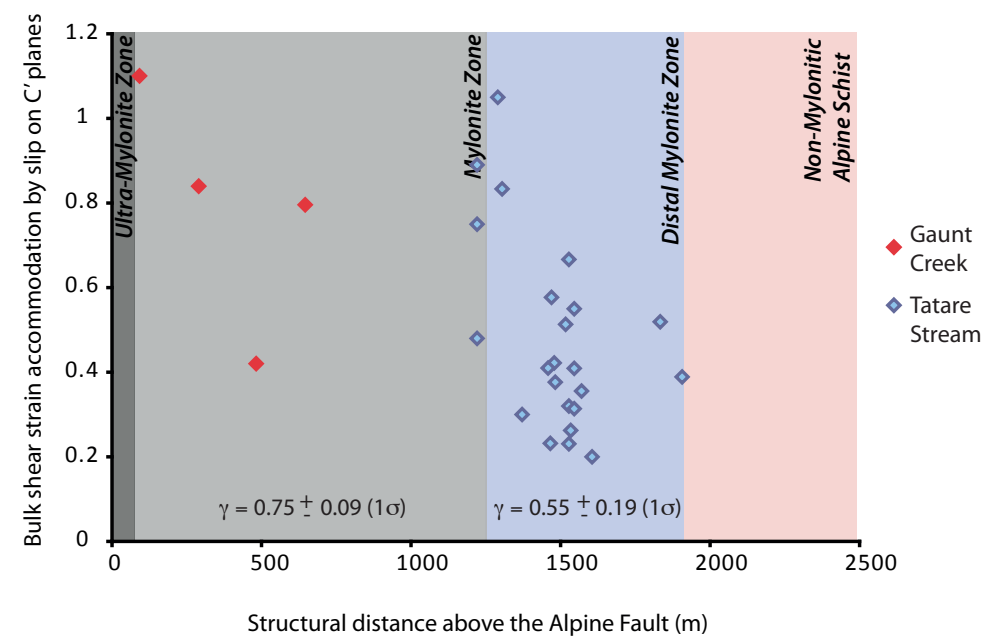

C.

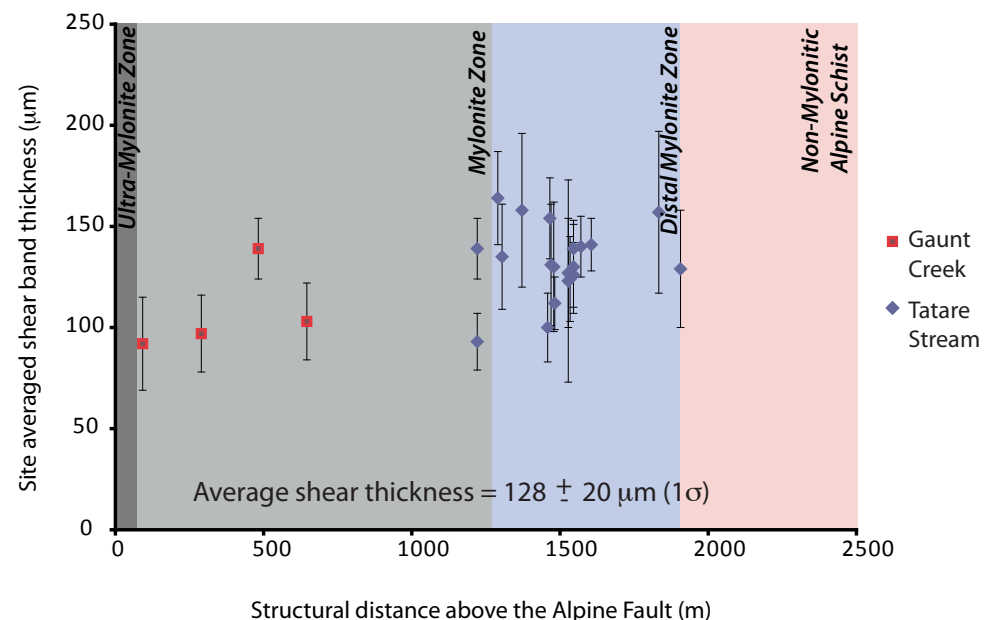

Fig. 10. (a) Scatter plot of mean $C^{\prime}$ spacing with distance from the Alpine fault. $C^{\prime}$ shear spacing is measured at thin-section scale. Error bar range is at $1 \sigma$. (b) Scatter plot of outcrop site-specific bulk shear strain accommodated by slip on $C^{\prime}$ planes with proximal distance from the Alpine Fault. Observations are from both Gaunt Creek (red) and Tatare Stream (c). Scatter plot of $C^{\prime}$ shear thickness with relation to structural position above the Alpine Fault in Gaunt Creek and Tatare Stream. 
large visible offsets. The C' shears cutting the pelitic-rich micaceous garnet schist records a bulk finite shear strain of $0.33 \pm 0.21(1 \sigma)(573 \mathrm{~mm}$ slip over C' orthogonal distance of $2.62 \mathrm{~m}$ ). At the outer SE edge of the distal mylonite zone the mean bulk finite shear strain accommodated by slip on shears is $0.38 \pm 0.3(1 \sigma)(4.73 \mathrm{~m}$ slip over C' orthogonal distance of $12.3 \mathrm{~m}$ ).

With progression from the distal mylonite towards the Alpine fault and the main mylonite zone, microscopic observations indicate an increasing bulk finite shear strain was accommodated by slip on C' shears. This result is attributed to the decrease in mean $C^{\prime}$ shear spacing with increasing proximal distance towards the Alpine Fault. Bulk finite shear strains accommodated by slip on C' shears can be calculated in a similar way to the outcrop scale finite shear strains. The calculated bulk finite shear strains at thin-section scale (Fig. 10c) yield similar results $(\sim 0.4$ at $1500 \mathrm{~m}$, Fig 10b) as determined from outcrop observations. The mean bulk finite shear strain for the distal mylonite zone is $0.55 \pm 0.19(1 \sigma)(180.18 \mathrm{~mm}$ of slip over C' orthogonal distance of $329 \mathrm{~mm}$ ) (Fig. 10b). Only the upper section of the main mylonite zone is expressed in Tatare Stream. Consequently, shear band spacings and offsets where also measured in thin section in a set of samples from Gaunt Creek, which span the rest of the mylonite zone. The C' shears that cut the main mylonite zone at that location record a bulk finite shear strain of $0.75 \pm 0.09(1 \sigma)$ (Table. 3).

As noted earlier, many proposed shear band evolutionary models suggest a rotation of the C' shears with progressive deformation. If this is the case, the dihedral angle between the C' shears and the SZB should change as a function of bulk finite strain. They will also change as a function of flow type (i.e., coaxial or non-coaxial). Developing a similar geometric shear zone model to that of Passchier (1991) (Fig. 2b) we have been able to simulate shear band rotation in a zone that has an accommodated bulk finite shear strain of $\sim 0.4$ parallel to the C' shears. The deforming zone in the simulation has a fixed width and length. The shear bands have a constant width and remain at a consistent length throughout the applied shear strain. The shear bands modelled in this zone were oriented $30^{\circ}$ from the SZB. A bulk finite shear strain of $\sim 0.4$ is applied parallel to the C' shear bands. The sides of the deforming zone (SZB) and of the rigid microlithons must align to maintain a constant deformation zone volume. In other words, the C' shears (also the rigid microlithons) are predicted to rotate clockwise by $2^{\circ}$ (antithetic to the main shear of 
the deforming zone) and a thinning of the initial zone is required. Simulating C", shears inclined at $60^{\circ}$ to SZB and applying a bulk finite shear strain of $\sim 0.4$ predicts a rotation of $14^{\circ}$ relative to the SZB. The dominant $C^{\prime}$ shear planes either may not rotate as a function of increasing finite strain or these C' shears are very late stage and have not accumulated enough strain to rotate enough to be statistically "visible". Passchier's (1991) bulk simple shear model for extensional C' shear bands is not applied in this study (Fig. 2b). The bulk simple shear model requires the microlithons and C' shear bands to deform. The foliation developed in the microlithons between the C' shears is continuous. In other words, the foliation is planar and not crenulated as expected if shortening of the microlithon has occurred. If shortening of the shear bands were to occur through progressive deformation, one should observe a variation in the C' thickness. These features are not observed within Tatare Stream samples (Fig. 10c).

\subsubsection{Intra-shear band finite shear strain estimates}

In both the distal mylonite and mylonite zones C' shears have a per-shear average width of $128 \pm 20 \mu \mathrm{m}(1 \sigma)$ (Table. $1 \&$ Fig. 10c). Dividing the mean pershear offset by this thickness allows us to measure the mean intra-shear band finite shear strain. This mean internal C' shear finite shear strain is calculated to be $15.5 \pm$ $5.4(1 \sigma)$ for $C^{\prime}$ shears the distal zone and $9.8 \pm 0.8(1 \sigma)$ for $C^{\prime}$ shears in the main mylonite zone (Table 1). These two values are statistically indistinguishable; so we cannot say that there has been more shear strain in the shear bands near to the Alpine Fault than distal to it.

\subsection{Discussion}

2.6.1 C' shear band variables (spacing, offset, thickness and $\gamma$ ) as function of increasing finite strain

A reduction in mean spacing between extensional $C^{\prime}$ shears from $\sim 1.0 \mathrm{~cm}$ to $\sim 0.25 \mathrm{~cm}$ at the thin-section scale and $\sim 6 \mathrm{~cm}$ to $\sim 0.2 \mathrm{~cm}$ at the outcrop-scale is observed as one enters the main mylonite zone from less deformed rocks of the distal mylonite to the SE (Figs. 11a \& b). At the outer SE edge of the distal mylonite zone (1758 $\mathrm{m}$ from the Alpine Fault) foliation parallel quartz laminates are as thick as 40 mm and C' shears are widely spaced $(\sim 117 \mathrm{~mm})$. Shear band boudins are developed 
in this layering, which have widely spaced inter-boudin surfaces (C') with high displacements (Fig. 12). Further into the distal mylonite zone (1458 m from the Alpine Fault) the foliation parallel quartz laminations decrease in thickness to range from $\sim 5-2 \mathrm{~mm}$. The extensional $\mathrm{C}^{\prime}$ shears observed in this thinly laminated quartz schist are closely spaced $(2-20 \mathrm{~mm})$ and are pervasively developed (Fig. 12). If the quartz schist has layers thicker than $20 \mathrm{~mm}$ the extensional C' shears develop in conjunction with shear band boudinage. Alternatively, if the foliation parallel quartz laminations are less than $20 \mathrm{~mm}$ thick the extensional C' shears are pervasive and closely spaced $(<20 \mathrm{~mm})$. In the main mylonite zone (1250 $\mathrm{m}$ from the Alpine Fault) the Alpine Schist is typically more micaceous than the adjacent distal zone. The extensional C' shears that cut pelitic-rich micaceous schist in the distal mylonite had the closest mean spacing. The observed decrease in the mean spacing between C' shears in the main part of the Alpine mylonite zone can be attributed to a reduction in the density and thickness of the foliation parallel quartz laminations and a more micaceous-rich schist lithology (Platt \& Vissers, 1980; Ramsay \& Lisle, 2000).

By contrast to the spacing, there is no apparent change in the per-shear amount of slip or mean width of the individual shear bands. The intra-shear band finite shear strain is similar in all parts of the late Cenozoic mylonite zone despite the strain gradient across it. We suggest that this relationship of consistent intra-shear band finite shear strain is most consistent with a strain hardening rheology during shear band development; such that at certain thresholds of finite shear strain (somewhere in the range of $9.8 \pm 0.8$ at $1 \sigma-15.5 \pm 5.4$ at $1 \sigma$ ) deformation ceased in the now hardened shear bands with further deformation causing initiation of new shear bands, especially in the mylonite zone were the C' spacing was found to be the smallest. Finite shear strains of $\sim 8$ were developed in experimentally sheared quartzites by Heilbronner \& Tullis (2006) which supports a high intra-shear band finite shear strain calculated in these C' shears. Ji et al., (2004) has shown that plastic deformation in layered quartz and anorthite composites initially localizes in the C' zones because of dynamic recrystallisation of these layered composites. In natural shear bands subsequent evolution of such shear bands may progress via dislocation creep processes into a hardening phase that limits the lifespan of an individual shear; hence we observe a threshold in finite shear strain. Moreover, Toy et al., (2008) noted that hardening might occur in shared quartzites in the Alpine Fault zone due to 
a. Schematic S and $C^{\prime}$ geometries (cross section NW - SE)

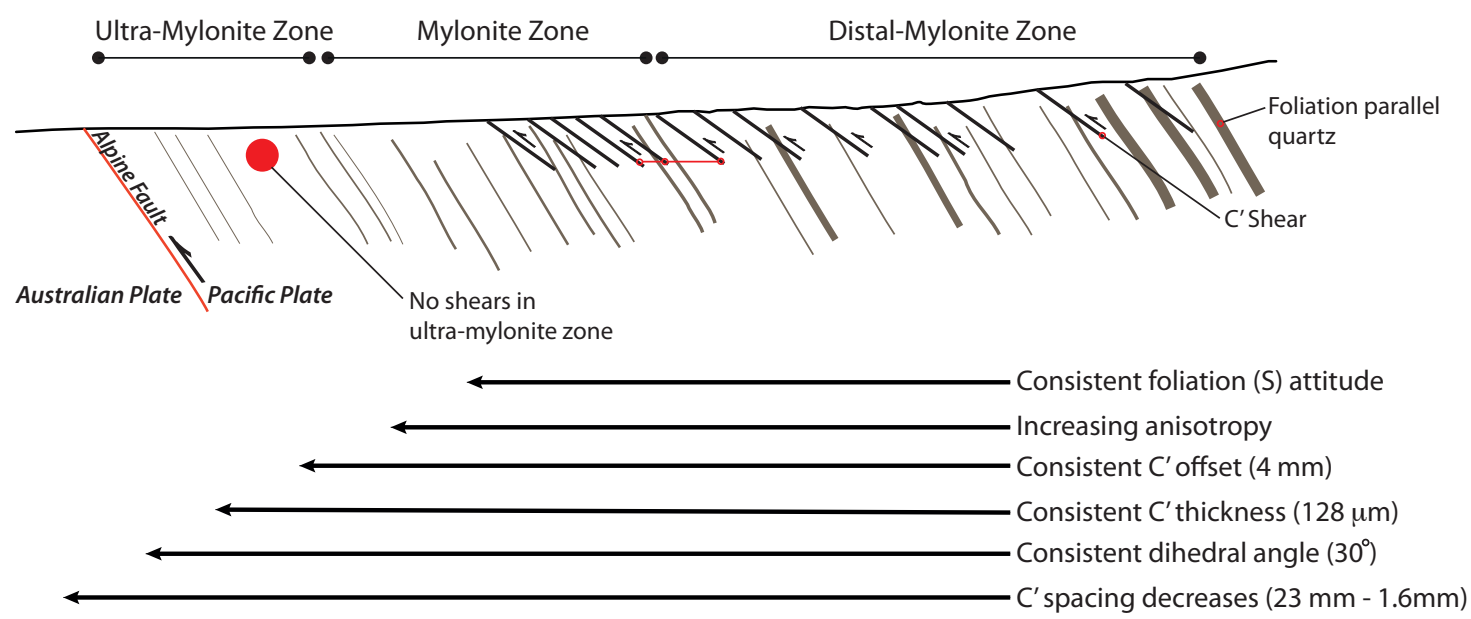

b. Schematic $S$ and $C^{\prime}$ geometries (plan view)

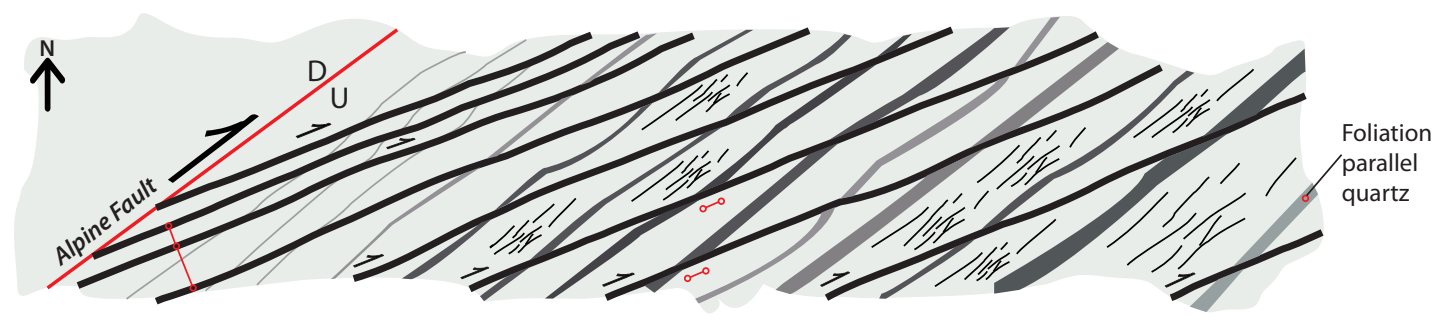

Fig. 11. (a) Schematic cross section NW-SE through Tatare Stream depicting the C' shear outcrop and thin-section observations with increasing finite shear strain and structural position relative to the shear zone boundary. Not to scale. Red lines show a decrease in $C^{\prime}$ shear spacing whilst approaching the shear zone boundary. (b) Outcrop plan view (not to scale) of $C^{\prime}$ shear orientations and attributes observed at outcrop and thin-section scales. Red lines denote the constant $C^{\prime}$ offset and the decrease in mean $\mathrm{C}^{\prime}$ shear spacing. 


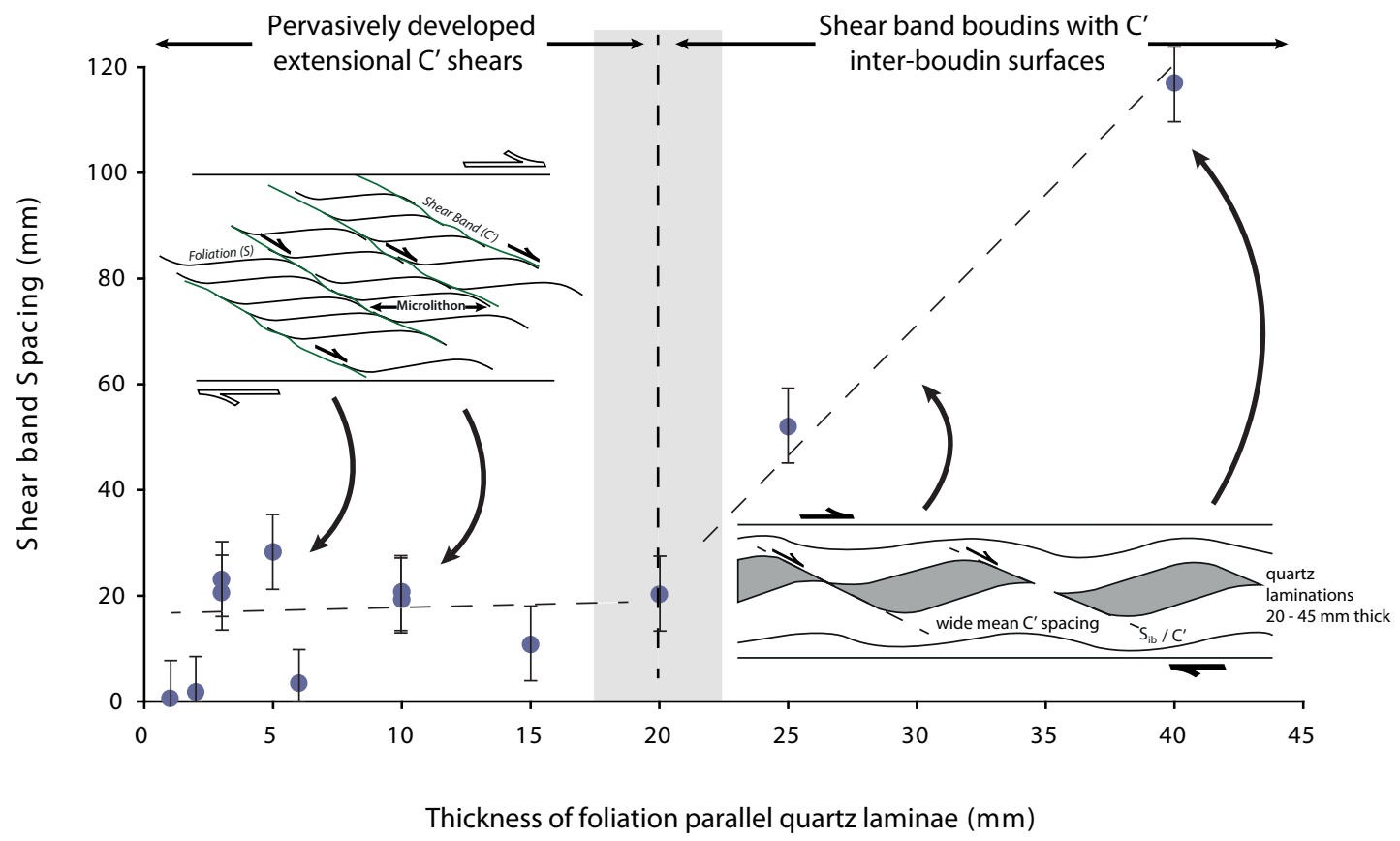

Fig. 12. Scatter plot of the mean site spacing between extensional $C^{\prime}$ shears $(n=580)$ relative to the foliation parallel quartz laminae thickness. A change from pervasive extensional shear bands to shear band boudins occurs when the layer cut is greater than $20 \mathrm{~mm}$. The $C^{\prime}$ shears then define the inter-boudin surface between boudins. 
(1) development of a strong CPO, and (2) subsequent exhumation to lower temperatures where a different slip system was favored. Using the mean values of shear band spacing and shear band finite offset we have estimated the bulk finite shear strain parallel to the shear bands to be in the range of $0.4-0.75$. This bulk finite shear strain increased slightly with increasing proximity to the Alpine Fault; perhaps as a result of hardening in the shear bands there to cause a greater distribution of shears.

Toy, Prior \& Norris (2008) described quartz CPO patterns in the main mylonite zone in the central Alpine Fault. Strong Y-maxima fabrics preserved in quartz indicate high ductile shear strains under amphibolite conditions. The mylonitic quartz grains had slip-systems activated during exhumation and low temperatures, which were confined to prism $<\mathrm{a}>$ or rhomb $<\mathrm{a}>$ systems. Very few quartz grains were suitably orientated for basal $<\mathrm{a}>$ slip in the mylonites; however cross-girdle CPOs preserved in quartz in the distal mylonites was interpreted to represent deformation at lower temperatures. When the mylonites are exhumed into lower temperatures slip depends on the orientations available. The distal mylonites had a range of orientations, whereas the mylonites were confined and strengthened. Toy, Prior \& Norris (2008) suggested that a geometrical hardening has occurred in the main mylonite zone when compared to rocks with different CPOs (distal mylonites) at the same temperature and strain-rate conditions. Toy, Pior \& Norris (2008) suggested that low temperature greenschist-facies deformation has stepped out of the main mylonite zone due to the geometrical hardening and may have been absorbed by the C' shears in the distal mylonite zone. The C' shears in Tatare Stream are lined with biotite and in some parts chlorite indicating some greenschist-facies retrogression. If the $C^{\prime}$ shears were to carry the entire greenschist-facies deformation, intra-shear band finite shear strains between 50 and 200 are required (Toy, 2007). The mean intra-shear band finite shear strain of $12.65 \pm 5.4(1 \sigma)$ for the distal mylonite suggests that a significant amount of the greenschist-facies deformation is absorbed by the adjacent microlithon component between C' shears (Fig. 1).

\subsubsection{Evidence for shear zone thinning during extensional shear band development.}

Boudinage is common in layered rocks (Platt \& Vissers, 1980). Foliation boudinage differs from classical layer boudins in that foliation boudins are not 
associated with any distinct compositional contrasts in the rock. Rather, they are related to layer parallel stretching and extensional fracturing in anisotropic foliated rocks (Platt \& Vissers, 1980; Arslan et al., 2008). Meter to centimeter symmetrical foliation boudinage is common in Tatare Stream, both in the distal mylonite and mylonite zones and implies a significant component of stretch parallel to the SZB. C' shears that cut mafic amphibolite and schist with thick quartz layers develop shear band boudins and provide evidence for foliation parallel extension. Aspect ratios for shear boudin blocks are typically 3-4 (Goscombe \& Passchier, 2003). Large displacements on their inter-boudin surfaces (C') have produced a back-tilted boudin train structure (Fig. 6b). Complete isolation of the shear boudins is observed in Tatare Stream as a result of high $(\sim 5 \mathrm{~cm})$ displacements (D) along this inter-boudin surface relative to the width of the boudin (W). This indicates that slip on the interboudin surface which is a C' shear band is one of the dominant mechanisms of layer parallel extension in Tatare Stream (Goscombe \& Passchier, 2003) (Fig. 3).

Conjugate sets of C' shears are found in both the distal mylonite and main mylonite zone in Tatare Stream. C' and C', shears, with opposite senses of displacement, are locally developed and are oriented at different angles to the shear plane (Fig. 6e). The C' shears occur at $30^{\circ}$ to the shear plane and are most abundant. The C" shears subtend higher angles to the shear plane, typically $55^{\circ}$ and are weakly developed. Conjugate shears with opposite shear sense indicate at least a component of co-axial shortening normal to the SZB (Platt \& Vissers, 1980). Typically the highangle C', set is thought to rotate rapidly into an unfavorable orientation for continued slip (Platt \& Vissers, 1980). A relatively small ( 0.4) bulk finite shear strain causes the C'" shears to rotate more rapidly than the C' shears. The development of conjugate sets of extensional shears in Tatare Stream suggests a SZB parallel stretch together with thinning of the Alpine Fault mylonite zone in Tatare Stream.

\subsubsection{Estimation of bulk vorticity using synthetic $C^{\prime}$ and antithetic $C$ '” shear band geometries}

The dihedral geometry of the intersecting C' and C' shear bands were analyzed as possible indicators of the non-coaxiality of flow in the Alpine Fault mylonite zone. Conjugate sets of extensional shears are to be expected in a non-simple shear flow regime that involves stretching parallel to the SZB (Platt \& Vissers, 1980; 
Simpson \& De Paor, 1993; Zheng et al., 2004; Kurz \& Northrup, 2008). Platt (1984) has similarly argued that conjugate sets of shear bands may indicate that the flow departed from bulk simple shear. Previous studies have suggested that C' and C', shears initiate parallel to planes of maximum angular shear strain rate (Platt \& Vissers, 1980; Simpson \& De Paor, 1993; Kurz \& Northrup, 2008) (Fig. 2a). These directions are predicted to occur parallel to the acute $(\mathrm{AB})$ and obtuse $(\mathrm{OB})$ bisectors of the eigenvectors of the flow (Simpson \& De Paor, 1993; Kurz \& Northrup, 2008) (Fig. 13). The orientation of the extensional eigenvector (flow apophyses) is fixed to the SZB, whereas the orientation of the contractional eigenvector depends on the pure shear contribution $\left(\mathrm{W}_{\mathrm{k}}\right)$ (Simpson \& De Paor, 1993).

In this paper we have shown that the extensional C' shear bands remain at a consistent $30^{\circ}$ angle with the SZB throughout the exposed parts of the Alpine mylonite zone in Tatare Stream with increasing proximity to the Alpine Fault. Assuming that these extensional C' shears have not rotated since their inception, and still coincide with the plane of maximum angular shear strain rate in the Alpine mylonite zone $(\mathrm{AB})$; one would predict that the contractional eigenvector of flow was oriented at $60^{\circ}$ to the SZB (Fig. 13) (see Simpson \& De Paor, 1993). As stated above the extensional eigenvector is parallel to the SZB, a direction that is well constrained in Tatare Stream. The angle $v$ between the eigenvectors is related to the kinematic vorticity number $\left(\cos v=\mathrm{W}_{\mathrm{k}}\right)($ Fig. 13). From the relationship that the contractional eigenvector lies at $60^{\circ}$ to the shear plane $\left(v=60^{\circ}\right)$, a $\mathrm{W}_{\mathrm{k}}$ of 0.5 is obtained using the above formulation. If the C' shears really did develop parallel to a plane of maximum shear strain one would predict that the C'" shears should develop parallel to the (conjugate) plane of maximum shear strain rate for the case of $\mathrm{W}_{\mathrm{k}} 0.5$. This would be predicted to lie parallel to the OB of the 2 eigenvectors. The conjugate extensional shears in Tatare Stream accommodate a mean bulk finite shear strain of $\sim 0.4$ (Table 1). As described earlier in this paper inputting a bulk finite shear strain of $\sim 0.4$ into Passchier's (1991) extensional shear band geometric model predicts a rotation of $14^{\circ}$ anticlockwise towards the SZB (fabric attractor) for the C', shears. A maximum rotation predicted for the $C^{\prime}$ shears is $2^{\circ}$. If the predicted rotation is restored, in other words the C"' shears are rotated back to their inception direction, the $C$ " shears should restore into parallelism with the previously calculated $\mathrm{OB}$, if the aforementioned theory of extensional shears developing parallel to the directions 


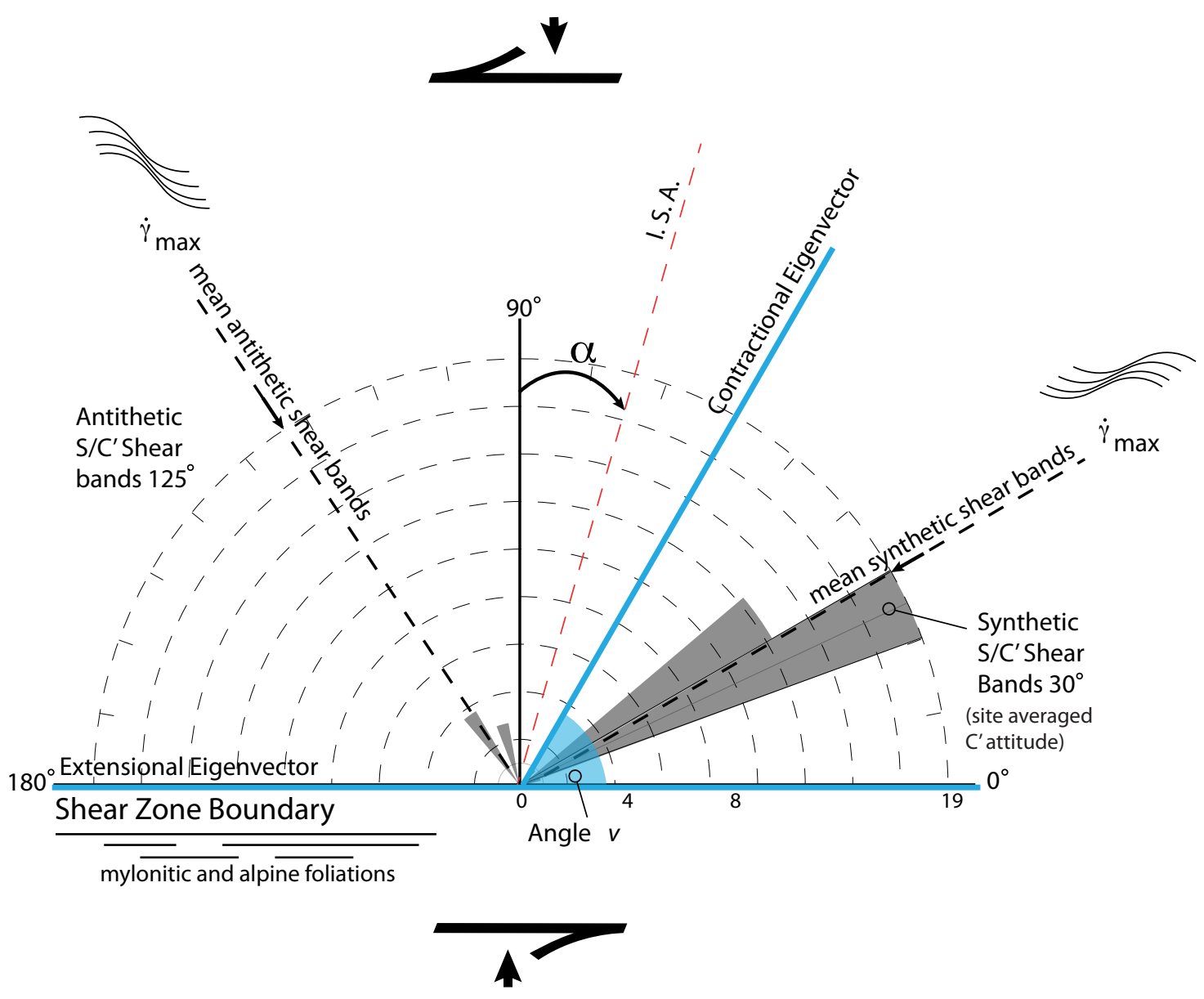

Fig. 13. Rose diagram generated from orientation data for $C^{\prime}$ and $C^{\prime \prime}$ shears. Each site in Tatare Stream (Fig. 5c) has a mean $C^{\prime}$ or $C^{\prime \prime}$ orientation plotted. The dashed line denotes the mean orientations for the $C^{\prime}$ and $C^{\prime \prime}$ sets. An estimate of Wk using the orientation of the $C^{\prime}$ and $C^{\prime \prime}$ shears determines the position of the contractional eigenvector. Angle $v$ is a measure of the orientation of the mean $C^{\prime}$ shear band in relation to the shear zone boundary. The red dashed line is the $\sigma 1$ or ISA3 position. Angle $a$ is the angle between $\sigma 1$ or ISA3 and the normal to the shear zone boundary. 
of maximum shear strain rate is correct. After restoring the observed angles the mean C" shear is disposed at $125^{\circ}$ anticlockwise from the foliation plane and SZB. In fact this is coincident with the previously constructed OB based on the data alone, leading us to infer that the shear bands did in fact nucleate parallel to planes of maximum instantaneous shear strain rate (Fig. 13). The data therefore appears to support the hypothesis that conjugate sets of extensional shear bands form in a direction parallel to the maximum angular shear strain rate at a late stage of deformation in an actively thinning shear zone. This allows their dihedral angle to be used as a kinematic vorticity gauge at least for the late stage of deformation.

Aternatively, others have suggested that C' and C'" shears may develop instead parallel to the maximum-effective-moment (MEM) orientations (Zheng et al., 2004). The MEM orientations are a function of the differential stress and the orientation of the extensional shear bands with respect to the $\sigma_{1}$ direction (Zheng et al., 2004). Price and Cosgrove (1990) suggest that the $\sigma_{1}$ (maximum contractional incremental stretching axis, $\mathrm{ISA}_{3}$ ) axis bisects the obtuse angle between the set of conjugate shear bands (Fig. 13). The angle in Tatare Stream between C' and C', before restoring the rotation is $109^{\circ}$ and $95^{\circ}$ after. Similar angles between conjugate shears in the range of $98^{\circ}-110^{\circ}$ have been reported elsewhere (White, 1979; White et al., 1980; Platt \& Vissers, 1980; Zheng et al., 2004; Kurz \& Northrup, 2008). Assuming that the MEM interpretation of C' and C' dihedral angles is valid and that the bisector of the planes is parallel to $\mathrm{ISA}_{3}$, the attitude of the incoming shear bands in Tatare Stream is a constructed $\mathrm{ISA}_{3}$ that lies in the M-plane at $47.5^{\circ}$ to the SZB (Fig. 13). An estimate of $\mathrm{W}_{\mathrm{k}}$ can be determined based on this inclination of $\mathrm{ISA}_{3}$ to the $\mathrm{SZB}$. $\mathrm{W}_{\mathrm{k}}$ is given by the relationship $W_{k}=\sin 2 \alpha$, where $\alpha$ is the angle between the $\sigma_{1}\left(\mathrm{ISA}_{3}\right)$ and the normal to the shear zone boundary (Weijermars, 1998; Zheng et al., 2009) (Fig. 13). In Tatare Stream the angle between the ISA and the normal to the shear zone boundary is $15^{\circ}$, resulting in a $\mathrm{W}_{\mathrm{k}}$ estimate 0.5 that is similar to the earlier one based on the C' shears dihedral angles. We have thus calculated that the Alpine mylonite zone, at least in the later stages of its development since inception of the extensional shear bands, has been subject to a thinning and a stretching type of general shear $\left(\mathrm{W}_{\mathrm{k}}\right.$ $0.5)$.

Estimates of kinematic vorticity from both the $\mathrm{AB} / \mathrm{OB}$ and the MEM orientations produce a similar value of 0.5 . If correct, this $\mathrm{W}_{\mathrm{k}}$ estimation for the Alpine mylonite 
zone implies there is a significant component $(\sim 62 \%)$ of co-axial deformation (thinning perpendicular to the SZB; stretching parallel to transport) in operation, in contrast to previous suggestions of simple shear dominated deformation there (Norris $\&$ Cooper, 2003). The significant pure shear component also underscores my conclusion that shear bands may be partly diagnostic of stretching shear zones (Platt \& Vissers, 1980; Passchier, 1991; Hafner \& Passchier, 2000).

\subsubsection{Flow kinematics of the Alpine mylonite zone.}

The ductile slip direction that we calculated for the Alpine Fault mylonite zone in Tatare Stream based on C' and C' $C^{\prime}$ intersections pitches $\sim 20^{\circ}$ more down-dip than the Pacific Plate motion vector (Fig. 8a) in the plane of the Alpine Fault. Slip on the Alpine Fault's central section, including in its mylonite zone, is often described as being "unpartitioned" such that the plate motion vector should be parallel to the slip vector on the Alpine Fault plate boundary structure. The data in this study does not support such an unpartitoned model. One explanation for possible lack of slip and partitioning (e.g., Koons et al., 2003) is that the very rapid rates of erosional exhumation there have caused a thermal weakening of the Pacific Plate crust against the Alpine Faults hanging wall, allowing plate motion to collapse into a weak, narrow zone that can simultaneously accommodate both the strike-slip and the dipslip components of motion. The calculated ductile shearing direction is spatially invariant in its disposition throughout both the distal mylonite and main mylonite zones (Fig. 8b).

The kinematics of how the Pacific Plate's hanging wall is ramped up the Alpine Fault are constrained by field observations of oblique-slip on near-vertical planes (back-shears) (Fig. 14a). Little et al., (2002) showed that an "excess" of strike-slip motion accumulates (relative to the azimuth of the plate motion) on the steeply dipping dextral-oblique shears; that is, that the component of margin parallel plate motion is partitioned into these structures. A corollary of this observation is that elsewhere in the hanging wall of the central part of the Alpine Fault deformation should be characterized by an "excess" of margin perpendicular motion in order for the composite deformation to sum to the plate motion vector. Little (2004) presented a 3D model for the progressive ductile deformation of the Alpine Fault's hanging wall in the central Southern Alps and predicted that a first order affect of the back 
shearing deformation would cause a "boost" in dip-slip rates on the Alpine Fault relative to that calculated simply from the incoming horizontal local velocity of the Pacific Plate.

The exhumation of the Pacific Plate's hanging wall via vertical back-shears, striking sub-parallel to the Alpine Fault, causes a clockwise rotation and steepening of the incoming velocity vector (Fig. 14a). Relative to a fixed Australian Plate the “incoming" Pacific Plate velocity trends $\sim 072^{\circ}$ and can be resolved into marginparallel and perpendicular components (e.g., DeMets et al., 1994; Walcott, 1998; Cande \& Stoke, 2004). Neotectonic studies indicate that the Alpine Fault has a margin-parallel rate of $\sim 21 \mathrm{~mm} / \mathrm{yr}$ and a Quaternary dip-slip rate of $\sim<12 \mathrm{~mm} / \mathrm{yr}$ in its central section (Norris \& Cooper, 2000). Translation of the Pacific Plate up the Alpine Fault $\left(\sim 65^{\circ}\right)$ ramp may introduce an additional vertical velocity to the ramped rocks as a result of the vertical $\left(90^{\circ}\right)$ back-shearing of the hanging wall (Fig. 14a). Assuming that the Alpine Fault ramp dips $65^{\circ}$, we can use this dip, in conjunction with the known margin-perpendicular velocity, to determine the dip-slip component and the additional vertical velocity caused by the vertical back-shearing of the hanging wall. The vertical back-shearing of the hanging wall up the Alpine Fault ramp predicts a $11.75 \pm 7^{\circ}(2 \sigma)$ clockwise rotation in the pitch of the plate velocity in the reference plane of the Alpine Fault. This predicted velocity rotation is within error of the calculated ductile slip direction pitch $\left(56 \pm 6^{\circ}(2 \sigma)\right)$ for the ramped hanging wall rocks. This calculated ductile slip direction supports a steeply dipping Alpine Fault in the central Southern Alps and provides complementary evidence for vertical back-shearing as the mechanics for oblique ramping of the incoming Pacific Plate hanging wall up the Alpine Fault ramp (Fig. 14a).

\subsection{Conclusions}

The central section of the Alpine Fault mylonite zone in Tatare Stream has pervasively developed extensional shear bands. These shear bands pervade the $600 \mathrm{~m}$ wide distal mylonite and at least $250 \mathrm{~m}$ of the outer margin of the main mylonite zone in Tatare Stream. Across these zones, a pronounced shear strain gradient is inferred to exist in proximity to the Alpine Fault. Despite this gradient, relatively little change in the geometry or offset of the shears occurs, suggesting that they are late stage and have undergone very little finite rotation after their inception. 


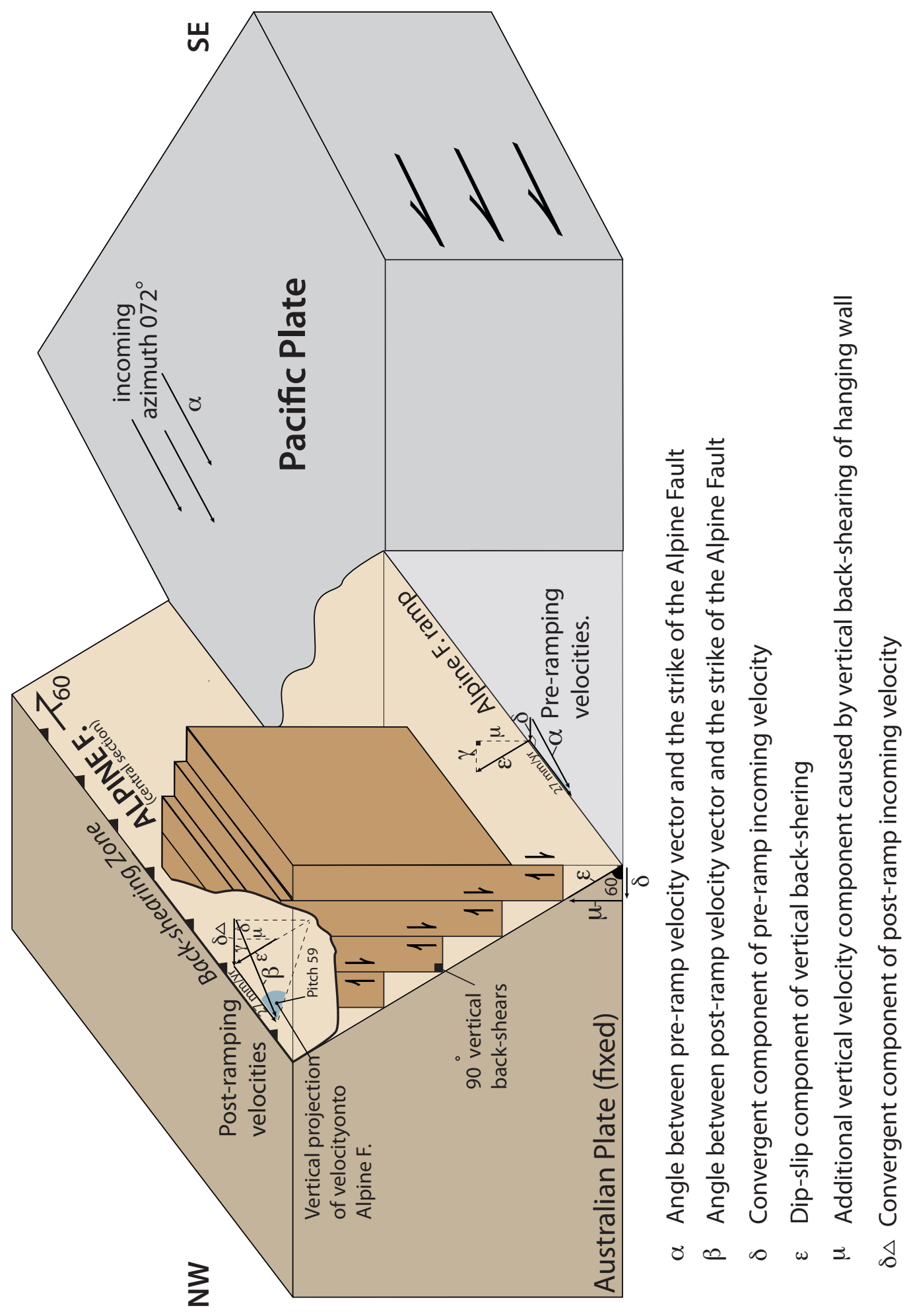

Fig. 14. (a) Schematic cartoon showing inferred cross-sectional relationship of ramping the hanging wall of the incoming Pacific Plate up the Alpine Fault. The vertical back-shears introduce an additional vertical velocity. Addition of the back-shearing deformation with the pre-ramping velocities (strike-slip and convergent) determined the orientation of the post-ramping velocity relative to the strike of the Alpine Fault. $\beta$ trends in the direction calculated in this study. 
Measurements of 728 C' shears at outcrop and thin-section microscopic scale have been considered in context of a well understood, neotectonic ductile shear zone.

1. The foliation attitude remains remarkably consistent at $053 / 63 \mathrm{SE}$ except for local deflections related to foliation boudinage and late stage local warping across the late Cenozoic strain gradient in the distal and main mylonite zone and into the non-mylonitic Alpine Schist. Because this foliation does not change its attitude on entering the Alpine shear zone with its strain gradient we infer that it is exactly parallel to the SZB of the Alpine Fault at depth; perhaps because the older non-mylonitic foliation was pre-aligned in that direction prior to late Cenozoic shearing. The foliation must be parallel to the "fabric attractor" (extensional apophysis) and provides a confident estimate for the attitude of the SZB in Tatare Stream. We therefore infer that the Alpine Fault shear zone dips at $\sim 63^{\circ}$ in this part of the central Southern Alps; an observation that may help to explain relatively high uplift rates in this region (e.g., Little et al., 2005).

2. The ductile shearing direction in the Alpine mylonite zone during shear band activity treads $090 \pm 6^{\circ}(2 \sigma)\left(38^{\circ}\right.$ pitch in Alpine Fault plane) for the Alpine mylonite zone. This ductile slip direction pitches further clockwise down-dip than existing estimates of the azimuth of the Pacific Plate motion in the plane of the Alpine Fault. The fact that the direction of ductile shear in this part of the mylonite zone is more fault-orthogonal, indicates that slip on this part of the Alpine Fault is apparently not "unpartitioned". We infer that the ramprelated deformation of the incoming Pacific Plate hanging wall of the Alpine Fault has had the effect of rotating any pre-existing slip directions to a more fault perpendicular orientation and boost in the local magnitude of dip-slip (see Little et al., 2002a) as a result of back-shearing deformation in the Alpine Fault's hanging wall.

3. The mean spacing between C' shears decreases slightly with proximity to the Alpine Fault and its high strain mylonite zones. Thickness of, and the mean finite per-shear slip do not vary. We have suggested that the consistency of the intra-shear band finite shear strain indicates that there is an element of strain hardening occurring in the mylonite, and that this caused the shear bands to lock up at a shear strain of $\sim 12.5$. The higher density (smaller mean 
spacing) of the shears in the main mylonite zone may indicate further shear band nucleation in that rapidly deforming zone as a result of such strain hardening.

4. Many structures in Tatare Stream indicate that the Alpine mylonite zone is a thinning/stretching shear zone. Foliation boudinage and shear band boudinage are common. Conjugate extensional shear bands indicate coaxial shortening normal to and extension parallel to the foliation.

5. The dihedral geometry of $C^{\prime}$ and $C$ " shears were used as an indicator to determine the kinematic vorticity of the Alpine mylonite zone. The detailed C' dataset in Tatare Stream supports the hypothesis that C' shears form parallel to directions of maximum angular shear strain rate. Estimates of kinematic vorticity from two different analytical methods using the extensional C' shears calculated a $\mathrm{W}_{\mathrm{k}}$ of 0.5 . Implied is a significant $(62 \%)$ co-axial component for the Alpine mylonite zone and the restriction of $\mathrm{C}^{\prime}$ shear bands to stretching and thinning shear zones. 


\section{Porphyroblast rotation: tracking garnet porphyroblasts 3. through the central Alpine mylonite zone, Southern Alps, New Zealand.}

\subsection{Introduction}

Large single crystals formed by metamorphic growth in an otherwise finegrained matrix are known as porphyroblasts. Porphyroblasts can potentially be used as recorders of deformational events where they trap pre-existing structural fabrics as inclusions during their growth. Porphyroblasts and their related microstructures can thus be valuable tools for the study of metamorphism and deformation, for example in shear zones. In this paper I undertake careful tracking of pre-deformational porphyroblast inclusions relative to a reference frame tied to the late Cenozoic shear zone boundary (SZB) of the Alpine Fault, across a gradient in finite strain to provide information into the kinematics of this neotectonic active natural shear zone.

The kinematics of rigid objects embedded in viscously deforming rocks undergoing non-coaxial or co-axial flow has been considered by many previous authors (e.g., Ghosh \& Ramburg, 1976; Ghosh, 1987; Marques \& Coelho, 2003). Previous studies typically interpret garnet porphyroblasts either to rotate or to remain "static" relative to a fixed external geographic reference frame. Over the past 25 years there has been much debate about how to interpret porphyroblast inclusion patterns (typically sigmoidal or spiral-shaped) in ductile deformation zones with respect to the kinematic histories that they may record. Less commonly described are porphyroblasts that contain straight, or slightly curved inclusion trails. Some geological studies have interpreted straight inclusion trails in porphyroblasts to rotate relative to a fixed external reference frame, such as the SZB in simple shear or general shear flow (e.g., Olesen, 1982; Barker, 1994, Johnson, 1999). Others have argued that the deformation partitioning around porphyroblasts has lead to their rotational stabilization with respect to this reference frame (e.g., Ramsay, 1962; Bell, 1985; Bell \& Johnson 1989; Fay et al., 2008;). In different case studies, both the rotational and non-rotational models have been shown to be feasible depending on the local conditions although in natural ductile shear zones, there is considerable evidence both experimental, numerical and field-based that rigid particles embedded in a more deformable matrix will rotate with respect to the SZB. To unambiguously Gillam, B. G. 
resolve the kinematic behavior of porphyroblasts in an active shear zone, certain criteria must be net. These include: (1) the attitude of the pre-deformational inclusion trails is well known, (2) the orientation of the SZB is known so that this can be used as a reference frame by which to measure changes in porphyroblast orientation, and (3) the porphyroblasts can be analyzed across a gradient in finite strain within that shear zone, and (4) the shearing post-dates the growth of the porphyroblasts (Jiang \& Williams, 2004; Johnson, 2009).

In this paper I will examine a suite of garnet porphyroblasts exhumed in an exposed amphibolite-facies ductile shear zone. This ductile shear zone (the Alpine mylonite zone) is located in a central part of the Southern Alps, in South Island, New Zealand. Stream cut exposures there have provided us with the opportunity to evaluate the rotational kinematics of inherited, pre-shearing (Mesozoic) garnet porphyroblasts in a ductile shear zone that has a well documented shear direction. The Alpine Fault, South Island, New Zealand is one of the best global examples of a deeply exhumed crustal-scale oblique-reverse fault. Rapid erosion and uplift in the Southern Alps on the hanging wall of the Alpine Fault has exposed a $\sim 2 \mathrm{~km}$ thick mylonitic shear zone structure that has been carried to the surface as a result of exhumation on its hanging wall (Norris \& Cooper, 2007; Toy, 2007; Toy et al., 2008) (Fig. 1). This study will take advantage of this natural laboratory to investigate the rotational kinematics of garnet porphyroblasts in natural ductile shear zones and to provide insight into the kinematics of flow in the Alpine mylonite zone at depth.

The chief goal is to understand how the garnet porphyroblasts have changed their orientation (relative to the SZB) as a result of late Cenozoic shear in the Alpine mylonite zone. At Tatare stream, near Franz Josef Glacier I have a precise estimate for the attitude of the SZB and will make all measurements relative to this datum. I present a data set of inclusion plane orientations in garnets based on multiple thin section cuts through each sample across a transect that spans a strain gradient from the unmylonitized wall rock and into the main central part of the Alpine mylonite zone. I use the "starting attitude" of inclusion planes in garnets in the external nonmylonitic part of the Alpine Schist as a basis to track garnet orientation changes through the adjacent distal mylonite (protomylonite) and mylonite zones. I argue that the typically spheroidal garnet porphyroblasts in both the distal mylonite and mylonite zones have, in general experienced a forward rotation of at least $90^{\circ}$ Gillam, B. G. 
relative to the SZB across this strain gradient in response to finite shearing in the Alpine mylonite zone. Lastly, I use the GhoshFlow program to predict inclusion trail orientations in the main mylonite zone at different shear strains and also use the program to estimate the kinematic vorticity number for Cenozoic ductile flow in the Alpine mylonite zone, paying particular attention to the rotational behavior of an elongate (non-spheroidal) subset of garnet porphyroblasts. The modeling suggests that the main mylonite zone has undergone a significant co-axial strain component $\left(\mathrm{W}_{\mathrm{n}} \sim 0.6\right)$ and is monoclinic. Furthermore, it indicates the zone experienced a finite shear strain $(\gamma)$ of $\sim 3.5$.

\subsection{Rotational and non-rotational models for porphyroblasts}

Whether porphyroblasts rotate relative to an external reference frame tied to geographic directions as a result of inhomogeneous deformation has been a topic of much debate. There are two competing hypotheses regarding porphyroblast rotation. One view states that porphyroblasts may either rotate or remain "static" with respect to a geographic reference frame or SZB as a result of deformation partitioning around them (Bell, 1981; Bell 1989; Fay et al., 2008). Another view acknowledges that rigid objects embedded in a flowing matrix will tend to rotate, either synthetically or antithetically, relative to the SZB depending on the ratio of pure to simple shear in the zone, the shape of the object, any clast-clast interaction, the degree of clast-matrix coupling, and the shear sense (e.g., Passchier et al., 1992; Gray \& Busa, 1994; Williams \& Jiang 1999; Trouw et al., 2008; Johnson 2009). Although garnets seem to have dominated the debate, many other studies on a range of other porphyroblasts have been investigated (e.g., Busa \& Gray, 1992; Holcombe \& Little, 2001; Johnson et al., 2009; Mezger 2010).

The first view supports that porphyroblasts can remain stable relative to a geographic reference frame during progressive deformation. Ramsay (1962) argued that during co-axial deformation histories spherical porphyroblasts might remain stably oriented while the matrix foliation would rotate around them as deformation proceeds. Bell (1981) graphically described inclusion trail geometries (called millipede structures) and suggested that porphyroblasts would not rotate in a noncoaxially straining environment, involving a component of bulk shortening, if the porphyroblasts did not deform internally. Bell's (1981) observation led to the idea 
that spiral inclusion trail geometries in garnet porphyroblasts could form from a series of near-orthogonal crenulation cleavages developing, rather than by rotation (Bell, 1985; Bell and Johnson, 1989; Passchier et al., 1992). Strain field modeling by Fay et al., (2008) endeavored to reproduce the original millipede structures in garnet porphyroblasts. Fay et al., (2008) modeled anastomosing zones of progressive shearing and shortening, where they argue that these porphyroblasts are decoupled from the matrix, which deforms chiefly by non-coaxial deformation. Instead the porphyroblasts behave like islands of co-axial deformation experiencing no rotation relative to a geographic reference frame. Such disagreements regarding spiral inclusion trails in porphyroblasts has highlighted the importance of careful field studies conducted in a well constrained kinematic framework to help resolve these ambiguities of interpretation, and to harness fully the potential reposition of deformation into fossilized porphyroblasts, especially in relation to shear zones.

More recent geological studies into porphyroblast kinematics have supported the rotational model. For example Trouw et al., (2008) measured internal inclusion angles in garnet porphyroblasts, where inclusions were concentrated at $90^{\circ}$ and $180^{\circ}$ relative to the external foliation. Their data supports a model in which the growth of the garnets preferentially took place orthogonal to the foliation and into the mica strain caps, causing an elongation of porphyroblasts in that direction. Because of this shape change garnet porphyroblasts subsequently became unstable and rotated relative to the SZB. Mezger (2010) shows that staurolite porphyroblasts have experienced variable, strain-related rotation with respect to the main schistosity that encloses them. The amount and sense of rotation experienced by the porphyroblasts was dependent on the initial aspect ratio $(\mathrm{R})$ of the staurolite porphyroblasts with foliation sub-parallel elongated porphyroblasts rotating very little, because they were in a stable position at the time when shearing commenced.

\subsection{Tectonic setting and structural framework}

\subsubsection{Alpine Fault and Southern Alps}

In the South Island, New Zealand, the dextral-reverse Alpine Fault $(\sim 25 \mathrm{Ma})$ (Sutherland et al., 2000) is the chief plate boundary structure between the Australian and Pacific Plates (Fig. 1). In the central Southern Alps this fault has an average strike of $053 \pm 2^{\circ}(2 \sigma)$ and it dips SE (Gillam et al., 2011 chapter 4 this thesis). In Gillam, B. G. 


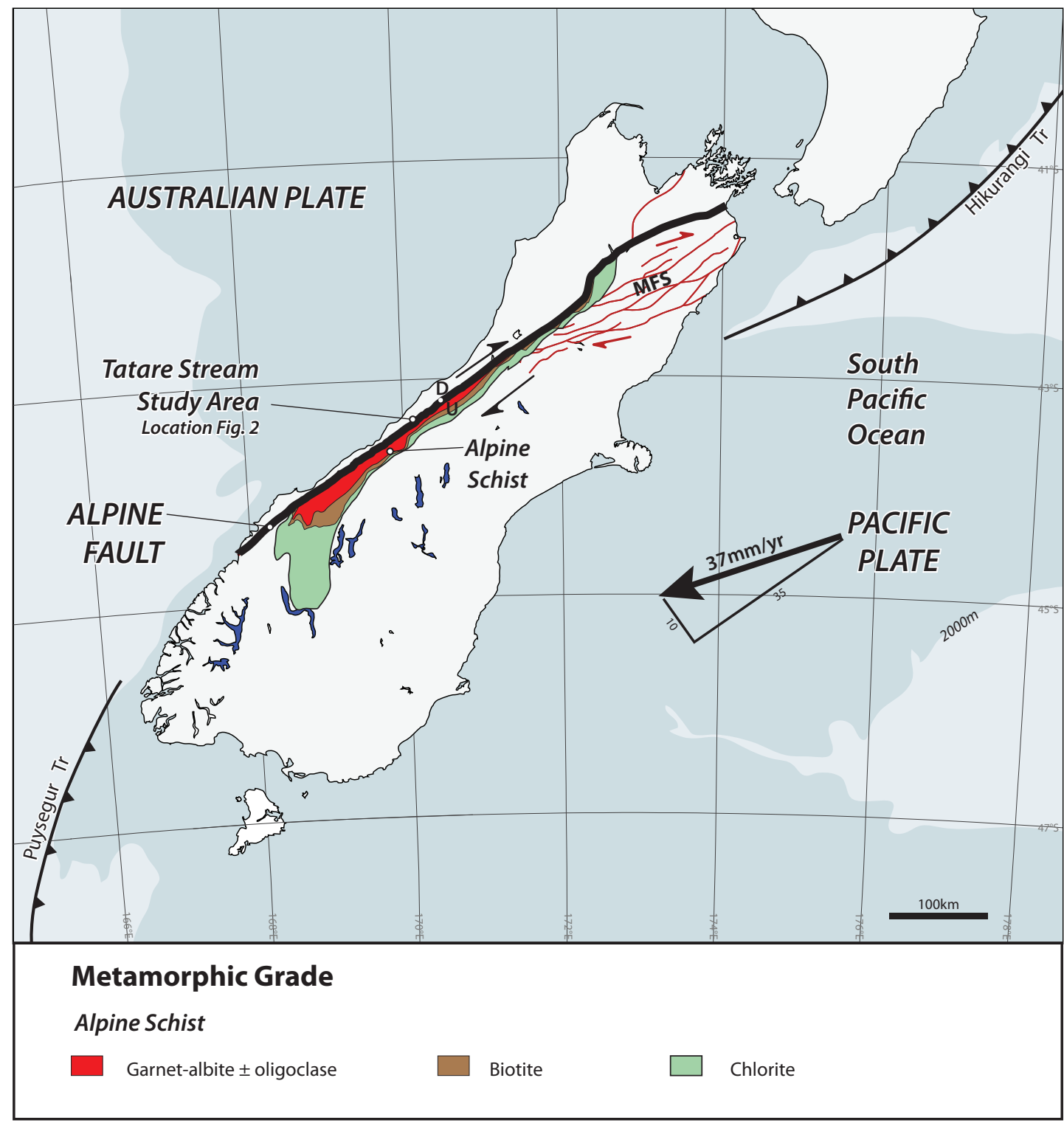

Fig. 1. Regional tectonic setting of the South Island of New Zealand showing the moden rate of plate motion between the Pacific Plate to the Australian Plate (using Nuvel 1A angular velocities from DeMets, et al. (1994), and the Alpine Fault Trace at Tatare Stream as a reference point), with normal and parallel motion with respect to the Alpine Fault. MFS - Marlborough Fault System. 2000m - bathymetric contour. Map also showing metamorphic grade of Alpine Schist. Data from N.Z. Geological Survey map (1979); Mortimer (2000); Murphy (2010). 
detail, its trace in that region is segmented in the near surface into a series of obliquereverse and vertical strike-slip sections (Norris \& Cooper, 2007). The Nuvel-1 A plate motion model, which incorporates the last $\sim 3 \mathrm{~m}$.y. of global seafloor spreading data, infers a plate motion vector of $\sim 37 \mathrm{~mm} \mathrm{yr}^{-1}$ on an azimuth of $71 \pm 2^{\circ}(2 \sigma)$ in the region of the central Southern Alps (DeMets et al., 1994). This plate motion vector trends $\sim 20^{\circ}$ anticlockwise of the strike of the Alpine Fault and is expressed by oblique convergence across the Southern Alps. Surface geological (e.g., Sibson et al., 1979; Norris \& Cooper 2007) and seismic reflection data (e.g., Davey et al., 1995; Kleffman et al., 1998) have been used to infer that the mean dip of the Alpine Fault at the surface to mid-crustal depths is typically $40-50^{\circ}$ to the SE. Neotectonic studies indicate that the Alpine Fault has a dextral strike-slip rate of $27 \pm 5 \mathrm{~mm} / \mathrm{yr}$, accommodating about $70-75 \%$ of the margin-parallel component of the PacificAustralia Plate motion (Norris \& Cooper, 2000). The rate of late Quaternary dip-slip on the Alpine Fault is quite variable along strike reaching a maximum of $\sim 12 \mathrm{~mm} / \mathrm{yr}$ in the especially mountainous central Southern Alps (Norris \& Cooper, 2000).

Rapid and deep erosion of the Alpine Schist on the uplifted hanging wall of the Alpine Fault has exposed a SE tilted section derived from the lower to middle crust of the Pacific Plate (Fig. 1). These rocks that abut the eastern edge of the Alpine Fault have been exhumed from depths of 20-30 km (e.g., Grapes, 1995) over the last 23-5 m.y. Tilting of the section is inferred to have been the result of up-ramping of the more deformable Pacific Plate crust westward on to the foot wall ramp of the Australian plate, as a result of serial back-shearing (Little et al., 2002a; Little 2004). The Alpine mylonite zone forms the structural base of this tilted crustal section and occurs as a strongly deformed zone, 1-2 km thick that is bounded to the west by the Alpine Fault (Sibson et al., 1979; Norris \& Cooper, 2007; Toy, 2007; Toy et al., 2008) (Fig. 2a).

The Alpine Schist is a $\sim 20 \mathrm{~km}$ wide strip of east tilted Barrovian metamorphic rocks ( 86 Ma, dominant mineral isograd development) (Vry et al., 2004) that constitutes the immediate hanging wall of the Alpine Fault. In the central section of the this strip the metamorphic grade decreases eastward and strictly upward from garnet-oligoclase zone (amphibolite-facies) in the mylonitic rocks adjacent to the Alpine Fault, to chlorite zone (greenschist-facies) in the east (Fig. 1). The mylonite zone and its non-mylonitic hanging wall consist chiefly of meta-greywacke derived Gillam, B. G. 
greyschist, with subordinate pelitic and mafic units (Little et al., 2002a; Toy et al., 2008). Along their SE margin the mylonite zone is bordered by a $\sim 0.4-0.7 \mathrm{~km}$ thick zone of protomylonitic schist (I will further refer to this as the distal mylonite zone) (Sibson et al., 1979; Toy et al., 2008). In this zone, preservation of crenulation structures inherited from the (Mesozoic) non-mylonitic Alpine Schist such as SWpitching fold and crenulation hinges $\left(\mathrm{L}_{2 \times 3}\right)$ are wide spread and characteristic; however, the rocks are also pervaded by younger, late Cenozoic extensional C' shear bands. In the main (central) part of the mylonite zone, farther to the NW, the dominant lineation in the schist is a quartz rodding lineation that has been inherited from its non-mylonitic precursor; however, has been strongly deformed in the dextral-reverse shear zone and now it plunges NE (Sibson et al, 1979; Little et al., 2002a; Toy, 2007).

In the non-mylonitic Alpine Schist a thin compositional laminated foliation $\left(\mathrm{S}_{2}\right)$ associated with mm-thick quartz laminae is the oldest fabric element in the Alpine Schist. This foliation was later crenulated to form the main foliation $\left(\mathrm{S}_{3}\right)$ in the nonmylonitic garnet zone Alpine Schist. This steeply dipping crenulation developed at near peak metamorphic conditions in the amphibolite-facies and was penecontemporaneous with growth of the garnet porphyroblasts (Little et al., 2002a). Near Franz Josef Glacier a detailed timing history for the growth of a single garnet is recorded by a Sm-Nd garnet-whole rock age of $\sim 95$ Ma for the inmost garnet core (see Vry et al., 2004), which thus completely pre-dates the inception of the Alpine Fault. The older, now crenulated, $\mathrm{S}_{2}$ foliation is preserved in the non-mylonitic Alpine Schist as the form of crenulation microfolds and as helicitic inclusion trails that were overgrown by syntectonic garnets (Little et al., 2002a; Vry et al., 2004). This crenulation fabric $\left(\mathrm{S}_{3}\right)$, with its related syn-tectonic garnets and their inclusion trails of $S_{2}$ is the starting material from which the Alpine mylonite zone was later formed in the late Cenozoic (Little et al., 2002a). The strike of the $S_{3}$ foliation is regionally oblique by $20-30^{\circ}$ anti-clockwise to the Alpine Fault (Little et al., 2002a). This crenulation fabric in the Tatare Stream area was already NE-striking parallel to the future Alpine Fault and mylonite zone (Fig. 2a). For this reason it was constructively reinforced and strengthened during the Cenozoic Southern Alps deformation (Little et al., 2002a). During the late Cenozoic, ductile deformation was strongly localized into the Alpine mylonite zone in proximity to the Alpine Fault 
causing overprinting and transposition of $\mathrm{S}_{3}$ in the concordantly disposed shear zone (Little et al., 2002a).

Finite shear strains in the mylonite zone have been estimated in parts of the Southern Alps (Norris \& Cooper, 2003). These estimates were based on a statistical analysis of deformational thinning of pegmatite dikes emplaced prior to shearing in the Alpine Schist that were later deformed into the Alpine mylonite zone (Norris \& Cooper, 2003). Depending on what type of flow is assumed for the Alpine mylonite zone (e.g., simple shear, or sub-simple shear that includes a pure shear thinning factor of up to 3 ) these thickness variations can be used to model the finite shear strain parallel to the Alpine Fault across the Alpine mylonite zone. For assumed rates of simple shear (thinning factor of 1.0) and thinning (factor of 3.0) shear strain estimates between 12 to 32 were modeled for the distal mylonites (lower estimates correspond to a thinning factor of 3, higher estimates to simple shear) and 100 to 200 in the central mylonite zone (Norris \& Cooper, 2003).

\subsubsection{Tatare Stream structural geology}

Tatare Stream (Figs. $1 \&$ 2) exposes an excellent structural section from the garnet zone non-mylonitic Alpine Schist, to the SE; through the shear-banded part of the distal mylonite zone, further to the NW; and including the upper part of the main Alpine mylonite zone in the most NW outcrops (Fig. 2a). The ultra-mylonite zone and the Alpine Fault are covered by alluvium. In Tatare Stream the dominant foliation in the non-mylonitic Alpine Schist (see insert in Fig. 2a) $\left(\mathrm{S}_{3}\right)$ strikes $053 \pm$ $2^{\circ}(2 \sigma)$ and dips $63 \pm 2^{\circ} \mathrm{SE}$ at $(2 \sigma)$. Vergence changes relative to $\mathrm{S}_{3}$ have been used to map several km-scale $F_{3}$ folds of $S_{2}$ (Fig. 2a). The dominant lineation in the nonmylonitic Alpine Schist is a crenulation lineation parallel to the intersection of the $\mathrm{S}_{2}$ and $\mathrm{S}_{3}$. This distinct lineation is typically expressed by a strong quartz rodding at the outcrop scale caused by the intersection of the $S_{2}$ quartz laminae with the $S_{3}$ plane. The $\mathrm{L}_{2 \times 3}$ intersection lineations and hinges of the km-scale $\mathrm{F}_{3}$ folds plunge $\sim 20^{\circ} \mathrm{SW}$ in Tatare Stream (Little et al., 2002a; Gillam et al., 2011 chapter 4 this thesis) (Fig. 2a arrow symbols).

A gradational contact is observed between the non-mylonitic Alpine Schist and the distal part of the Alpine mylonite zone (Fig. 2a). The latter is defined by the appearance of ubiquitous extensional C' shear bands that pervade the rock at $\mathrm{mm}$ to Gillam, B. G. 


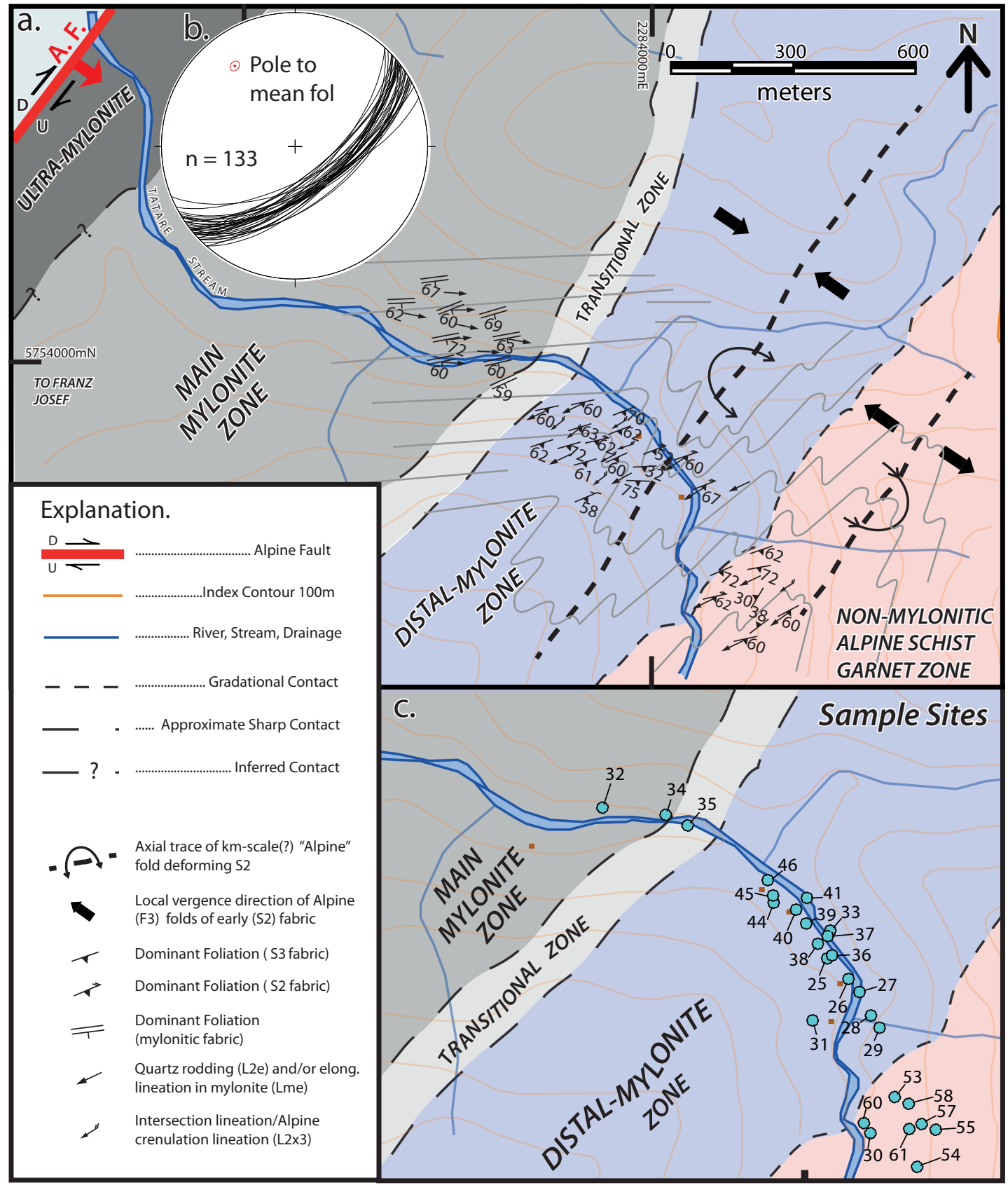

Fig. 2. (a) Bedrock structural geology of the Alpine Schist at Tatare Stream near Franz Josef Glacier. Trace of Alpine Fault is from Norris and Cooper (1995). Position of ultra-mylonite is approximated from the thickness distributions in Gaunt Creek to the north from Toy et al., (2008). (b) Stereographic projection of 133 non-mylonitic, distal mylonite, and mylonitic foliations attitudes in Tatare Stream with a mean foliation pole $323 / 27$ and $95 \%$ confidence ellipse on mean pole. (c) Sample localities in Tatare Stream for thin-section analysis. 
$\mathrm{cm}$-scale and that cut and offset the older, yet still distinct, $\mathrm{S}_{3}$ foliation. The distal mylonite zone is $\sim 600 \mathrm{~m}$ thick in Tatare Stream. There, the lower boundary of the main mylonite zone against the ultra-mylonites does not outcrop; however from the known mylonite outcrop and position of the Alpine Fault trace, a total thickness of $800 \mathrm{~m}$ is estimated for the Alpine mylonite zone (including the unexposed ultramylonites). With increasing proximity to the Alpine Fault, further to the NW, the $\mathrm{S}_{3}$ fabric becomes increasingly planar and finely quartz laminated in appearance as a result of a progressive increase in the degree of late Cenozoic mylonitic overprint. This overprint is also expressed by an increased appression of the $F_{3}$ crenulation micro-folds of $S_{2}$ and the transposition of the $S_{2}$ planar remnants so that they become indistinguishable from $\mathrm{S}_{3}$. The distal mylonite zone preserves the characteristically $\mathrm{SW}$-pitching $\mathrm{L}_{2 \times 3}$ intersection/quartz-rodding lineation inherited from the nonmylonitic Alpine Schist. This lineation retains the SW plunge despite the deformation in the distal mylonite zone as this deformation is localized into shear bands. The distal mylonite zone has informally been referred to as the "curly schist" (Reed, 1964); a term that relates to the sigmoidal deflection of the $\mathrm{S}_{3}$ foliation between adjacent bounding C' shears on either side of the microlithon. The sense of deflection of $\mathrm{S}_{3}$ across the C' shear bands is everywhere consistent with dextralreverse shear that is synthetic with the Alpine Fault.

In Tatare Stream the distal mylonite zone and mylonite zone are separated by a $\sim 50 \mathrm{~m}$ wide, transitional zone (Fig. 2a). Across this transitional zone the SWpitching $\mathrm{L}_{2 \times 3}$ lineation (quartz rods) changes pitch by $\sim 140^{\circ}$ in an anticlockwise sense to achieve the gently NE-pitching orientation that is typical of the main mylonite zone. In detail, the transitional zone is not gradational as the change in lineation orientation occurs in a punctuated fashion between m-scale domains of foliation packets of both NE and SW lineation plunges.

The uppermost $\sim 250 \mathrm{~m}$ of structural section of the main mylonite zone is exposed in Tatare Stream (Fig. 2a). There, the mylonite fabric includes the same strong quartz rodding lineation, which I infer to be inherited from the adjacent non-mylonitic Alpine Schist, but which has been distortionally reoriented to a NE plunge (see also Toy, 2007; Toy et al., 2011; Gillam et al., 2011 chapter 4 this thesis). In Tatare Stream the lineation in the main part of the mylonite zone plunges NE at an average angle of $16^{\circ}$. The main mylonite zone, like the distal mylonite zone to the SE, Gillam, B. G. 
contains mm-spaced extensional C' shears that cut and deflect the mylonitic foliation $\left(\mathrm{S}_{\mathrm{m}}\right)$. A remarkable feature of the Tatare Stream section is that across the entire finite strain gradient related to the transition between non-mylonitic to mylonitic rocks the attitude of the foliation (variably non-mylonitic, distal mylonite, and mylonitic) remains consistent at $053 / 63 \mathrm{SE}$.

In the mylonitic and protomylonitic zones at Tatare Stream the dominant quartzofeldspathic (metagreywacke) protolith is locally interlayered with $\sim 1-2 \mathrm{~m}$ thick zones of micaceous pelitic schist and amphibolite mafic schist. The distal and main mylonite zones consist chiefly of quartzofeldspathic greyschist that includes $0.5 \mathrm{~mm}$ thick quartz laminae that are foliation parallel, and lesser lenticular concordant quartz veins up to $4 \mathrm{~cm}$ thick; that are also mostly foliation parallel. Both are cut and offset by the C' shear bands. Mafic amphibolite and pelitic-rich schist are interlayered with greyschist in lenses $1-2 \mathrm{~m}$ thick. In Tatare Stream, the main part of the mylonite zone contains a slightly greater abundance of micaceous pelitic schist than does the distal mylonite zone adjacent to it to the SE, which is more uniformly quartzofeldspathic in composition.

\subsection{Measuring porphyroblast inclusion trail orientations relative to the Alpine Fault shear zone boundary in Tatare Stream}

This study uses the known attitude of the SZB of the Alpine mylonite zone; and the finite shear strain gradient within that shear zone, as stepping-stones to understanding how pre-existing garnet porphyroblasts may have rotated as a result of deformation in that zone. As previously stated, a number of unknowns have hindered some previous studies into the rotational behavior of porphyroblasts. By contrast ductile shear zone exposures in Tatare Stream and their modern geodynamic context (i.e., shear zone framework) satisfies all of these potential pitfalls to be overcome. Thus, the spatial pattern of porphyroblasts and inclusion trail geometries can be evaluated in terms of the flow kinematics of the Alpine mylonite zone and the behavior of rigid objects embedded in such zones. I have adopted similar assumptions to that of Ghosh \& Ramberg (1976) and Ghosh (1987) where the garnets observed and measured in Tatare Stream are (1) 100\% clast matrix coupled, (2) undergo steady-state homogenous deformation, and (3) have no clast interaction. 
I know the attitude of the Alpine mylonite zone SZB precisely because the dominant foliation attitude remains consistent at 053/63SE across the imposed late Cenozoic strain gradient between the non-mylonitic Alpine Schist and the main mylonite zone (Fig. 2b). On this basis of this observation, I infer that the nonmylonitic to mylonitic foliation is everywhere exactly parallel to the SZB attitude because only planes that are disposed parallel to the SZB will remain in a stable orientation throughout the superposition of an intense shearing overprint and related finite strain gradient (see Gillam et al., 2011 chapter 4 this thesis). The Alpine Fault SZB can be confidently identified as striking 053 and dipping $63^{\circ} \mathrm{SE}$. I choose this datum as the reference frame for evaluation of porphyroblast rotation.

The examined garnet porphyroblasts have been measured across a wellcharacterized shear strain gradient that postdates their growth. The mylonites in Tatare Steam are derived from the quartzofeldspathic "greyschist" equivalent of their non-mylonitic wall rocks (Vry et al., 2004). A progressive reduction in grain size in the main mylonite zone and the increasing planarity and thinly laminated nature of the foliation reflects that the mylonites in Tatare Stream have experienced higher finite shear strains than the adjacent distal mylonite and the non-mylonitic Alpine Schist. The mylonitic deformation is late Cenozoic in age and post dates the nucleation and growth of the precursor non-mylonitic garnets by $>50 \mathrm{Ma}$. Norris \& Cooper (2003) quantified this gradient in finite shear strain by reference to the progressive deformational attenuation of pre-mylonitic pegmatite dikes across the mylonite zone.

\subsubsection{Garnet porphyroblasts in Tatare Stream.}

Several oriented samples $(n=28)$ were collected in Tatare Stream at sites that span the above mentioned strain gradient in the Alpine mylonite zone, including the starting material of the Alpine Schist wall rock (Fig. 2c). In the non-mylonitic Alpine Schist and distal mylonite zone the garnet porphyroblasts have a diameter between 1 $-6 \mathrm{~mm}$, whereas in the main mylonite zone garnets are all approximately $2 \mathrm{~mm}$ in size (Fig. 3a - c). Both straight and crenulated inclusions geometries are common with the majority of the garnets having an inclusion trail that is straight in the center of the grain and curved near the edges (Fig. $3 \mathrm{a}-\mathrm{c}$ ). These curved inclusion edges can be attributed to the garnet overgrowing the limbs of $\mathrm{D}_{3}$ crenulation microfolds syn- 


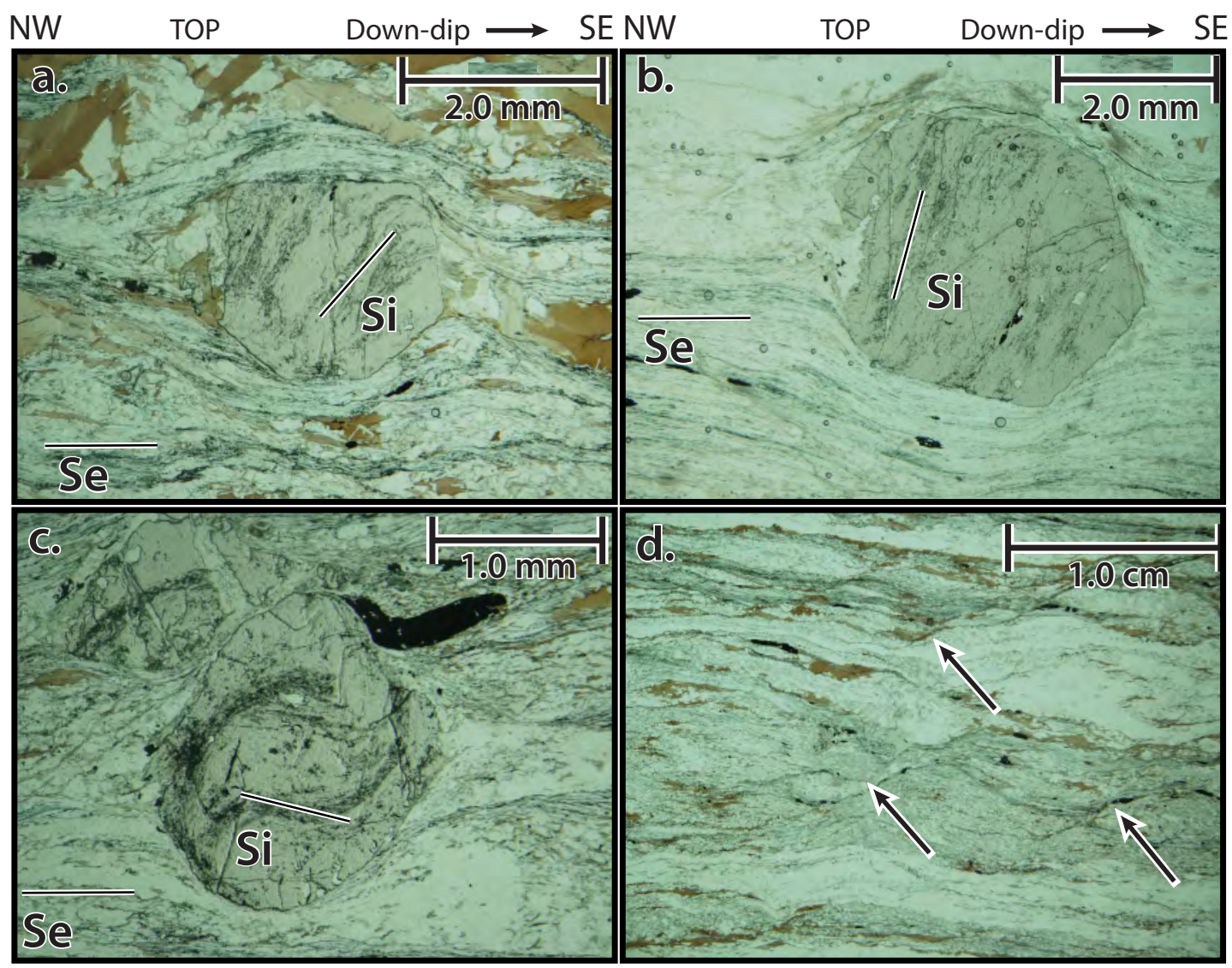

Fig. 3. Photomicrographs of typical garnet porphyroblasts and their planar to slightly crenulated internal inclusion trails (Si) of graphite and minor quartz. Se is the dominant external foliation (S3 of $\mathrm{Sm}$ ) and is shown horizontally in each image. Down-dip is to the right in all the images and all cuts are parallel to the shear direction and perpendicular to the foliation. (a) Garnet porphyroblast with inclusion trail geometry in the non-mylonitic Alpine Schist; note the continuity between the Si and Se. (b) Similar inclusion trail geometries in garnet porphyroblasts in the distal mylonite zone; most garnets in Tatare Stream have an equant shape. Note continuity between Se and Si on upper margin of garnet and truncation on lower margin. (c) Garnet porphyroblast in the main mylonite zone. Rotation of garnets in the anticlockwise direction looking NE relative to non-mylonitic Alpine Schist starting orientation. (d) Extensional $C^{\prime}$ shear bands (arrows) from the same outcrop as the garnet in b. These extensional shear bands have a dextral-reverse sense of shear, corresponding to top to the left sense of shear in the outcrop, compatible with the anticlockwise sense of rotation of the equant shaped garnets and their inclusion trails away from their non-mylonitic orientation (a). 
kinematic with $\mathrm{D}_{3}$ to yield the apparently deflected outer margin of the inclusion trails (by up to $\sim 90^{\circ}$ ), and with continuity between the internal and external foliations (Fig. 3a-c). I measure the orientation of the straight central inclusion section relative to the SZB and track its orientation as the garnets are swept into the Alpine mylonite zone. I am aware that these internal inclusions are three-dimensional, but here I will adopt a 2D sectional and statistical approach of measuring the mean $3 \mathrm{D}$ orientation of the central planar inclusion trails in these garnet porphyroblasts. Moreover, I have also assumed that the 2D sectional shape of the garnet porphyroblast reflects its three-dimensional shape. In other words, the circular garnets in the 2D cuts are spheroidal in three-dimensions. The preservation of the straight inclusion segments suggests in the center of the grains the garnets nucleated inter-kinematically prior to the beginning of the $\mathrm{D}_{3}$ crenulation event, or during the latters earliest stages (Little et al., 2002a). The straight inclusion trails are graphitic inclusions together with minor quartz \pm epidote \pm randomly oriented ilmenite porphyroblasts that overgrew $\mathrm{S}_{2}$. Electron microprobe analyses on garnets in the mylonitic samples (Fig. 2c sample 32) in Tatare Stream display prograde compositional zoning trends that are also common in non-mylonitic Alpine Schist garnets (Fig. 4). No significant increase in $\mathrm{Ca}$ and/or decrease in $\mathrm{Fe}$ are observed at the rim indicating that the garnet growth predates the mylonitization (see e.g., Upton, 1995; Vry et al., 2004).

Each sample was cut into three different oriented thin-sections, all of them perpendicular to the foliation. One of these thin-sections was cut parallel to the ductile shearing direction (pitches $58^{\circ}$ in the constant foliation plane) for the central Alpine mylonite zone in Tatare Stream and is orthogonal to the intersection of the C' shear bands with the foliation (see Gillam et al., 2011 chapter 2 this thesis). The remaining thin-section cuts were made at a pitch angle of $\pm 45^{\circ}$ to either side of this known ductile shearing direction. One hundred and fifty six garnet porphyroblasts were observed on thin-section cuts parallel to the shear direction in the non-mylonitic $(n=6)$, distal mylonite $(n=6)$ and mylonite zone $(n=2)$ samples. The $45^{\circ}$ cuts $(n=$ 14) were used to observe an additional 79 apparent sectional observations of straight inclusion cores.

I have adopted a two-prong approach for measuring the rotational kinematics of garnet porphyroblasts in Tatare Stream. First I measure the orientation of the straight central inclusion trails in apparently spheroidal garnets (relative to the SZB) in the Gillam, B. G. 
a.

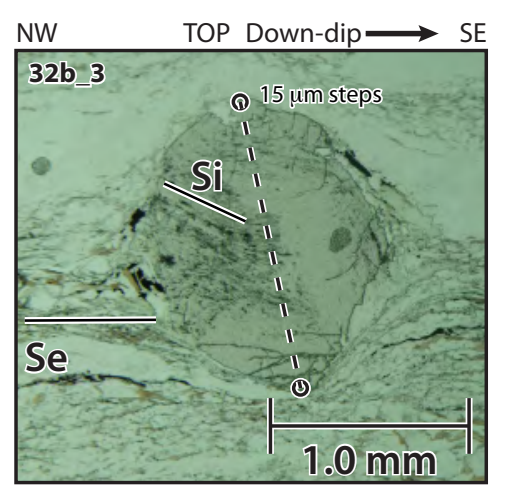

b.

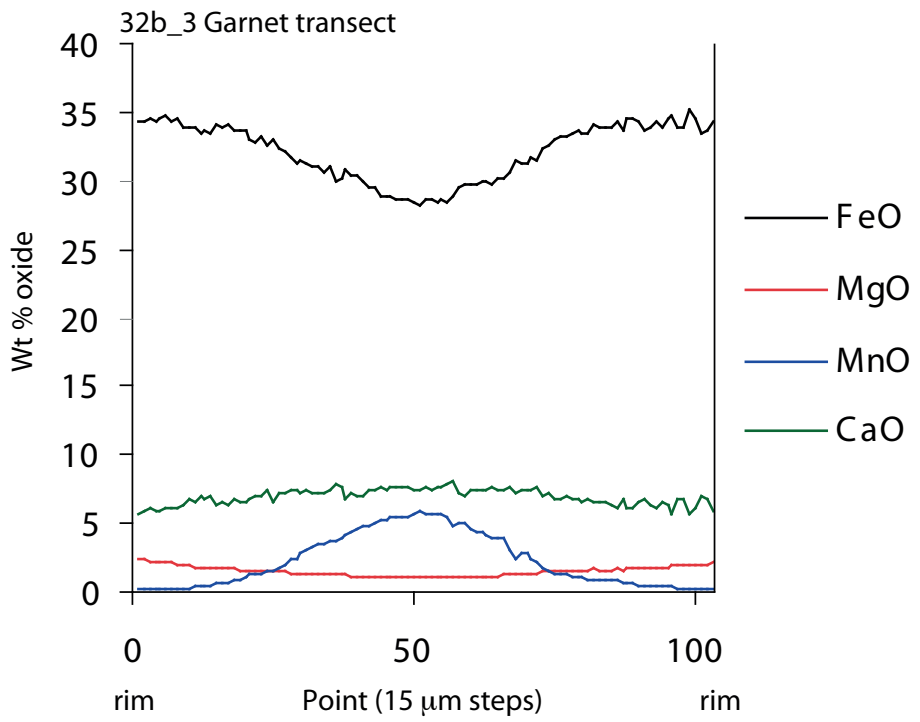

Fig. 4. (a) Transect across an equant garnet porphyroblats in smaple 32b (see Fig. $2 c$ for location) from the main mylonite zone, Tatare Stream. This garnet is the third analyzed in this sample by the Electron microprobe at Victoria University of Wellington. Analytical data for this garnet can be found in appendix c (this thesis). (b) Compositional zoning profile for garnet 32b_3. Transect is from rim to rim in 15 $\mu \mathrm{m}$ steps. Common prograde zonation profile as seen in garnets from the non-mylonitic Alpine Schist wall rocks. 
ductile shearing parallel cut throughout the Alpine mylonite zone. I compare the distal mylonite and main mylonite zone garnet inclusion trail orientations (relative to the foliation and SZB) to the orientation of inclusion trails in the pre-shearing nonmylonitic garnets. This will allow calculation of a rotation direction and amount, if any, in response to shearing in the Alpine mylonite zone. I use the GhoshFlow program to forward model the angular distribution of inclusion trails in spheroidal non-mylonitic garnets at 5 different shear strains, in attempt to reproduce the inclusion trail distribution measured in the main mylonite zone. The second approach was to use more elongate garnets and again the GhoshFlow program, which requires the long axis orientation and the internal inclusion orientation to forward model the distribution of garnets shapes and their inclusion orientation for a particular shear strain and kinematic vorticity number. This modeling will help to constrain the kinematic vorticity number and the finite shear strain experienced during late Cenozoic ductile flow in the distal and main mylonite zones.

\subsubsection{Garnets in the pre-shearing Mesozoic non-mylonitic Alpine Schist}

I have made detailed geometrical descriptions of garnet inclusions in samples of non-mylonitic Alpine Schist in the hanging wall of the Alpine mylonite zone. Only straight to marginally deflected (crenulated) central inclusion trails were measured (Fig. 3a). A small proportion ( $\sim 15 \%)$ of garnet porphyroblasts in the non-mylonitic Alpine Schist have inclusions that have been deflected by $90^{\circ}$ at the outer edge from the main internal inclusion trails. Across this deflection the internal inclusions trails maintain continuity with the adjacent external foliation outside the garnet (Figs. 3a \& b). The vergence direction defined by the asymmetric inclusion trails in the garnet porphyroblasts is variable in the non-mylonitic Alpine Schist samples. Approximately equal proportions of both up-dip and down-dip vergences were observed. Mixed vergence suggests that Alpine Schist garnets nucleated where $\mathrm{S}_{2}$ and $S_{3}$ were perpendicular, for example in the hinge zone of large Alpine folds. Mixed vergence directions were observed for similarly sigmoidal shaped inclusion trails in the distal mylonite and main mylonite zone samples (Fig. $3 \mathrm{a}-\mathrm{c}$ ).

A small percentage of garnet porphyroblasts $(<5 \%)$ in the non-mylonitic Alpine Schist have inclusion free cores and inclusion rich rims. Such inclusion free garnet core could be remnants from older precursors in the Haast Schist or a relict detrital 
core. Whatever their origin, no inclusion free cores are observed in the distal mylonite and main mylonite zones and for this reason this type of garnet porphyroblasts was not analyzed in this study.

\subsubsection{Garnet porphyroblast aspect ratio $(R)$}

Garnet porphyroblasts in Tatare Stream tended to be mostly spherical in hand sample and circular in thin-section. The aspect ratio $(\mathrm{R})$ is defined to be the length of the garnet long axis divided by the length of the short axis (Fig. 5a). The dominant aspect ratio (56\%) throughout the non-mylonite, distal mylonite, and main mylonite schist ranges between 1.0 and 1.2 (Fig. 6). Twenty nine percent of the garnets in the mylonite and the non-mylonite Alpine Schist have R-values between 1.2 - 1.6. Rare $(15 \%)$ garnets with aspect ratios $>1.6$ were observed. This bias towards the smaller $\mathrm{R}$-values could be a relict of a too small a sample. Such larger aspect ratio grains potentially could be sensitive kinematic recorders, as they should be particularly prone to any sort of rotation in thinning shear zones where there is a pure shear component to the deformation, depending on its initial orientation and the flow type in that zone. Unfortunately the few larger R-value garnets in Tatare Stream had internal inclusion trail geometries that were poorly defined and hard to interpret. As a result the orientation and tracking of the internal inclusions was difficult in the few highest aspect ratio garnets making them unreliable for analysis. Thus, this study was limited to an analysis of garnets with aspect ratios between 1.0 and 1.5.

3.4.4 Angle $\beta$ between long axis of garnets $(R=1-1.5)$ and the shear zone boundary

Long axis orientations were measured for garnets with aspect ratios between 1.0 and 1.5 in Tatare Stream. The orientation angle is defined as follows: $0^{\circ}$ where the long axis is normal to the foliation (SZB) with larger angles being measured anticlockwise relative to this direction; an angle of $90^{\circ}$ means that the long axis is parallel to the foliation (Fig. 5a). In the non-mylonitic Alpine Schist I found an apparently scattered distribution of long axis orientations relative to the foliation $\left(\mathrm{S}_{3}\right)$ (Fig. 7c). In the distal mylonite zone, garnets with aspect ratios between 1.0 and 1.2 are widely distributed in angle from $10^{\circ}$ to $180^{\circ}$ (Fig.7e). However, the long axes of the larger aspect ratio garnets $(1.4-1.5)$ are mostly sub-parallel to the foliation in that zone. The mylonite zone exhibits an apparent clustering of long axes towards 


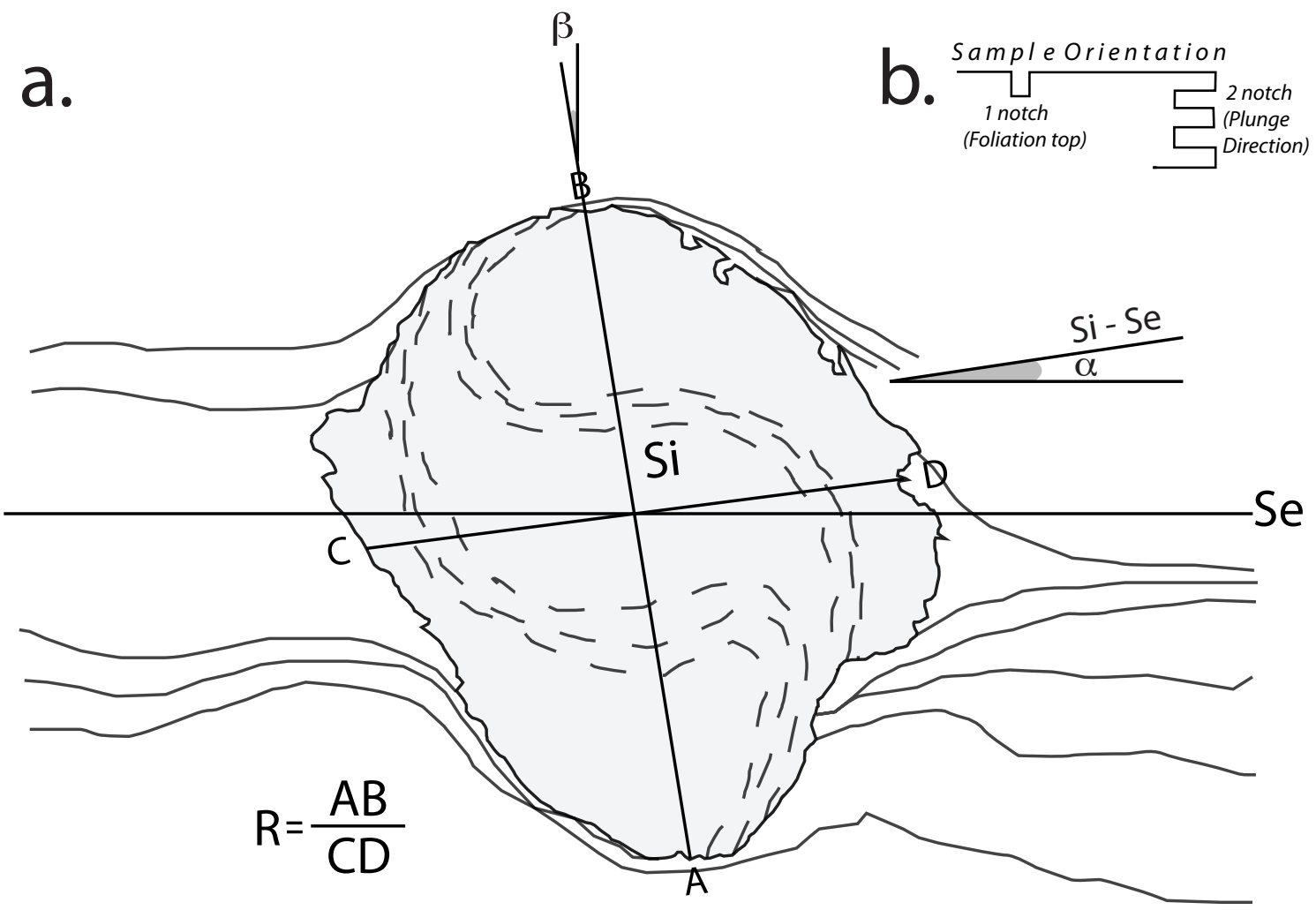

Fig. 5. (a) Definition of sectional geometric parameters for garnet porphyroblast observed in thinsection. The angles $\beta$ and a can be easily measured in thin-section. In each section the angle $\beta$ is measured normal to the foliation whilst $\alpha$ is measured in the rotation sense relative to the down-dip direction and the external foliation in that sample. (b) Sample orientation details; two notches is the down-dip direction for that sample, one notch is the foliation top. 


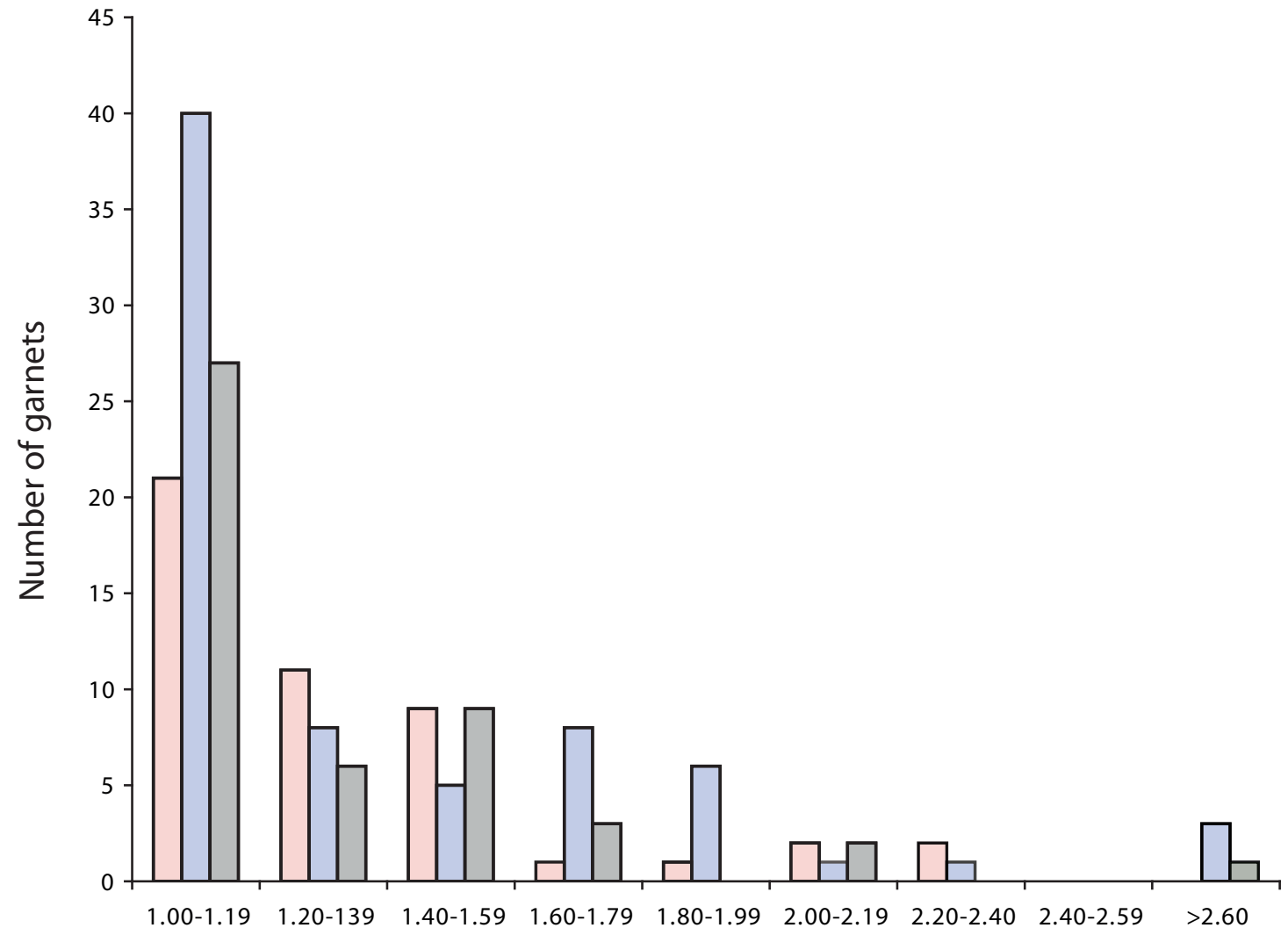

Aspect Ratio (R)

Fig. 6. Histogram of garnet porphyroblast aspect ratios (R) in sections perpendicular to the foliation and parallel to the ductile shearing direction in the Alpine mylonite zone and in thin sections cut at pitch angles $45^{\circ}$ on either side of that direction. The colours repersent which zone the garnets are from: light red is the non-mylonitic Alpine Schist, light blue is the distal mylonite zone, and grey is the main mylonite zone. Garnets in the non-mylonitic Alpine Schist, distal mylonite, and mylonite zone have similar distributions with most aspect ratios less than 1.5 . 
a.

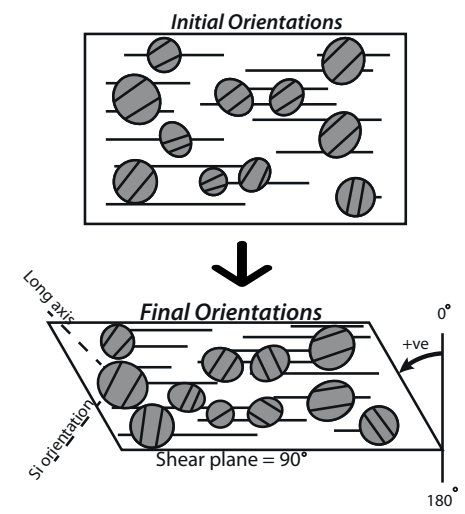

b.

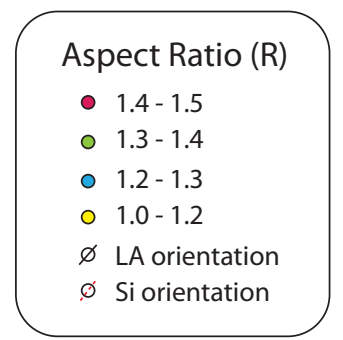

Undeformed Non-Mylonitic Alpine Schist

C.

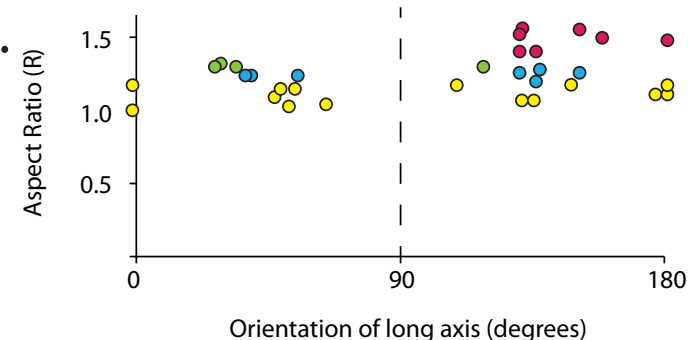

d.

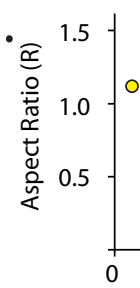
80

Distal-Mylonite

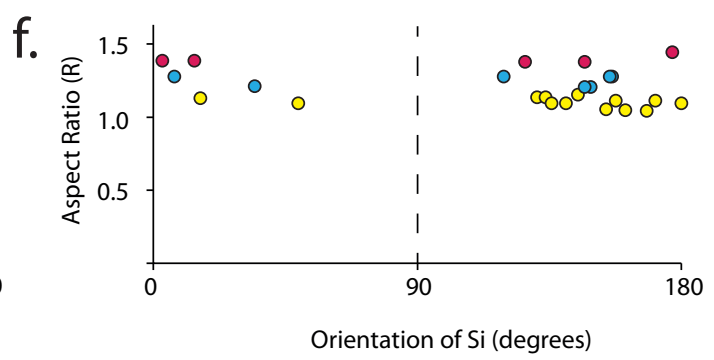

Mylonite

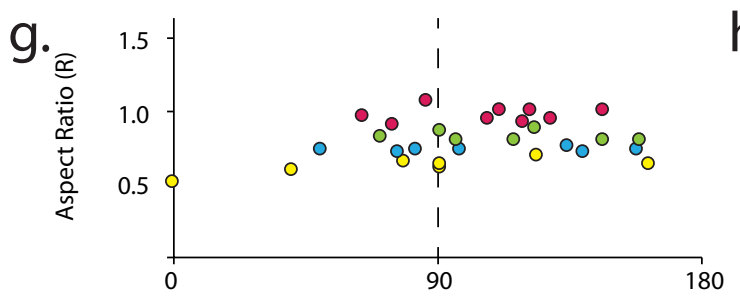

Orientation of long axis (degrees)

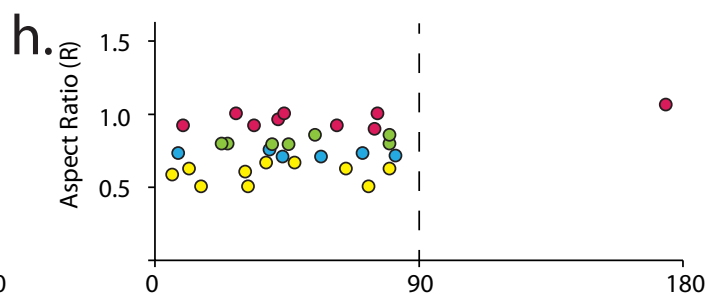

Orientation of Si (degrees)

Fig. 7. (a) Illustration of garnet porphyroblasts with internal inclusion orientations relative to the shear plane in the non-mylonitic Alpine Schist. The zero angle is normal to the shear plane, the angle measured is postive in the direction of shear, and the shear plane in the shear direction is $90^{\circ}$. (b) Legend for plotted binned aspect ratios. (c-h) Garnet long axis (LA) and straight central internal inclusion trail orientation (Si) scatter plots for different aspect ratios in the non-mylonitic Alpine Schist, distal mylonite and main mylonite zone. The red box in $\mathrm{d}$ refeclts and encompasses the range of inclusion trail orientations observed in the non-mylonitic starting wall rocks. Red dots reflect the mean inclusion trail orientation in the non-mylonitic Alpine Schist. This red zone is required for the offsetting of the GhoshFlow plots in figures to follow. 
attitudes that are sub-parallel to the foliation across a wider range of aspect ratios than does the distal zone (Fig. $7 \mathrm{~g}$ ).

3.4.5 Garnet porphyroblast internal inclusion trial angle $(\alpha)$ for garnets with $R$ values $1-1.2$.

The angle between the external foliation and the straight central segment of a straight or crenulated inclusion trail in a garnet is defined as $\alpha$. This angle was measured across the strain gradient in Tatare stream. As mentioned, the first approach was to concentrate on and measure the central inclusion trail orientation in apparently circular garnets. Here I have measured and plotted (Fig. 8) the central inclusion orientation for garnets with aspect ratios between 1.0 and 1.2. The mean internal inclusion trail angle for the non-mylonitic Alpine Schist samples $(n=21$ garnets in 6 samples) is $46 \pm 20^{\circ}(1 \sigma)$ anticlockwise of the foliation looking NE (Fig. $8 \mathrm{a})$. In the distal mylonite zone the measured mean internal inclusion trail orientation was $81 \pm 20^{\circ}(1 \sigma)(\mathrm{n}=40$ garnets in 6 samples $)$ anticlockwise of the foliation looking NE (Fig. 8b). In the main mylonite zone further to the NW the internal inclusion planes as viewed in shear parallel sections are spread over a wider range of orientations compared to those in the less-deformed non-mylonitic Alpine Schist and distal mylonite zone (Fig. 8c). There are no inclusion trail orientations that populate in the right-hand (down-dip) "quadrant" of figure 8c. This is a result of a small sample set and a sampling bias towards the "spherical" sub-population of garnet grains that have zero individuals in that quadrant. In other words, more elongate grains $(\mathrm{R}>1.5)$ would tend to back-rotate placing inclusion trails in this "right-hand quadrant". The mean internal inclusion trail angle in the main mylonite zone $(n=27$ garnets in 2 samples) is $127 \pm 34^{\circ}(1 \sigma)$ (Fig. 8c).

\subsubsection{Estimation of bulk finite shear strain from porphyroblast rotation}

Equant garnets $(\mathrm{R}=1.0-1.2)$ in the Alpine mylonite zone forward rotated with respect to the external foliation in the non-mylonitic Alpine Schist and the SZB, which is parallel to that foliation. In non-coaxial flow, rigid spherical particles that are fully coupled to the surrounding matrix are predicted to undergo a finite rotation that is equal to half the bulk shear strain (Jeffrey, 1922). The difference in inclusion orientation between the non-mylonitic and distal mylonite implies an apparent forward (dextral-reverse) rotation of $35^{\circ}$ relative to the foliation and the SZB. Gillam, B. G. 
$\mathbf{\alpha}$ (Si- Se) Garnets porphyroblasts with aspect ratios between $1.0-1.2$

a.

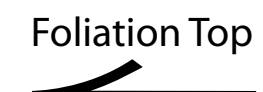

\section{Non-Mylonitic Alpine Schist}

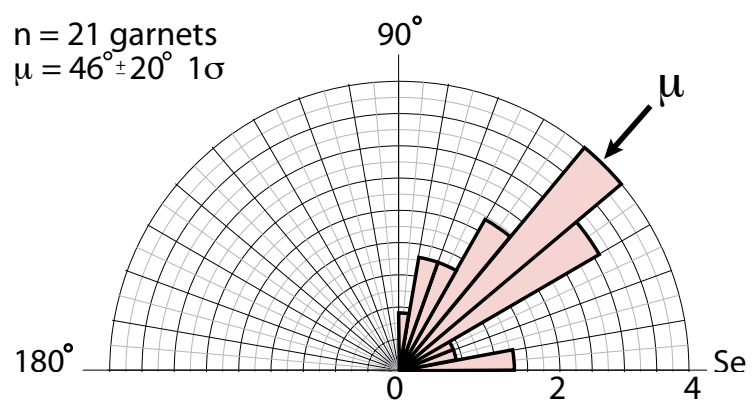

b.
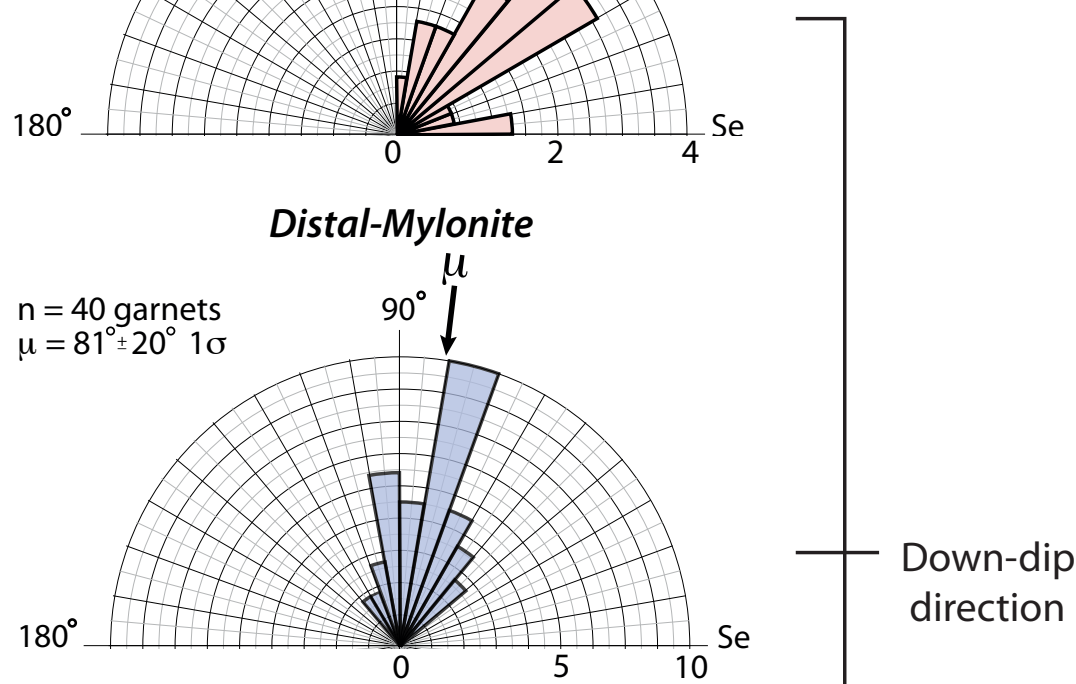

C.

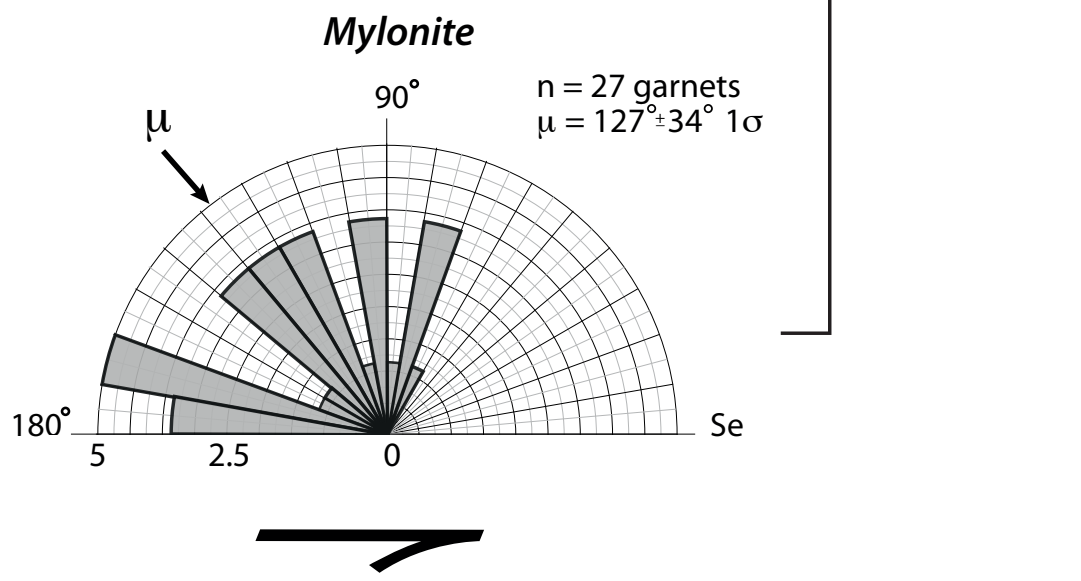

Fig. 8. Rose plots of the straight central core inclusion trail orientations (a see Fig. 5a) in garnet porphyroblasts with aspect ratios between 1.0-1.2 across the central Alpine mylonite strain gradient, Tatare Stream. Angles are measured anticlockwise from the down-dip direction in a given sample relative to the external foliation (Se). (a) Apparent angular distribution of inclusion trails in circular garnets in the non-mylonitic wall rock. Arrow is the mean inclusion orientation in that structural zone. (b, c) Apparent angular distribution of distal mylonite and main mylonite inclusions trails relative to the external foliation. 
Implied from this rotational behavior for these garnets in distal mylonite zone is a $\gamma=$ 1.2. The orientation of inclusion trails in the mylonite zone implies an apparent forward rotation of at least $81^{\circ}$ in the up-dip direction (dextral-reverse) as a result of the difference in strain in passing between the non-mylonitic Alpine Schist and main mylonite zone. The sense of rotation (anticlockwise of reference frame looking NE in Fig. 8) is synthetic to the dextral-reverse sense of shear in the Alpine mylonite zone. The average forward rotation that affects apparent spheroidal garnets in the mylonite zone implies a dextral-reverse shear strain of $\gamma=2.8$. The most anticlockwise rotated inclusion planes in the main mylonite zone imply a maximum rotation that is up to locally $132^{\circ}$, which would correspond to a shear stain of $\gamma=4.6$. The much more variable orientation of garnet inclusions observed in the main mylonite zone, in contrast to the distal mylonite zone may suggest that the shear strain experienced by these garnets could be higher than the first approximation from the mean rotation $(\gamma=2.8)$ and that it involved some multiple revolutions of $>360^{\circ}$.

To forward model the non-mylonitic Alpine Schist inclusion trail dip orientations (Fig. 8a) I use GhoshFlow to predict inclusion trail dips at different shear strains, and compare these predictions to the inclusion trail dips measured in the main mylonite zone (Fig. 9). The GhoshFlow program forward models the distribution of internal inclusion plane orientations as a function of the host porphyroblasts long axis orientations and their aspect ratios. A shear strain of $3.5\left(100^{\circ}\right.$ forward rotation from the mean non-mylonitic inclusion trail) reproduces the range of inclusion trail dips and the mean orientation measured in the main mylonite zone (Figs. 9b \& 8c). I have further predicted inclusion trail dips for higher shear strains (Fig. 9c - f). A $460^{\circ}$ revolution $(\gamma=16)$ predicted a range of inclusion trail dips that were larger and had a different mean orientation than that measured in the main mylonite zone. Moreover, multiple revolutions of $5(\gamma=66)$ and $8(\gamma=104)$ predicted even larger inclusion trail dip ranges (Fig. 9d \& e). A shear strain of 106 reproduced the same mean inclusion trail dip orientation, albeit with a slighter larger range of predicted values. From these predictions I infer that the small, scattered, and shape bias data set in the main mylonite suggests a finite shear strain of $\sim 3.5$; however, the similar mean orientation and spread of inclusion trail dips for a finite shear strain estimate of 106 can be a suitable estimation for the main mylonite zone. Nevertheless, the data measured and 
non-mylonitic Alpine Schist

a.

$180^{\circ}$

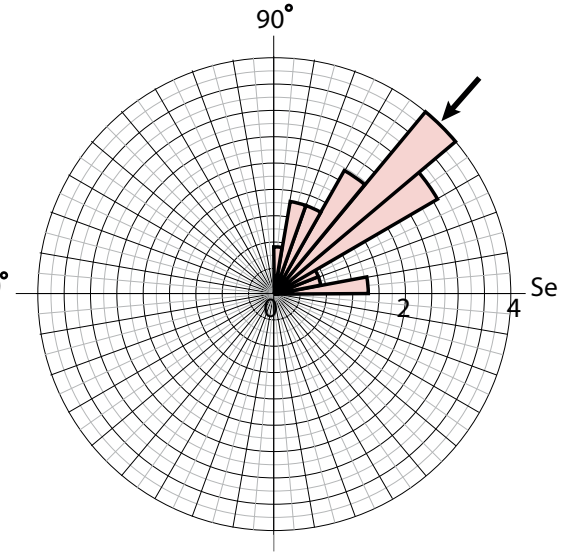

$$
\gamma=16
$$

C.

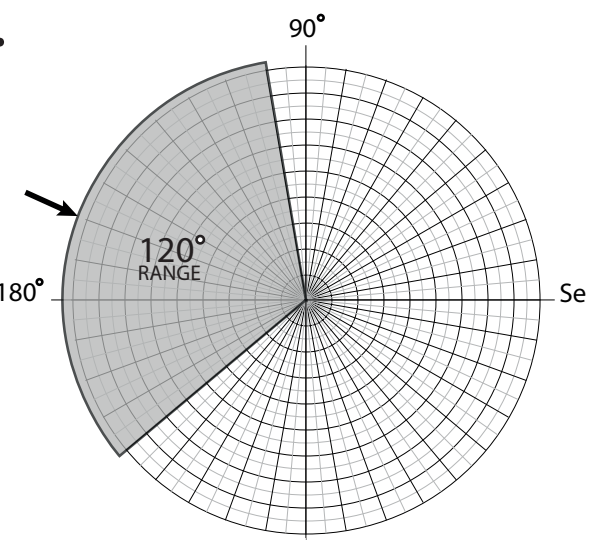

e. $\quad \gamma=104$

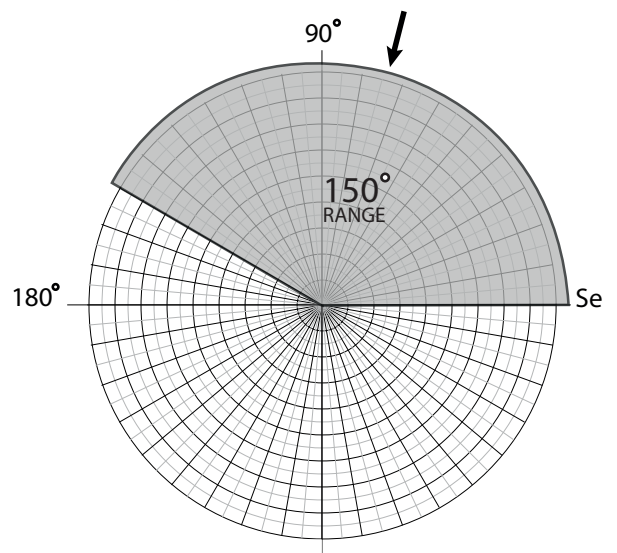

$\gamma=3.5$

b.

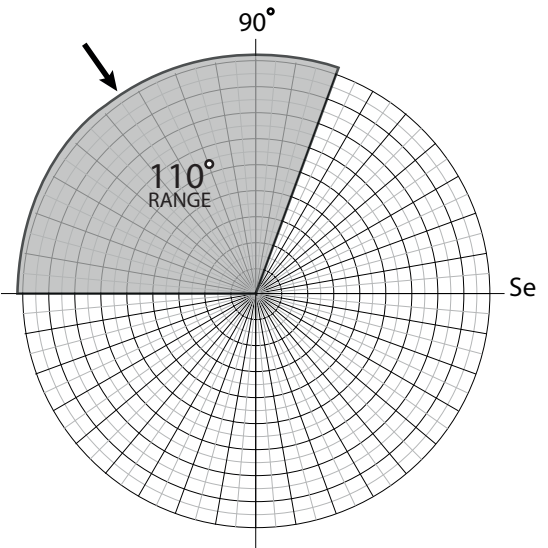

$\gamma=66$

d.

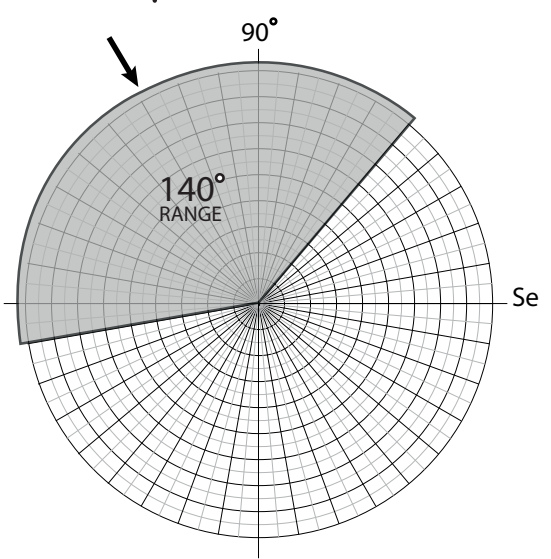

f. $\gamma=106$

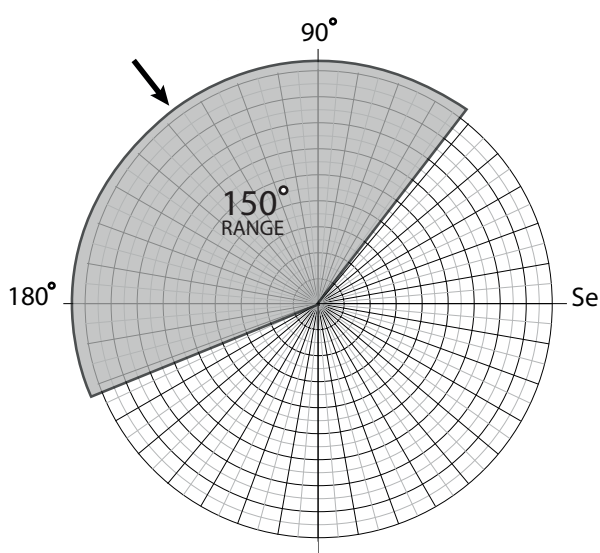

Fig. 9. Forward modeled inclusion trail dips using GhoshFlow and it assumptions (see text). The range in inclusion trail dips in near circular garnets with aspect ratios between 1 - 1.2 are forward modeled using shear strains of 3.5, 16, 66, 104, 106 and a Wk of 0.5 (see chapter 2) in an effort to reproduce the observed pattern of inclusion trail dips in the main mylonite zone, Tatare Stream (see Fig. 8c). Reference directions for plots is the same as in Fig. 8. (a) The starting mean inclusion trail dip (black arrow) and range (bars) in the non-mylonitic for the GhoshFlow predictions. (b) GhoshFlow prediction of the angular range of inclusion trail dips (grey box) for a shear strain of 3.5. Arrow is the mean dip orientation (c) GhoshFlow prediction of the angular range of inclusion trail dips (grey box) for a shear strain of 16. (d) GhoshFlow prediction of the angular range of inclusion trail dips (grey box) for a shear strain of 66. (e) GhoshFlow prediction of the angular range of inclusion trail dips (grey box) for a shear strain of 104. (f) GhoshFlow prediction of the angular range of inclusion trail dips (grey box) for a shear strain of 106. 
the predictions made in this study supports a minimum provisional finite shear strain estimate of $\sim 3.5$ for the main mylonite zone.

\subsubsection{D orientation of internal inclusions in garnet porphyroblasts $(R=1-1.5)$}

Multiple thin-section cuts made on each of the oriented samples in Tatare Stream have allowed determination of the "best-fit" three-dimensional attitude of the central inclusion planes by combining the apparent dips on all 3 planes. I have used a Matlab $^{\circledR}$ code (see Gillam et al., 2011 chapter 2 this thesis) to determine the "best fitting" central inclusion plane to clusters of apparent inclusion plane orientations in the 3 different thin-section cuts. The mean strike of the non-mylonitic Alpine Schist central inclusion planes in garnets is $024 \pm 18^{\circ}(2 \sigma)$ and the mean dip is $37 \pm 18^{\circ} \mathrm{SE}$ $(2 \sigma)$ (Fig. 10a). The attitude of inclusion planes in garnets in the distal mylonite zone strike $033 \pm 20^{\circ}(2 \sigma)$ and $\operatorname{dip} 30 \pm 20^{\circ} \mathrm{NW}(2 \sigma)$ (Fig. 10b). The mean attitude of central inclusions in garnets in the mylonite zone strike $068 \pm 10^{\circ}(2 \sigma)$ and dip $60 \pm$ $10^{\circ} \mathrm{NW}(2 \sigma)$ (Fig. 10c). Based on the three-dimensional attitudes, a best-fit rotational axis can be calculated that can relate these orientations to one another by a simple rigid body rotation that takes place between the non-mylonitic Alpine schist and the mylonite zone. The best-fit rotational axis trends $053 \pm 20^{\circ}(2 \sigma)$ and plunges $1 \pm 20^{\circ}(2 \sigma) \mathrm{NE}$ (Fig. 11). I note that this is approximately perpendicular to the shear vector and approximately parallel to the vorticity vector (see Gillam et al., 2011 chapter 2 this thesis).

\subsection{Discussion}

\subsubsection{Evidence for porphyroblast rotation}

Garnet porphyroblasts tracked from the non-mylonitic Alpine Schist into the main mylonite zone appear to experience a forward rotation relative to the SZB that is synthetic to the known dextral-reverse kinematics of the Alpine mylonite zone. The largest apparent forward rotation relative to the SZB is observed in garnets from the mylonite zone $\left(81^{\circ}\right)$. Garnets in the distal mylonite zone underwent a smaller forward rotation $\left(35^{\circ}\right)$ relative to the SZB (Fig. 8a - c). Interestingly, the nearly spheroidal garnets $(\mathrm{R}=1.0-1.2)$ appear not to have undergone a back rotation. The R-values in Tatare Stream are far to close to unity for the grains to reach a stable orientation in the flow (e.g., Masuda et al., 1995). For a sub-simple shear thinning 
a.

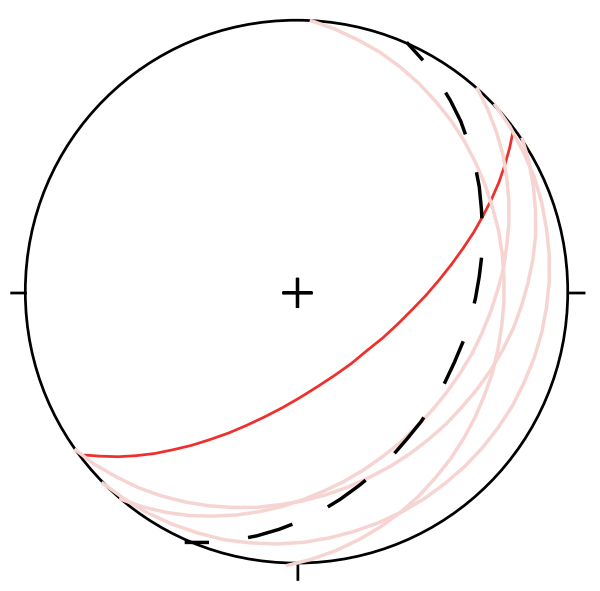

Mean Strike: $024 \pm 18^{\circ}$

Mean Dip: $37 \pm 18^{\circ}$

$\mathrm{n}=4$

Error 95\%

b.

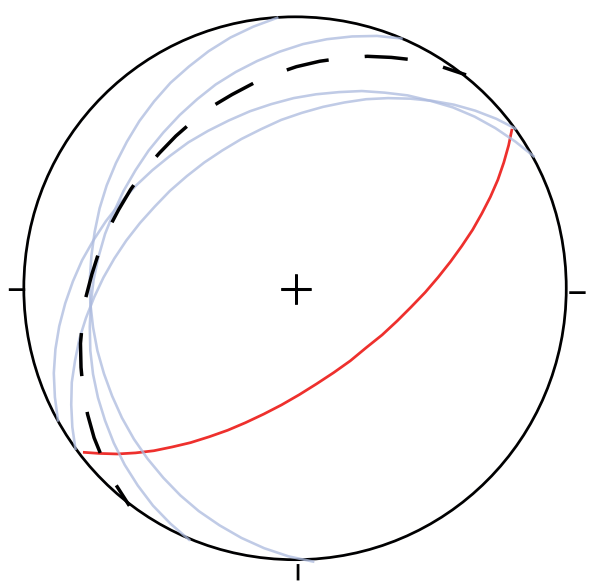

Mean Strike: $218 \pm 20^{\circ}$

Mean Dip: $30 \pm 20^{\circ}$

$\mathrm{n}=4$

Error 95\%

C.

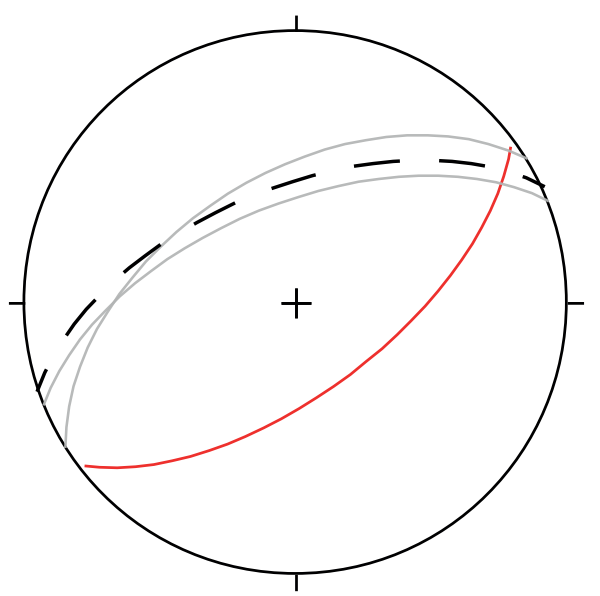

Mean Strike: $248 \pm 10^{\circ}$

Mean Dip: $60 \pm 10^{\circ}$

$\mathrm{n}=2$

Error 95\%

Fig. 10. Stereographic plots of the mean attitudes of the deflected central straight inclusion planes in the non-mylonic Alpine Schist, distal mylonite, and mylonite zones. (a) non-mylonitic Alpine Schist. (b) distal mylonite zone. (c) main mylonite zone. 


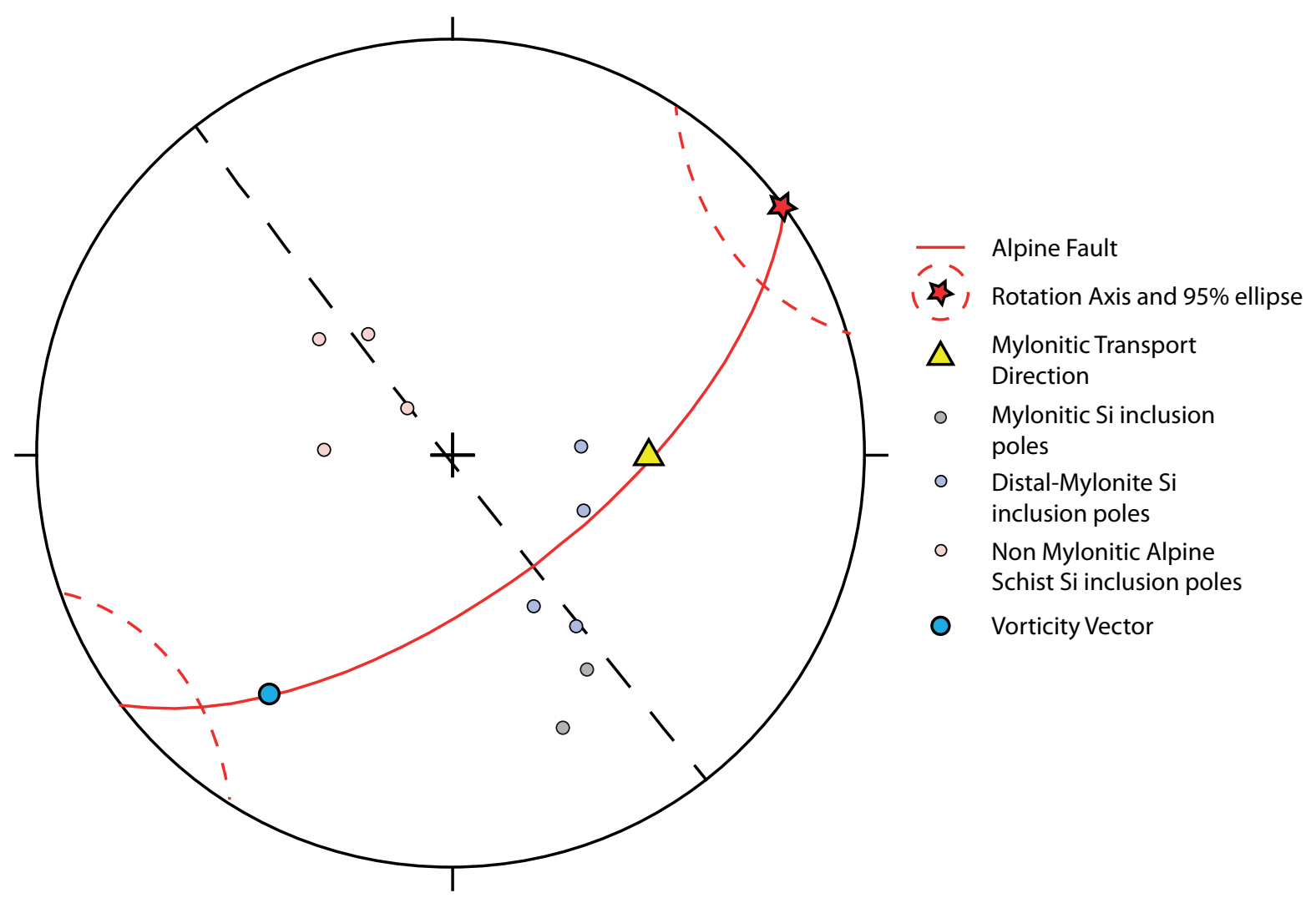

Fig. 11. Stereographic plot of poles to the deflected straight central inclusion planes in the non-mylonitic, distal mylonitic, and mylonitic schist. The mean rotational axis trends 053/1. The dashed ellipse is the $95 \%$ confidence range for that mean rotational axis. Plotted is the mean ductile shearing vector (yellow triangle) and its vorticity vector (blue dot) for the central Alpine mylonite zone in the pane of the SZB (see Gillam et al., 2011 chapter 2 this thesis). 
flow with a $\mathrm{W}_{\mathrm{k}}$ of 0.5 the critical shape of a rigid porphyroblast must be greater than 1.58 to reach a stable position (Xypolias, 2010). I infer that the equant shaped garnets did not reach a stable position in the flow, and that they all rotated in a forward direction.

The key premise for the supporters of the non-rotational porphyroblastic model is that there is a decoupling of flow between the porphyroblast and its surrounding matrix. Porphyroblasts that are decoupled from the matrix are thought to be locked in localized zones of co-axial deformation and are prevented from rotating with respect to local ISAs (instantaneous stretching axes) that are tied relative to geographic coordinates (Bell, 1985; Fry et al., 2008). The garnets in this study were emplaced before any late Cenozoic shearing took place on the Alpine Fault. Because I know the orientation of the SZB, I have been able to track the rotation of these garnet porphyroblasts relative to the SZB, which in this case is exactly parallel to the foliation.

Neither the foliation rotation model for porphyroblast non-rotation (e.g. Ramsay, 1962) nor the multi-orthogonal foliation model can satisfactorily explain the observed simple forward rotation of inherited planar inclusion trails in Tatare Stream. In particular, there is no series of near-orthogonal foliations developed subsequent to garnet nucleation to support a non-rotation of these Tatare Stream garnets. The same inclusion planes in a single set of prograde garnets (Fig. 4) that grew prior to the formation of the Alpine mylonite zone have been tracked into and across that zone.

\subsubsection{Vorticity modeling of rigid garnet porphyroblasts in Tatare Stream}

Detailing the geometries of porphyroblast long axes and inclusion orientations an estimate for vorticity of flow can be obtained based on the previously stated assumptions (Ghosh \& Ramberg, 1976; Ghosh, 1987; Holcombe \& Little; 2001). Using the analytical equations and assumptions from Ghosh \& Ramberg (1976) and Ghosh (1987) the amount and sense of rotation of a rigid object embedded in a ductile matrix relative to the external foliation can be used to calculate an estimate of the kinematic vorticity number. The second approach into the rotational kinematics of garnet porphyroblasts in Tatare Stream utilizies the GhoshFlow program developed by Holcombe (1999) and applying it in a similar way as Holcombe \& Gillam, B. G. 
Little (2001) for biotite porphyroblasts in the non-mylonitic Alpine Schist. My goal is to place constraints on the magnitude of finite shear strain and kinematic vorticity number of late Cenozoic flow in the Alpine Fault mylonite zone.

As input, the GhoshFlow program evaluates the distribution of internal inclusion plane orientations as a function of the host porphyroblasts long axis orientations and their aspect ratios. The GhoshFlow program is a forward modeling approach that iteratively calculates a modeled distribution of porphyroblast geometries as a function of the chosen inputs, which are: (1) shear strain $(\gamma)$ and (2) a kinematic vorticity number $\left(\mathrm{W}_{\mathrm{k}}\right)$. The GhoshFlow program assumes that the garnet porphyroblasts in the starting underformed state have internal inclusions that are parallel to the external foliation, that this foliation is parallel to the SZB, and that porphyroblasts begin with a random distribution of long axes. In the case of the nonmylonitic Alpine Schist, the pre-mylonitic inclusion planes were initially discordant to their enclosing external crenulation foliation (Fig. $7 \mathrm{~d} \& 8 \mathrm{a}$ ). This discordance requires the input data for the program to be corrected for this uniform angular discordance in starting attitude $\left(46^{\circ}\right)$ of $\mathrm{S}_{\mathrm{i}}$ relative to the foliation and SZB but otherwise does not affect the modeling in any way. The light red box in figures $7 \mathrm{~d}$ and $12 \mathrm{~b}$ highlights the discordance in $\mathrm{S}_{\mathrm{i}}$. This box encompasses a suitable range for the pre-mylonitic $S_{i}$ orientations, where the red dots denote the average $S_{i}$ orientation.

The predicted angular distributions of porphyroblast long axis orientation and $\mathrm{S}_{\mathrm{i}}$ orientations as a function of $\mathrm{R}$ have been calculated for a range of $\gamma$ and $\mathrm{W}_{\mathrm{k}}$ and compared to observed garnet porphyroblast data. I have completed six different model runs using the GhoshFlow program. In a first run, a $\gamma=1.2$ and a $\mathrm{W}_{\mathrm{k}}$ of 0.5 were input into the GhoshFlow program to model the distribution of garnet orientations and inclusion plane orientations relative to the foliation in the distal mylonite zone (Fig. 12c). A shear strain of 1.2 was chosen for this run on the basis of the mean rotation of the near equant garnets in the distal mylonite zone, which has half that value (in radians). The $\mathrm{W}_{\mathrm{k}}$ of 0.5 was chosen to match a previous estimate for the distal zone based on shear band dihedral angle analysis (see Gillam et al., 2011 chapter 2 this thesis). For these inputs, GhoshFlow modeled angular distribution of porphyroblasts (with R-values up to 1.5) is broadly consistent with data in the distal mylonite zone (Fig. 12c). As a second run I input the previously Gillam, B. G. 
a.

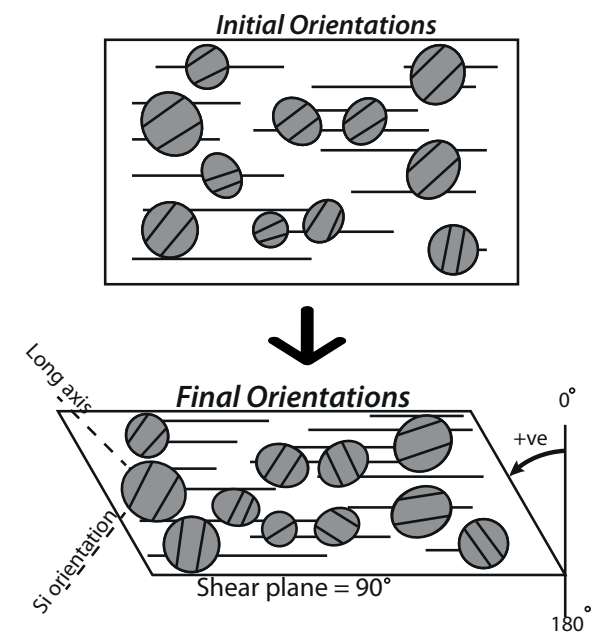

C.

Run 1

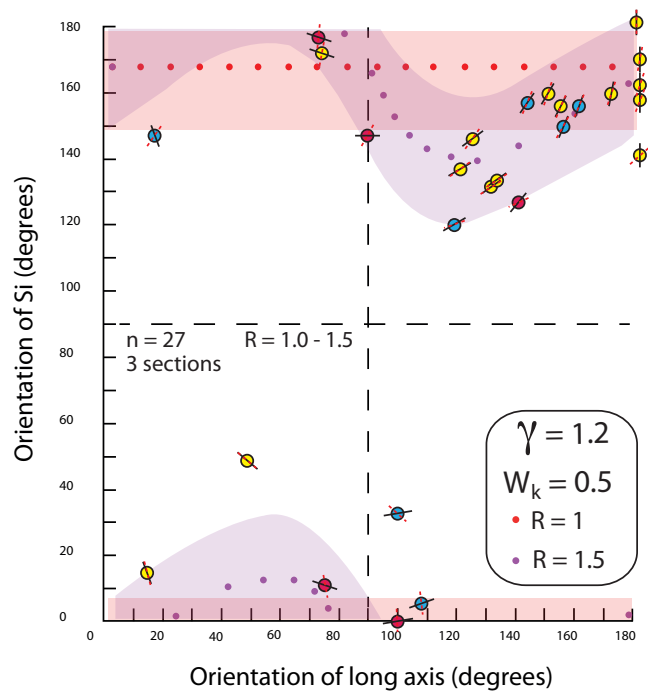

b. Undeformed Non-Mylonitc Alpine Schist

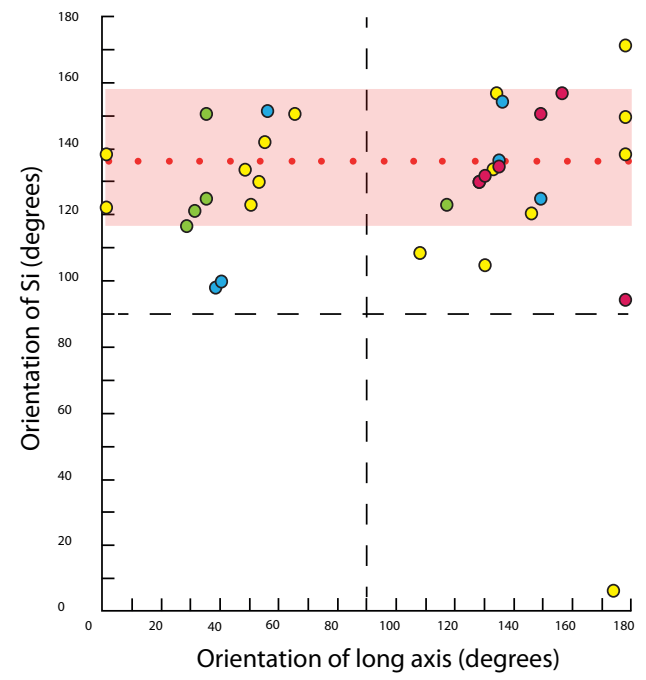

d.

Run 2

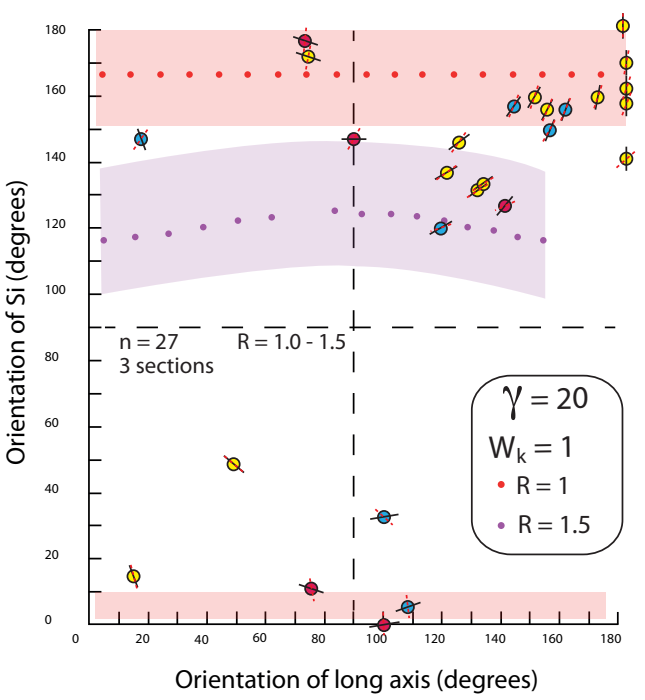

Fig. 12. Garnet long axis orientation versus Si orientation plots for different combinations of bulk shear strain and kinematic vorticity number. Coloured dots are the observed bined aspect ratios of garnet porphyroblast long axis versus Si orientations in Tatare Stream. Shaded regions are the GhoshFlow model predictions for the given input parameters ( $\gamma$ and Wk) (noted in the rectangle in each plot) for porphyroblasts with aspect ratios of 1 (red shaded region) and 1.5 (purple shaded region) (a) See Fig. 7a. (b) Long axis verses Si initial orientation plot for specific aspect ratios for the pre-shearing wall rock. Red band is the range of internal inclusion trails observed in the non-mylonitic wall rock. Red dots is the mean Si orientation before late Cenozoic shearing (see Fig. 7d). (c, d) Run 1 and 2 (d) of GhoshFlow with parameters for the distal mylonite zone (rectangle inset in plots). Superimposed (circles) on the GhoshFlow predictions (shaded regions) is the observed long axis and Si data from 27 garnets in the distal mylonite zone. 
suggested values for $\gamma$ and $\mathrm{W}_{\mathrm{k}}$ for the distal mylonite zone as stated in Norris \& Cooper (2003) $\left(\gamma=20\right.$ and $\left.\mathrm{W}_{\mathrm{k}}=1\right)$ (Fig. 12d). These parameters yield a GhoshFlow porphyroblast distribution that did not match the observed angles of garnets and their inclusions in the distal mylonite in Tatare Stream (Fig, 12d). A "best-fitting" GhoshFlow prediction is inferred when the superimposed (observed) garnet data points (coloured dots $=$ observed Tatare Stream garnet data) fit within the shaded areas. In other words, the shaded purple region reflects the GhoshFlow predicted orientations (for particular input parameters) for porphyroblasts with aspect ratios of 1.5; therefore, most, if not all, of the red dots $(\mathrm{R}=1.5)$ of the observed data should fall into the realm of the purple shaded area for a "best-fitting" model. The garnets in the main mylonite zone have experienced a larger forward rotation. For a third run of GhoshFlow I input a shear strain of $\gamma=2.8$ and a $W_{k}$ of 0.5 . The measured garnet porphyroblast angular distributions seem to partially match with GhoshFlow predictions for these input parameters (Fig. 13a). In detail however, there is a misfit between the model and the observations especially the larger aspect ratio garnets $(\mathrm{R}$ = 1.5) (non-matching GhoshFlow purple band with observed (red) $\mathrm{R}=1.5$ garnets). This discordance suggests that the flow has deviated from simple shear. In run four, I input a $\gamma=120$ and $\mathrm{W}_{\mathrm{k}}=1$ as suggested for the main mylonite zone by Norris \& Cooper (2003). These parameters yield a GhoshFlow porphyroblast distribution that did not match the observed angles of garnets and their inclusions (Fig. 13b).

The Ghoshflow models are very sensitive to changes in the kinematic vorticity number. For example in run five, varying the $\mathrm{W}_{\mathrm{k}}$ value from 0.5 to 0.6 or 0.7 alters the shape of the modeled plot for the distal zone garnets significantly (Figs. 14a \& b). Most sensitive are the larger aspect ratio grains, which may back-rotate depending on the relative proportions of simple and pure shear. Altering the $\mathrm{W}_{\mathrm{k}}$ to 0.6 and 0.7 produced GhoshFlow outputs that did not match the distal mylonite garnets as well as in the initial run one, which assumed a $\mathrm{W}_{\mathrm{k}}$ of 0.5 (Figs $14 \mathrm{a}-\mathrm{b}$ \& 12c). Moreover, increasing the finite shear strain for this distal mylonite zone from 1.2 to 1.8 produced a GhoshFlow angular distribution that was not as consistent as run one (Fig. 14c).

In run six I have varied the $\gamma$ and $\mathrm{W}_{\mathrm{k}}$ from run 3 to produce alternate GhoshFlow predictions for the main mylonite zone garnets and their inclusion orientations (Fig. $15 \mathrm{a}-\mathrm{c})$. An increased kinematic vorticity number of 0.7 appears to be a better fitting Gillam, B. G. 
a.

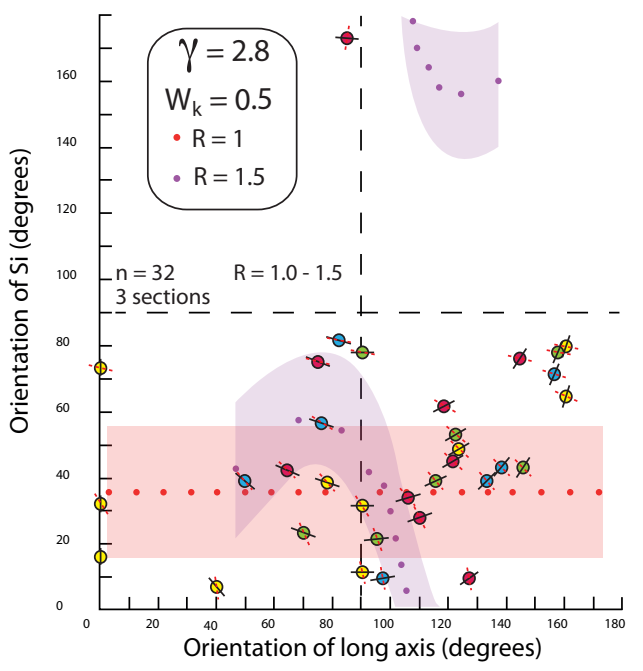

b.
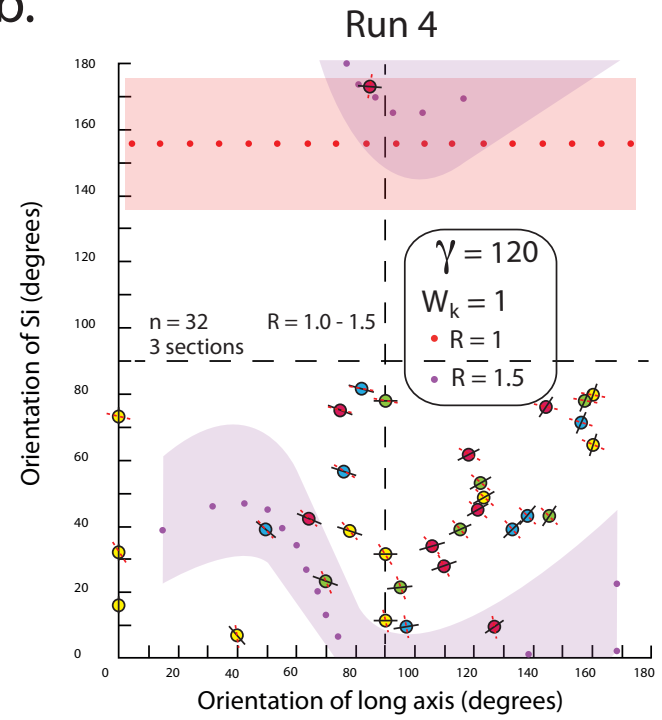

Fig. 13. Long axis versus Si plots for different combinations (rectangle inset in each plot) of bulk shear strain and kinematic vorticity number in the main mylonite zone. (a, b) Run 3 and 4 are GhoshFlow predictions for porphyroblast aspect ratios of 1 (red region) and 1.5 (purple region) for the main mylonite zone. Shaded areas are the predicted distribution of aspect ratios up to 1.5 by GhoshFlow model. Superimposed (circles) is the measured long axis and Si data from 32 garnets in the main mylonite zone. 


\section{Run 5}

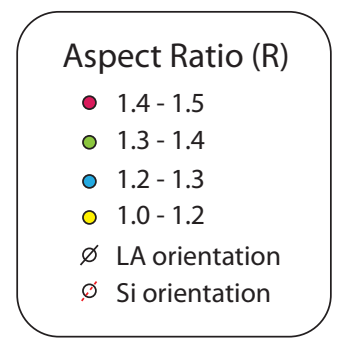

a.

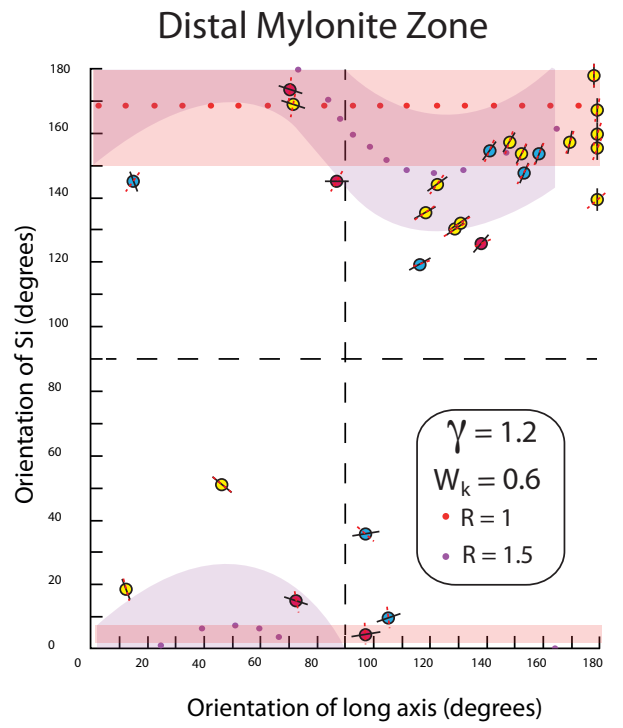

b.

Distal Mylonite Zone

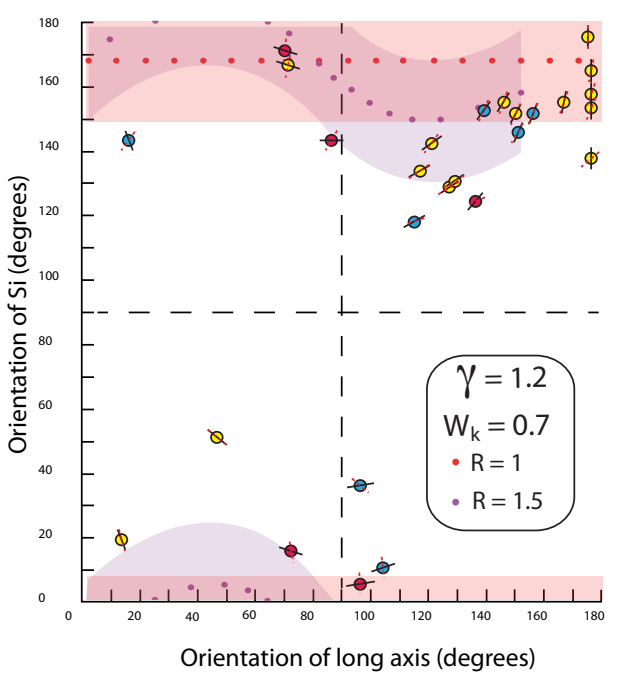

C.

Distal Mylonite Zone

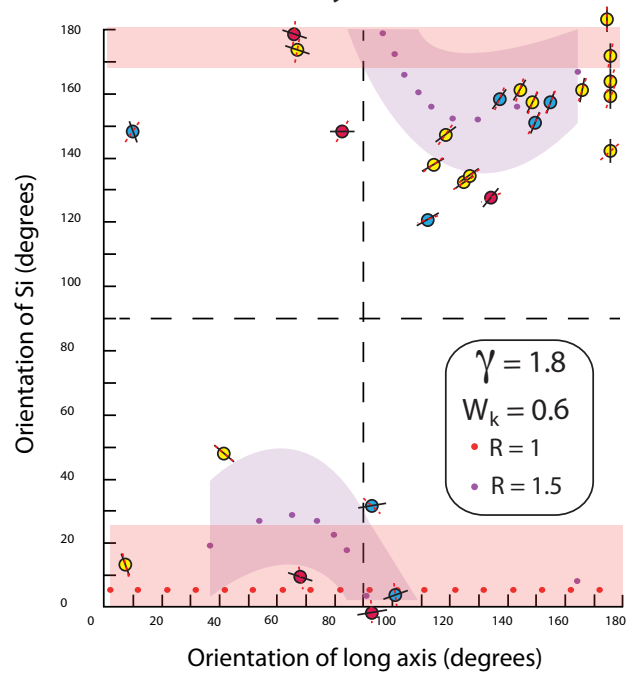

Fig. 14. Long axis versus Si plots for different combinations of bulk shear strain and kinematic vorticity number in the distal mylonite zone. $(a, c)$ Run 5 plots varying kinematic vorticity number and bulk shear strain (rectanglar box displays parameters). Shaded areas are the predicted distribution of aspect ratios up to 1.5 from the GhoshFlow model. Superimposed (circles) is the measured long axis and Si data from 27 garnets in the distal mylonite zone. 
model that the 0.5 estimate in run 3 (Fig. 15b). Increasing the finite shear strain in the main mylonite zone (3.5) the observed garnet data is broadly consistent with the GhoshFlow prediction and appears to be a better fitting model than run 3 (Fig. 15c). The data set used in this modeling is small and scattered; nevertheless it has produced some provisional results that are consistent with other kinematic indicators for the Alpine mylonite zone (see Gillam et al., 2011 chapter 2 and 3 this thesis).

3.5.3 Estimation of bulk finite shear strains and flow kinematics in the Alpine mylonite zone.

The best-fitting bulk finite shear strain magnitudes from the modeling of the garnet porphyroblast data show total simple shear strains for the distal mylonite and main mylonite zones that are significantly lower at 1.2 and 3.5 than previous estimates of 12 and 200 (e.g., Norris \& Cooper, 2003). In the distal mylonite zone the inclusion trail orientations are less variable than in the main mylonite zone and the internal and external foliations are typically continuous across the garnet-matrix interface (Fig. 3b). I therefore suggest that the GhoshFlow based estimate for finite shear in the distal mylonite zone and that based on the mean angular rotation $\left(35^{\circ}\right)$ for the equant garnet grains is a good estimate for the finite shear strain in that zone. Garnets in the main mylonite zone display a lack of continuity between the external and internal foliations across the garnet-matrix interface. GhoshFlow inclusion trail predictions show that for a finite shear strain of $\sim 3.5$ these predictions reproduce the measured main mylonite data (Fig. 8c); nevertheless, this data set is small, scattered, and lacks a diverse range in aspect ratios, and for these reasons the finite shear strains estimated here are only provisional and could be as high as 106 (Fig. 9f).

The porphyroblast rotational data, especially for the distal mylonite zone supports previous inferences (e.g., Gillam et al., 2011 chapter 2 this thesis) for a $\mathrm{W}_{\mathrm{k}}$ that is less than 1.0 (simple shear) and close to 0.5 . The GhoshFlow modeling best fits the observed porphyroblast data for the distal mylonite at a $\mathrm{W}_{\mathrm{k}}$ of 0.5 and for the main mylonite zone at 0.7 . Previous studies have suggested that the Alpine mylonite zone is one that is dominated by simple shear $\left(\mathrm{W}_{\mathrm{k}}=1\right)$ (Norris \& Cooper, 2003) whereas the GhoshFlow modeling here supports a more general co-axial flow for late Cenozoic flow in the Alpine mylonite zone. 


\section{Run 6}

\section{Aspect Ratio (R) \\ - $1.4-1.5$ \\ - $1.3-1.4$ \\ - $1.2-1.3$ \\ - $1.0-1.2$ \\ $\varnothing$ LA orientation \\ $\varnothing$ Si orientation}

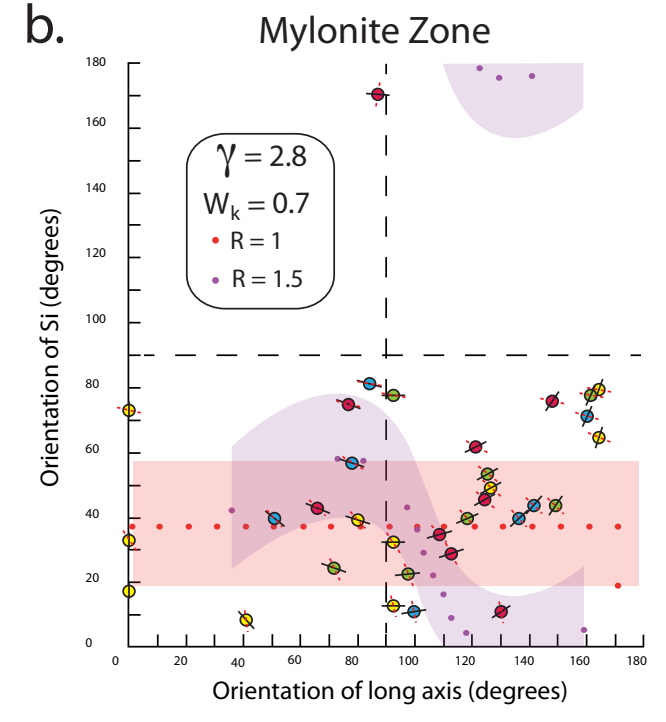

a.

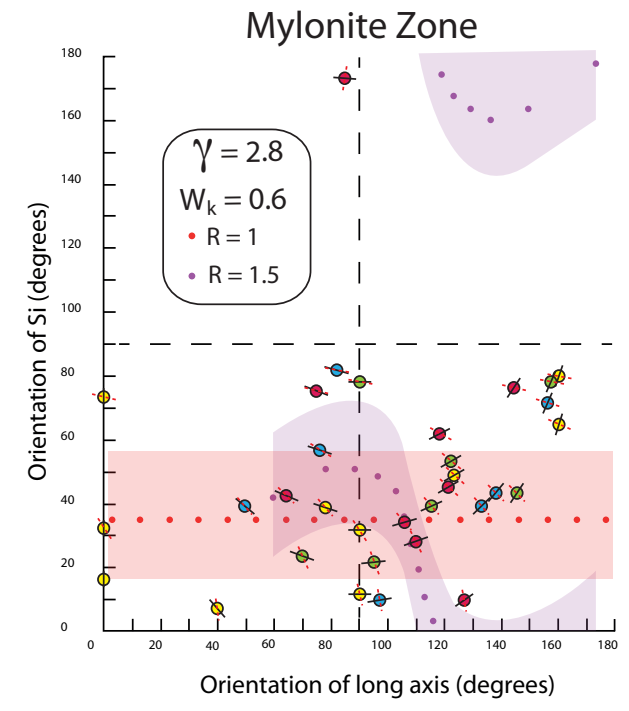

C.

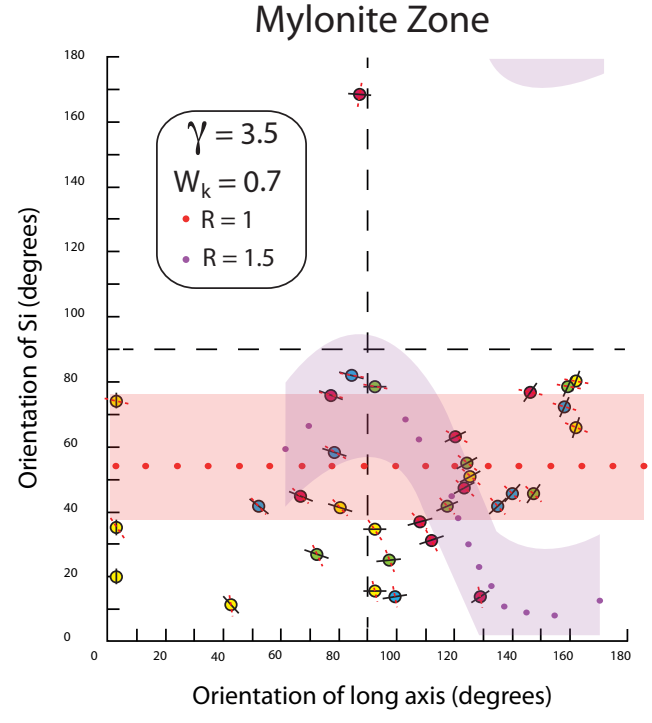

Fig. 15. Long axis versus Si plots for different combinations of bulk shear strain and kinematic vorticity number in the main mylonite zone. $(a, c)$ Run 6 plots varying kinematic vorticity number and bulk shear strain (rectanglar box displays parameters). Shaded areas are the predicted distribution of aspect ratios up to 1.5 from the GhoshFlow model. Superimposed (circles) is the measured long axis and Si data from 32 garnets in the main mylonite zone. 
Analysis of three-dimensional internal inclusion trail geometries in porhyroblastic garnets in the distal mylonite and mylonite zone and the rotational axis that relates these mean orientations to one another support the previous estimate of the mean slip vector in the Alpine mylonite zone (Gillam et al., 2011 chapter 2 this thesis). I calculated a mean ductile sip vector in the Alpine mylonite zone that trends $090 \pm 6^{\circ}(2 \sigma)$. The rotational axis for the deflection of the garnet inclusion planes is sub-parallel to the intersection of C' shear bands with the mean foliation, as is expected if the garnets are rotating in response to a vorticity vector perpendicular to the shear direction (Fig. 11). This adds further supporting evidence (e.g., Gillam et al., chapter 4 this thesis) for monoclinic ductile flow symmetry in the Alpine mylonite zone.

\subsection{Conclusions}

In this study 156 garnet porphyroblast orientations and inclusion plane geometries were measured in 28 samples in the non-mylonitic, distal mylonite, and main mylonite zone for their information content relating to late Cenozoic flow in the central part of the Alpine mylonite zone, Tatare Stream. I have tested whether the garnets have rotated relative to the SZB during the late Cenozoic shearing.

1. Garnets in Tatare Stream nucleated inter-kinematically between the $D_{2}$ and $D_{3}$ deformational events or early during incipient crenulation during $D_{3}$ trapping a straight, and apparently planar central segment of inclusion trails in their cores. These prograde zone garnets were inherited into the mylonite zone from the adjacent non-mylonitic Alpine Schist without alteration from the late Cenozoic mylonitization, and behaved as rigid porphyroblasts during that younger shearing.

2. I have argued that the dominant foliation in the Alpine mylonite zone and its non-mylonitic wall rocks is exactly parallel to the SZB, because it does not change attitude across the Alpine mylonite zone related finite strain gradient. Thus, the foliation provides a robust SZB parallel reference frame against which to track porphyroblast rotations that may occur in response to that shearing related strain gradient.

3. The equant shaped garnet porphyroblasts $(\mathrm{R}=1.0-1.2)$ in both the distal and mylonite zones have experienced a forward rotation relative to the SZB of up 
to $81^{\circ}$. In the distal mylonite zone the garnets have a mean forward rotation of $35^{\circ}$ relative to the shear zone wall rocks. This rotation of spheroidal clasts suggests that a finite shear strain of $\gamma=1.2$ was experienced in that distal mylonite zone. In the higher strain main part mylonite zone, a mean forward rotation of spheroidal garnets of $81^{\circ}$ relative to the wall rock orientations is consistent with a minimum finite shear strain of $\gamma=2.8$. This minimum provisional estimate is much smaller that that suggested by Norris \& Cooper (2003) who used attenuation of pegmatite dikes to model strain in the Alpine mylonite zone.

4. Forward modeling the population of garnet porphyroblasts with aspect ratios up to 1.5 using the GhoshFlow program suggest a $W_{k}$ of 0.5 and $\gamma=1.2$ for the distal mylonite zone and $\mathrm{W}_{\mathrm{k}}=0.7$ and a minimum $\gamma=3.5$ for the main part of the mylonite zone. This modeling supports previous inferences (Gillam et al., 2011 chapters $2 \& 4$ this thesis) for a $\mathrm{W}_{\mathrm{k}}$ close to 0.5 and a more general co-axial late Cenozoic flow in the central Alpine mylonite zone. 


\section{Flow kinematics in the central part of the Alpine Fault mylonite zone, Tatare Stream, Southern Alps, New Zealand.}

\subsection{Introduction}

A localized zone that accommodates a relative displacement of rocks across the zone is known as a shear zone. Shear zones can occur on a range of scales from submicroscopic shear bands and slip planes in metals, to kilometer wide zones of intense crustal deformation (White et al., 1980). In addition to simple shear, general shear zones may involve stretching and/or shortening parallel to the walls of the zone. Natural shear zones may be active for millions of years and acquire large finite deformations as they evolve (Passchier, 1991 \& Passchier and Trouw, 2005). Determining a robust and quantitative kinematic description of displacement and strain in natural shear zones maybe important, especially in the case of a shear zone that is a plate boundary structure, such as the Alpine Fault in New Zealand where the pattern of ductile flow at depth may influence seismic behavior.

The structural geology of ductile shear zones and their fabric development has been much studied, especially for those dominated by simple shear (Passchier, 1998). Many zones are thought to be largely formed by progressive simple shear in a zone between relatively rigid wall rocks (Ramsay, 1980; Ramsay \& Huber, 1983). Shear zones with deformation histories that deviate from simple shear are probably common in nature, however deformation is likely to be three dimensional, and to involve combinations of stretching and shortening parallel and perpendicular to the shear zone boundary (SZB) (Simpson \& De Paor, 1993; Passchier, 1998). Current theoretical models of shear zones are typically formulated in terms of finite strain or instantaneous flow. The finite strain approach is geometrical whereas instantaneous flow models consider velocities at an instant in time (e.g., Fossen \& Tickoff, 1993). The simplest type of general shear zone model has monoclinic symmetry characterized by the vorticity vector for the zone being parallel to one of the principle strain axes describing the "co-axial" component of the flow (Lin et al., 1998). More complex kinematic modeling of general shear zone evolution generate deformation and flow fields that have triclinic symmetry (e.g., Jiang \& Williams, 
1998; Lin et al., 1998; Jiang et al., 2001; Toy, 2007). These more complex models involve a conceptual superposition of simple shear with co-axial deformation; however, co-axial strain axes are all oblique to the vorticity vector and also to the direction of ductile shearing orthogonal to it.

The Alpine Fault, South Island, New Zealand is one of the best global examples of a deeply exhumed but active crustal-scale oblique-reverse fault. Rapid erosion and uplift in the Southern Alps on the hanging wall of the Alpine Fault has exposed a $\sim 2$ $\mathrm{km}$ thick mylonitic shear zone structure and has been carried to the surface as a result of exhumation of its hanging wall (Grapes, 1995). This formed during the last several million years on that plate boundary (Little et al., 2002a). This study will take advantage of this natural laboratory to investigate the kinematics of the late Cenozoic ductile flow in the mylonite zone and its relationship to the well-known plate motions that have taken place external to that zone.

Earlier studies (e.g. Norris \& Cooper, 2003) have concluded that the flow type in the Alpine mylonite zone has been one of predominantly simple shear (i.e., kinematic vorticity numbers from $\sim 0.95-1.0$ ) (Norris \& Cooper, 2003). By contrast Little et al., 2002a and Little (2004) use field data and kinematic modeling to suggest that finite transpressional flow has affected rocks of the Alpine mylonite zone in the hanging wall of the Alpine Fault. Other theoretical models of flow in the Alpine mylonite zone have suggested that the bulk deformation path there has been triclinic (e.g., Jiang et al., 2001; Toy et al., 2011 in review) involving both oblique-reverse shearing and up-dip stretching. These authors argue that triclinic shearing models can explain stretching lineation data in the mylonite zone concluding that the Alpine Fault is a dextral-reverse and triclinic, thinning shear zone.

This paper will use structural field data in an especially well-exposed, and in many ways, especially simple, part of the mylonitic shear zone in the central part of the Southern Alps, New Zealand. I will use these data to constrain the late Cenozoic ductile flow in the Alpine mylonite zone. This study will bring together several kinematically informative structural field observations including the attitude of the SZB and of extensional C' shear bands. In addition, I will examine the pattern of deformational reorientation of pre-mylonitic inherited lineations as they are swept into the mylonite zone. 
I will first resolve the dip of the exhumed Alpine mylonite SZB. I show that the constant foliation attitude exposed in the Tatare Stream, despite a gradient in finite shear strain between the non-mylonitic and mylonitic rocks indicates that the foliation is here essentially parallel to the SZB. Second, I will calculate the ductile shearing direction from the geometry of pervasively developed C' shears intersecting this SZB parallel foliation (S). Finally, I will calculate the direction of shear zone parallel, co-axial, ductile stretching and constrain the magnitude of stretching and thinning of the zone by reference to the two-dimensional distribution and strain of the intertied intersection line in the plane of the SZB. Measuring the attitudes of the inherited intersection lineation exactly in the plane of the SZB will allow us to deconvolve the direction and magnitude of the co-axial stretching components assuming constant volume deformation. I will infer that a significant SZB parallel stretch is recorded in the formation of the lineation's attitude into the mylonite zone, and indeed, by the pervasive nature of the extensional shear bands themselves. The parallelism between the calculated $\mathrm{X}$ direction of the co-axial strain component and the calculated shear direction on the Alpine mylonite zone leads us to conclude that the late Cenozoic Alpine mylonite zone is a stretching and thinning general shear zone of monoclinic symmetry.

\subsection{Geological setting and structural framework}

\subsubsection{Alpine Fault and Southern Alps}

In the South Island, New Zealand, the dextral-reverse Alpine Fault ( $\sim 25 \mathrm{Ma})$ (Sutherland et al., 2000) is the chief plate boundary fit between the Australian and Pacific Plates (Fig. 1). In the central Southern Alps this fault has an average strike of $053 \pm 2^{\circ}(2 \sigma)$ and it dips SE (Gillam et al., 2011 chapter 4 this thesis). In detail, its trace in that region is segmented in the near surface into a series of oblique-reverse and vertical strike-slip sections (Norris \& Cooper, 2007). The Nuvel-1 A plate motion model, which incorporates the last $\sim 3 \mathrm{~m}$.y. of global seafloor spreading data, infers a plate motion vector of $\sim 37 \mathrm{~mm} \mathrm{yr}^{-1}$ on an azimuth of $71 \pm 2^{\circ}(2 \sigma)$ in the region of the central Southern Alps (DeMets et al., 1994). This plate motion vector trends $\sim 20^{\circ}$ anticlockwise of the strike of the Alpine Fault and is expressed by oblique convergence across the Southern Alps. Surface geological (e.g., Sibson et al., 1979; Norris \& Cooper 2007) and seismic reflection data (e.g., Davey et al., 1995; 


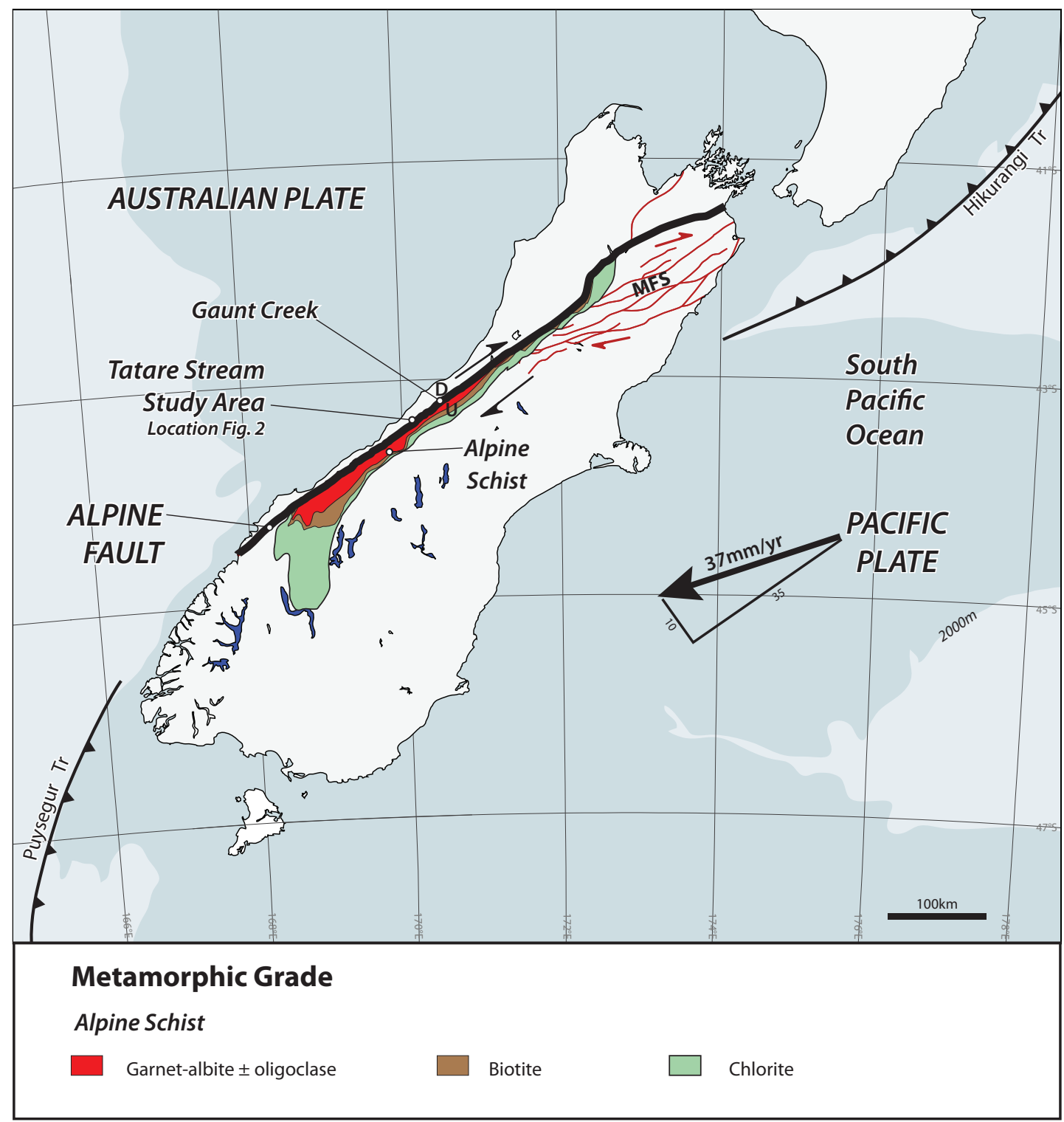

Fig. 1. Regional tectonic setting of the South Island of New Zealand showing the moden rate of plate motion between the Pacific Plate to the Australian Plate (using Nuvel 1A angular velocities from DeMets, et al. (1994), and the Alpine Fault Trace at Tatare Stream as a reference point), with normal and parallel motion with respect to the Alpine Fault. MFS - Marlborough Fault System. 2000m - bathymetric contour. Map also showing metamorphic grade of Alpine Schist. Data from N.Z. Geological Survey map (1979); Mortimer (2000); Murphy (2010). 
Kleffman et al., 1998) have been used to infer the mean dip of the Alpine Fault at the surface to mid-crustal depths is typically $40-50^{\circ}$ to the SE. Neotectonic studies indicate that the Alpine Fault has a dextral strike-slip rate of $27 \pm 5 \mathrm{~mm} / \mathrm{yr}$, accommodating about $70-75 \%$ of the margin-parallel component of the PacificAustralia Plate motion (Norris \& Cooper, 2000). The rate of late Quaternary dip-slip on the Alpine Fault is quite variable along strike reaching a maximum of $\sim 12 \mathrm{~mm} / \mathrm{yr}$ in the especially mountainous central Southern Alps (Norris \& Cooper, 2000).

Rapid and deep erosion of the Alpine Schist on the uplifted hanging wall of the Alpine Fault has exposed a SE tilted section derived from the lower to middle crust of the Pacific Plate (Fig. 1). These rocks that abut the eastern edge of the Alpine Fault have been exhumed from depths of 20-30 km (e.g., Grapes, 1995) over the last 23-5 m.y. Tilting of the section is inferred to have been the result of up-ramping of the more deformable Pacific Plate crust westward on to the foot wall ramp of the Australian plate, as a result of serial back-shearing (Little et al., 2002a; Little, 2004). The Alpine mylonite zone forms the structural base of this tilted crustal section and occurs as a strongly deformed zone, 1-2 km thick that is bounded to the west by the Alpine Fault (Sibson et al., 1979; Norris \& Cooper 2007; Toy, 2007; Toy et al., 2008).

The Alpine Schist is a $\sim 20 \mathrm{~km}$ wide strip of east tilted Barrovian metamorphic rocks ( $\sim 86 \mathrm{Ma}$ ) (Vry et al., 2004) that constitutes the immediate hanging wall of the Alpine Fault. Across this strip the metamorphic grade decreases eastward and strictly upward from garnet-oligoclase zone (amphibolite-facies) in the mylonitic rocks adjacent to the Alpine Fault, to chlorite zone (greenschist-facies) in the east (Fig. 1). The mylonite zone and its non-mylonitic hanging wall consist chiefly of metagreywacke derived greyschist, with subordinate pelitic and mafic units (Little et al., 2002a; Toy et al., 2008). Along their SE margin the mylonite zone is bordered by a $\sim 0.4-0.7 \mathrm{~km}$ thick zone of protomylonitic schist (I will further refer to this as the distal mylonite zone) (Sibson et al., 1979; Toy et al., 2008). In this zone, preservation of crenulation structures inherited from the (Mesozoic) non-mylonitic Alpine Schist such as SW-pitching fold and crenulation hinges $\left(\mathrm{L}_{2 \times 3}\right)$ is wide spread and characteristic; however, the rocks are also pervaded by younger, late Cenozoic extensional C' shear bands. In the main (central) part of the mylonite zone, farther to 
the NW, the dominant lineation in the schist is a quartz rodding lineation that has been inherited from its non-mylonitic precursor; however, has been strongly deformed in the dextral-reverse shear zone and now it plunges NE (Sibson et al., 1979; Little et al., 2002a; Toy, 2007).

In the non-mylonitic Alpine Schist a thinly compositional laminated foliation $\left(\mathrm{S}_{2}\right)$ associated with mm-thick quartz laminae is the oldest fabric element still preserved in the Alpine Schist. This foliation was later crenulated to form the main foliation $\left(\mathrm{S}_{3}\right)$ in the non-mylonitic garnet zone Alpine Schist. This steeply dipping crenulation developed at near peak metamorphic conditions in the amphibolite-facies and was penecontemporaneous with growth of the garnet porphyroblasts (Little et al., 2002a). The older now crenulated $\mathrm{S}_{2}$ foliation is preserved in the non-mylonitic Alpine Schist as the form of crenulation microfolds and as helicitic inclusion trails that were overgrown by syntectonic garnets (Little et al., 2002a; Vry et al., 2004). This crenulation fabric $\left(\mathrm{S}_{3}\right)$, with its related syntectonic garnets and their inclusion trails of $\mathrm{S}_{2}$ is the starting material from which the Alpine mylonite zone was later formed in the late Cenozoic (Little et al., 2002a). The strike of the $S_{3}$ foliation is regionally oblique by $20-30^{\circ}$ anti-clockwise to the Alpine Fault (Little et al., 2002a). This crenulation fabric in the Tatare Stream area was already NE-striking parallel to the future Alpine Fault and mylonite zone (Fig 2a). For this reason it was constructively reinforced and strengthened during the Cenozoic Southern Alps deformation (Little et al., 2002a). During the late Cenozoic, ductile deformation was strongly localized into the Alpine mylonite zone in proximity to the Alpine Fault causing strong overprinting and transposition of $\mathrm{S}_{3}$ in that concordantly disposed shear zone (Little et al., 2002a).

Finite shear strains in the mylonite zone have been estimated in parts of the Southern Alps (Norris \& Cooper, 2003). These estimates were based on a statistical analysis of deformational thinning of pre-shearing pegmatite dikes in the Alpine Schist that were later deformed into the Alpine mylonite zone (Norris \& Cooper, 2003). Depending on what type of flow is assumed for the Alpine mylonite zone (e.g., simple shear, or sub-simple shear that includes a pure shear thinning factor of up to 3) these thickness variations can be used to model the finite shear strain parallel to the Alpine Fault across the diffuse zones in the Alpine mylonite zone. For 
assumed rates of simple shear (thinning factor of 1.0) and thinning (factor of 3.0) shear strain estimates between 12 to 32 were modeled for the distal mylonites (lower estimates correspond to a thinning factor of 3 , higher estimates to simple shear) and 100 to 200 in the central mylonite zone (Norris \& Cooper, 2003).

\subsubsection{Tatare Stream structural geology}

Tatare Stream (Figs. $1 \&$ 2) exposes an excellent structural section from the garnet zone non-mylonitic Alpine Schist, to the SE; through the shear-banded part of the distal mylonite zone, further to the NW; and including the upper part of the main Alpine mylonite zone in the most NW outcrops (Fig. 2a). The ultra-mylonite zone and the Alpine Fault are covered by alluvium. In Tatare Stream the dominant foliation in the non-mylonitic Alpine Schist (see insert in Fig. 2a) $\left(\mathrm{S}_{3}\right)$ strikes $053 \pm$ $2^{\circ}(2 \sigma)$ and dips $63 \pm 2^{\circ} \mathrm{SE}$ at $(2 \sigma)$. Vergence changes relative to $\mathrm{S}_{3}$ have been able to be used to map several km-scale $F_{3}$ folds of $S_{2}$ (Fig. 2a). The dominant lineation in the non-mylonitic Alpine Schist is crenulation lineation parallel to the intersection of the $\mathrm{S}_{2}$ and $\mathrm{S}_{3}$. This distinct lineation is typically expressed by a strong quartz rodding at the outcrop scale caused by the intersection of the $S_{2}$ quartz laminae with the $S_{3}$ plane. The $\mathrm{L}_{2 \times 3}$ intersection lineations and hinges of the km-scale $F_{3}$ folds plunge $\sim 20^{\circ} \mathrm{SW}$ in Tatare Stream (Little et al., 2002a; Gillam et al., 2011 chapter 4 this thesis) (Fig. 2a arrow symbols).

A gradational contact is observed between the non-mylonitic Alpine Schist and the distal part of the Alpine mylonite zone (Fig. 2a). The latter is defined by the appearance of ubiquitous extensional C' shear bands that pervade the rock at $\mathrm{mm}$ to $\mathrm{cm}$-scale and that cut and offset the older, yet still distinct $\mathrm{S}_{3}$ foliation. The distal mylonite zone is $\sim 600 \mathrm{~m}$ thick in Tatare Stream. There, the lower boundary of the main mylonite zone against the ultra-mylonites does not outcrop; however from the known mylonitic outcrop and Alpine Fault trace a total thickness of $800 \mathrm{~m}$ is estimated for the Alpine mylonite zone (including the unexposed ultra-mylonites). With increasing proximity to the Alpine Fault, further to the NW, the $\mathrm{S}_{3}$ fabric becomes increasingly planar and finely quartz laminated in appearance as a result of a progressive increase in the degree of late Cenozoic mylonitic overprint. This overprint is also expressed by an increased appression of the $\mathrm{F}_{3}$ crenulation microfolds of $S_{2}$ and the transposition of the $S_{2}$ planar remnants so that they become 


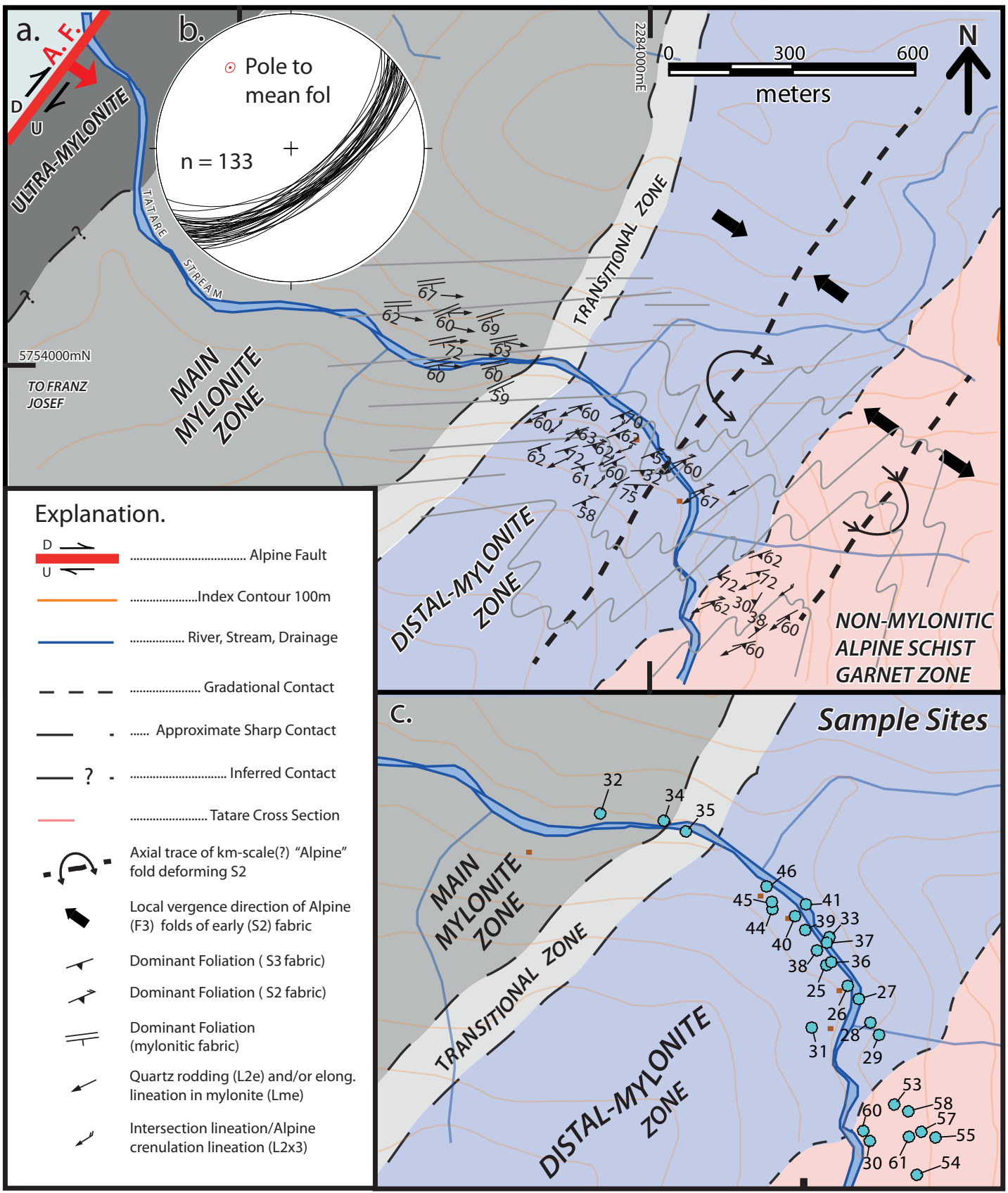

Fig. 2. (a) Bedrock structural geology of the Alpine Schist at Tatare Stream near Franz Josef Glacier. Trace of Alpine Fault is from Norris and Cooper (1995). Position of ultra-mylonite is approximated from the thickness distributions in Gaunt Creek to the north from Toy et al., (2008). (b) Stereographic projection of 133 non-mylonitic, protomylonitic, and mylonitic foliations attitudes in Tatare Stream with a mean foliation pole 323/27 and 95\% confidence ellipse on mean pole. (c) Sample localities in Tatare Stream for thin-section analysis. 
indistinguishable from $\mathrm{S}_{3}$. The distal mylonite zone preserves the characteristically SW-pitching $\mathrm{L}_{2 \times 3}$ intersection/quartz-rodding lineation inherited from the nonmylonitic Alpine Schist. This lineation retains the SW plunge despite the strongly shear band-localized deformation in the distal mylonite zone. The distal mylonite zone has informally been referred to as the "curly schist" (Reed, 1964); a term that relates to the sigmoidal deflection of the $\mathrm{S}_{3}$ foliation between adjacent bounding $\mathrm{C}$ ' shears on either side of the microlithon. The sense of deflection of $\mathrm{S}_{3}$ across the C' shear bands is everywhere consistent with dextral-reverse shearing that is synthetic with the Alpine Fault.

The uppermost $\sim 250 \mathrm{~m}$ of structural section of the main mylonite zone is exposed in Tatare Stream (Fig. 2a). There, the mylonite fabric includes the same strong quartz rodding lineation, which I infer to be inherited from the adjacent non-mylonitic Alpine Schist, but which has been distortionally reoriented to a NE plunge (see also Toy, 2007; Toy et al., 2011 in review; Gillam et al., 2011 chapter 4 this thesis). In Tatare Stream the lineation in the main part of the mylonite zone plunges NE at and average angle of $16^{\circ}$. The main mylonite zone like the distal mylonite zone to the SE, contains mm-spaced extensional C' shears that cut and deflect the mylonitic foliation $\left(\mathrm{S}_{\mathrm{m}}\right)$. A remarkable feature of the Tatare Stream section is that across the entire finite strain gradient related to the transition between non-mylonitic to mylonitic rocks the attitude of the foliation (variably non-mylonitic, distal mylonite, and mylonitic) remains consistent at 053/63SE throughout the entire finite strain gradient expressed by fabric development in the Alpine mylonite zone and its wall rocks to the SE.

In the mylonitic and protomylonitic zones at Tatare Stream the dominant quartzofeldspathic (metagreywacke) protolith is locally interlayered with $\sim 1-2 \mathrm{~m}$ thick zones of micaceous pelitic schist and amphibolite mafic schist. The distal and main mylonite zones consist chiefly of quartzofeldspathic greyschist that includes $\sim 2$ $\mathrm{mm}$ thick quartz laminae that are foliation parallel and lesser lenticular concordant quartz veins up to $4 \mathrm{~cm}$ thick; that are also mostly foliation parallel. Both are cut and offset by the C' shear bands. Mafic amphibolite and pelitic-rich schist are interlayered with greyschist in lenses $1-2 \mathrm{~m}$ thick. In Tatare Stream, the main part of the mylonite zone contains a slightly greater abundance of micaceous pelitic schist 
than does the distal mylonite zone adjacent to it to the SE, which is more uniformly quartzofeldspathic in composition.

Various different styles of boudinage are present in mylonite zone in Tatare Stream. Symmetrical foliation boudinage occurs in the strongly foliated quartz laminated schist (Platt \& Vissers, 1980; Arslan et al., 2008). These most commonly include small-scale pull-apart structures defined by diamond or lozenge deformed veins consisting of quartz or calcite (Fig. 3d). The foliation around the center of the void has been pinched inwards so that the structures superficially resemble layer boudins. These structures differ from classical boudins in that they do not occur in trains and are not associated with any obvious layer parallel compositional contrasts. The thicker foliation parallel quartz veins and the mafic amphibolite units display shear band boudinage indicating that the thick quartz and mafic rocks were both stiffer than the quartz schist in the mylonitic rocks (Fig. 3c). These shear band boudins are synthetic in shear sense to that of the bulk shear zone and have elongate and curved, lenticular shapes with back rotation against the sense of shear (see also Goscombe \& Passchier, 2003). Complete isolation of boudins commonly occurred, so that the boudins elements occur in trains separated by the inter-boudin shear surface (either $\mathrm{S}_{\mathrm{ib}}$ or C'). Lastly, where interlayering occurs the more classical type of layer boudinage is observed (Fig. 3a \& b). Foliation parallel quartz veins apparently behave as stiff layers as they have been boudinaged between surrounding pelitic-rich schist zones. The more typical quartz laminated greyschist undergoes foliation boudinage to form a foliation lens that is $20-30 \mathrm{~cm}$ thick by $\sim 1 \mathrm{~m}$ long. Such boudins resemble a teardrop shape aligned parallel to the foliation and separated from one another by a dilative cavity infilled with quartz and calcite. All these forms of boudinage observed in Tatare Stream indicate that there has been finite extension parallel to the dominant foliation and at right angles to the $\mathrm{S} / \mathrm{C}$ ' intersection line.

\subsection{Tatare Stream mylonite zone: the transitional zone.}

The structural transition between the distal mylonite and main mylonite zone, is little described in the literature, but well exposed in Tatare Stream. In Tatare Stream the transition takes place across a zone that is $\sim 50 \mathrm{~m}$ wide (Figs. $2 \mathrm{a} \& 4$ ). Across this transitional zone, dominant, SW-pitching intersection/quartz rodding lineation 

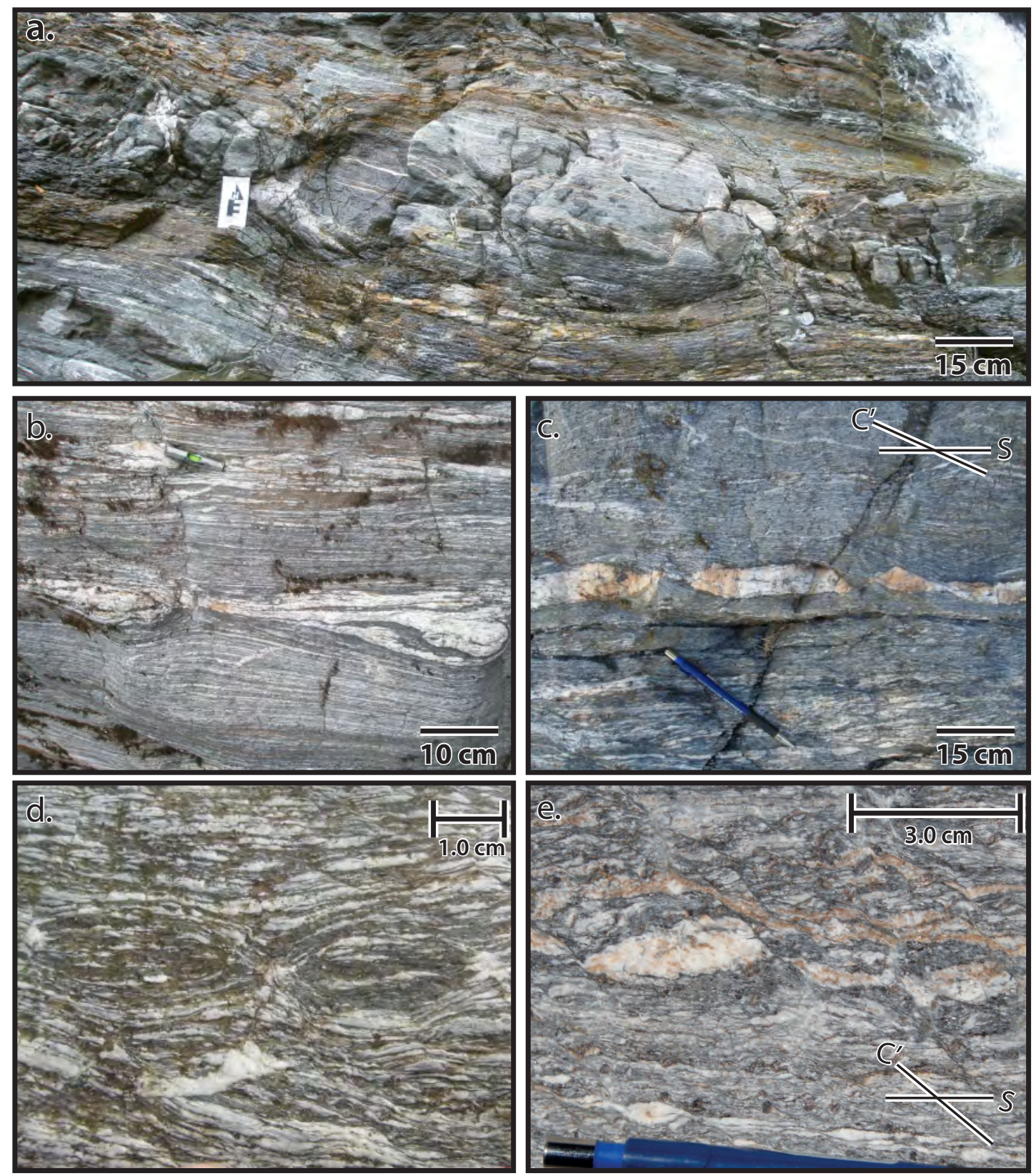

Fig. 3. Structural field observations in Tatare Stream. (a) Large meter-scale layer boudinage of a $\sim 70$ $\mathrm{cm}$ thick mafic layer. (b) Layer boudinage of thick quartz veined schist packets adjacent to more pelitic-rich schist. (c) Isolated shear band boudins in a $\sim 5 \mathrm{~cm}$ thick foliation parallel concordant quartz vein. Large displacements on inter-boudin surfaces $\left(C^{\prime}\right)$ have produced a back-tilted boudin train structure. (d) Symmetric foliation boudins in strongly foliated quartz laminated schist. (e) Extensional $C^{\prime}$ shears cutting and deflecting the older foliation in the quartz meta-greywacke protolith of the mylonite zone. 


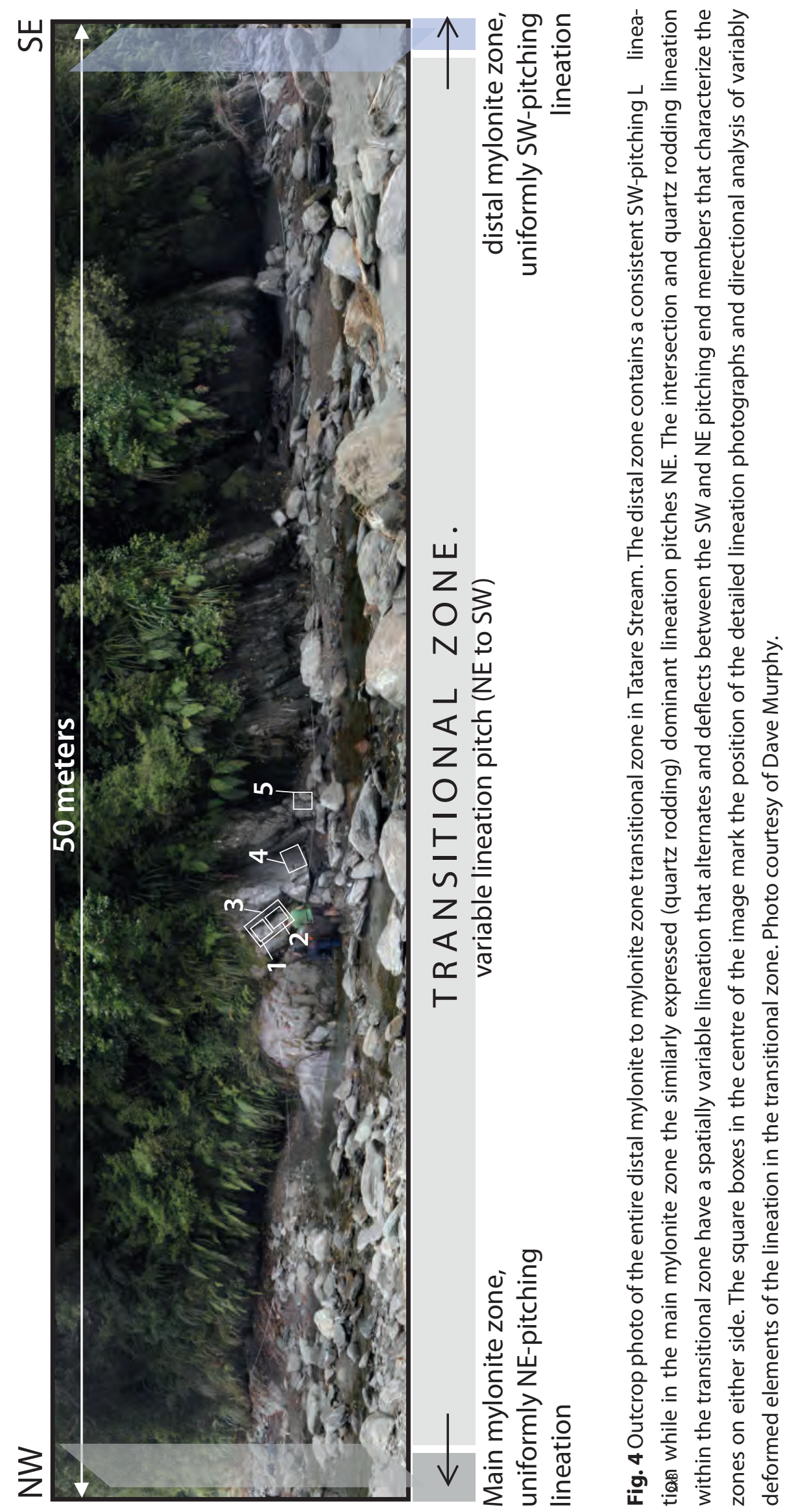


inherited from the non-mylonitic Alpine Schist changes pitch by $\sim 140^{\circ}$ within the constantly dipping foliation plane, deflecting from a $\sim 20^{\circ} \mathrm{SW}$ in that pane to a $\sim 17^{\circ}$ NE pitch. The $50 \mathrm{~m}$ wide zone of the transition is recognizable by the characteristic "flip-flopping" of the otherwise similar looking lineation between these two end member trends (Fig. 5a \& b). This takes place on a scale of decimeters to meters, between planes of otherwise homogenous schist and without any tight folding of the foliation. Instead the foliation is planar and homiclinal throughout.

The lithological composition of the transitional zone is the same metagreywacke as the adjacent main mylonite and distal mylonite zones. Typically the transitional zone consists of the same thinly laminated quartz $(\sim 2 \mathrm{~mm})$ greyschist interlayered with $\mathrm{cm}$-thick, foliation parallel quartz veins that characterize the rest of the distal mylonite zone structurally above it. Down-section of the transitional zone, in the main mylonite zone, further to the NW, the foliation is exactly parallel to that in the distal mylonite zone, albeit more thinly laminated and flaggy and now containing a uniformly NE-pitching quartz rodding lineation. The transitional zone foliation remains at a consistent attitude across the entire zone, striking 053 and dips $63^{\circ} \mathrm{SE}$. C' shears are not visible in outcrop but are present in the transitional zone at the microscopic scale as observed in thin-section.

\subsection{Shear zone boundary orientation: attitude of the Alpine shear zone at depth}

A suitable frame of reference is required to determine the kinematics of flow in a ductilely deforming general shear zone. The availability of such a reference frame will be dependent upon the scale of observation. Ideally the shear zone boundary is chosen as the kinematic reference frame. In practice, this boundary is often unexposed or its attitude is unknown. In the Southern Alps the SE dipping Alpine Fault is assumed to be parallel to the boundaries of the ductile shear zone that this feature has exhumed from depth, but surprisingly few direct data exist on the dip of this boundary (SZB of the Alpine mylonite zone). Internal vorticity describes the average rate of rotation of passive material lines relative to the instantaneous stretching axes (ISA) (Means et al., 1980; Lister \& Williams, 1983; Jiang, 1999; Xypolias, 2010). In a general shear zone undergoing homogenous deformation there will be always two directions of passive material lines that do not rotate relative to the ISA's (Weijermars, 1991; Simpson \& De Paor, 1993). These are the eigenvectors 

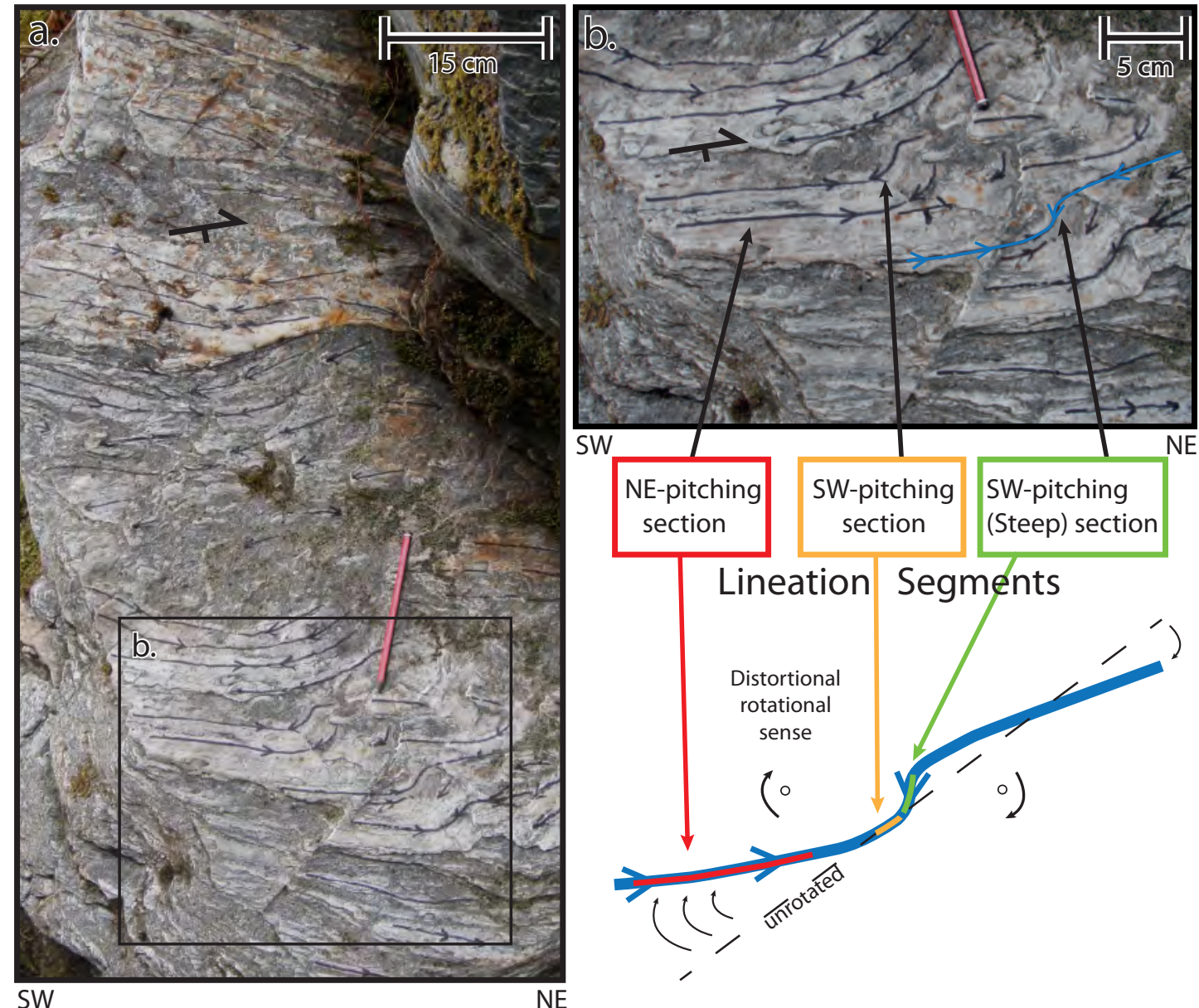

Fig. 5. Outcrop photographs taken of the deformed lineation as seen on foliation parallel quartz laminae. (a) Variability in the $\mathrm{L}_{2 \times 3}$ lineation indicated by the black arrows. Two different quartz sheets visible: top left, and bottom right. Orientation of the outcrop face depicted by structural symbol (055/57SE) (b) Close-up photograph of Fig 5a. This photograph and the cartoon below depicts the 3 different segments of the lineation that were used to determine the orientation of the maximum finite elongation $X$ direction and the sectional finite strain ellipse for $2 \mathrm{D}$ co-axial deformation on planes parallel to the SZB. 
of the flow or flow apophyses of the velocity tensor. The flow apophyses control the geometry of the flow type and can be recognized as being either extensional or contractional, depending on whether they attract or repulse material lines (Xypolias, 2010). In a shear zone the extensional apophysis will coincide with the boundaries of a stretching shear zone, and this is often referred to as the fabric attractor (Passchier, 1997).

In Tatare stream I can use the fabric attractor concept to resolve the attitude of the SZB in the Alpine mylonite zone. For our purposes, the key observation is that the foliation attitude remains consistent at $053 \pm 2^{\circ}$ dipping $63 \pm 2^{\circ}(2 \sigma) \mathrm{SE}$ across the non-mylonitic to mylonite transition, despite the imposed late Cenozoic finite shear strain that increases in intensity across those zones and towards the Alpine Fault (e.g., Norris \& Cooper, 2003) (Fig. 2a \& b). This relationship was also recognized by Little et al., (2002a) who interpreted it as reflecting an overprinting of mylonitic shearing deformation on a foliation that was already pre-disposed in an attitude sub-parallel to the late Cenozoic SZB. A consistent foliation attitude across the imposed Cenozoic finite strain gradient implies that the foliation has not rotated as a result of the large finite deformation. Therefore, one infers that this foliation is essentially parallel to the "fabric attractor" (extensional flow apophysis). In other words, because the foliation does not change its attitude on entering the Alpine shear zone with its strain gradient, I infer that its exactly parallel to the SZB of the Alpine Fault mylonite zone that formed in the lower crust, because the outer non-mylonitic $\mathrm{S}_{3}$ foliation was already aligned in that direction prior to late Cenozoic shearing. Significant foliation extension is evident from meter to centimeter foliation boudinage and the development of shear band boudins (Fig. 3). This suggests that the SZB's were stretched and this must have occurred in a stretching and thinning shear zone.

The mean foliation attitude represents a robust dip for the SZB of the Alpine mylonite zone. The pre-shearing wall rock $S_{3}$ foliation and the $S_{m}$ foliation dips consistently at $63 \pm 2^{\circ}(2 \sigma)$ SE. This estimate for the dip of the ductile shear zone of the central Alpine Fault is significantly steeper, about $10-15^{\circ}$, than other estimates for the dip of the Alpine Fault at depth (e.g., Sibson et al., 1979; Davey et al., 1995; Kleffman et al., 1998). Given its homiclinal dip over $\sim 2 \mathrm{~km}$ of mylonitic section and 
its shear zone parallel attitude, I think that our dip estimate for Tatare Stream is one of the best so far determined for the Alpine mylonite zone, and by inference, also the Alpine Fault plane. This method for establishing the position of the SZB is not affected by near surface topography or interpretation of reflectors on seismic profiles. Unlike the segmented nature of the Alpine Fault trace elsewhere in the central Southern Alps, the Alpine Fault at Tatare Stream, even in the near surface, appears to be a simple planar oblique-reverse zone rather than a vertical strike-slip or oblique-reverse segment; therefore this dip estimate may be especially representative of the Alpine Fault in this central part of the Southern Alps.

\subsection{Direction of ductile shearing in the Alpine mylonite zone}

Knowing the attitude of the SZB of the Alpine mylonite zone in Tatare Stream allows us to proceed towards determining the direction of ductile shearing in that plane. This we will do by measuring the mean attitude of extensional C' shear bands and their intersection line with the foliation precisely at 25 outcrops in the distal mylonite and mylonite zones. I infer that the movement plane (M-plane) and direction of ductile shearing lies perpendicular to this intersection line in contrast to previous interpretations of ductile shear sense in the mylonite zone based on its lineation attitudes. Our slip vector calculation is not based on assumption about the type of lineation (inherited object lineation versus stretching lineation) and its relation to the state of finite strain in the zone or the flow kinematics of the zone (e.g. simple shear).

Site-specific mean shear band C' orientations were determined by acquiring multiple apparent dip lines on a diversity of planes both in outcrop and in thin section. The mean shear band orientations were determined by finding the best sitespecific average plane to fit the angular apparent dips seen in the variably oriented thin-section planes and outcrop faces (See Gillam et al., 2011 chapter 2 this thesis). Importantly here, I observed no statistically significant change in C' attitude over the $700 \mathrm{~m}$ of Alpine mylonite zone, and no change in attitude with increasing proximity towards the Alpine Fault. The average $(\mathrm{n}=48)$ strike of the $C^{\prime}$ shears is $064 \pm 3.7^{\circ}$ $(2 \sigma)$, and the average dip is $38 \pm 3.1^{\circ}$ to the SE $(2 \sigma)$. By intersecting this mean shear band attitude with that of the mean foliation in Tatare Stream a mean intersection line in the SZB is calculated. Orthogonal to this, I calculate a mean ductile slip 


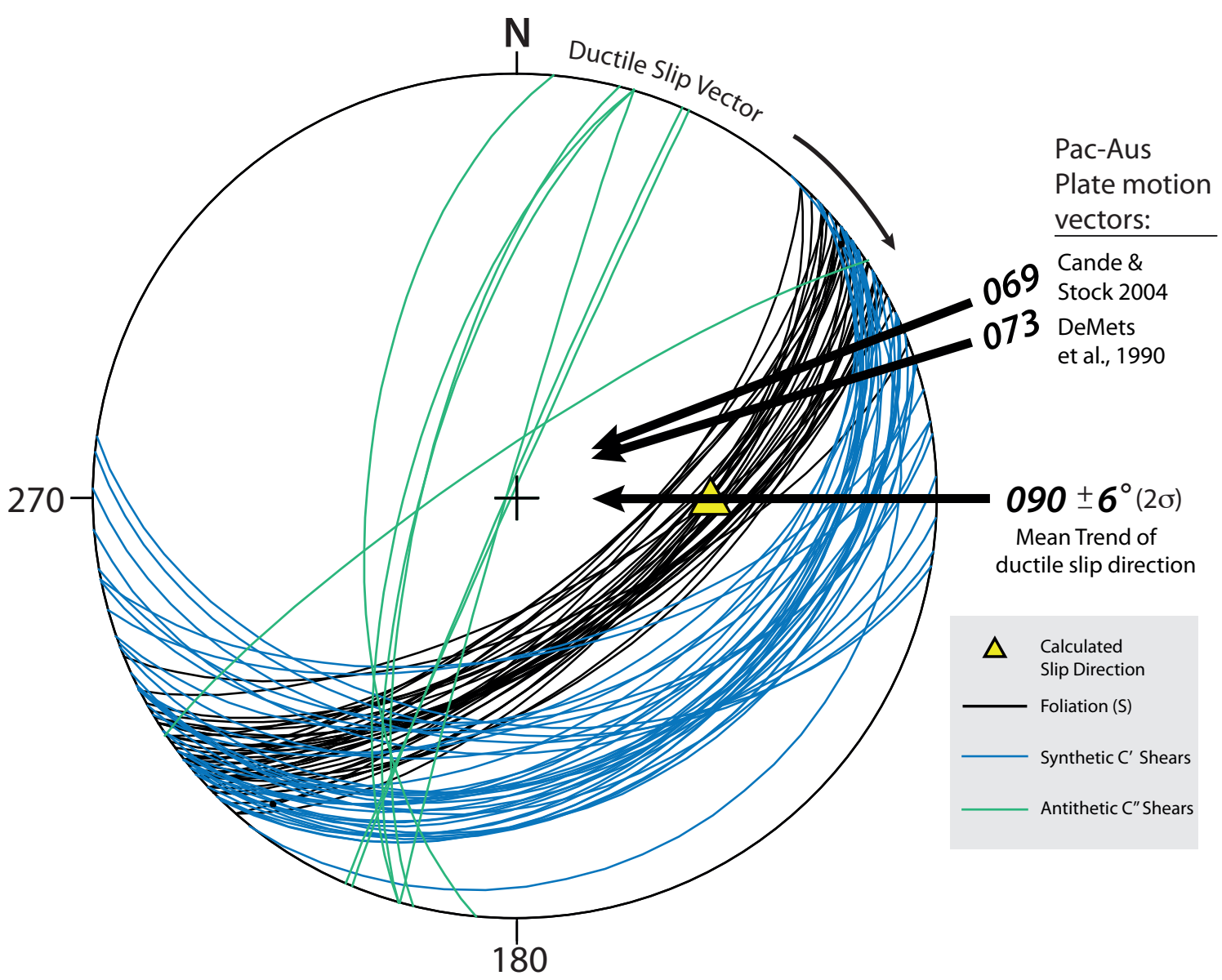

Fig. 6. Attitude of extensional synthetic $C^{\prime}$ and antithetic $C^{\prime \prime}$ shears at Tatare Stream. The ductile slip vector was calculated as the perpendicular to the intersection lineation of the $S$ and $C^{\prime}$ planes that lies in the mylonitic foliation plane (parallel to the Alpine Fault). 
vector in the Alpine mylonite zone that trends $090 \pm 6^{\circ}(2 \sigma)$ and plunges $59 \pm 6^{\circ}$ to the NE (Fig. 6).

\subsection{Lineation deformation in the transition zone between the distal and main mylonite zone}

Structural field studies by Sibson et al., (1979) in the Alpine Schist and adjacent mylonite zone documented changes in the dominant lineation orientation across their mutual boundary, which he attributed to finite deformation of the inherited (nonmylonitic) lineation, at least in part. The dominant intersection/quartz rodding lineation pitches SW in the non-mylontic Alpine Schist and distal mylonite zone, whereas in the main mylonite zone the lineation pitches NE. Deflection of the nonmylonitic Alpine Schist SW-pitching lineation to the NE-pitching trends on entering the mylonite zone has also been described in other more recent Alpine Schist geological studies (e.g. Little et al., 2002a; Toy, 2007). It also occurs in Tatare Stream (Fig. 7a \& d). Following earlier workers I have interpreted much of the lineation in the mylonite zone, especially the quartz rodding, to be inherited from the intersection lineation in the non-mylonitic Alpine Schist and distal mylonite zone to have been reoriented as a result of finite deformation in the main part of the mylonite zone. I have further assumed that the mylonite zone exposed in Tatare Stream is derived from non-mylonitic schist that has similar characteristics to the exposures in Tatare Stream (e.g., non-mylonitic Alpine Schist lineation orientations).

The lineation in the transitional zone in Tatare Stream is spatially variable in its pitch between SW and NE on a length scale of decimeters to meters (Figs. $5 \& 8$ ). In order to document this transition I did a detailed compass-tape traverse collecting lineation data across the full width of the transitional zone. The foliation attitude is consistent across the 50-meter section of transitional zone (Fig. 4). The lineation is conspicuous on foliation parallel quartz sheets within this zone as is typical of the $\mathrm{L}_{2 \times 3}$ intersection/rodding lineation throughout the non-mylonitic and distal mylonite zones (Fig. 5). Changes in the lineation pitch were documented along this transect at wherever a lineation could be measured on exposed foliation planes. In addition to measuring the lineation pitch I also recorded the lithology and foliation parallel quartz lamination thickness. 
a.
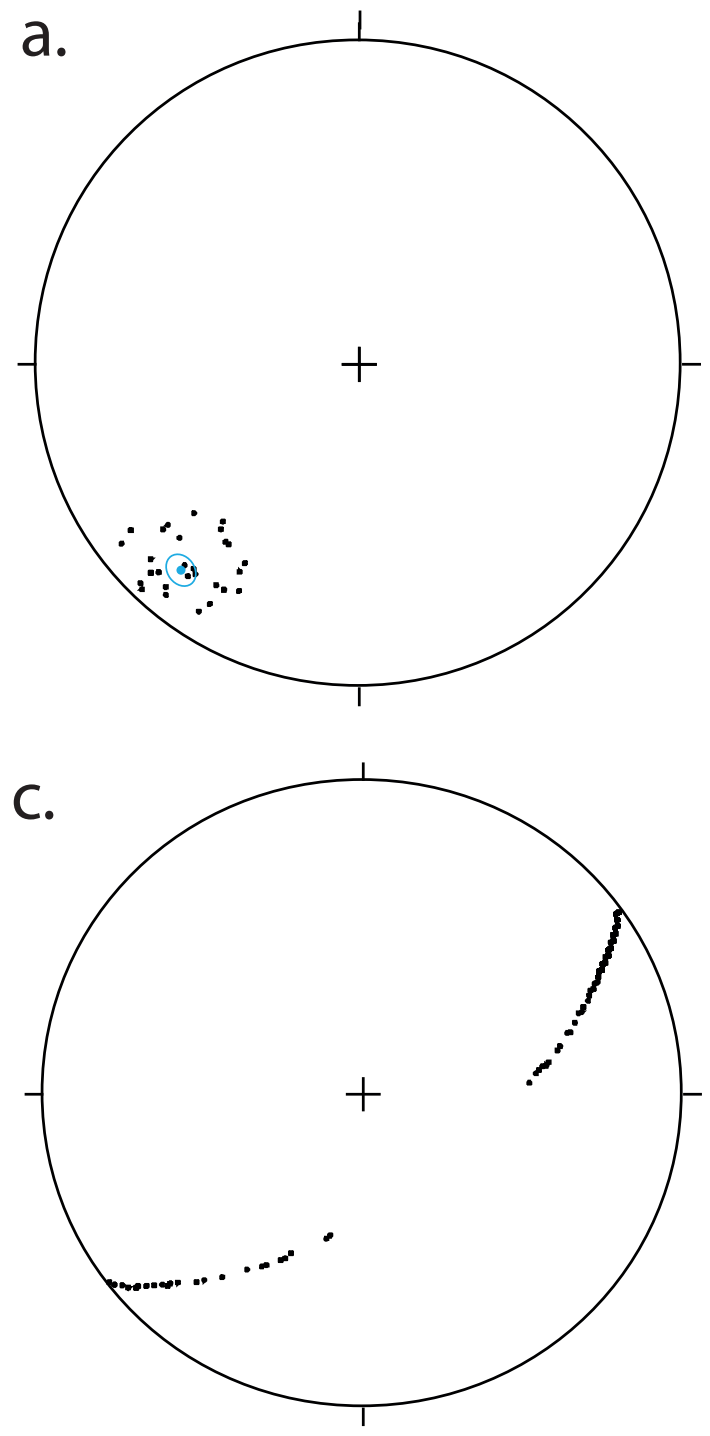

b.
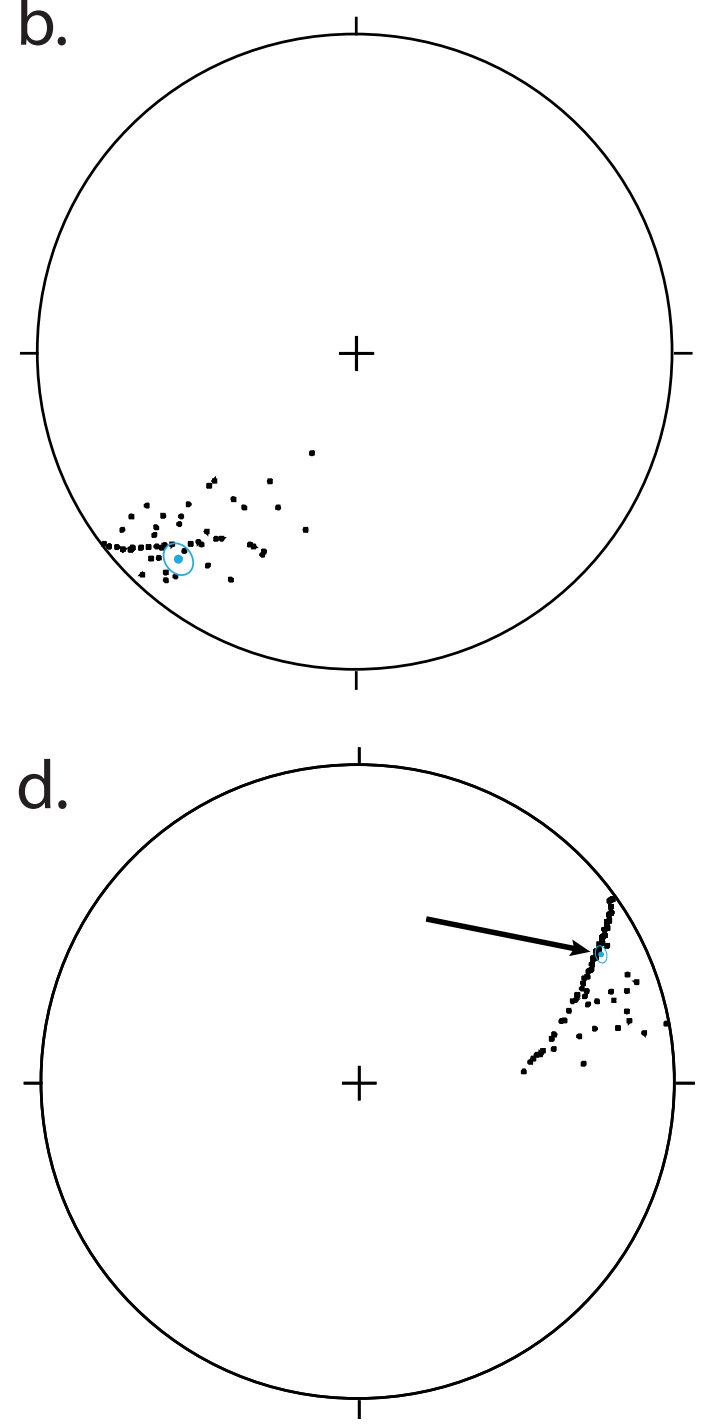

Fig. 7. Stereographic plots showing the orientation of the dominant Alpine Schist intersection $\left(\mathrm{L}_{2 \times 3}\right)$ and quartz rodding lineation in Tatare Stream. (a) non-mylonitic Alpine schist. $\mathrm{n}=33$. mean vector $=221 / 17$. Blue dot is the mean vector orientation and blue circle is a $95 \%$ confidence ellipse around the mean. (b) distal mylonite zone. $n=57$. mean vector 223/18. Blue dot and circle is same as above. (c) transitional zone lineation orientations. Bi-modal distribution. NE and SW-pitching lineations. $n=$ 165 (d) mylonite zone plus NE-pitching lineations observed in the high strain part of the transitional zone. Arrow denotes the mean vector orientation. $n=149$. mean vector $062 / 15$. Blue notation as above. 
In the distal mylonite zone up-section from the transitional zone the mean lineation $\left(\mathrm{L}_{2 \times 3}\right)$ pitches on average $20^{\circ} \mathrm{SW}$ (Fig. $7 \mathrm{~b}$ ). Within the transitional zone this lineation is deflected in one of 2 possible ways, either it experience an anti-clockwise steepening in plunge or a clockwise swallowing in plunge with respect to its "incoming", less deformed orientation outside the zone (Fig. 5). In the non-mylonitic Alpine Schist this lineation $\left(\mathrm{L}_{2 \times 3}\right)$ has a natural variability and must have been curvilinear rather than strictly linear or straight. This results in a pre-deformational pitch variation of $\sim 40^{\circ}$ outside the transitional zone. Depending on the particular original pitch of the lineation, its subsequent deformation deflection on entering the main part of the mylonite zone has been rotated clockwise or anticlockwise. Our data in the transitional zone show that most of the "incoming" SW-pitching lineations have been rotated in a clockwise direction towards shallower plunges. A few (4.8\%) have been rotated anticlockwise to achieve steeper plunges (Fig. 8). Midway into the transition zone $(\sim 25 \mathrm{~m})$ from its boundary with the distal mylonite zone there is a dominance of lineations that have been rotated clockwise towards the shallow NE pitches (Fig. 8). Some SW-pitching relict $\mathrm{L}_{2 \times 3}$ lineations (8\%) are still present in some foliation packets but their abundance dies out with increasing proximity towards the main mylonite zone. As the transitional zone merges with the main part of the mylonite zone the variability in the dominant lineation direction diminishes and only NE-pitching quartz rods are observed. There the mean lineation (called $\mathrm{L}_{\mathrm{m}}$ ) on average exiting the zone pitches $17^{\circ} \mathrm{NE}$ (Figs. 7c \& 8). It is important to note that all of these pitch changes occur in foliation parallel quartz sheets that are inferred to be exactly parallel to the SZB of the Alpine mylonite zone. The deformation that has disturbed and reoriented the original SW-pitching lineation in the mylonite zone can be visualized as a purely two-dimensional deformation in a plane that is coincident with the SZB. If the Alpine mylonite zone was a simple shear zone there would not be deformation or lineation rotation in this plane, as it would coincide with a circular section of the strain ellipsoid. I therefore conclude that the Alpine mylonite zone deformation has included a co-axial strain component acting in the plane of the SZB and it is this component, and this component only, that has resulted in the observed strain induced lineation deflections. 


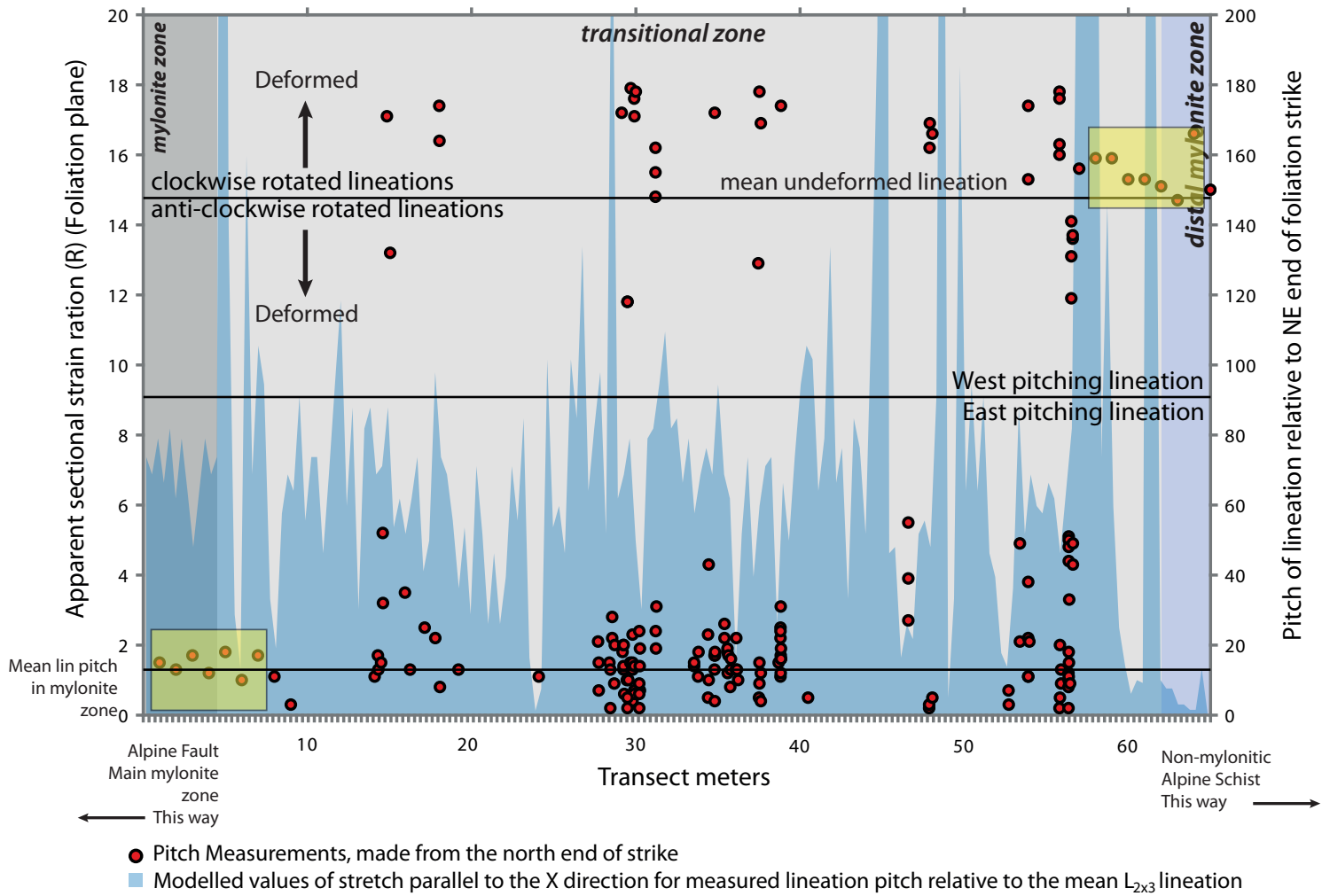

Fig. 8. Scatter and area plots of the highly variable orientation of the deformed lineation in the transitional zone in Tatare Stream. Red circles depict lineation pitch relative to the NE end of the foliation strike (mean foliation attitude is 053/63SE). Yellow boxes indicate the orientation of the lineations "entering" and "exiting" the main part of the mylonite zone. Vertical axis on left shows apparent sectional strain ratio from Wettstein's formula required to deform the mean undeformed lineation into the incremental orientations of the lineation observed in the transitional zone. 
4.6.2 Co-axial finite stretching direction parallel to the SZB of the Alpine mylonite zone

Material lines affected by a homogenous finite strain in a plane rotate clockwise or anti-clockwise with respect to the maximum finite elongation direction in that plane. An increase in finite sectional strain is predicted to cause an increasing rotation of linear passive markers towards the $\mathrm{X}$ direction of the finite strain ellipsoid in that plane (Ramsay, 1976). For a co-axial (irrotational) sectional deformation the $\mathrm{X}$ direction will not rotate relative to the strike of that foliation and it will attract material lines as a function of progressive deformation (fabric attractor) (Passchier, 1998). The data from the transitional zone reveal an approximately normal distribution of lineation pitches in the (constantly oriented) foliation plane. Outside the transitional zone the mean orientation of the distal mylonite inherited lineation (equivalent to $\mathrm{L}_{2 \times 3}$ ) is $223 / 18 \pm 3.5(2 \sigma)$ and the mean orientation in the mylonite zone $\left(\mathrm{L}_{\mathrm{m}}\right)$ is $62 / 15 \pm 1.7(2 \sigma)$. To deform the $\mathrm{SW}$-pitching inherited $\mathrm{L}_{2 \times 3}$ lineation to the NE-pitch that is characteristic of the high-strain mylonite zone on the NW side of the transitional requires a sectional finite strain that is considerable and calculable provided that the $\mathrm{X}$ direction the sectional strain ellipse can be first identified.

The orientation of the co-axial finite strain ellipse on the SZB parallel plane of the foliation can be ascertained by analysing strain induced lineation deflections at the $\mathrm{cm}$-scale, and in particular, changes in lineation curvature. I have determined the maximum finite elongation direction, $\mathrm{X}$, of the sectional strain ellipse as follows. Photographs were taken of 5 different lineation-covered foliation faces in the transitional zone (Fig. 4). The trace of the variably deflected lineation was mapped on each of these faces (Fig. 5a \& b). Several lineation pitch types were identified on these photos and it was found that an individual lineation trace was often curvilinear or segmented, such that it described several of these different pitch types along its length (Fig. 5). These types are: (1) oversteepened SW lineation pitch (i.e., steeper than that of the $\sim 20^{\circ}$ pitching non-mylonitic Alpine Schist lineations) (2) a lineation with a plunge to the SW similar to the non-mylonitic Alpine Schist or a (3) shallowly NE-pitching lineation (Fig. 5b). Of key importance here are the lineations of type 2 that remain undeflected relative to inherited, SW-pitching non-mylonitic Alpine Schist lineations. I infer that these lineation segments have not experienced 
any distortional rotation during the sectional deformation and therefore that they are parallel to one of the axes of the strain ellipse; whereas the other segments have been rotated away from that direction. This relationship indicates that the unrotated lineation segments were (and remain) parallel to the minor (sectional Y) axis of the two-dimensional finite strain ellipse. The X direction, I construct perpendicular to these unrotated limbs on the curved lineation traces. This I interpret to be the direction, $\mathrm{X}$, of the co-axial stretching component acting parallel to the SZB of the Alpine mylonite zone.

Lineation pitch types 1 and 3 occur on opposite "quadrants" of the sectional strain ellipse and have rotated towards $\mathrm{X}$ from different directions anti-clockwise and clockwise respectively. Those inherited lineations that happened to be SW pitching parallel to the $\mathrm{Y}$ direction of the sectional strain ellipse were fixed in that stable orientation. These contrasts in behaviour have lead to the curved morphology of the lineations on a given foliation plane (Fig. 5). In this way I have been able to identify the pitch of the sectional $\mathrm{X}$ direction of the finite strain in the foliation plane at 8 sites. This pitch was found to be 59 (from the NE). This corresponds to a mean trend of $89 \pm 3.8^{\circ}(2 \sigma)$ and plunge $49 \pm 3.8^{\circ}(2 \sigma)$. Importantly, this is within error of the mean slip vector direction.

\subsubsection{Finite magnitude of co-axial stretching and thinning}

Knowing the pitch of the sectional $\mathrm{X}$ direction allows calculation of the sectional

strain ratio $\mathrm{R}\left(\frac{1+e_{1}}{1+e_{2}}\right)$ that could accomplish any distortional lineation reorientation, and based on an assumption of homogenous strain and passive material line behavior for the lineations I apply Wettstein's formula (eq.1).

$$
\operatorname{Tan} \theta^{\prime}=\frac{\operatorname{Tan} \theta}{R}
$$

where

$$
R=\frac{1+e_{1}}{1+e_{2}}
$$

and

$\left(1+e_{1}\right)=$ Finite stretch parallel to $\mathrm{X}$

$$
\left(1+e_{2}\right)=\text { Finite stretch parallel to } \mathrm{Y}
$$

and

$$
\theta=\text { Angle of undeformed lineation to } \mathrm{X}
$$




$$
\theta^{\circ}=\text { Angle of deformed lineation to } \mathrm{X}
$$

The mean $\theta$ is calculated to be $20^{\circ}$ based on the observed mean pitch of the $\mathrm{L}_{2 \times 3}$ lineation outside the transitional zone and the above cited pitch of the $\mathrm{X}$ direction; however, it is locally variable because of the curvilinear nature of that lineation in detail (mean pitch is $20 \pm 3.8^{\circ}$ at $2 \sigma$ ).

In the transitional zone, where the deformed lineation vary in their pitch, $\theta^{\prime}$ must also vary and the calculated strain ratio, $\mathrm{R}$, in the transitional zone is variable. This zone has inhomogeneous strain. To deform a lineation from SW-pitching nonmylonitic Alpine Schist orientation to the final pitches in the transitional zone a variable $\mathrm{R}$ value of up to 20 is required. This analysis does not consider the original variability in lineation pitches and the angle $\theta$; so this apparent $\mathrm{R}$ ratio variability is almost certainly too large. In particular the largest and the smallest calculated $\mathrm{R}$ values are probably artefacts of this affect. Applying Wettstien's formula to describe the change in the mean lineation pitches in going from the distal mylonite to main mylonite zones implies a two dimensional strain ratio, $\mathrm{R}$, of $\sim 5.7 \pm 1.5(2 \sigma)$ in the foliation plane.

As a first approximation, I will consider a case of three dimensional plane strain, such that there has been no extension in the Y. This implies a value of $\left(1+e_{1}\right)=\mathrm{R}=$ $\sim 5.7$ for the co-axial finite stretch magnitude in the mylonite zone. For constant volume deformation the corresponding co-axial SZB perpendicular thinning factor $\left(1+e_{3}\right)$ is simply equation 3 . This results in a foliation orthogonal stretch of $0.18 \pm$ $0.05(2 \sigma)$ (thinning).

$$
\frac{1}{\left(1+e_{1}\right)}=\frac{1}{5.7}
$$

In the transitional zone, undeforming the observed lineations by $R^{*}=\frac{1}{R}$ should restore the distorted lineation back to its original pitch. In figures $9 \mathrm{a} \& \mathrm{~b}$ I undertake a retrodeformation of the observed lineation traces by applying a reciprocal deformation equivalent to the mean $\mathrm{R}$ value of $\sim 5.7 \pm 1.5(2 \sigma)$. Using Adobe Illustrator, a circle containing deformed lineations was stretched in the $\mathrm{Y}$ direction by the reciprocal stretch of $\sim 5.7 \pm 1.5(2 \sigma)$. This retrodeformation restores the 
a.

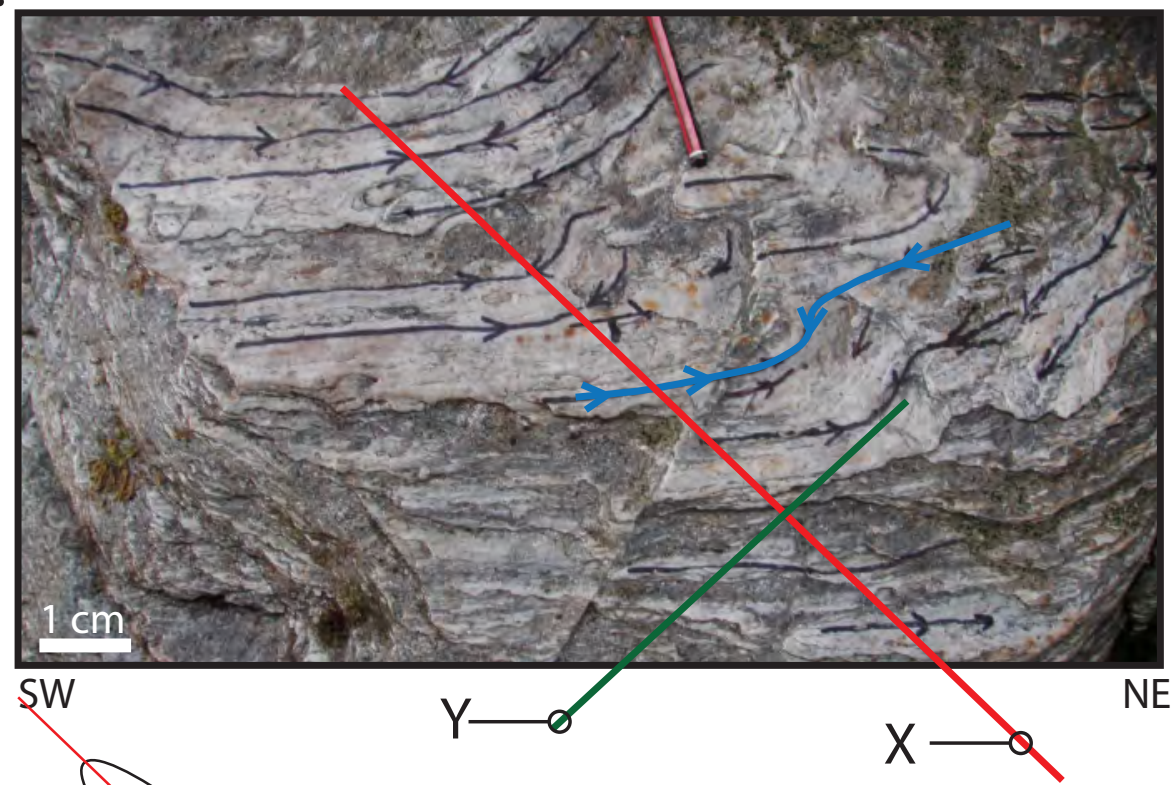

b.

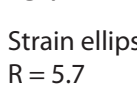

lineation deformed in

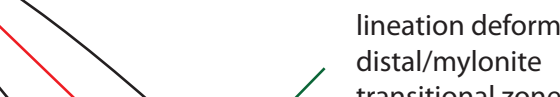
transitional zone

c.

\section{one}

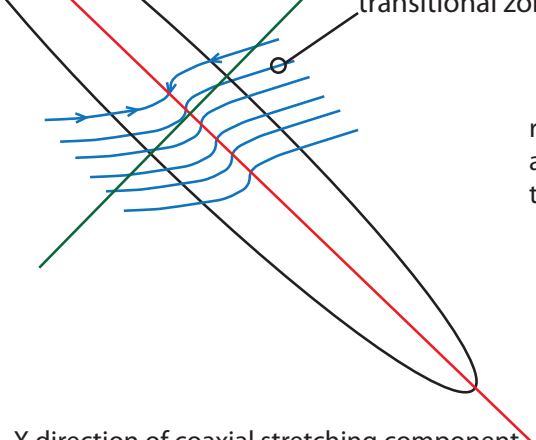

$X$ direction of coaxial stretching component retrodeformed circle and original lineation traces

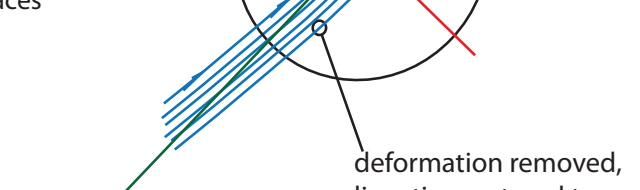

lineation restored to original SW linear plunge

Fig. 9. Orientation of the finite strain ellipse on a 2D SZB-parallel plane showing the effect of late Cenozoic homogenous strain in the Alpine mylonite zone on an originally curv-linear non-mylonitic lineation. (a) Foliation parallel quartz sheet with lineation traces emphasized by the black arrows. For the location of this photo see Fig. 5. Red and green lines denote the strain axes (fabric attractors and repulsors) for the 2D finite stain ellipse on the foliation plane. $X$ is the maximum finite elongation direction, $Y$ is the intermediate direction. (b) Lineations traced on the outcrop photographs were placed in a strain ellipse that has been distorted by a sectional ratio of 5.7. (c) Retrodeformed circle and lineation pattern. 
original strain ellipse back to a circle and undistorts the strongly curved lineations in the photographs back to an original almost linear SW pitch (Fig. 9c). This retrodeformation highlights the implications of having a curvilinear lineation inherited and further deformed in the transitional zone. The smallest variation in the original lineation pitch is strongly amplified when a finite strain is superposed, which has $\mathrm{X}$ at a high angle to the original mean trend of that lineation (e.g. centre of Fig. 9c).

\subsection{Discussion}

\subsubsection{Transitional zone foliation development and deformed lineation patterns}

The variable lineation pitches in the transitional zone (Fig. 8) indicate: (1) original variability in lineation pitch and (2) strongly heterogeneous strain from place to place within that zone. The schist in the transitional zone includes: (a) greyschist with $\mathrm{cm}$-thick foliation parallel laminae, (b) micaceous-pelitic schist lacking quartz lamine, and (c) mafic amphibolite lenses. Earlier I described the several types of foliation and layer boudinage structures that extend the schist parallel to the foliation plane. Boudinaged packets of thinly quartz-laminated schist occur as high aspect ratio $(\mathrm{R}=$ boudin length/boudin width) boudins $(\mathrm{R}=>3.0)$ with highly separated neck regions that are typically infilled with mylonitic rocks derived from pelitic schist (Fig. 3a \& b). The layer boundinage of the cm-thick quartz veins are stronger than the more micaceous schist that surrounds them. Holyoke \& Tullis (2006) have suggested that within a ductile shear zone, the localized zones of highest strain rate will be preferentially partitioned into the mixed-phase regions (e.g., biotite-feldsparquartz-bearing pelitic schist). This partitioning will cause weakening and strain localization of the pelitic schist. Pure quartz layers remaining are predicted to act as a more competent lithological layer. This is consistent with our observations in Tatare Stream.

Local strength contrasts in lithology between more and less of those packets in the transitional zone may explain the variable lineation plunge ("flip-flopping" of pitch direction) in that heterogeneous deformed zone acting in response to the coaxial strain parallel and perpendicular to the SZB (Fig. 8). The lineation is best expressed as laterally continuous quartz rods or intersections that occur on the quartz 
laminae parallel to the foliation (Fig. 5). I suggest that simple foliation boudinage can explain the variability in lineation orientations in the transitional zone (Fig. 10). In this zone the boudinage of stiffer quartz laminated schist (laminations $\sim 10 \mathrm{~mm}$ ) yield highly necked zones separated by stiffer less deformed boudins with relatively undistorted lineations that still pitch SW (Fig. 10). The meter-scale foliation boudins are characteristic of the stiffer more thickly laminated schist packets. These have lineations that have experienced a negligible distortional rotation as a result of the co-axial strain component and remain in a SW-pitching orientation. The strongly necked schist packets are typically micaceous or pelitic. These are up to approximately $5 \mathrm{~m}$ in length parallel to the foliation and are inferred to be highly stretched causing the original SW-pitching lineation to be strongly deflected either clockwise or anti-clockwise, depending on its initial angle to Y. If this proposed model is correct, it predicts that an observable $\sim 6$ fold reduction in the thickness of quartz laminae will distort the lineation to a NE-pitch. The quartz laminae in the distal mylonite zone range from $2-40 \mathrm{~mm}$ and precisely measuring a $\sim 6$ fold reduction of an originally $2 \mathrm{~mm}$ thick quartz layer has a significant measurement uncertainty. The relationship of layer thickness to lineation pitch orientation in Figure $10 \mathrm{~b}$ suggests that the more clockwise-distorted NE-pitching lineations are embedded in thinner foliation (SZB) parallel quartz laminae.

As expected the lineations found in the boudinaged mafic amphibolite layers, which are inferred to be the stiffest and least deformed lithology, pitch to the SW in the transitional zone. The SW-pitching orientation of these lineations confirms that the mafic lithology units are stiff mechanical layers, and that the variability in the lineation pitch and the strain in the transitional zone are at least in part lithologically controlled. These mafic units are sparse $(n=2)$ and occur as isolated boudins; they do not contain the distortionally reoriented NE-pitching lineations.

We have forward modeled the distribution of non-mylonitic Alpine Schist lineations measured in Tatare Stream using Wettstien's formula and Matlab ${ }^{\circledR}$. We assume three dimensional plane strain, a stretching direction of $89 \pm 3.8^{\circ}(2 \sigma)$, and a stretching magnitude of $\sim 6$ that distorts the entire population of non-mylonitic lineations. The distributions predicted by this modelling (see appendix D) are qualitatively similar to those in the main mylonite zone; however, the model has 


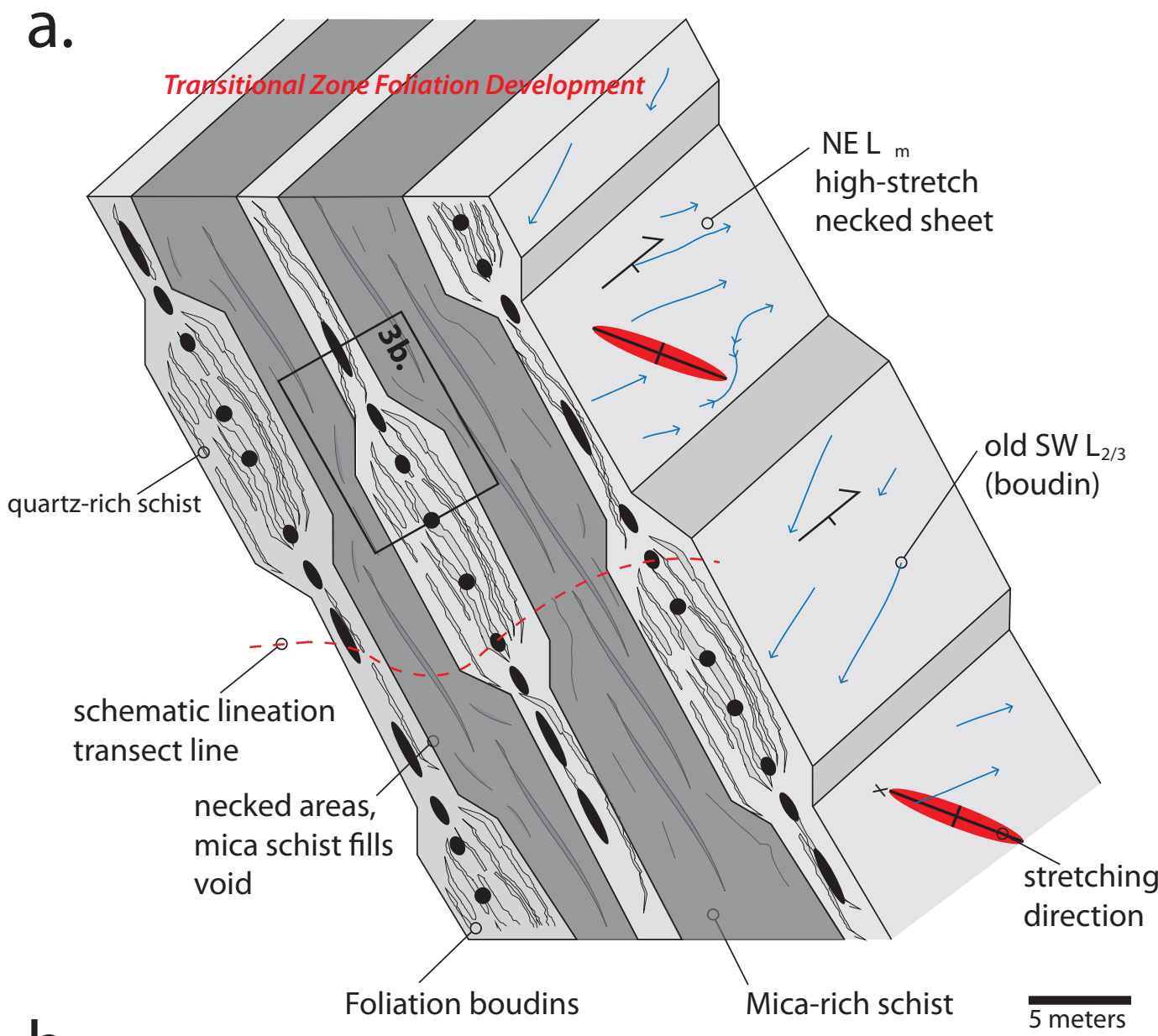

b.

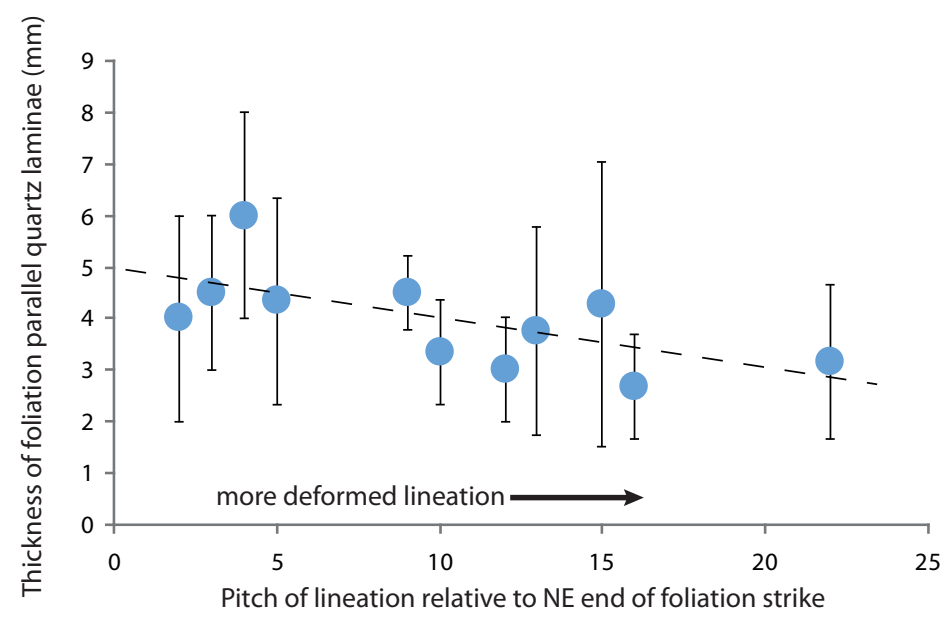

Fig. 10. (a) Model for the heterogeneity of lineation pitch and apparent layer parallel strain in the transitional zone, Tatare Stream. The necked areas (between boudins) are highly stretched and contain the NE-pitching lineation. The main boudin section contains the SW-pitching lineation. Red dashed line indicates a proposed location for the observed outcrop of the transitional zone in Tatare Stream (sampling high and low stretch areas) (Fig. 4). (b) Scatter plot of quartz rodding lineation pitch relative to the thickness of the foliation parallel quartz laminae. 
highlighted that a population of the non-mylonitic lineations experience little or no rotation (SW-pitching) as a result of the foliation parallel stretch. In other words, for a $\sim 6$ fold stretch lineations oriented parallel to or sub-parallel to the minor (sectional Y) axis will not rotate (either clockwise or anticlockwise), or will rotate insignificantly; therefore, lineations with a SW-pitch should still be evident in the main mylonite zone. None of the "unrotated" SW-pitching lineation segments are observed in the main mylonite zone, Tatare Stream. The absence of this SW-pitching mylonitic population could be attributed to one of the following possibilities: (1) the mylonite zone in Tatare Stream is an incomplete exposure with only its upper section $(\sim 250 \mathrm{~m})$ exposed; (2) the lithology of the exposed main mylonite zone is micaceous-rich and this compositional element has controlled the lineation orientation; (3) the main mylonite zone exposed in Tatare Stream was derived from non-mylonitic schist with a relatively consistent lineation orientation in comparison to the non-mylonitic schist exposed in Tatare Stream.

Toy (2007) has suggested an alternative explanation for the reorientation of the lineation in the main mylonite zone, in which the pre-existing quartz rods/fold hinges are included in discretely spaced C' shear bands. Top-to-the west shearing on these C' shears progressively reorients the lineation into a NE plunge in the main mylonite zone. Toy (2007) suggests that the conspicuously curved morphology of some quartz rodding lineations (on foliation parallel quartz sheets) are formed from only a part of that quartz rodding lineation being included, and reoriented by the C' shear. In Tatare Stream I do not observe this type of reorientation, albeit the appearance of ubiquitous extensional C' shears there; however, I do not discount this type of lineation reorientation in other parts of the Alpine mylonite zone (e.g., Gaunt Creek, Fig. 1).

\subsubsection{Bulk flow kinematics in the Alpine Fault mylonite zone}

Flow and strain accumulation in a simple shear dominated monoclinic shear zone is now reasonably well understood (Ramsay \& Huber, 1983). In any type of steadystate homogenous flow, three orthogonal instantaneous stretching axes (ISA ISA $_{2}$ $\mathrm{ISA}_{3}$ ) can be defined (Passchier, 1991). Monoclinic flows can be completely characterized by the following: the ISAs orientations and their rates of stretching and orientation of the vorticity vector (w) (Passchier, 1998; Jiang et al., 2001). The bulk 
flow type governs the dispositions of the ISAs relative to the SZB's of the zone (i.e., angles differ for simple vs general vs pure shear). The angle between the vorticity vector and the ISAs determines the symmetry of the flow (Xypolias, 2010). The plane that lies normal to the vorticity vector has been termed the vorticity normal section (Jiang \& Williams, 1998) (also called the movement plane or M-plane). For monoclinic flow this plane will be the mirror plane of symmetry. For example, in a simple flow type, the vorticity vector is parallel to the ISA 2 . If the vorticity vector is oblique to all of the ISAs the flow is triclinic. Although monoclinic flows reproduce an end member for the general and vertical case, they may be a common case for natural shear zones (Jiang et al., 2001; Xypolias, 2010).

Past modeling of the lineations in the central Alpine mylonite zone, which are widely dispersed in the plane of the Alpine foliation has suggested that bulk deformation path has been triclinic (Jiang et al., 2001; Toy, 2007). Jiang et al., (2001) modeled the pattern of mylonitic lineations acquired by Sibson et al., (1979); however to do this they assumed that the direction the simple shear component of strain is parallel to the Pacific Plate motion vector and that relationship I have shown in this paper to be incorrect, at least in Tatare Stream. The lack of a co-planar distribution of lineations in their inferred vorticity-normal plane led them to conclude that the Alpine Fault shear zone is triclinic (Jiang et al., 2001). Moreover, they assumed that all lineations were newly formed stretching lineations related to the Alpine mylonite deformation, only, and without any inherited object lineations. Recently Toy (2007) and Toy et al., (2011 in review) applied a similar 3D triclinic strain model to the central Alpine Fault mylonite zone, adopting the similar model parameters used by Lin et al., (1998) while adjusting them to the Alpine Fault specifications. Like Lin et al., (1998) Toy (2007) assumed a perfectly up-dip direction of co-axial stretching perpendicular to the Alpine Fault's strike. Lin et al., (1998) considered a shear zone model with a constant volume and constant strike length, which allowed their ductile shearing vector to have a dip-slip component. Toy (2007) has shown that with an increasing pure shear component in the mylonite zone deformed lineations developed in the mylonite zone (inherited from the nonmylonitic Alpine Schist) will distort in their pitch towards the down-dip direction of the Alpine Fault (the assumed direction of co-axial X). In this triclinic model, the coaxial component, rather than the simple shearing of the flow is largely responsible 
for the deformation of the inherited lineations. These authors suggest that the simple shear component is partitioned into slip on the C' shears. Our results support aspects of this modeling with two important exceptions: (1) our inferred direction of co-axial stretching $(\mathrm{X})$ is not in the down dip direction of the Alpine Fault but oblique to it (pitch of $59^{\circ}$ ), (2) this direction is parallel to our measured slip vector direction of ductile shearing indicating a shear zone deformation of monoclinic rather than triclinic symmetry. A further important conclusion of this study is that the direction of ductile shearing in the Alpine mylonite zone pitches $\sim 20^{\circ}$ more down-dip than the projection of the plate motion vector on to the plane of the SZB (Fig. 11).

The simplest model for the kinematics of the Alpine Fault mylonite zone at depth would be to assume a situation of steady-state homogenous finite deformation with the conservation of volume. Because the foliation plane is parallel to the SZB plane in the transitional zone I have been able to isolate the pure shear component of deformation considering a simple two-dimensional deformation on that plane, and in particular its affect on inherited lineations in that plane. The direction of maximum finite elongation $\mathrm{X}$ in this plane trends $\sim 090$ (pitches $59^{\circ}$ ). I believe this records finite strain related to the co-axial component only.

\subsubsection{Bulk finite kinematic vorticity of the Alpine Fault mylonite zone}

The kinematic vorticity number $\left(\mathrm{W}_{\mathrm{k}}\right)$ is a useful measure of the non-coaxiality (superposition of pure to simple shear strain) in naturally deformed rocks (Means et al., 1980). By definition $W_{k}$ is a description of instantaneous deformation and not the finite deformation. If one assumes steady-state deformation, however, then a mean kinematic vorticity $\mathrm{W}_{\mathrm{n}}$ can be calculated from finite deformation parameters as follows from equation 20 from Fossen \& Tickoff (1993) (here, eq. 4).

$$
W_{k}=\gamma\left\{2\left(\operatorname{In} k_{1}\right)^{2}+2\left(\operatorname{In} k_{2}\right)^{2}+\gamma^{2}\right\}^{-\frac{1}{2}}
$$

Where $\gamma$ is the bulk finite shear strain, and $k_{1}$ and $k_{2}$ are the extension and contraction along the maximum finite elongation direction. The $\mathrm{W}_{\mathrm{k}}$ number has values equal or greater than 0 , and flow with $\mathrm{W}_{\mathrm{k}}=0$ is said to be co-axial. In other words, the degree of non-coaxiality increases with increasing $W_{k}$ values. For plane strain and equal-area deformation $\mathrm{W}_{\mathrm{n}}=\mathrm{W}_{\mathrm{k}}$. An estimate for the finite shear strain 


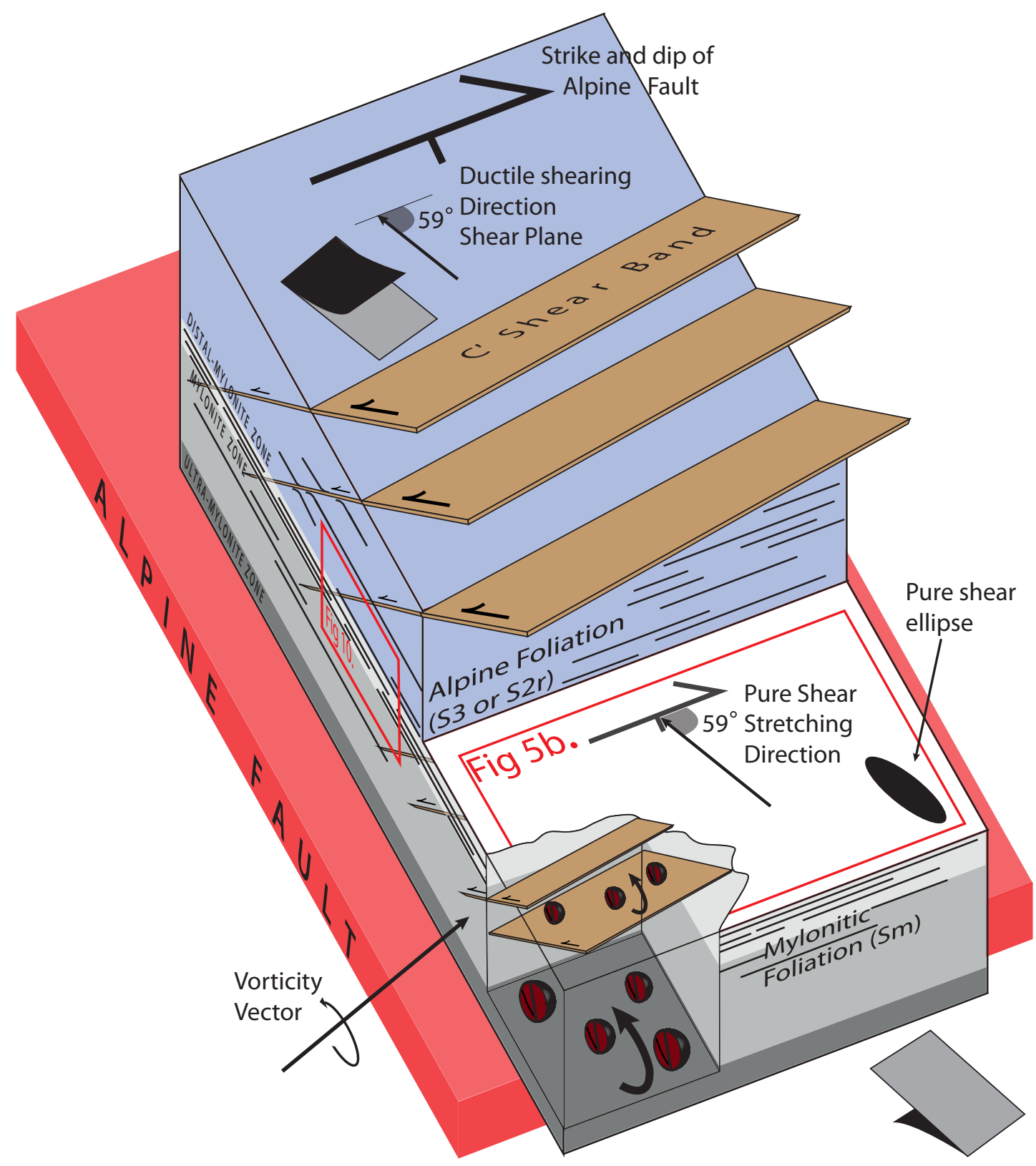

Fig. 11. Monoclinic stretching shear zone model for the lower crustal Alpine Fault mylonite zone. Note the parallelism of pure shear stretching and ductile shearing directions. Foliation in the Alpine mylonite zone is exactly parallel to the ductile SZB and the Alpine Fault. Extensional C' shear bands cut the foliation at an oblique angle to define the vorticity vector orthogonal to the shearing direction. Garnet porphyroblasts located between $C^{\prime}$ shears in the microlithons have forward-rotated by $\sim 80$ about the vorticity vector (see Gillam \& Little, 2011 chapter 3 this thesis). 
experienced in the main part of the Alpine mylonite zone in Tatare Stream is obtained from the GhoshFlow modeling of the equant garnet porphyroblasts (see Gillam \& Little, 2011 chapter 3 this thesis). This modeling implies a minimum finite shear strain of 3.5. The two-dimensional strain ratio, $\mathrm{R}$, of $\sim 5.7 \pm 1.5(2 \sigma)$ is $k_{1}$ and $k_{2}$ is the reciprocal of the ratio. Using these values, the above equation produces an estimate for $\mathrm{W}_{\mathrm{n}}$ of $0.8 \pm 0.06(2 \sigma)$.

Similar values of $\mathrm{W}_{\mathrm{k}}$ have been estimated from other independent proxies in the Alpine mylonite zone. The geometrical orientation of C' shears parallel to the planes of maximum shear strain rate estimate $a W_{k}$ of 0.5 for the Alpine mylonite zone (Gillam et al., 2011 chapter 2 this thesis). These extensional C' shears are a late stage feature in the history of the Alpine mylonite shear zone, and as such may record the later stages of deformation when the flow became more co-axially dominated. The $\mathrm{W}_{\mathrm{k}}$ determined from vorticity modeling of garnets in the Alpine mylonite zone agrees with the finite $\mathrm{W}_{\mathrm{n}}$ for a general flow in the Alpine mylonite zone (Gillam \& Little, 2011 chapter 3 this thesis). The garnet rotational history represents a longer-term and more path-integrated deformation in the Alpine mylonite zone than the C' shears. For example, an earlier more simple shear dominated shear path may have been followed by a progression into a more stretching shear zone later in its history as the late stage C' shears formed.

In geological literature different types of three-dimensional ductile shear zones have been modeled, with the most commonly described shear zone types being transpression, transtension, stretching and shortening shear zones (Harland, 1971; Sanderson \& Marchini, 1984; Means, 1989; Fossen \& Tikoff, 1993; Jiang \& White, 1995; Tikoff \& Greene, 1997; Passchier, 1998; Jiang et al., 2001; Little, 2004). Most of these models are based on specific flow types with monoclinic symmetry, steadystate deformation, and the absence of volume change (Passchier, 1998). The finite $\mathrm{W}_{\mathrm{n}}$ estimate of 0.8 for the Alpine mylonite zone albeit based on assumptions of steady-state deformation implies that there has been a co-axial component for late Cenozoic flow in the Alpine mylonite zone. Previous studies have advanced the idea that the Alpine Fault mylonite zone has been a simple shear dominated shear zone (i.e., $\mathrm{W}_{\mathrm{k}}$ 's ranging from $\sim 0.95-1.0$, Norris \& Cooper, 2003). The estimate of finite $\mathrm{W}_{\mathrm{n}}$, by contrast, suggests that the Alpine Fault mylonite zone has undergone a more 
general flow and that this flow has been monoclinic with the direction of co-axial shear zone stretching being coincident with the direction of simple shearing on the SZB. Moreover, this direction is not parallel to the Pacific-Australian plate motion vector trend, but pitches $20^{\circ}$ down-dip of it.

A monoclinic stretching and thinning (e.g., Means, 1989) shear zone model can explain the observations of finite deformation in the Alpine mylonite zone in Tatare Stream; including C' extensional shear band attitudes and deformation of linear markers in the plane of the SZB. The Tatare Stream locality is remarkable for the simple, planar and unsegmented nature of the Alpine Fault zone, for its excellent exposure, and for the way that key aspects of the finite deformation can be "factorized" into simple two-dimensional sectional deformation. As discussed, the modeling of the distribution of the inherited Alpine Schist lineations determined a sectional strain ratio, $\mathrm{R}$, of $\sim 5.7 \pm 1.5(2 \sigma)$ in the plane of the SZB. For constant volume deformation and with $1+e_{2}=1.0$, rocks within the current $\sim 2 \mathrm{~km}$ thick distal mylonite and main mylonite zones in Tatare Stream were originally $\sim 10 \pm 0.7(2 \sigma)$ $\mathrm{km}$ thick. A range of foliation boudinage, layer boudinage, and extensional C' shear bands provide strong complementary evidence that the Alpine mylonite zone was extending parallel to its direction of shearing during the late Cenozoic mylonitic deformation. This still active neotectonic Alpine mylonite zone is a stretching and thinning general shear zone of monoclinic symmetry (Fig. 11).

\subsection{Conclusions}

1. The foliation attitude remains remarkably consistent at 053/63SE across the late Cenozoic strain gradient and into the non-mylonitic Alpine Schist wall rock. Because the foliation does not change its attitude across a marked strain gradient between non-mylonitic and mylonitic rocks, I infer that the foliation was already pre-disposed parallel to the Alpine Fault SZB prior to the late Cenozoic shearing. The foliation is fixed in attitude, and therefore records the "fabric attractor" (extensional apophysis). By inference I infer that amphibolite facies ductile shear zone related to the Alpine Fault dips $63^{\circ} \mathrm{SE}$ in this part of the Southern Alps. In contrast to other parts of the central Southern Alps, the Alpine Fault zone is practically simple, planar and unsegmented in the near surface at Tatare Stream. 
2. The ductile shearing direction in the Alpine mylonite zone as measured from the intersection of extensional shear bands with that zone pitches $58^{\circ}$ in that plane. This corresponds to a map-view trend that is $\sim 20^{\circ}$ clockwise of the Pacific Plate motion vector azimuth. The Alpine shear zone is not perfectly "unpartitioned" but caries an "excess" of dip-slip relative to the incoming plate motion as predicted by Little (2004).

3. A mean sectional strain ellipse ratio of $5.7 \pm 1.5(2 \sigma)$ parallel to the maximum finite elongation $\mathrm{X}$ direction is required to deform the mostly SWpitching inherited $\mathrm{L}_{2 \times 3}$ into the mean NE-pitching lineation that typifies the main part of the Alpine mylonite zone, Tatare Stream. Variability in lineation pitch is observed across $\sim 50 \mathrm{~m}$ wide zone that is transitional between the distal and mylonite zones. I attribute this variability to the heterogeneous coaxial stretching in that zone related to decimeter-meter spatial scale of necking and boudinage. Whereas in the main mylonite zone the finite strain is uniformly very high (e.g., Norris \& Cooper, 2003).

4. The parallelism of the mylonite ductile shearing direction (trending 090) and maximum finite elongation direction, relating to the co-axial stretching and thinning of the zone (trending 090), suggests the bulk deformation flow path in the central Alpine Fault mylonite zone has been approximately monoclinic. I estimate a $\mathrm{W}_{\mathrm{n}}$ of 0.8 based on the observed finite shearing of the mylonite zone recorded in the rotation of equant garnet porphyroblasts (Gillam \& Little, 2011 chapter 3 this thesis); and on the co-axial strain I observed deforming the inherited lineations in that zone. Based on the assumptions of steady-state deformation this $\mathrm{W}_{\mathrm{n}}$ agrees with other recent $\mathrm{W}_{\mathrm{k}}$ estimates in the Alpine mylonite zone for a general flow (e.g., Gillam et al., 2011 chapter 2 this thesis). 


\section{Thesis Conclusions}

This thesis has brought together field and microstructural observations at Tatare Stream, central Southern Alps, to investigate the behaviour and kinematics of the late Cenozoic ductile flow in the central Alpine mylonite zone. By contrast to the rest of the central part of the central Southern Alps, Tatare Stream near Franz Josef Glacier appears to be a simple steeply dipping inclined dextral-reverse fault at the surface and is not segmented. It exposes ductilely deformed mylonitic fault rocks that have been exhumed during the past $\sim 3 \mathrm{~m}$. y. via oblique reverse-slip on the Alpine Fault. An analysis of the structures and microstructures in the progressively deformed nonmylonitic to mylonitic Alpine Schist have led me to the following conclusions about the ductile flow in that zone:

1. The foliation attitude remains remarkably consistent at 053/63SE except for local deflections related to foliation boudinage and late stage warping across the late Cenozoic strain gradient from the non-mylonitic wall rocks and through the Alpine mylonite zone. From this relationship, the foliation is inferred to be parallel to the "fabric attractor" (Passchier 1991) (extensional apophysis) and shear zone boundary. Perhaps this situation reflects that the outer non-mylonitic $S_{3}$ foliation was already disposed in the future shear plane direction at this locality prior to the onset of late Cenozoic shearing. By inference I infer that the amphibolite facies ductile shear zone related to the Alpine Fault dips $63^{\circ} \mathrm{SE}$ in this central section of the Southern Alps, which is significantly steeper, about $10-15^{\circ}$, than previous estimates of the dip of the Alpine Fault but which supports the suggestion of Little et al., (2005) that the central part of the Southern Alps is characterized by a relatively steep Alpine Fault dip.

2. Extensional shear bands cut the distal and the main parts of the Alpine mylonite zone in Tatare Stream. These pervade the $\sim 600 \mathrm{~m}$ wide distal mylonite at $\mathrm{mm}-\mathrm{cm}$ scale and also at least $\sim 250 \mathrm{~m}$ of the outer margin of the main mylonite zone (only this part is exposed in Tatare Stream). Little or no change in the geometry of these shears occurs across the entire finite shear 
strain gradient of the Alpine mylonite zone, suggesting that the shears nucleated at a late stage of the shear zone evolution and have undergone very little finite rotation after inception. The average C' strike is $064 \pm 3.7^{\circ}(2 \sigma)$, and their average dip is $38 \pm 3.1^{\circ}$ to the SE $(2 \sigma)$. Inferred to be orthogonal to the mean $\mathrm{C}^{\prime} /$ foliation intersection lineation, the mean ductile slip vector during shear band activity is calculated to trend at $090 \pm 6^{\circ}(2 \sigma)$. In map view this trends $20^{\circ}$ clockwise of estimates for the azimuth of Pacific Plate motion. This discordance in trend indicates that slip on this central part of the Alpine Fault is not fully "unpartitioned" but rather that the Alpine Fault has a slight "excess" of dip-slip relative to the rigid plate motion. This steepening in the slip direction can be explained as being a result of vertical back shearing of the Pacific Plate as it is tilted on to the Alpine Fault ramp at depth, a deformation that would introduce a new vertical component to the incoming Pacific velocity, as originally suggested by Little (2004).

3. Thickness of, and the mean finite per-shear slip of C' shears do not vary across the increased shear strain gradient and with increased proximity towards the Alpine Fault; whereas the mean spacing between C' shears decreases slightly into the higher strain main mylonite zone. I suggest that the consistency of the intra-shear band finite shear strain and the increase in density of the structures in the main mylonite zone indicates that the C' shears have a strain hardening rheology, causing them to lock up at a shear strain of $\sim 12.65 \pm 5.4(1 \sigma)$ after which further deformation causes new shears to form in previously undeformed rock. The observed dihedral angles between synthetic $\left(30^{\circ} \pm 2.2\right.$ at $\left.2 \sigma\right) C^{\prime}$ and antithetic $\left(135^{\circ}\right) C^{\prime \prime}$ shears and the foliation (SZB) support the hypothesis that extensional shears initiate parallel to the planes of maximum angular shear strain rate. Two different analytical methods using the geometrical disposition of C' and C', shears leads to an estimate of the kinematic vorticity number $\left(\mathrm{W}_{\mathrm{k}}\right)$ of 0.5 for the Alpine mylonite zone. The new data on the shear bands and their co-existence with numerous boudinage structures that extend the foliation parallel to the SZB support the idea that extensional shear bands form in stretching and thinning shear zones. 
4. Garnet porphyroblasts in Tatare Stream nucleated during the early stages of the "Alpine" $\mathrm{D}_{3}$ deformation that accompanied the peak conditions of the regional Barrovian metamorphism. In the mylonite zone the garnets have prograde compositional zoning profiles that are inherited from the nonmylonitic Alpine Schist. This has suggested that garnets in the Alpine mylonite zone have been inherited from the adjacent non-mylonitic wall rock and that then have undergone little or no further growth and behaved as rigid porphyroblasts during the subsequent late Cenozoic mylonitization. In the distal mylonite and the main mylonite zone spheroidal-shaped garnet porphyroblasts have forward rotated (relative to their attitude in the nonmylonitic Alpine Schist) in response to the late Cenozoic finite shear strain. The mean inclusion trails in the distal mylonite zone have been forward rotated by $35^{\circ}$ and in the main mylonite zone these inclusions have further forward rotated by $46^{\circ}$. GhoshFlow modelling of garnet porphyroblasts suggest kinematic vorticity numbers for flow in the central Alpine mylonite zone of 0.5 (distal mylonite) and 0.7 (main mylonite zone) and finite shear strain values of 1.2 and 3.5, respectively; but these results are based on sparse data (especially for elongate clasts) and these results must be considered as provisional only.

5. The $\sim 50 \mathrm{~m}$ wide structural transition between the distal mylonite and the main mylonite zone is well-exposed in Tatare Stream. Across this transition, are distorted lineation attitudes from SW-plunging (in the distal mylonite and non-mylonitic zone) to NE-plunging. The lineations are gently SW-pitching in the distal mylonite and NE-pitching in the main mylonite zone. In the transitional zone itself, the lineation pitch is spatially variable alternating between SW and NE on a length scale of decimeters to meters. Some individual lineations are strongly deflected on the foliation plane through $\sim 40^{\circ}$; a relationship that $\mathrm{I}$ attribute to magnification of a slight original curvature in the lineations as different lineation segments rotated towards $\mathrm{X}$ in different quadrants of the sectional strain ellipse. From these relationships a mean sectional strain ellipse ratio of $5.7 \pm 1.5(2 \sigma)$ is calculated on the foliation (SZB) plane, which I attribute to the co-axial component of 
deformation (only). The direction of this co-axial stretching is $89 \pm 3.8^{\circ}(2 \sigma)$. This and other boudinage structures in Tatare Stream indicate that the Alpine mylonite zone is a stretching and thinning shear zone.

6. The parallelism of the mylonite ductile shearing direction (090) calculated from the mean $C^{\prime}$ and foliation intersection and maximum finite elongation $\mathrm{X}$ direction in the foliation (SZB) plane; here attributed to the co-axial component only, suggests the bulk deformation flow path in this part of the central Alpine Fault mylonite zone has been approximately monoclinic. The shear direction mentioned above is supported by the rotational axis calculated for the deflection (forward rotation) of the garnet inclusion planes is subparallel to the vorticity vector that one would expect for that shear direction. Combining an estimate of the finite shear strain in the mylonite zone based on the forward rotation of garnets (3.5) with the thinning estimate $(5.7 \pm 1.5$ $(2 \sigma)$, assuming plane strain) derived from the $2 \mathrm{D}$ lineation reorientation, I obtain an estimate of $\mathrm{W}_{\mathrm{n}}$ of 0.8 , a value that agrees with other above cited estimates based on shear band dihedral angles and GhoshFlow modeling porphyroblast rotation patterns.

7. These data suggest that the Alpine Fault mylonite zone has undergone monoclinic stretching and thinning (e.g., Means, 1989); that is, in addition to dextral-reverse simple shearing the zone is stretched parallel to the inclined (090 trending) shear vector and shortened orthogonal to its walls (thinned). 


\section{REFERENCES.}

Allmendinger, R. W. (2005). Stereonet. Program for stereographic projection.

Arslan, A., Passchier, C. W., Koehn, D. (2008). Foliation Boudinage. Journal of Structural Geology. 30. $291-309$.

Barker, A. J. (1994). Interpretation of porphyroblast inclusion trails: limitations imposed by growth kinetics and strain rates. Journal of Metamorphic Geology. 12. $681-694$.

Bell, T. H. (1981). Foliation development: The contribution, geometry and significance of progressive bulk inhomogenous shortening. Tectonophysics. 75 . $273-296$.

Bell, T. H. (1985). Deformation partitioning and porphyroblast rotation in metamorphic rocks: a radical reinterpretation. Journal of Metamorphic Geology. 3. $109-118$.

Bell, T. H. \& Johnson, S. E. (1989). Porphyroblast inclusion trails: the key to orthogenesis. Journal of Metamorphic Geology. 7. $279-310$.

Blenkinsop, T., \& Treloar, P. (1995). Geometry, classification and kinematics of S-C fabrics. Journal of Structural Geology. 17. 397-408.

Bobyarchick, A. R. (1986). The eigenvalues of steady state flow in Mohr space. Tectonophysics. $122.35-51$.

Busa, M. D., Gray, N. H. (1992). Rotated staurolite porphyroblasts in the Littleton Schist at Bolton, Connecticut, USA. Journal of Metamorphic Geology. 10. 627 -636 .

Cande, S. C. and Stock, J. (2004). Pacific - Antarctica - Australia motion and the formation of the Macquarie Plate. Geophysical Journal International. 157. 399 $-414$.

Cloos, H. (1947). Boudinage. Transactions of the American Geophysical Union. $28.626-632$. 
Davey, F. J., Henyey, T., Kleffmann, S., Melhuish, A., Okaya, D., Stren, T. A., Woodward, D. J. (1995). Crustal reflections from the Alpine Fault zone, South Island, New Zealand. New Zealand Journal of Geology and Geophysics. 38. $601-604$.

DeMets, C., Gordan, R. G., Angus, D. F., Stein, S. (1994). Effect of recent revisions to the geomagnetic reversal time scale on estimates of current plate motions. Geophysical Research Letters. 21. 2191 - 2194.

Dennis, A. \& Secor, D. T. (1987). A model for the development of crenulations in shear zones with applications from the Southern Appalachian Piedmont. Journal of Structural Geology. 9. 809 - 817.

Efron, B., \& Tibshirani, R. J. (1994). An Introduction to the Bootstrap. Boca Raton, FL: CRC Press.

Fay, C., Bell, T. H., Hobbs, B. E. (2008). Porphyroblast rotation verses nonrotation: Conflict resolution! Geology. 36. $307-310$.

Fossen, H., \& Tikoff, B. (1993). The deformation matrix for simultaneous simple shearing, pure shearing and volume change, and its application to transpression-transtension tectonics. Journal of Structural Geology. 15. 413 422.

Ghosh, S. K. (1987). Measure of non-coaxiality. Journal of Structural Geology. 9. $111-113$.

Ghosh, S. K., Ramberg, H., (1976). Reorientation of inclusions by combination of pure and simple shear. Tectonophysics. 34. 1 - 70 .

Goscombe, B. D., Passchier, C. W. (2003). Asymmetric boudins as shear sense indicators - an assessment from field data. Journal of Structural Geology. 25. $575-589$.

Grapes, R. H. (1995). Uplift and exhumation of the Southern Alps, New Zealand. Journal of Metamorphic Geology. 10. 171 - 180. 
Gray, N. H., \& Busa, M. D. (1994). The three-dimensional geometry of simulated porphyroblast inclusion trails: inert marker, viscous flow models. Journal of Metamorphic Geology. 12. 575 - 587.

Hafner, M., Passchier, C. W. (2000). Development of S-C' type cleavage in paraffin wax using a circular shear rig. Journal of Virtual Explorer. 2. 16 - 17.

Harland, W. B. (1971). Tectonic transpression in Caledonian Spitzbergen. Geological Magazine. 108. 27 - 42.

Heibronner, R., \& Tullis, J. (2006). Evolution of c axis pole figures and grain size during dynamic recrystallization: Results from experimentally sheared quartzite. Journal of Geophysical Research. 111. B10202

Hill, R. (1950). The mathematical theory of plasticity. Oxford University Press, Oxford.

Holcombe, R. J. (1999). Geoclculator, GEOrient. Programs to plot and calculate planar and linear attitudes.

Holcombe, R. J. (2001). Ghoshflow. Rotation of rigid passive objects in plane strain general shear.

Holcombe, R. J., \& Little, T. A., (2001). A sensitive vorticity gauge using rotated porphyroblasts, and its application to rocks adjacent to the Alpine Fault, New Zealand. Journal of Structural Geology. 23. 979 - 989.

Holyoke, C. W., \& Tullis, J. (2006) Formation and maintenance of shear zones. Geology. 34. $105-108$.

Holyoke, C. W., Tullis, J. (2006). Mechanisms of weak phase interconnection and the effects of phase strength contrast on fabric development. Journal of Structural Geology. 28. $621-640$.

Jeffery, G. B. (1922). The motion of ellipsoidal particles immersed in a viscous fluid. Royal Society of London Proceedings. 102. 161 - 179.

Ji, S., Jiang, Z., Rybacki, E., Wirth, R., Prior, D., Xia, B. (2004). Strain softening and microstructural evolution of anorthite aggregates and quartz-anorthite 
layered composites deformed in torsion. Earth and Planetary Science Letters. $222.377-390$.

Jiang, D. (1999). Vorticity decomposition and its application to sectional flow characterization. Tectonophysics. 301. $243-259$.

Jiang, D., \& White, J. C. (1995). Kinematics of rock flow and the interpretation of geological structures, with particular reference to shear zones. Journal of Structural Geology. 17. 1249 - 1265.

Jiang, D., \& Williams, P. F. (1998). High strain zones: a unified model. Journal of Structural Geology. 20. 1105 - 1120.

Jiang, D., Lin, S., Williams, P. F. (2001). Deformation path in high-strain zones, with reference to slip partitioning in transpressional plate-boundary regions. Journal of Structural Geology. 23. 991 - 1005.

Jiang, D., \& Williams, P. F. (2004). Reference frame, angular momentum, and porphyroblast rotation, Journal of Structural Geology. 26. 2211 - 2224.

Johnson, S.E. (1999). Porphyroblast microstructures: A review of current trends. American Mineralogist. 84. 1711 - 1726.

Johnson, S. E. (2009). Porphyroblast rotation and strain localization: Debate settled! Geology. 37. $636-666$.

Kleffman, S., Davey, F., Melhuish, A., Stern, T., Team, S. (1998). Crustal structure in the central South Island, New Zealand, from the Lake Pukaki seismic experiment. New Zealand Journal of Geology and Geophysics. 41.39 -49 .

Koons, P. O. Norris, R. J. Craw, D. Cooper, A. F. (2003). Influence of exhumation on the structural evolution of transperssional plate boundaries: an example from Southern Alps, New Zealand. Geology. 31. 3 - 6.

Kurz, G. A., \& Northrup, C. J. (2008). Structural analysis of mylonitic rocks in the Cougar Creek Complex, Oregon-Idaho using the porphyroclast hyperbolic distribution method, and potential use of $\mathrm{SC}^{\prime}$-type extensional shear bands as 
quantitative vorticity indicators. Journal of Structural Geology. 30. 1005 1012.

Lin, S., Jiang, D., Williams, P. F. (1998). Transpression (or transtension) zones of triclinic symmetry: natural examples of theoretical modeling. In R. E. Holdsworth, R. A. Strachan, and J. F. Dewey (Eds), Continental Transpressional and Transtensional Tectonics. Vol 135 of Special Publications. 41 - 57. London: Geological Society.

Lister, G. S., \& Williams, P. F. (1983). The partitioning of deformation in flowing rock masses. Tectonophysics. $92.1125-1137$.

Little, T., Holcombe, R., \& Ilg, B. (2002a). Ductile fabrics in the zone of active oblique convergence near the Alpine Fault, New Zealand: Identifying neotectonic overprint. Journal of Structural Geology. 24. 193-217.

Little, T. (2004). Transpressive ductile flow and oblique ramping of lower crust in a two-sided orogen: insight from quartz grain-shape fabrics near the Alpine Fault, New Zealand. Tectonics. 23. TC2013.

Little, T., Cox, S., Vry, J., \& Batt, G. (2005). Variations in exhumation level and uplift rate along the oblique-slip Alpine Fault, central Southern Alps, New Zealand. Geological Society of America Bulletin. 117. 193-217.

Marques, F. O., \& Coelho, S. (2003). 2-D shape preferred orientations of rigid particles in transtensional viscous flow. Journal of Structural Geology. 25.841 -854 .

Masuda, T., Michibayashi, K., Ohta, H. (1995). Shape preferred orientation of rigid particles in a viscous matrix: re-evaluation to determine kinematic parameters of ductile deformation. Journal of Structural Geology. 17. $115-$ 129.

Means, W. D. (1989). Stretching Faults. Geology. 17. 893 - 896.

Means, W. D., Hobbs, B. E., Lister, G. S., Williams, P. F. (1980). Vorticity and non-coaxiality in progressive deformations. Journal of Structural Geology. 2. $371-378$. 
Mezger, J. E. (2010). Rotation of irregular staurolite porphyroblasts in a simple shear dominated shear zone controlled by initial growth orientation and aspect ratio. Journal of Structural Geology. 32. 1147 - 1157.

Mortimer, N., (2000). Metamorphic discontinuities in orogenic belts: example of garnet-biotite-albite zone in the Otago Schist, New Zealand. International Journal of Earth Sciences. 89(2) 295 - 306.

Murphy, D. B. (2010). Metamorphism and the P-T history of Alpine Schist from the Newton Range, Southern Alps, New Zealand. M. Sc. thesis, Victoria University of Wellington.

New Zealand Geological Survey, (1972). Geological map of New Zealand 1:1,000,000, South Island ( $1^{\text {st }}$ Edn $)$, DSIR, Wellington.

Norris, R. J., \& Cooper, A. F. (1995). Origin of small-scale segmentation and transpressional thrusting along the Alpine Fault, New Zealand. Geological Society of Amearica Bulletin. 107. 231 - 240.

Norris, R. J., \& Cooper, A. F. (2000). Late Quaternary Slip rates and slip partitioning on the Alpine Fault. Journal of Structural Geology. 23. 507-520.

Norris, R. J., \& Cooper, A. F. (2003). Very high strains recorde in mylonites along the Alpine Fault, New Zealand: Implication for the deep structure of plate boundary faults. Journal of Structural Geology. 25. 2141-2158.

Norris, R. J., \& Cooper, A. F. (2007). The Alpine Fault, New Zealand: surface geology and field relationships. In D. Okaya, A continental Plate Boundary: Tectonics at south Island, New Zealand (p. 157-175). American Geophysical Union.

Olesen, N. O. (1982). Heterogeneous strain of a phyllite as reveled by porphyroblast matrix relationships. Journal of Structural Geology. 4. 971 984.

Passchier, C. W. (1991). Geometric constraints on the development of shear bands in rocks. Geol Mijnb, 70, 203-211. 
Passchier, C. W. (1997). The fabric attractor. Journal of Structural Geology. 19. $113-127$

Passchier, C. W. (1998). Monoclinic model shear zones. Journal of Structural Geology. 20. $1121-1137$.

Passchier, C. W., Trouw, R. A., Zwart, H. J., Vissers, R. L. M. (1992) Porphyroblast rotation: eppur si muove? Journal of Metamorphic Geology. 10. $283-294$.

Passchier, C. W., \& Trouw, R. (2005). Microtectonics (Vol. 2). Berlin, Germany: Springer.

Platt, J., \& Vissers, R. (1980). Extensional structures in anisotropic rocks. Journal of Structural Geology, 2, 397-410.

Platt, J. (1984). Secondary cleavages in ductile shear zones. Journal of Structural Geology. 6. 439-442.

Price, N. J. \& Cosgrove, J. W. (1990). Analysis of Geological Structures, Cambridge University Press, Cambridge, UK, 502pp.

Ramsay, J. G. (1962). The geometry and mechanics of formation of "similar" type folds. Journal of Geology. 70. $309-327$.

Ramsay, J. G. (1976). Displacement and strain. Philosophical Transactions of the Royal Society of London, Series A, mathematical and Physical Sciences. 283. 3 -25 .

Ramsay, J. G. (1980). Shear zone geometry: a review. Journal of Structural Geology. 2. $83-101$.

Ramsay, J. G., \& Huber, M. L. (1983). The Techniques of Modern Structural Geology. Volume 1: Strain Analysis. Academic Press, London.

Ramsay, J. G., \& Lisle, R. J. (2000). The Techniques of Modern Structural Geology, Volume 3: Applications of Continuum Mechanics in Structural Geology. New York: Academic Press. 
Rast, N. (1956). The origin and significance of boudinage. Geological Magazine. $93.341-363$.

Reed, J. J. (1964). Mylonites, cataclasites, and associated rocks along the Alpine Fault, South Island, New Zealand. New Zealand Journal of Geology and Geophysics. 7. 645-684.

Sanderson, D. J., \& Marchini, R. D. (1984). Transpression. Journal of Structural Geology. 6. $449-549$.

Sibson, R. H., White, S. H., Atkinson, B. K. (1979). Fault rock distribution and structure within the Alpine Fault Zone: a preliminary account In: Walcott, R. I. Cresswell, M. M. (Eds.). The origin of the Southern Alps. Bulletin of the Royal Society of New Zealand. 18. 55-65

Sibson, R., White, S. H., Atkinson, B. K. (1981). Structure and disribution of fault rocks in the Alpine Fault Zone, New Zealand. Geological Society of London Special Publication. 9. 197-210.

Simpson, C. \& De Paor, D. G. (1993). Strain and kinematic analysis in general shear zones. Journal of Structural Geology. 15.1 - 20

Slack, J. F., Palmer, M. R., Stevens, B. P. J., Barnes, R. G. (1993). Origin and significance of tourmaline rich rocks in the Brocken Hills district, Australia. Economic Geology. 88. 505 - 541.

Sutherland, R., Davey, F., Beavan, J. (2000). Plate boundary deformation in South Island, New Zealand, is related to inherited lithospheric structure. Earth and Planetary Science Letters. 177. 141 - 151.

Tikoff, B., \& Greene, D. (1997). Stretching lineations in transpressional shear zones: an example from the Sierra Nevada Batholith, California. Journal of Structural Geology. 19. $29-41$.

Toy, V. G. (2007). Rheology of the Alpine Fault Mylonite Zone: deformation processes at and below the base of the seismogenic zone in a major plate boundary structure. PhD thesis, University of Otago. 
Toy, V., Prior, D., \& Norris, R. (2008). Quartz fabrics in the Alpine Fault mylonites: Infulence of pre-existing preferred orientations on fabric development during progressive uplift. Journal of Structural Geology, 30 (5), 602-621.

Toy, V. G., Norris, R. J., Prior, D. J., Walrond, M., Cooper, A. F. (2011). Relationship between kinematic indicators and strain during syn-deformation exhumation of an oblique transpressive plate boundary shear zone: the Alpine Fault, New Zealand. (in review).

Trouw, R. A. J., Tavares, F. M., Robyr, M. (2008). Rotated Garnets: a mechanism to explain the high frequency of inclusion trail curvature angles around $90^{\circ}$ and $180^{\circ}$. Journal of Structural Geology. 30. 1024 - 1033.

Uemura, T. (1965). Tectonic analysis of the boudin structure in the Muro group, Ku Peninsula, Southwest Japan. Journal of Earth Sciences. 13. 99 - 114.

Upton, P. (1995). Deformation induced reaction in the Alpine Fault mylonites, Southern Alps, New Zealand. Geological Society of Australia Abstracts, Clare Valley Conference. 40. p 164.

Varian, H. (2005). Bootstrap Tutorial. Mathematica Journal, 9, 768-775.

Vry, J. K., Baker, J., Mass, R., Little, T. A., Grapes, R., Dixon, M. (2004). Zoned (Cretaceous and Cenozoic) garnet and the timing of high grade metamorphism, Southern Alps, New Zealand. Journal of Metamorphic Geology. 22. 137 - 157.

Walcott, R. I. (1998). Models of oblique compression: Late Cenozoic tectonics of the South Island New Zealand. Reviews of Geophysics. 36. 1 - 26.

Weijermars, R. (1991). The role of stress in ductile deformation. Journal of Structural Geology. 13. 1061 - 1078.

Weijermars, R. (1998). Taylor-mill analogues for patterns of flow and deformation in rocks. Journal of Structural Geology. 20. 77 - 92.

White, S. (1979). Large strain deformation: report on a tectonic studies group discussion meeting held at Imperial College, London; introduction. Journal of Structural Geology. 1. 333-339. 
White, S., Burrows, S., Carreras, J., Shaw, N., \& Humphreys, F. (1980). On mylonites in ductile shear zones. Journal of Structural Geology. 2. 175-187.

Wightman, R., (2000). The fabrics and ductile microstructures in the Alpine Schist and mylonite zone near Fox Glacier, New Zealand. B.Sc. (Hon) thesis, Victoria University of Wellington.

Williams, P., \& Price, G. (1990). Origin of kink bands and shear band cleavages in shear zones: an experimential study. Journal of Structural Geology, 12, 145-164.

Williams, P. F., \& Jiang, D. (1999). Rotated Garnets. Journal of Metamorphic Geology. 17.

Xypolias, P. (2010) Vorticity analysis in shear zones: A review of methods and applications. Journal of Structural Geology. 32. 2072 - 2092.

Zheng, Y., Wang, T., Ma, M., Davis, G. A. (2004). Maximum effective moment criterion and the origin of low angle normal faults. Journal of Structural Geology. 26. $271-285$.

Zheng, Y., Wang, T., Zhang, J. (2009). Comment on "Structural analysis of mylonitic rocks in the Cougar Creek Complex, Oregon-Idaho using the porphyroclast hyperbolic distribution method, and potential use of SC'-type extensional shear bands as quantitative vorticity indicators". Journal of Structural Geology. 31. 541 - 543. 


\section{APPENDICES.}

Appendix A: Structural field data

Orientations of lineations, foliations, shear planes, and other structural data collected in Tatare Stream and Gaunt Creek. It also lists sample information. For nomenclature used see Southern Alps database readme.

Appendix B: Extensional (C') shear band data

Transect-derived data on the spacing of and offsets on extensional C' shears in macroscopic (outcrop) and microscopic (thinsection) scale. For shear band orientation code (SBOC) and figures refer to attached $\mathrm{CD}$ and readme file.

Appendix C: Garnet porphyroblast data

Tabulated data on inclusion trail attitudes. Appendix C contains a garnet classification chart, which is used for distinguishing between different inclusion trail geometries. Appendix $\mathrm{C}$ tabulates Electron microprobe compositional analysis of garnets in the main mylonite zone.

Appendix D: Lineation orientation data

A transect of detailed lineation orientation data that was collected in the field in the transitional zone between the distal and main mylonite zones. Appendix D further contains stretch modelling figures of schist lineations using a Matlab ${ }^{\circledR}$ code.

Appendix E: Tatare Stream Maps

A3 plates of Tatare Stream sample locations, structural data, and a NW - SE cross section.

Appendix F: SBOC code CD

Back Cover

Contained is a Matlab ${ }^{\circledR}$ code used to determine best-fit $C^{\prime}$ attitudes and associated errors. Code requires an input file and outputs an excel file and figures. Also on the CD is a readme file for using the code. 
ถัँ

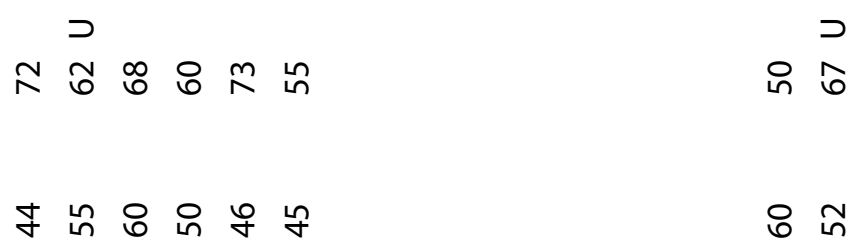

ถู้ ฝั้

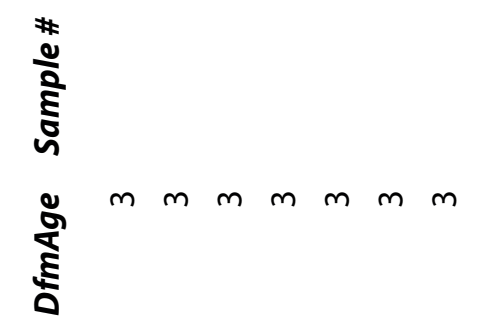

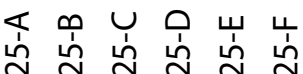 \\ 定}

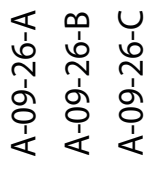

ฐั้

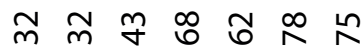

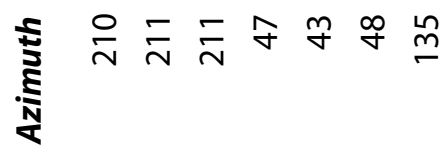

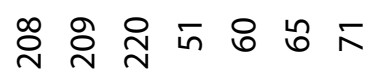

竎蒡

ָָ

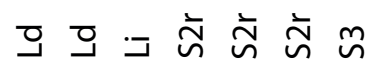

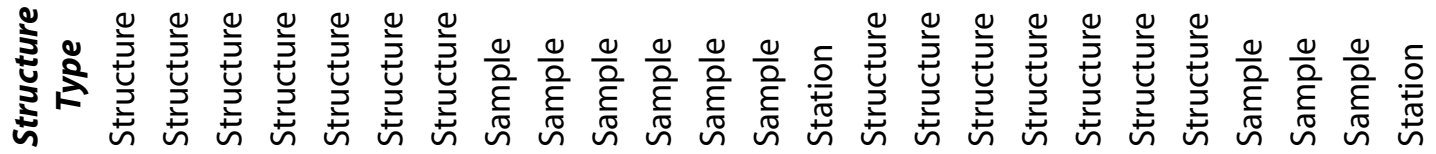

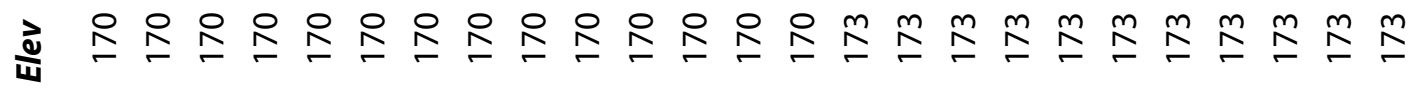

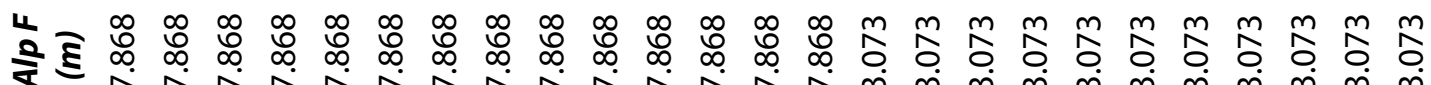

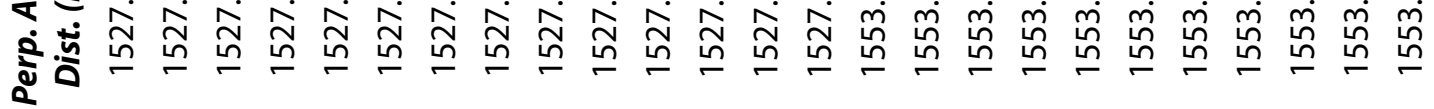

๕ $\tilde{\circ}$ ธี ท

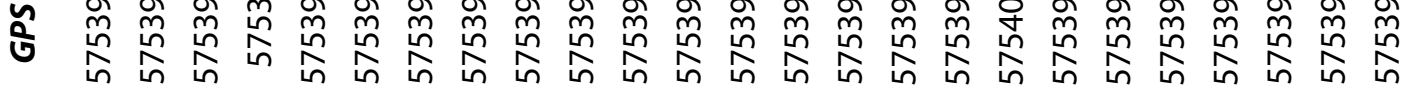

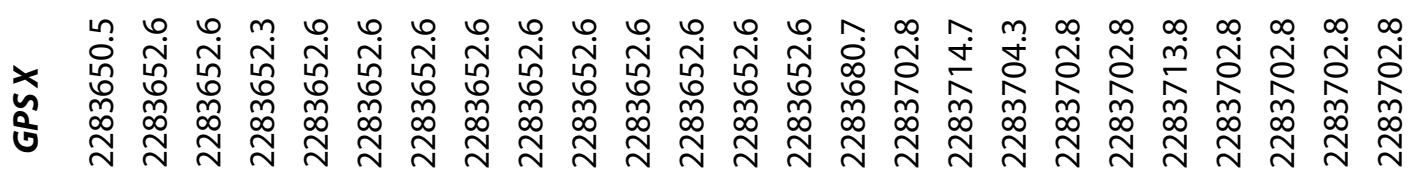

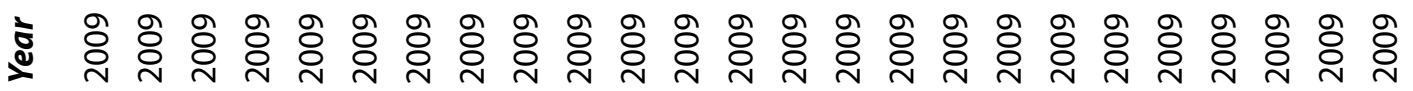

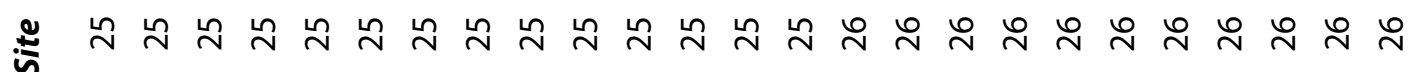

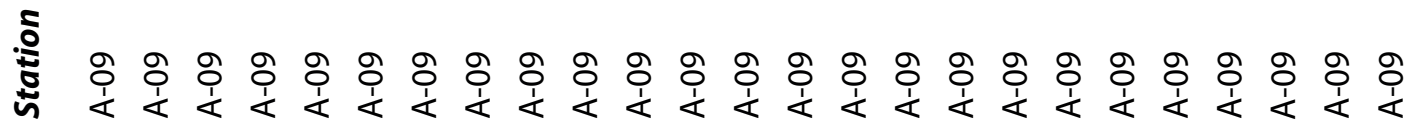

৩৷ 


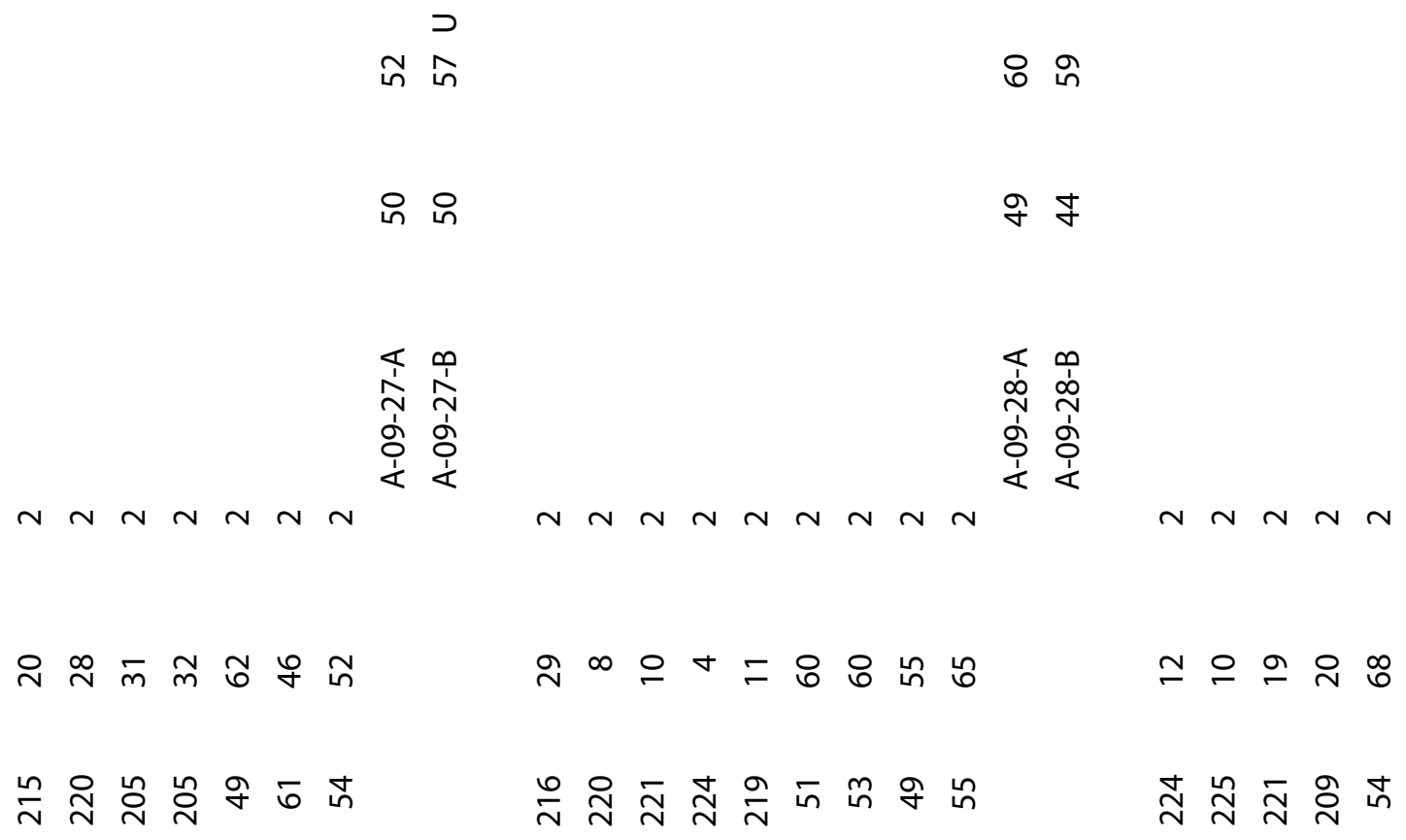

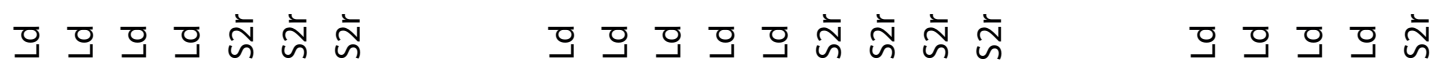

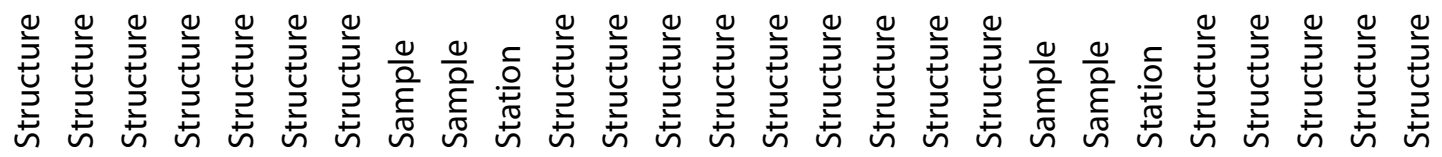

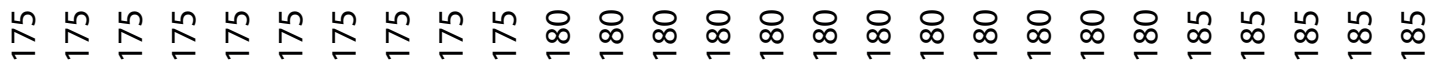

ర ర్లి

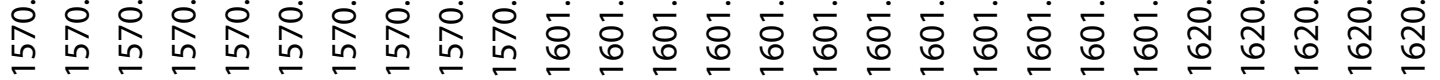

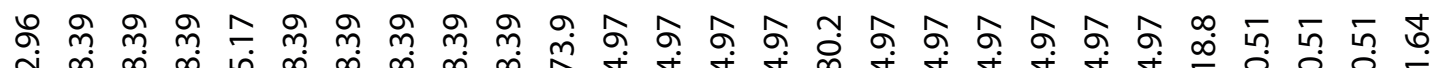

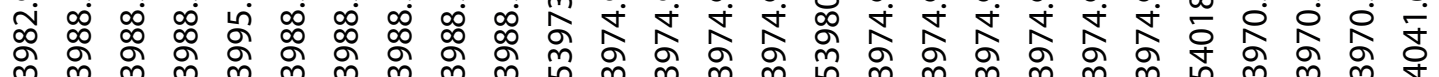

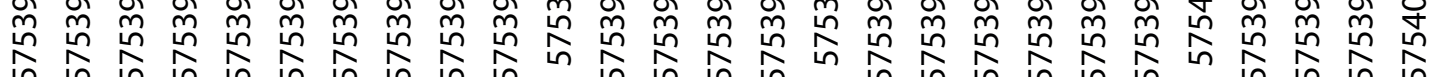

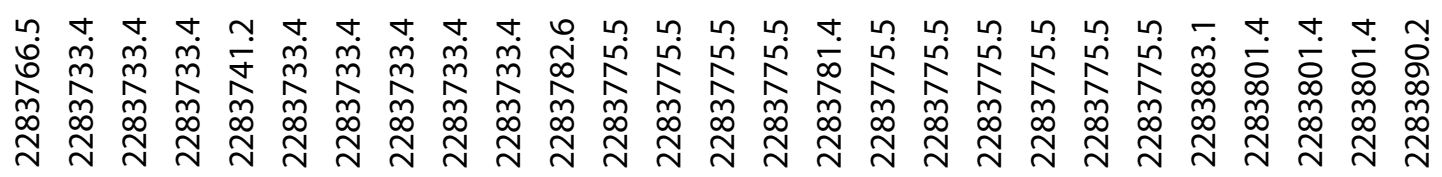

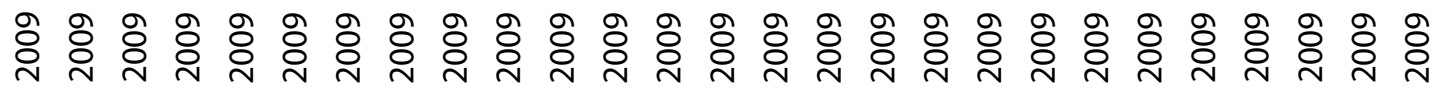

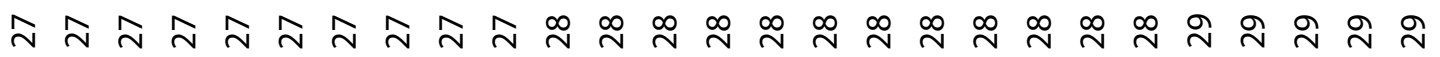

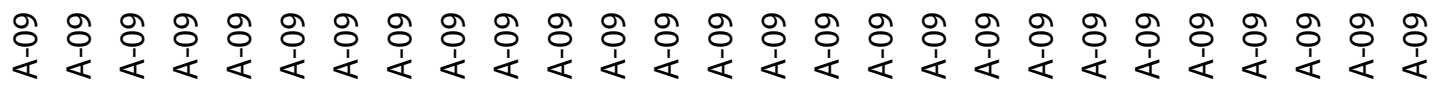
D 


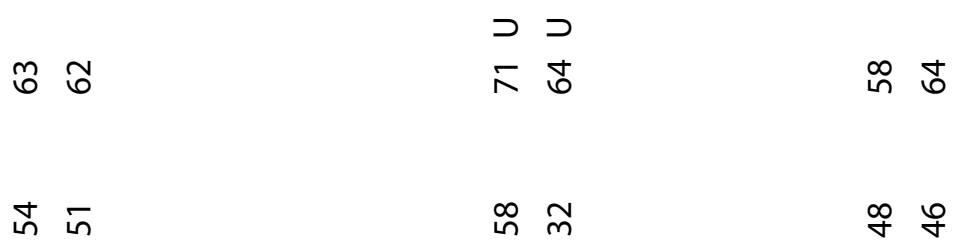

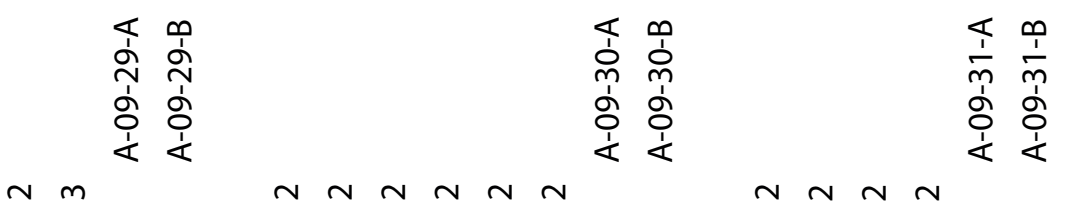

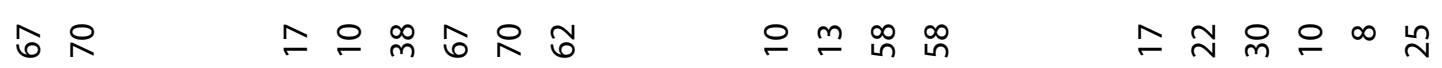

g)

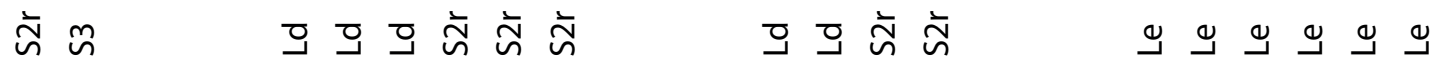

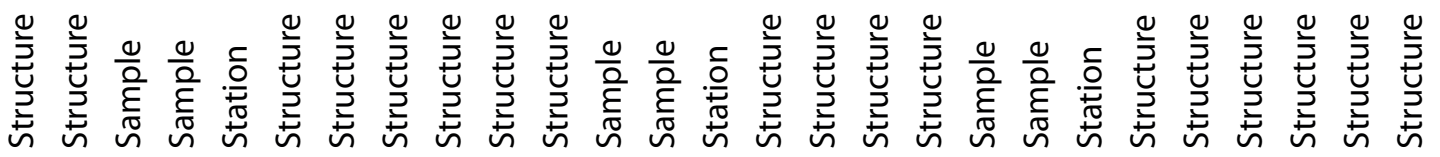

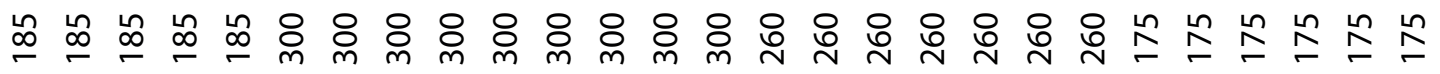

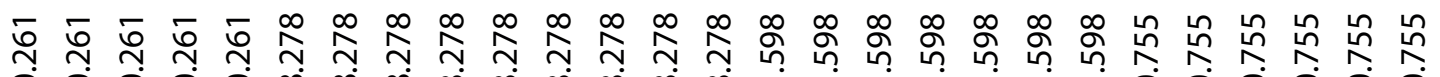

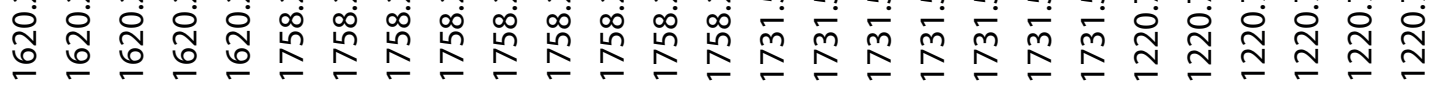

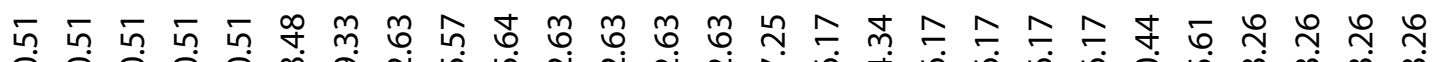

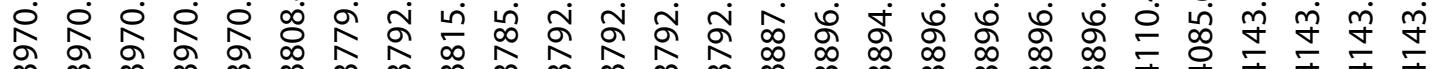

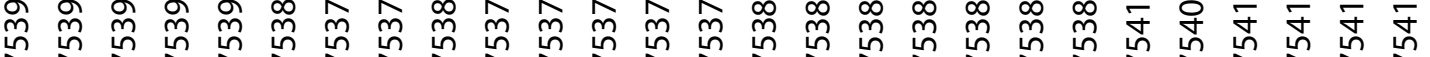

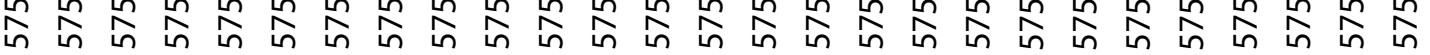

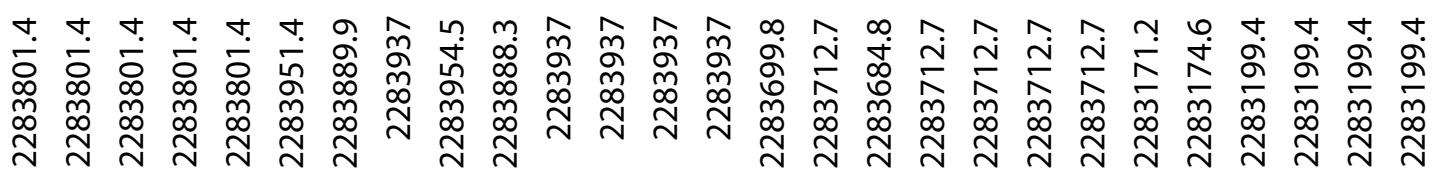

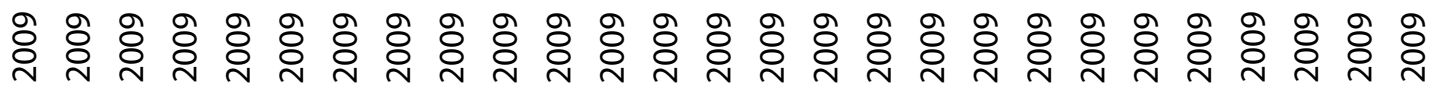

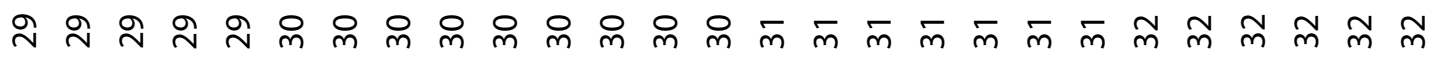

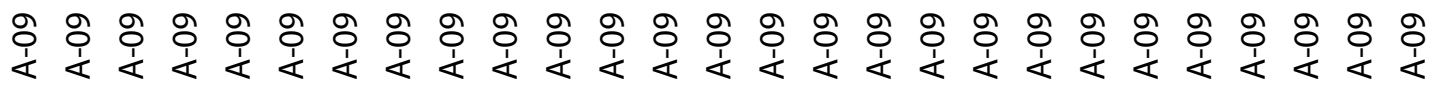
D 


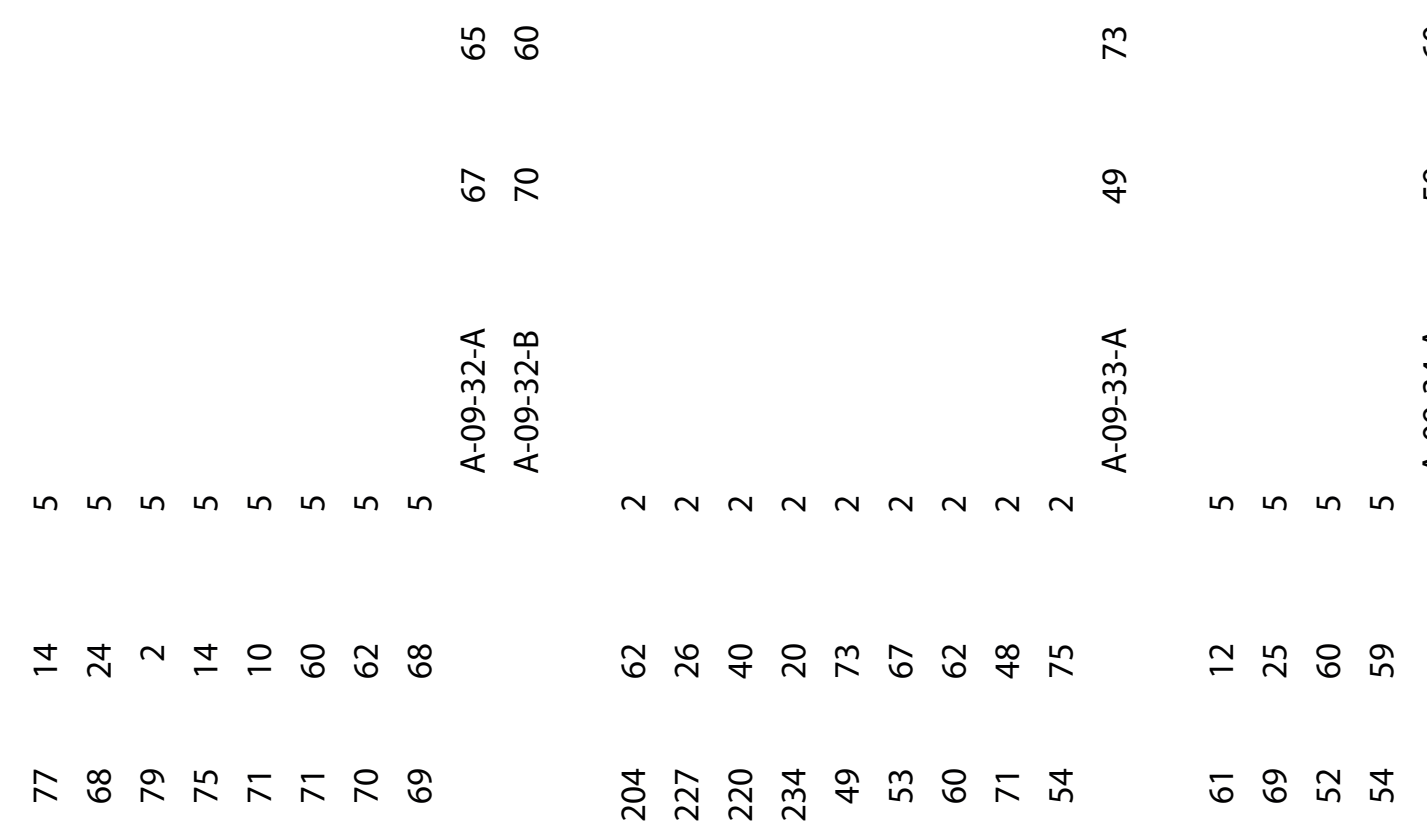

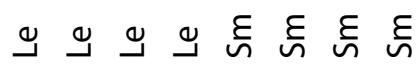

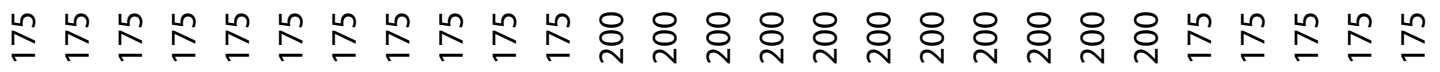

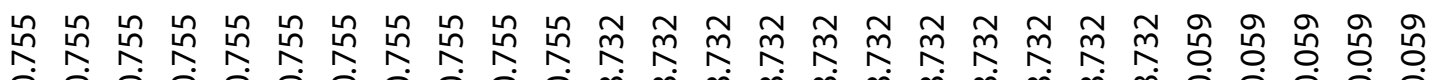

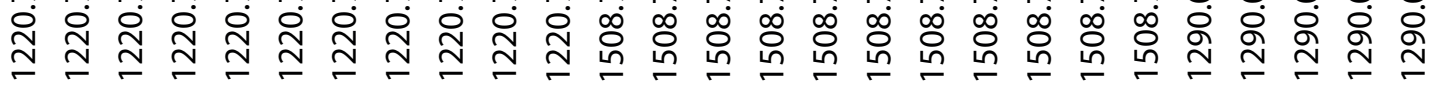

๗ூ

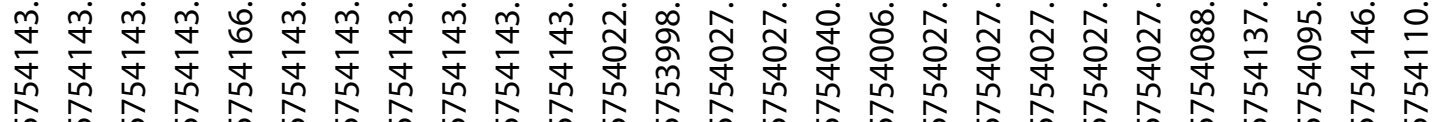

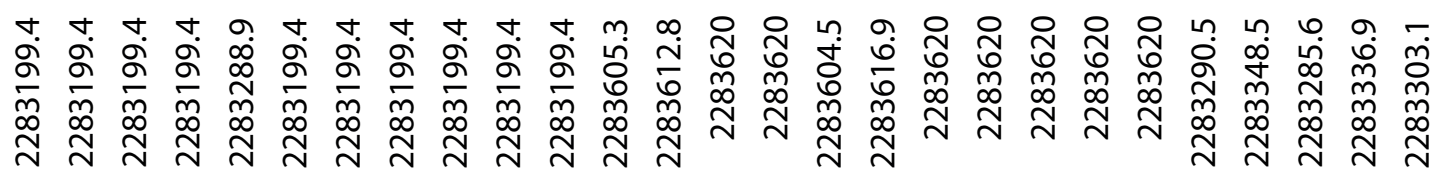

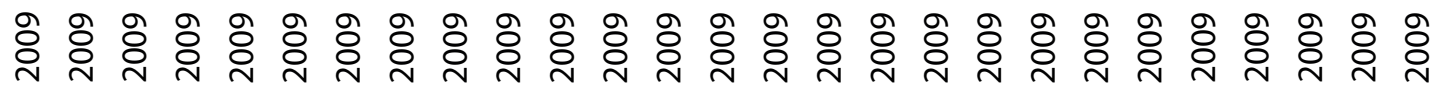
$\tilde{m} \tilde{m} \tilde{m} \tilde{m} \tilde{m} \tilde{m} \tilde{m} \tilde{m} \tilde{m} \tilde{m} \tilde{m} \tilde{m} \tilde{m} \tilde{m} \tilde{m} \tilde{m} \tilde{m} \tilde{m} \tilde{m} \tilde{m} \tilde{m} \tilde{m} \dot{m} \dot{m} \dot{m} \dot{m} \dot{m}$

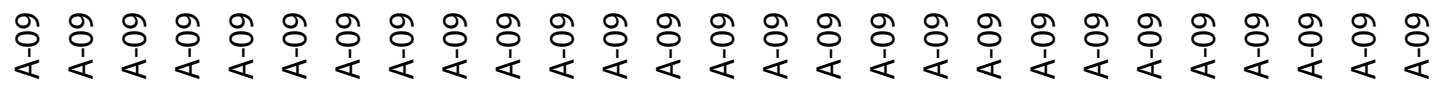
D 
8

ก

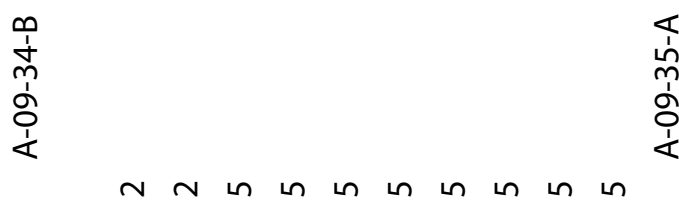

タะะ

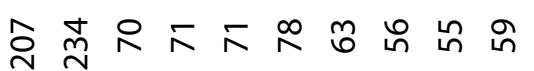

i̊

8

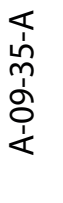

용 i

R

우웍

g

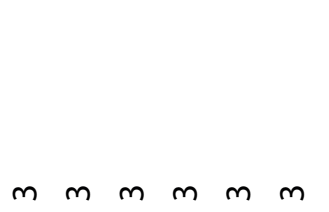

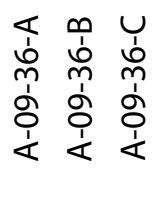

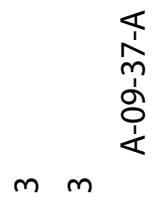

ป

$a ?$

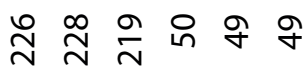

$\stackrel{m}{\sim}$ q

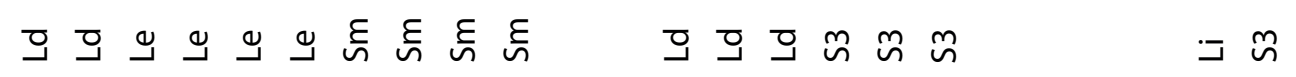

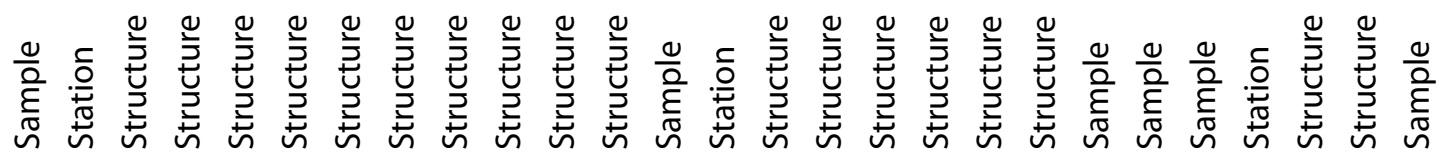

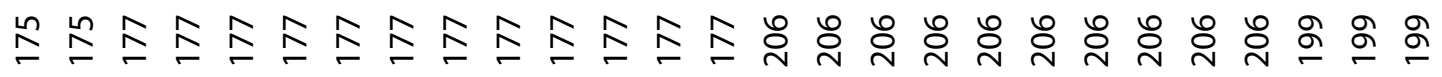

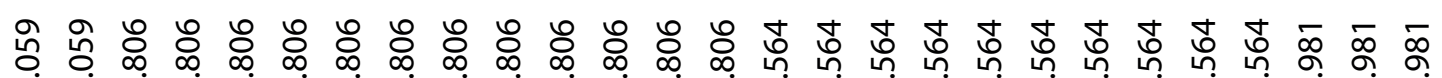

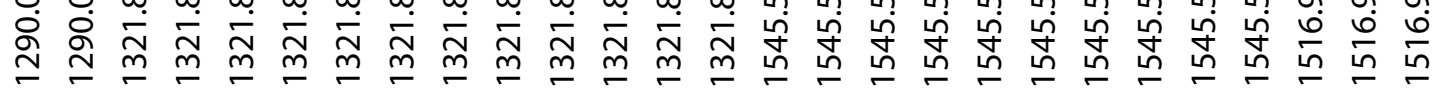

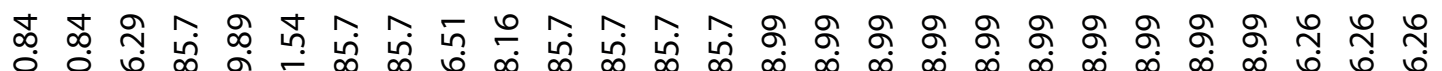

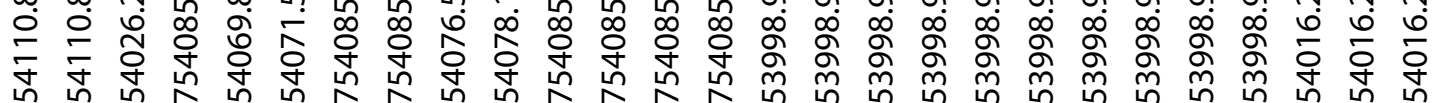

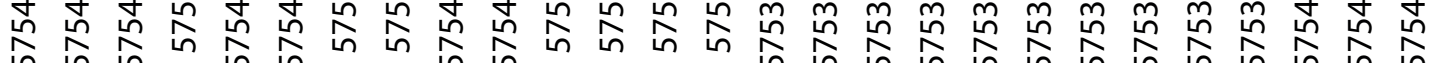

ॠ̄ं

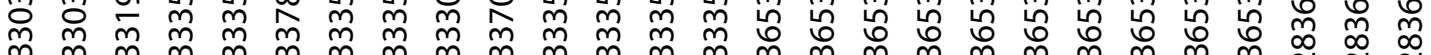

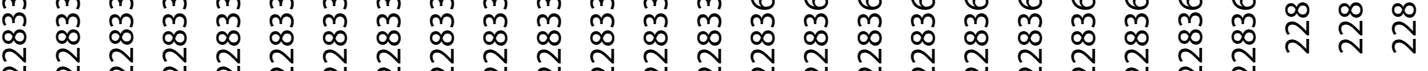
N N N N N N N N N N N N N N

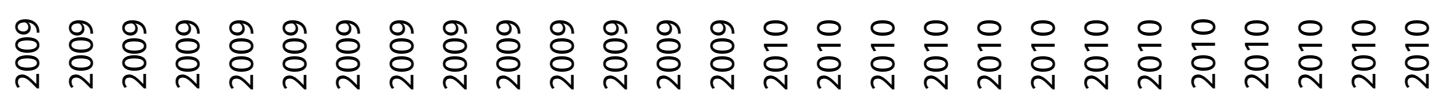

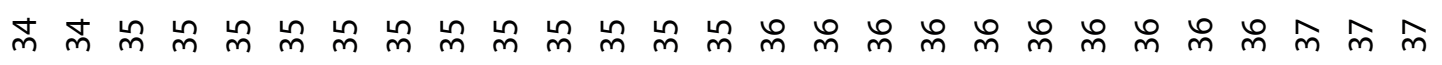

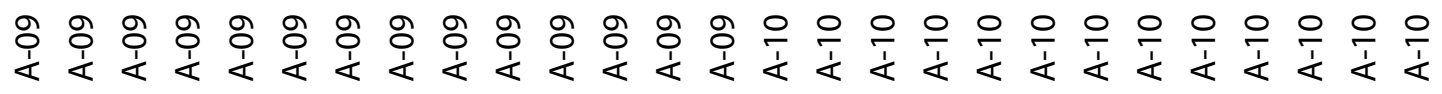
U 


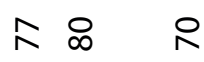

i̊ ก $\stackrel{\infty}{x}$

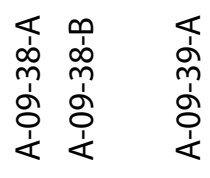

$m m m$

$\div \overline{8}$

సึ in

$$
\text { 交 }
$$

$m m m m m$

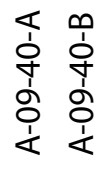

f i

ก

$\stackrel{\infty}{\circ} 6$

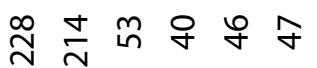

穴 in

สิ ถิ ถึ

$=n n$

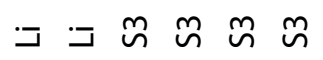

$=n$

$=n n$

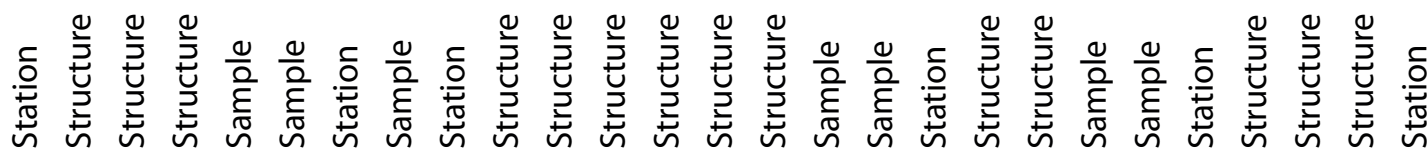

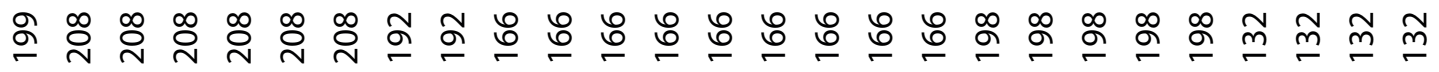

ळ

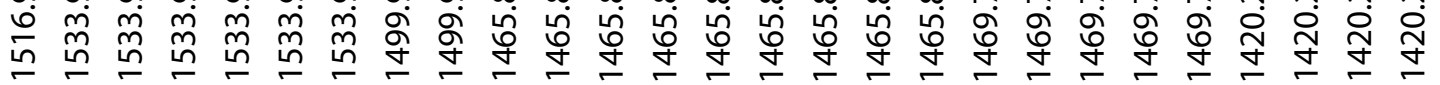

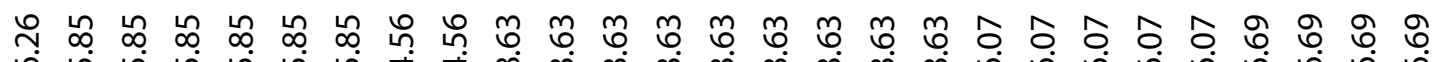

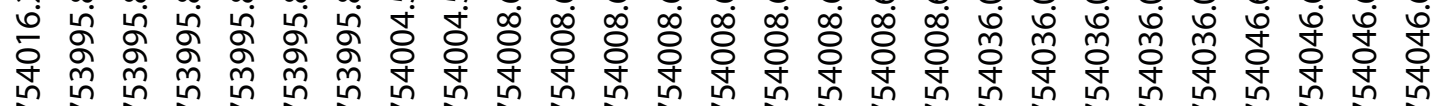

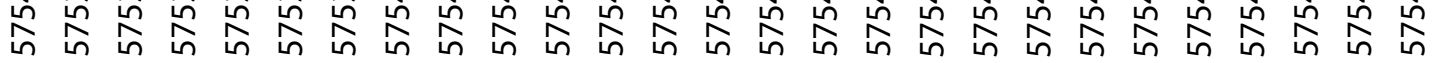

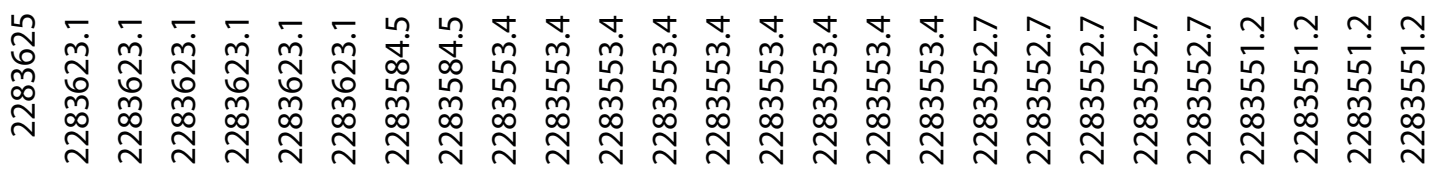

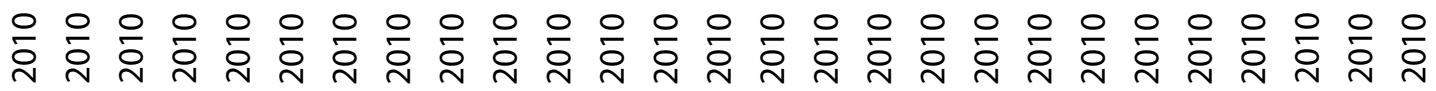

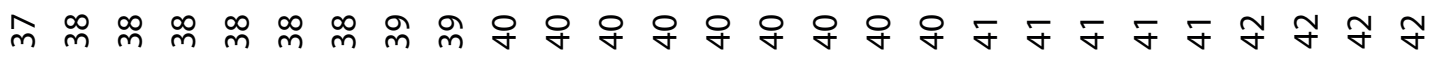

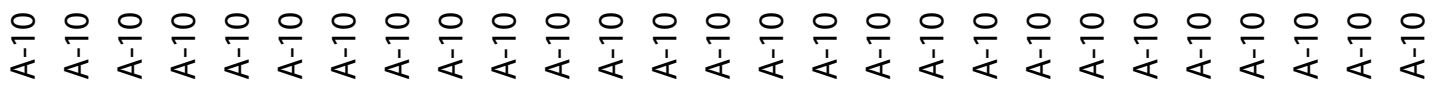
밍 


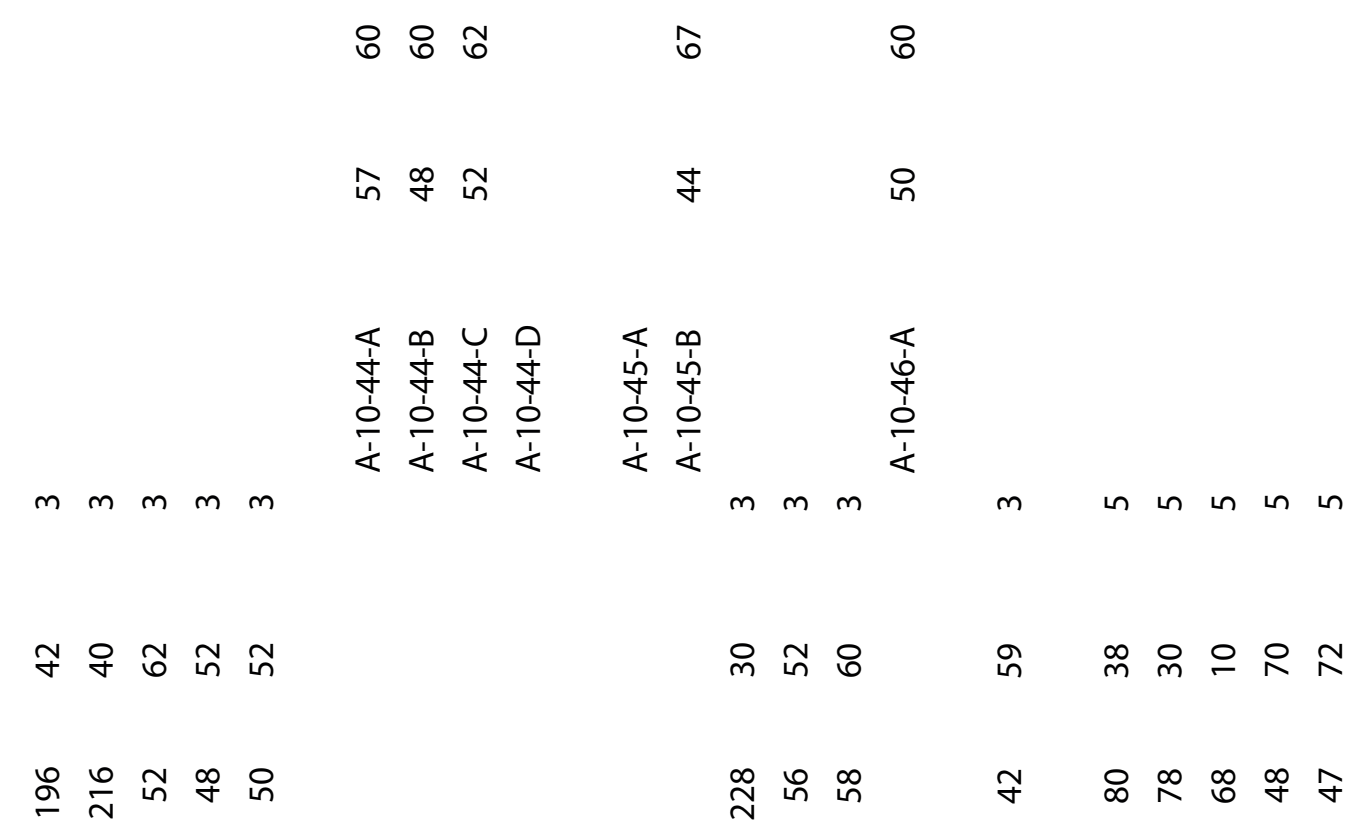

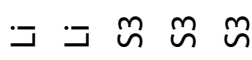

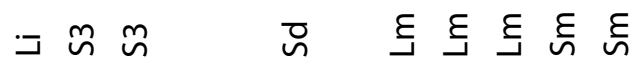

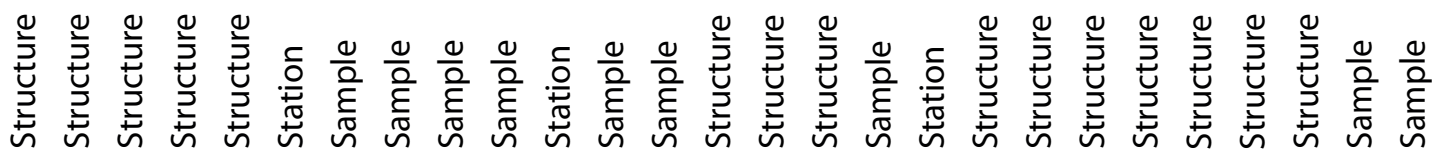

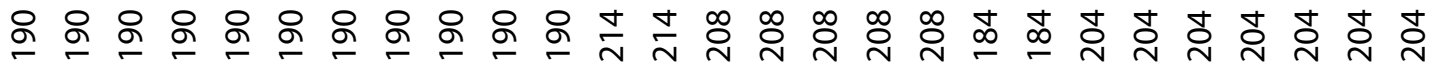

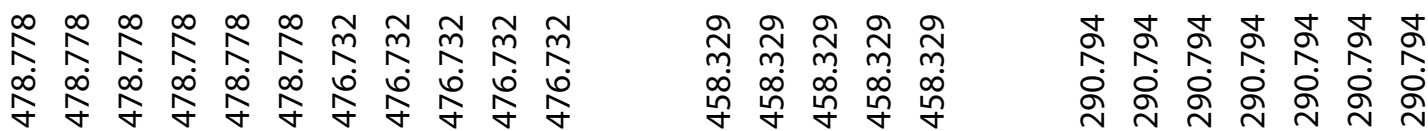

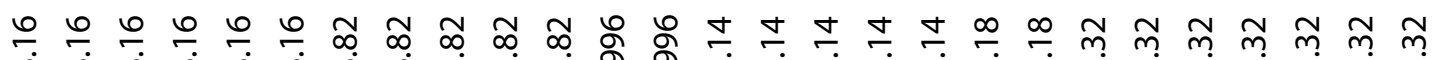

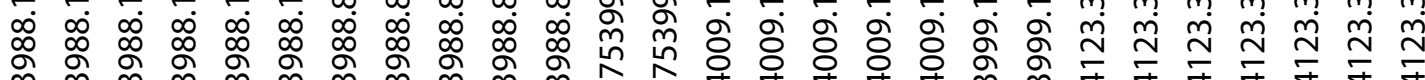

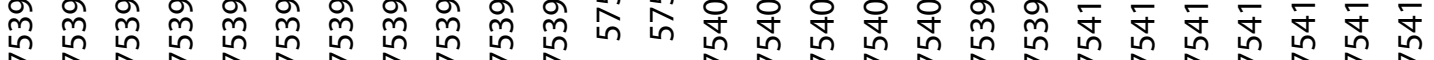

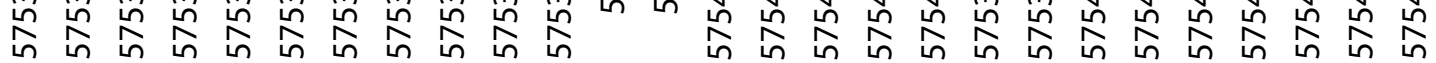

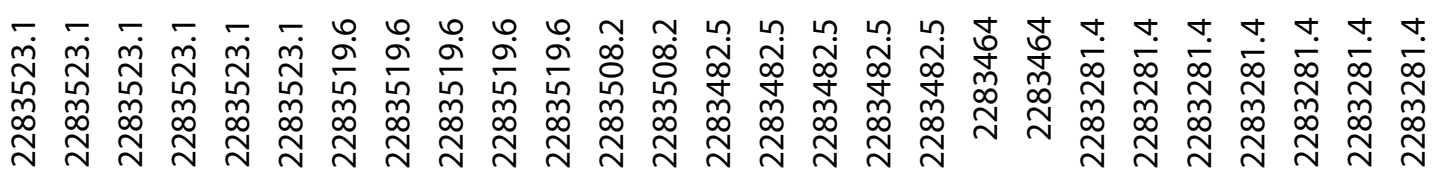

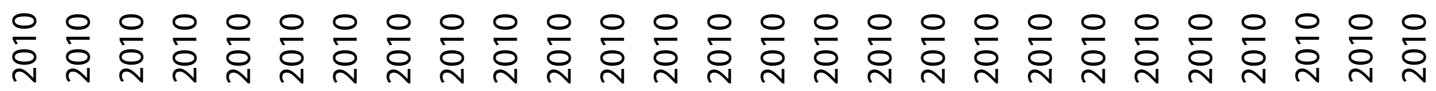

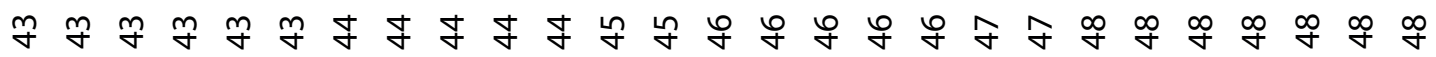

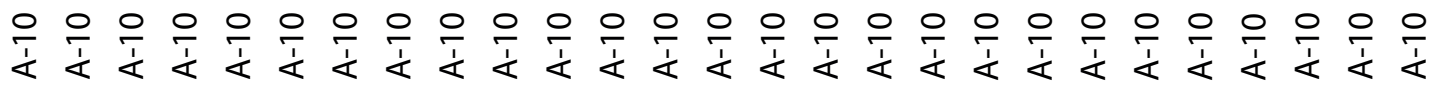
U খ 
冓

กิ กิ

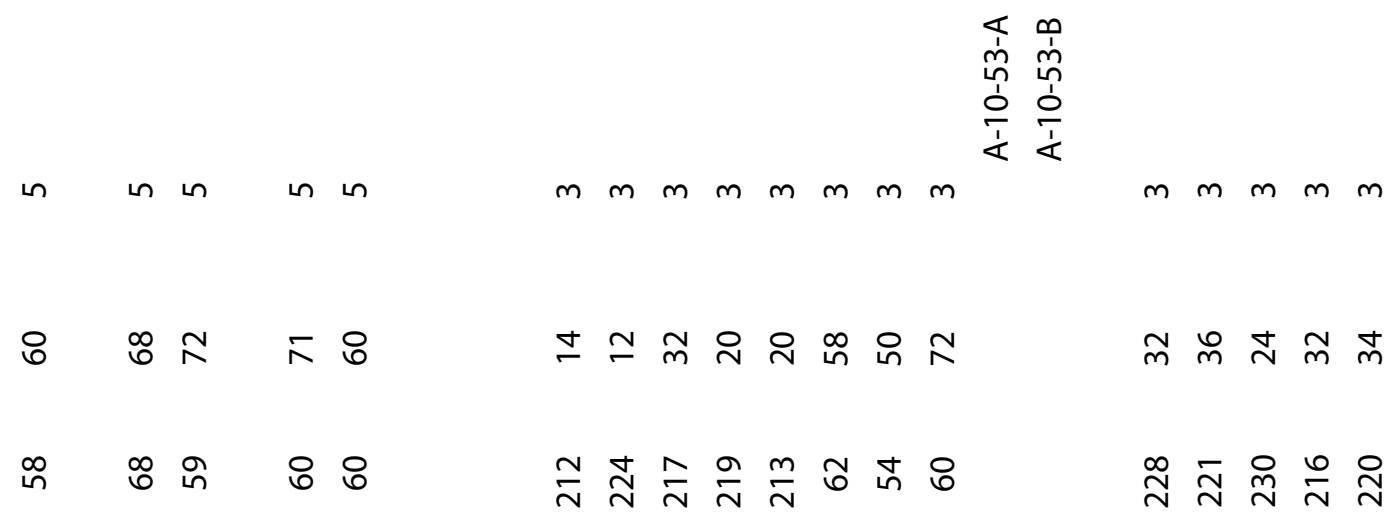

¿ ¿

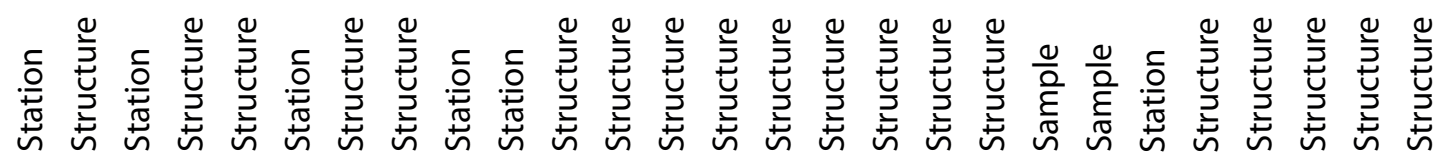

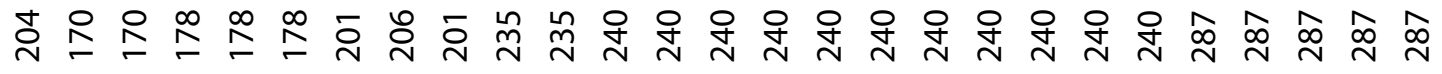

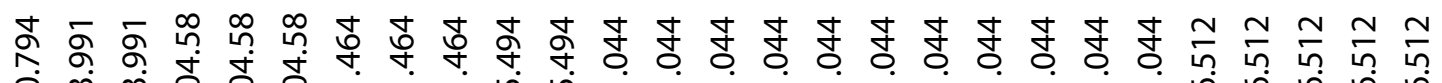

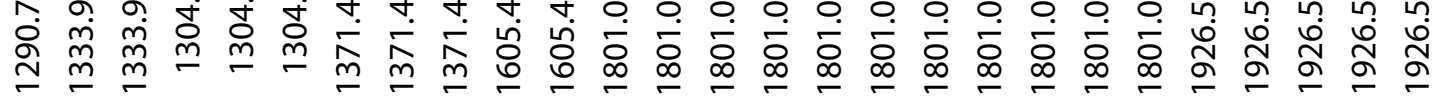
m

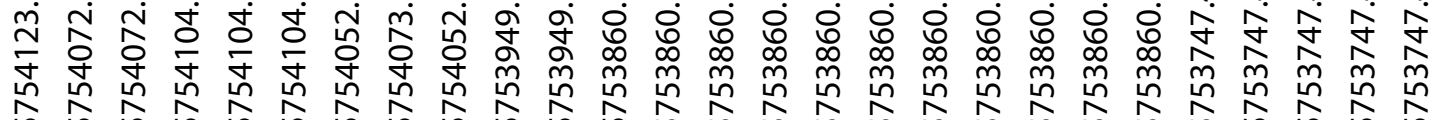

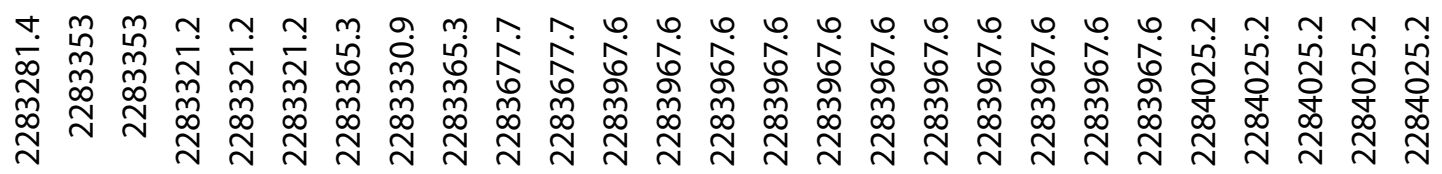

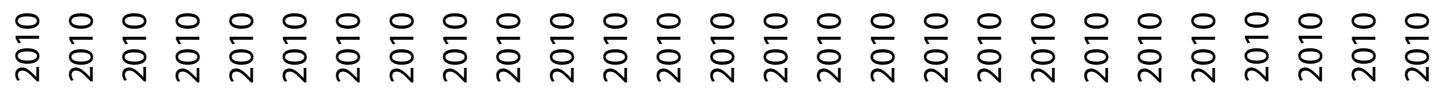

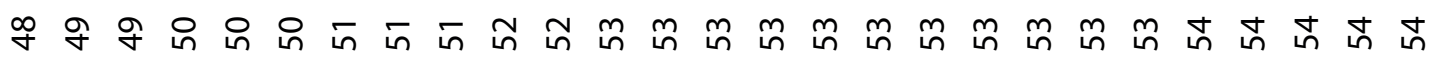

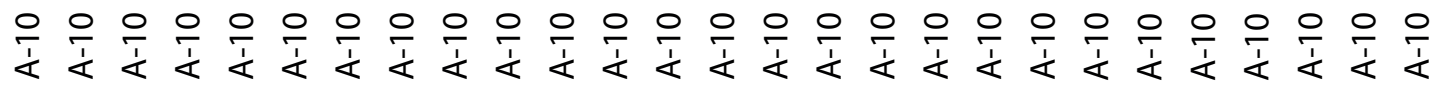

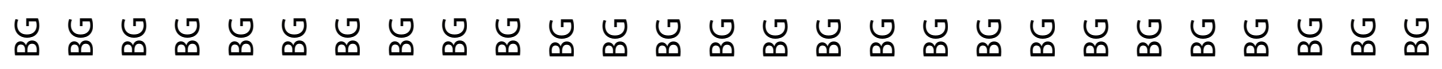


กี

ำ

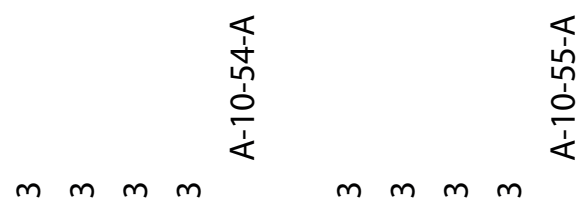

$\infty 8$ ก ก ก

요 $\stackrel{m}{\circ}$ ช

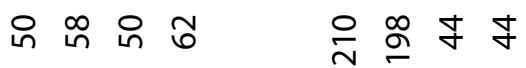

8

กิ 8

f

ㅇํ ₹

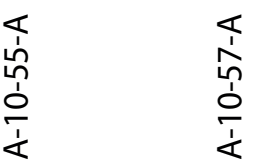

$\ln \underset{\sim}{ } \mathbb{\infty}$

กิ ถิ

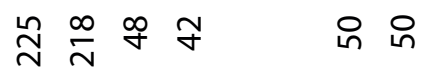

$n \tilde{n} \tilde{n} n$

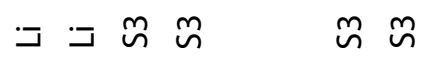

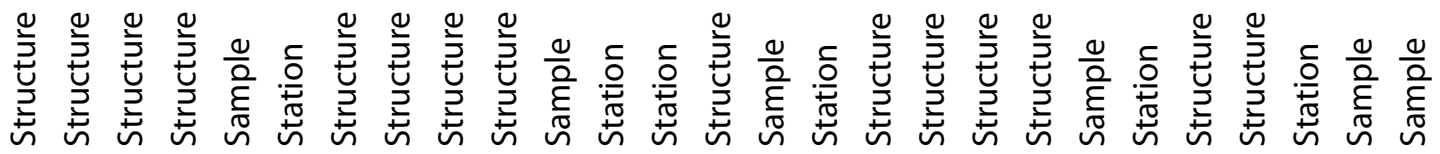
六

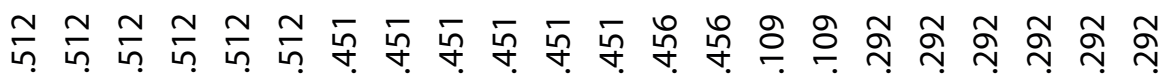

๙ิ

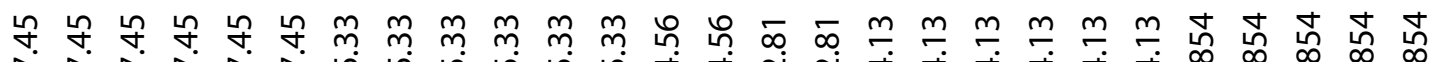

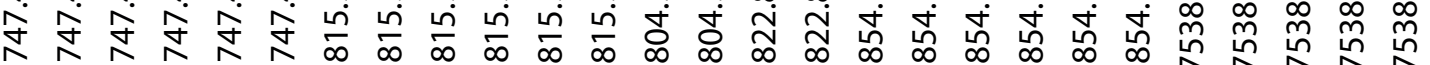

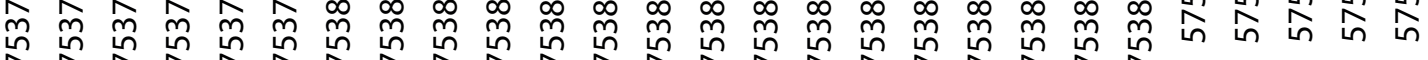

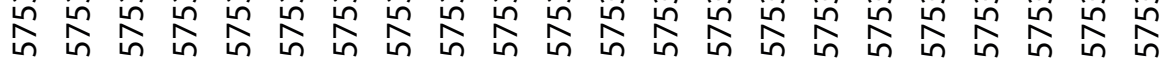

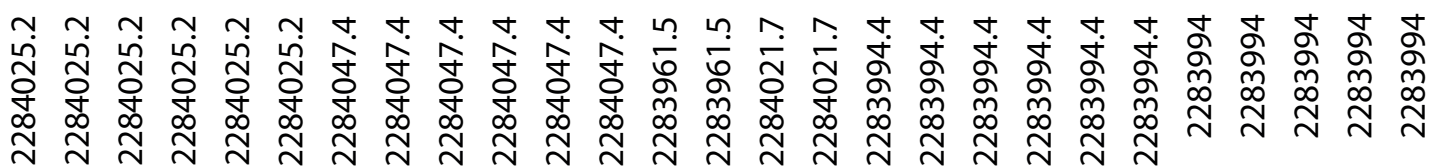

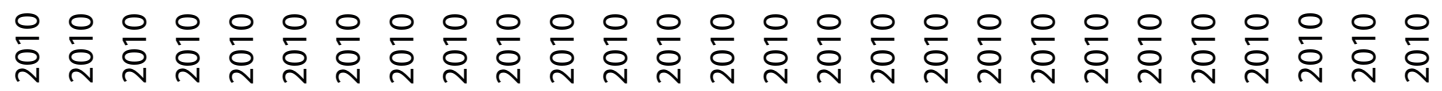

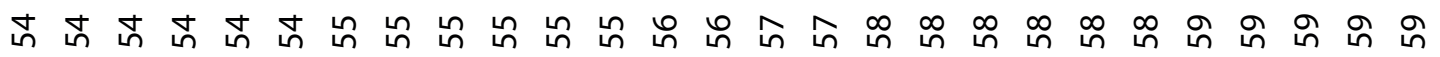

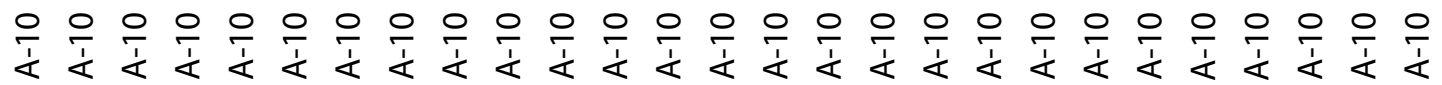
ড্ৰ 


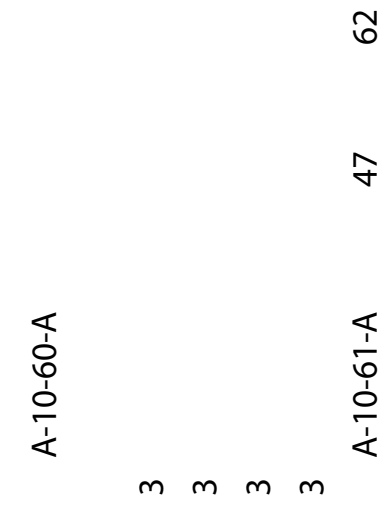

$\widetilde{\sigma}$

$\hat{子}$

$\frac{\frac{1}{1}}{\frac{1}{1}}$

$\therefore \wedge$

กิ

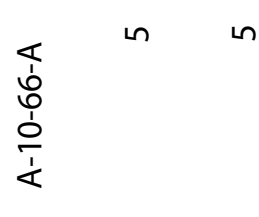

in in

m

$\stackrel{n}{\wedge}$

잉 운

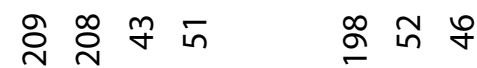

ㅇํㅇ

กิ

$\stackrel{\sim}{\infty}$

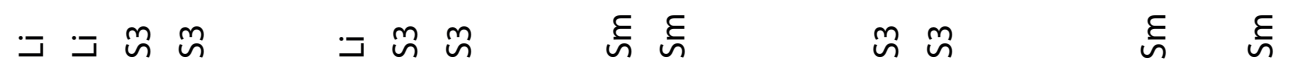

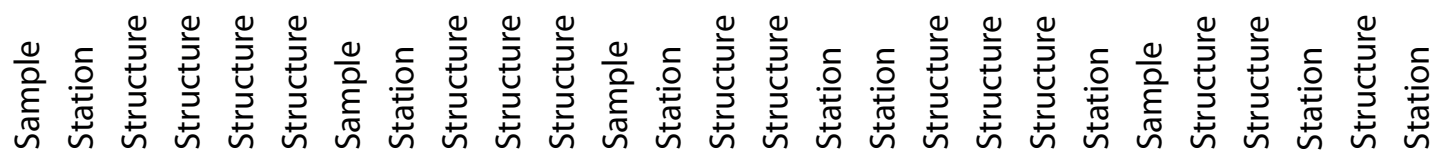

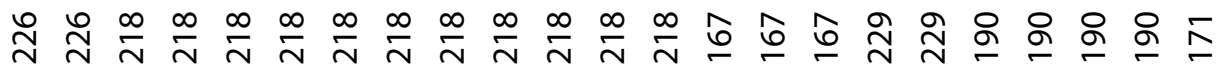

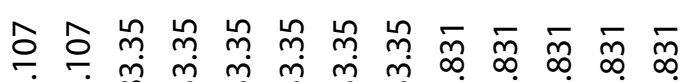

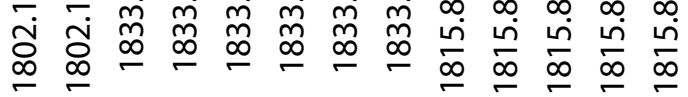

ơ ơำ

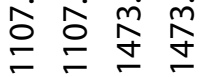

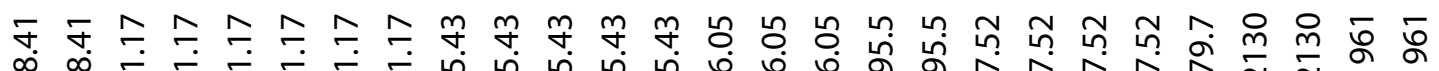

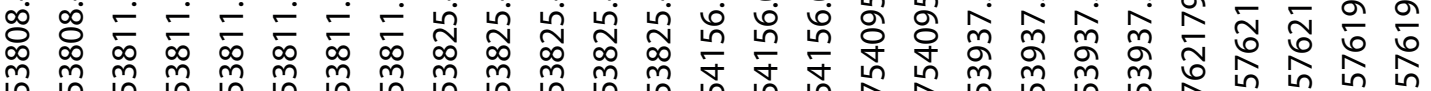

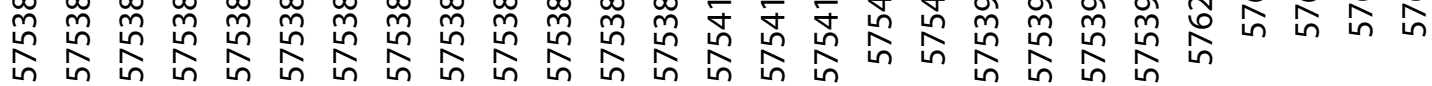

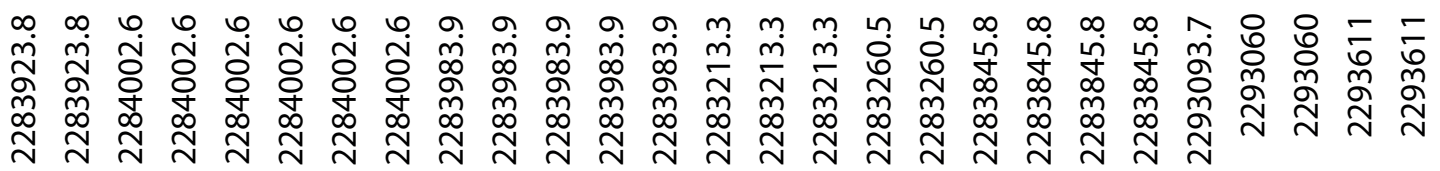

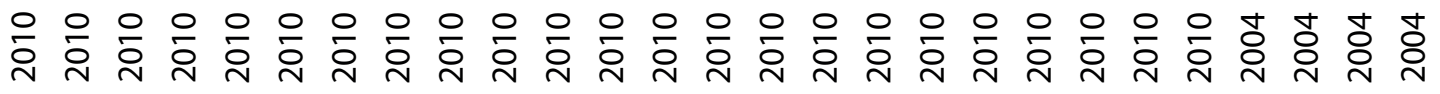

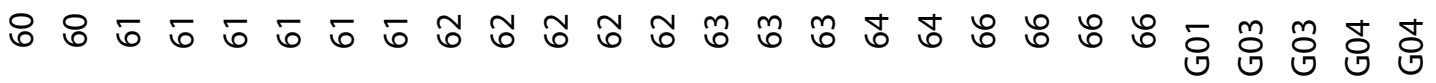

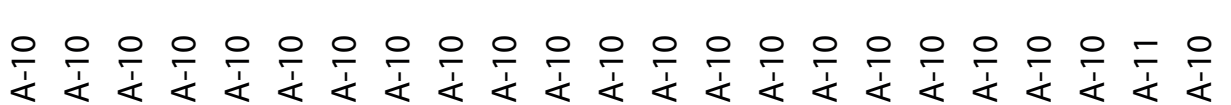
$\bar{\sim} \bar{\sim}$ O 
$\curvearrowright \circ \circ \div$

$\ddot{0}$ in in $\stackrel{\infty}{m}$

$\therefore \quad\left[\begin{array}{lll}n & \overline{0}\end{array}\right.$

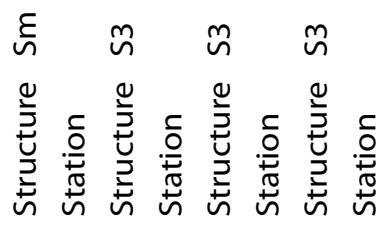

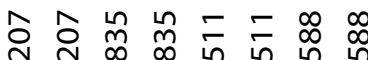

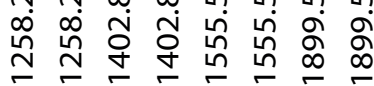

บ บัน

ஸे तิ

in in in in in

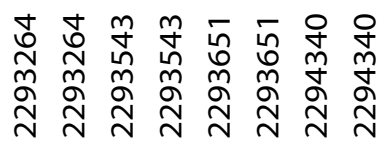

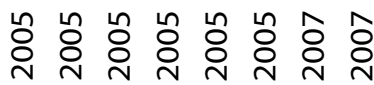

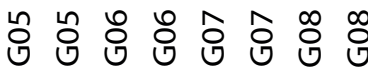

$\bullet \quad 0 \stackrel{\infty}{\sim} \sim \sim \sim N$

ร5 55555

Gillam, B. G. 


\section{Macroscopic Outcrop Extensional Shear Bands}

Tatare Stream

2010-2011

Geologists Ben Gillam

Tim Little

Dave Murphy

$\begin{array}{lll}\text { Layers } & \text { Thin Qtz } & \boldsymbol{I}=\text { intercept of } C^{\prime} \\ & \text { Thick Qtz } & \text { TI }=\text { True intercept of } C^{\prime} \\ \text { Mafic } & \mathbf{O}=\text { Offset on } C^{\prime} \\ \text { Grt Bio } & \text { TO }=\text { True Offset on } C^{\prime}\end{array}$

Site 25

Face Name A

Face Strike 128/NE/42

Parameter

C'Intercept (mm)

True Intercept (mm) C'Offset (mm) True C'Offset (mm)

Layer

B

30

$58 \quad 30$

C

D B C

$77 \quad 47$

165

$\mathrm{D}$

B C

D B C D

$\begin{array}{llllll}240 & 56.7 & 29.3 & 234.8 & 13 & 12\end{array}$

$\begin{array}{lll}5.9 & 1.0 & 1.0\end{array}$

$77 \quad 47$

$75.3 \quad 46.0$

146

$\begin{array}{llll}17 & 12.7 & 11.7 & 16.6\end{array}$

$96 \quad 50$

$93.9 \quad 48.9$

142

$13.7 \quad 5.9$

11570

$112.5 \quad 68.5$

104

$13.7 \quad 2.0$

$140 \quad 80$

$136.9 \quad 78.3$

$3 \quad 10$

$9.8 \quad 3.9$

$180 \quad 93$

176.191 .0

124

$\begin{array}{ll}2.9 & 9.8\end{array}$

$230 \quad 110$

$225.0 \quad 107.6$

$11.7 \quad 3.9$

$270 \quad 120$

$264.1 \quad 117.4$

21

$\begin{array}{ll}2.0 & 1.0\end{array}$

$310 \quad 145$

$303.2 \quad 141.8$

103

$9.8 \quad 2.9$

150

146.7

160

156.5

178

174.1

193

188.8

205

200.5

210

205.4

220

215.2

233

227.9

245

239.6

257

251.4

278

271.9

290

283.7

300

293.4

312

305.2

333

325.7

350

342.4

365

357.0

370

361.9

382

373.7

Gillam, B. G. 
Site 25

Face Name B

Face Strike 127/NE/40

Parameter C'Intercept ( $\mathrm{mm})$ True Intercept C'Offset ( $\mathrm{mm})$ True C'Offset

\begin{tabular}{|c|c|c|c|c|c|c|c|c|}
\hline Layer & $A$ & B & $A$ & $B$ & A & $B$ & $A$ & B \\
\hline & 12 & 10 & 11.7 & 9.7 & 2 & 5 & 1.9 & 4.9 \\
\hline & 20 & 20 & 19.5 & 19.5 & 9 & 6 & 8.8 & 5.8 \\
\hline & 27 & 30 & 26.3 & 29.2 & 2 & 1 & 1.9 & 1.0 \\
\hline & 35 & 45 & 34.1 & 43.8 & 2 & 14 & 1.9 & 13.6 \\
\hline & 58 & 57 & 56.5 & 55.5 & 6 & 9 & 5.8 & 8.8 \\
\hline & 76 & 82 & 74.1 & 79.9 & 6 & 2 & 5.8 & 1.9 \\
\hline & 82 & 109 & 79.9 & 106.2 & 3 & 3 & 2.9 & 2.9 \\
\hline & 90 & 125 & 87.7 & 121.8 & 2 & 20 & 1.9 & 19.5 \\
\hline & 100 & 145 & 97.4 & 141.3 & 3 & 11 & 2.9 & 10.7 \\
\hline & 120 & 165 & 116.9 & 160.8 & 1 & 3 & 1.0 & 2.9 \\
\hline & 126 & 210 & 122.8 & 204.6 & 1 & 13 & 1.0 & 12.7 \\
\hline & 140 & 225 & 136.4 & 219.2 & 2 & 14 & 1.9 & 13.6 \\
\hline & 147 & 240 & 143.2 & 233.8 & 3 & 12 & 2.9 & 11.7 \\
\hline & 151 & 250 & 147.1 & 243.6 & & & & \\
\hline & 171 & 270 & 166.6 & 263.1 & & & & \\
\hline & 186 & 283 & 181.2 & 275.7 & & & & \\
\hline & 222 & 295 & 216.3 & 287.4 & & & & \\
\hline & 240 & 305 & 233.8 & 297.0 & & & & \\
\hline & 248 & 310 & 241.6 & 302.0 & & & & \\
\hline & 255 & 325 & 248.5 & 316.7 & & & & \\
\hline & 280 & 335 & 272.8 & 326.4 & & & & \\
\hline & 290 & 385 & 282.6 & 375.1 & & & & \\
\hline & 305 & 430 & 297.2 & 419.0 & & & & \\
\hline & 330 & 460 & 321.5 & 448.2 & & & & \\
\hline & 350 & 490 & 341.0 & 477.4 & & & & \\
\hline & 370 & 510 & 360.5 & 496.9 & & & & \\
\hline & 380 & 530 & 370.3 & 516.4 & & & & \\
\hline & 420 & 570 & 409.2 & 555.4 & & & & \\
\hline & 440 & 600 & 428.7 & 584.6 & & & & \\
\hline & 453 & 635 & 441.4 & 618.7 & & & & \\
\hline & 470 & 660 & 458.0 & 643.1 & & & & \\
\hline & 500 & & 487.2 & & & & & \\
\hline & 530 & & 516.4 & & & & & \\
\hline & 565 & & 550.5 & & & & & \\
\hline & 610 & & 594.4 & & & & & \\
\hline & 640 & & 623.6 & & & & & \\
\hline & 655 & & 638.2 & & & & & \\
\hline & 670 & & 652.8 & & & & & \\
\hline
\end{tabular}

Gillam, B. G. 
Site 25

Face Name C

Face Strike 100/NE/41

Parameter

C'Intercept ( $\mathrm{mm}$ )

True Intercept ( $\mathrm{mm}$ )

C'Offset (mm)

\begin{tabular}{|c|c|c|c|c|c|c|c|c|c|c|c|c|}
\hline Layer & A & B & $C$ & $D$ & $A$ & $B$ & C & D & $A$ & $B$ & C & D \\
\hline & 80 & 14 & 20 & 5 & 76.9 & 13.5 & 19.2 & 4.8 & 3 & 4 & 7 & 1 \\
\hline & 160 & 18 & 65 & 22 & 153.8 & 17.3 & 62.5 & 21.1 & 28 & 11 & 17 & 3 \\
\hline & 180 & 32 & 90 & 60 & 173.0 & 30.8 & 86.5 & 57.7 & 10 & 3 & 25 & 10 \\
\hline & 230 & 46 & 145 & 80 & 221.1 & 44.2 & 139.4 & 76.9 & 15 & 3 & 17 & 10 \\
\hline & 275 & 57 & 240 & 120 & 264.3 & 54.8 & 230.7 & 115.4 & 15 & 12 & 16 & 7 \\
\hline & 340 & 65 & 290 & 135 & 326.8 & 62.5 & 278.8 & 129.8 & 12 & 4 & 1 & 1 \\
\hline & 410 & 77 & 345 & 155 & 394.1 & 74.0 & 331.6 & 149.0 & 22 & 5 & & 8 \\
\hline & 475 & 85 & 425 & 175 & 456.6 & 81.7 & 408.5 & 168.2 & 22 & 10 & & 7 \\
\hline & 510 & 96 & 455 & 195 & 490.2 & 92.3 & 437.4 & 187.4 & 9 & 10 & & 9 \\
\hline & 535 & 110 & & 230 & 514.3 & 105.7 & & 221.1 & 15 & 40 & & 10 \\
\hline & 570 & 136 & & 270 & 547.9 & 130.7 & & 259.5 & & 10 & & 15 \\
\hline & 600 & 145 & & 297 & 576.8 & 139.4 & & 285.5 & & 14 & & 5 \\
\hline & 635 & 178 & & 307 & 610.4 & 171.1 & & 295.1 & & 12 & & 4 \\
\hline & 665 & 186 & & 335 & 639.2 & 178.8 & & 322.0 & & 3 & & 10 \\
\hline & 715 & 195 & & 350 & 687.3 & 187.4 & & 336.4 & & & & 4 \\
\hline & 745 & 199 & & 370 & 716.1 & 191.3 & & 355.7 & & & & 7 \\
\hline & 785 & 225 & & 385 & 754.6 & 216.3 & & 370.1 & & & & \\
\hline & 815 & 245 & & 397 & 783.4 & 235.5 & & 381.6 & & & & \\
\hline & 825 & 265 & & 430 & 793.0 & 254.7 & & 413.3 & & & & \\
\hline & 860 & 275 & & 445 & 826.7 & 264.3 & & 427.8 & & & & \\
\hline & & 307 & & 490 & & 295.1 & & 471.0 & & & & \\
\hline & & 495 & & 505 & & 475.8 & & 485.4 & & & & \\
\hline & & 505 & & 535 & & 485.4 & & 514.3 & & & & \\
\hline & & 523 & & 555 & & 502.7 & & 533.5 & & & & \\
\hline & & 545 & & 575 & & 523.9 & & 552.7 & & & & \\
\hline & & 580 & & 585 & & 557.5 & & 562.3 & & & & \\
\hline & & 598 & & 595 & & 574.8 & & 572.0 & & & & \\
\hline & & 605 & & 625 & & 581.6 & & 600.8 & & & & \\
\hline & & 625 & & 710 & & 600.8 & & 682.5 & & & & \\
\hline & & 640 & & 745 & & 615.2 & & 716.1 & & & & \\
\hline & & 655 & & 760 & & 629.6 & & 730.6 & & & & \\
\hline & & 675 & & 775 & & 648.9 & & 745.0 & & & & \\
\hline & & 685 & & 790 & & 658.5 & & 759.4 & & & & \\
\hline & & 690 & & 805 & & 663.3 & & 773.8 & & & & \\
\hline & & 710 & & 825 & & 682.5 & & 793.0 & & & & \\
\hline & & & & 850 & & & & 817.1 & & & & \\
\hline & & & & 870 & & & & 836.3 & & & & \\
\hline & & & & 885 & & & & 850.7 & & & & \\
\hline & & & & 910 & & & & 874.7 & & & & \\
\hline & & & & 970 & & & & 932.4 & & & & \\
\hline & & & & 985 & & & & 946.8 & & & & \\
\hline
\end{tabular}

Gillam, B. G. 
Site 25

Face Name D

Face Strike 063/NW/43

Parameter C'Intercept ( $\mathrm{mm})$ True Intercept C'Offset ( $\mathrm{mm}$ ) True C'Offset

$\begin{array}{ccccccccc}\text { Layer } & \text { A } & \text { B } & \text { A } & \text { B } & \text { A } & \text { B } & \text { A } & \text { B } \\ & 18 & 180 & 14.0 & 139.9 & 2 & 17 & 1.6 & 13.2 \\ 28 & 235 & 21.8 & 182.6 & 7 & 6 & 5.4 & 4.7 \\ 35 & 250 & 27.2 & 194.3 & 7 & 6 & 5.4 & 4.7 \\ 45 & 295 & 35.0 & 229.3 & 11 & 15 & 8.5 & 11.7 \\ 60 & 335 & 46.6 & 260.3 & 4 & 1 & 3.1 & 0.8 \\ 70 & & 54.4 & & 15 & & 11.7 & \\ 83 & & 64.5 & & 17 & & 13.2 & \\ 130 & & 101.0 & & 15 & & 11.7 & \\ 155 & & 120.5 & & & & & \\ 190 & & 147.7 & & & & & \\ 210 & & 163.2 & & & & & \\ 245 & & 190.4 & & & & & \\ 275 & 213.7 & & & & & & \\ 325 & 225.4 & & & & & & \end{array}$

Site 25

Face Name E

Face Strike 097/SE/47

\begin{tabular}{|c|c|c|c|c|c|c|c|c|c|c|c|c|}
\hline \multirow{2}{*}{$\begin{array}{r}\text { Parameter } \\
\text { Layer }\end{array}$} & \multicolumn{3}{|c|}{ C'Intercept (mm) } & \multicolumn{3}{|c|}{ True Intercept (mm) } & \multicolumn{3}{|c|}{ C'Offset (mm) } & \multicolumn{3}{|c|}{ True C' Offset ( $\mathrm{mm})$} \\
\hline & $A$ & B & $C$ & $A$ & $B$ & $C$ & $A$ & $B$ & $C$ & A & $B$ & $C$ \\
\hline & 20 & 40 & 20 & 2.1 & 4.2 & 2.1 & 10 & 2 & 25 & 1.0 & 0.2 & 2.6 \\
\hline & 40 & 70 & 90 & 4.2 & 7.3 & 9.4 & 4 & 2 & 48 & 0.4 & 0.2 & 5.0 \\
\hline & 60 & 85 & 200 & 6.3 & 8.9 & 20.9 & 6 & 7 & 25 & 0.6 & 0.7 & 2.6 \\
\hline & 80 & 105 & 270 & 8.4 & 11.0 & 28.2 & 7 & 5 & 8 & 0.7 & 0.5 & 0.8 \\
\hline & 95 & 135 & 300 & 9.9 & 14.1 & 31.4 & 10 & 2 & 9 & 1.0 & 0.2 & 0.9 \\
\hline & 110 & 155 & 340 & 11.5 & 16.2 & 35.5 & 8 & 2 & 10 & 0.8 & 0.2 & 1.0 \\
\hline & 130 & 180 & 400 & 13.6 & 18.8 & 41.8 & 3 & 14 & 40 & 0.3 & 1.5 & 4.2 \\
\hline & 150 & 195 & 490 & 15.7 & 20.4 & 51.2 & 10 & 2 & 16 & 1.0 & 0.2 & 1.7 \\
\hline & 195 & 210 & 510 & 20.4 & 22.0 & 53.3 & & 15 & 5 & & 1.6 & 0.5 \\
\hline & 210 & 240 & 540 & 22.0 & 25.1 & 56.4 & & 3 & 34 & & 0.3 & 3.6 \\
\hline & 230 & 300 & 580 & 24.0 & 31.4 & 60.6 & & & & & & \\
\hline & 250 & 315 & 595 & 26.1 & 32.9 & 62.2 & & & & & & \\
\hline & 285 & 335 & 600 & 29.8 & 35.0 & 62.7 & & & & & & \\
\hline & 295 & 365 & 645 & 30.8 & 38.2 & 67.4 & & & & & & \\
\hline & & 410 & 670 & & 42.9 & 70.0 & & & & & & \\
\hline & & 440 & 690 & & 46.0 & 72.1 & & & & & & \\
\hline & & 465 & 760 & & 48.6 & 79.4 & & & & & & \\
\hline & & 500 & 810 & & 52.3 & 84.7 & & & & & & \\
\hline
\end{tabular}


Site 25

Face Name $F$

Face Strike 120/NE/42

$\begin{array}{rcccc}\text { Parameter } & \text { I } & \text { TI } & \text { O } & \text { TO } \\ \text { Layer } & \text { Layer A } & \text { A } & \text { A } & \text { A } \\ & 15 & 14.8 & 3 & 2.96 \\ & 25 & 24.7 & 3 & 2.96 \\ & 45 & 44.4 & 1 & 0.99 \\ 52 & 51.4 & 4 & 3.95 \\ & 65 & 64.2 & 7 & 6.91 \\ 78 & 77.0 & 8 & 7.90 \\ 88 & 86.9 & & \\ 100 & 98.8 & & \\ 106 & 104.7 & & \\ 117 & 115.6 & & \\ 135 & 133.3 & & \\ 153 & 151.1 & & \end{array}$

Site 25

Face Name G

Face Strike 142/NE/42

$\begin{array}{rcccc}\text { Parameter } & \text { I } & \text { TI } & \text { O } & \text { TO } \\ \text { Layer } & \text { A } & \text { A } & \text { A } & \text { A } \\ & 5 & 4.94 & 3 & 2.96 \\ & 20 & 19.75 & 3 & 2.96 \\ & 30 & 29.63 & 4 & 3.95 \\ & 38 & 37.53 & 9 & 8.89 \\ & 47 & 46.42 & 4 & 3.95 \\ & 59 & 58.27 & 10 & 9.88 \\ & 70 & 69.14 & 1 & 0.99 \\ 80 & 79.02 & 3 & 2.96 \\ 92 & 90.87 & 4 & 3.95 \\ 105 & 103.71 & & \\ 115 & 113.58 & & \\ 125 & 123.46 & & \\ 134 & 132.35 & & \\ 145 & 143.21 & & \\ 160 & 158.03 & & \\ 168 & 165.93 & & \\ 180 & 177.78 & & \\ 185 & 182.72 & & \\ 193 & 190.62 & & \\ 207 & 204.45 & & \end{array}$

Gillam, B. G. 
Site 36

Face Name H

Face Strike 124/NE/24

Parameter

C'Intercept (cm)

Layer

A B C

True Intercept $(\mathrm{cm})$

C'Offset (mm) True C'Offset ( $\mathrm{mm}$ )

\begin{tabular}{|c|c|c|c|c|c|c|c|c|c|c|c|}
\hline 2 & 5.5 & 2.3 & 1.782 & 4.901 & 2.0493 & 1 & 2 & 4 & 0.891 & 1.782 & 3.564 \\
\hline 2.5 & 8 & 4.3 & 2.2275 & 7.128 & 3.8313 & 6 & 2 & 2 & 5.346 & 1.782 & 1.782 \\
\hline 3.6 & 9 & 5.4 & 3.2076 & 8.019 & 4.8114 & 6 & 8 & 12 & 5.346 & 7.128 & 10.69 \\
\hline 4.7 & 11 & 8 & 4.1877 & 9.801 & 7.1281 & 4 & 5 & 8 & 3.564 & 4.455 & 7.128 \\
\hline 5.7 & 12.3 & 11 & 5.0787 & 10.96 & 9.8011 & 2 & 4 & 4 & 1.782 & 3.564 & 3.564 \\
\hline 6 & 15.2 & 13.8 & 5.346 & 13.54 & 12.296 & 4 & 1 & 7 & 3.564 & 0.891 & 6.237 \\
\hline 7 & 16.9 & 14.4 & 6.237 & 15.06 & 12.83 & 12 & 2 & 6 & 10.69 & 1.782 & 5.346 \\
\hline 8.1 & 19 & 18 & 7.2172 & 16.93 & 16.038 & 2 & 3 & 7 & 1.782 & 2.673 & 6.237 \\
\hline 9 & 22.2 & 20 & 8.0191 & 19.78 & 17.82 & 2 & 3 & 13 & 1.782 & 2.673 & 11.58 \\
\hline 10.6 & 25.4 & 22 & 9.4447 & 22.63 & 19.602 & 3 & 6 & & 2.673 & 5.346 & \\
\hline 11.5 & 27.2 & 24.1 & 10.247 & 24.24 & 21.473 & 2 & & & 1.782 & & \\
\hline 13 & 28.5 & 27 & 11.583 & 25.39 & 24.057 & 5 & & & 4.455 & & \\
\hline 15 & 30 & 31.8 & 13.365 & 26.73 & 28.334 & 2 & & & 1.782 & & \\
\hline 15.9 & 33.7 & & 14.167 & 30.03 & & 5 & & & 4.455 & & \\
\hline 16.7 & 36.8 & & 14.88 & 32.79 & & 5 & & & 4.455 & & \\
\hline 17.4 & 37.9 & & 15.504 & 33.77 & & 3 & & & 2.673 & & \\
\hline 17.9 & 39.3 & & 15.949 & 35.02 & & 2 & & & 1.782 & & \\
\hline 18.8 & & & 16.751 & & & 6 & & & 5.346 & & \\
\hline
\end{tabular}

20

17.82

18.711

19.869

20.939

21.83

24.5

22.364

25.1

24.324

28.3

25.215

29.3

26.106

30.7

27.354

32

28.512

34

30.294

34.5

30.74

35.8

31.898

36.8

32.789

39.2

34.927

39.5

35.195

41.5

36.977

42.4

37.779

43.6

38.848

46.4

41.343 
Site 37

Face Name I

Face Strike 110/NE/63

\begin{tabular}{|c|c|c|c|c|}
\hline Parameter & $I(\mathrm{~cm})$ & TI & 0 & TO \\
\hline \multirow[t]{18}{*}{ Layer } & A & A & A & A \\
\hline & 2.5 & 2.4257 & 4 & 3.8812 \\
\hline & 3.1 & 3.0079 & 1 & 0.9703 \\
\hline & 4.8 & 4.6574 & 3 & 2.9109 \\
\hline & 5.7 & 5.5307 & 2 & 1.9406 \\
\hline & 7.3 & 7.0832 & 1 & 0.9703 \\
\hline & 8.1 & 7.8594 & 3 & 2.9109 \\
\hline & 8.7 & 8.4416 & 5 & 4.8515 \\
\hline & 10.9 & 10.576 & 1 & 0.9703 \\
\hline & 11.2 & 10.867 & 3 & 2.9109 \\
\hline & 11.7 & 11.352 & & \\
\hline & 12.8 & 12.42 & & \\
\hline & 13.9 & 13.487 & & \\
\hline & 15.7 & 15.234 & & \\
\hline & 16.3 & 15.816 & & \\
\hline & 20.1 & 19.503 & & \\
\hline & 22.4 & 21.735 & & \\
\hline & 25.3 & 24.548 & & \\
\hline
\end{tabular}

Site 40

Face Name J

Face Strike 128/NE/62

Parameter I $\quad$ (cm) $\quad$ TI 0

\begin{tabular}{rrrc} 
Layer & \multicolumn{1}{c}{ A } & A & A \\
10.9 & 9.0365 & 18 & 14.923 \\
15 & 12.436 & 20 & 16.581 \\
20.3 & 16.829 & 22 & 18.239 \\
23 & 19.068 & 6 & 4.9742 \\
25.4 & 21.058 & 7 & 5.8033 \\
29.2 & 24.208 & 4 & 3.3162 \\
33.7 & 27.939 & 28 & 23.213 \\
45.7 & 37.887 & 2 & 1.6581 \\
47.6 & 39.462 & 5 & 4.1452 \\
68 & 56.375 & 168 & 139.28 \\
91.1 & 75.525 & 3 & 2.4871 \\
93.6 & 77.598 & 4 & 3.3162 \\
98.5 & 81.66 & 2 & 1.6581 \\
111.4 & 92.355 & 69 & 57.204
\end{tabular}

Gillam, B. G. 
Site 41

Face Name K

Face Strike 144/NE/72

Parameter C'Intercept (cm) True Intercept C'Offset ( $\mathrm{mm})$ True C'Offset

\begin{tabular}{|c|c|c|c|c|c|c|c|c|}
\hline Layer & $A$ & B & $A$ & B & $A$ & B & $A$ & B \\
\hline & 2.3 & 1.8 & 2.133 & 1.6689 & 1 & 3 & 0.9272 & 2.782 \\
\hline & 5.5 & 3 & 5.1 & 2.7816 & 5 & 5 & 4.6359 & 4.636 \\
\hline & 9.5 & 4.5 & 8.808 & 4.1723 & 2 & 2 & 1.8544 & 1.854 \\
\hline & 11.9 & 6 & 11.03 & 5.5631 & 3 & 5 & 2.7816 & 4.636 \\
\hline & 17 & 9 & 15.76 & 8.3447 & 3 & 3 & 2.7816 & 2.782 \\
\hline & 22.6 & 10.5 & 20.95 & 9.7354 & 1 & 6 & 0.9272 & 5.563 \\
\hline & & 12.5 & & 11.59 & & 2 & & 1.854 \\
\hline & 6 & 15 & & 13.908 & & 15 & & 13.91 \\
\hline & & 15.5 & & 14.371 & & 8 & & 7.417 \\
\hline & & 16.5 & & 15.299 & & 6 & & 5.563 \\
\hline & & 19 & & 17.616 & & 4 & & 3.709 \\
\hline & & 20.3 & & 18.822 & & 8 & & 7.417 \\
\hline & & 24.4 & & 22.623 & & 2 & & 1.854 \\
\hline & & 29.5 & & 27.352 & & 2 & & 1.854 \\
\hline
\end{tabular}

Site 42

Face Name L

Face Strike 130/NE/83

\begin{tabular}{|c|c|c|c|c|}
\hline Parameter & $I(\mathrm{~cm})$ & $T I$ & 0 & TO \\
\hline \multirow[t]{22}{*}{ Layer } & A & $A$ & $A$ & $A$ \\
\hline & 1.6 & 1.3265 & 1 & 0.829 \\
\hline & 3.5 & 2.9016 & 1 & 0.829 \\
\hline & 4.5 & 3.7307 & 2 & 1.6581 \\
\hline & 5.2 & 4.311 & 2 & 1.6581 \\
\hline & 6.2 & 5.14 & 1 & 0.829 \\
\hline & 8 & 6.6323 & 2 & 1.6581 \\
\hline & 9.7 & 8.0417 & 6 & 4.9742 \\
\hline & 11.3 & 9.3681 & 5 & 4.1452 \\
\hline & 12.3 & 10.197 & 6 & 4.9742 \\
\hline & 13.6 & 11.275 & 1 & 0.829 \\
\hline & 15.7 & 13.016 & 3 & 2.4871 \\
\hline & 20.2 & 16.747 & 1 & 0.829 \\
\hline & 21 & 17.41 & & \\
\hline & 21.7 & 17.99 & & \\
\hline & 23.5 & 19.482 & & \\
\hline & 24.5 & 20.311 & & \\
\hline & 25.5 & 21.14 & & \\
\hline & 27.2 & 22.55 & & \\
\hline & 28 & 23.213 & & \\
\hline & 29 & 24.042 & & \\
\hline & 30 & 24.871 & & \\
\hline
\end{tabular}

Gillam, B. G. 
$30.5 \quad 25.286$

31.225 .866

$32 \quad 26.529$

32.827 .192

$34 \quad 28.187$

Site 45

Face Name $M$

Face Strike 130/NE/32

\begin{tabular}{|c|c|c|c|c|}
\hline Parameter & $I(\mathrm{~cm})$ & $T I$ & 0 & TO \\
\hline \multirow[t]{36}{*}{ Layer } & A & A & A & A \\
\hline & 2 & 1.891 & 3 & 2.8366 \\
\hline & 5 & 4.7276 & 4 & 3.7821 \\
\hline & 6.2 & 5.8622 & 6 & 5.6731 \\
\hline & 7.5 & 7.0914 & 3 & 2.8366 \\
\hline & 9 & 8.5097 & 2 & 1.891 \\
\hline & 13 & 12.292 & 8 & 7.5641 \\
\hline & 15.5 & 14.656 & 4 & 3.7821 \\
\hline & 18.5 & 17.492 & 15 & 14.183 \\
\hline & 22 & 20.801 & 8 & 7.5641 \\
\hline & 24.5 & 23.165 & 5 & 4.7276 \\
\hline & 26 & 24.583 & 20 & 18.91 \\
\hline & 28 & 26.475 & 8 & 7.5641 \\
\hline & 30 & 28.366 & 2 & 1.891 \\
\hline & 31.5 & 29.784 & 6 & 5.6731 \\
\hline & 34.7 & 32.809 & 3 & 2.8366 \\
\hline & 38 & 35.93 & 2 & 1.891 \\
\hline & 40.5 & 38.294 & 4 & 3.7821 \\
\hline & 42.7 & 40.374 & 3 & 2.8366 \\
\hline & 44.9 & 42.454 & 5 & 4.7276 \\
\hline & 48.1 & 45.479 & 3 & 2.8366 \\
\hline & 50 & 47.276 & 2 & 1.891 \\
\hline & 51.6 & 48.789 & 2 & 1.891 \\
\hline & 53.6 & 50.68 & 1 & 0.9455 \\
\hline & 55.1 & 52.098 & 6 & 5.6731 \\
\hline & 58 & 54.84 & & \\
\hline & 60 & 56.731 & & \\
\hline & 62.5 & 59.095 & & \\
\hline & 64.5 & 60.986 & & \\
\hline & 71 & 67.132 & & \\
\hline & 74.5 & 70.441 & & \\
\hline & 79 & 74.696 & & \\
\hline & 82 & 77.533 & & \\
\hline & 85.5 & 80.842 & & \\
\hline & 88 & 83.206 & & \\
\hline & 91 & 86.042 & & \\
\hline
\end{tabular}

Gillam, B. G. 
\begin{tabular}{rr}
95.5 & 90.297 \\
98.5 & 93.134 \\
102.5 & 96.916 \\
107 & 101.17 \\
110.5 & 104.48 \\
115.5 & 109.21 \\
116.4 & 110.06 \\
119 & 112.52 \\
123 & 116.3 \\
126 & 119.14 \\
131 & 123.86 \\
136 & 128.59 \\
141.3 & 133.6 \\
145.8 & 137.86 \\
147.5 & 139.46 \\
149 & 140.88 \\
151 & 142.77 \\
157.5 & 148.92 \\
158.5 & 149.86 \\
160 & 151.28 \\
163 & 154.12 \\
170 & 160.74 \\
180.5 & 170.67 \\
181.5 & 171.61 \\
183.5 & 173.5 \\
185.7 & 175.58 \\
186.8 & 176.62 \\
189 & 178.7 \\
191 & 180.59 \\
193.4 & 182.86 \\
196.5 & 185.79 \\
198.4 & 187.59 \\
200.5 & 189.58 \\
204 & 192.89 \\
210 & 198.56 \\
\hline &
\end{tabular}

Gillam, B. G. 
Site 46

Face Name N

Face Strike 053/NW/43

$\begin{array}{lllll}\text { Parameter I } & \text { (cm) TI } & 0 & \text { TO }\end{array}$

Layer Layer A Layer A Layer A Layer A

$\begin{array}{llll}13 & 12.432 & 90 & 86.067\end{array}$

$\begin{array}{llll}18 & 17.213 & 30 & 28.689\end{array}$

$\begin{array}{llll}28 & 26.777 & 15 & 14.345\end{array}$

$\begin{array}{llll}39 & 37.296 & 15 & 14.345\end{array}$

$\begin{array}{llll}54 & 51.64 & 30 & 28.689\end{array}$

$\begin{array}{llll}61.2 & 58.526 & 40 & 38.252\end{array}$

$\begin{array}{llll}67 & 64.072 & 20 & 19.126\end{array}$

$\begin{array}{llll}72 & 68.854 & 70 & 66.941\end{array}$

$\begin{array}{llll}81.7 & 78.13 & 120 & 114.76\end{array}$

Gillam, B. G. 


\section{Microscopic Thin-section Extensional Shear Bands}

Tatare Stream

2010-2011

Geologists Ben Gillam

Tim Little

Dave Murphy

\begin{tabular}{|r|r|r|r|r|r|r|r|r|}
\hline Sample & 25B/90 & & & & & & & \\
\hline Parameter & $\begin{array}{c}C^{\prime} \text { intercept } \\
(\mathrm{mm})\end{array}$ & $\begin{array}{c}C^{\prime} \text { offset } \\
(\mathrm{mm})\end{array}$ & C' spacing $^{\text {Mean } C^{\prime}}$ & $\begin{array}{c}\text { Mean } \\
\text { offset }\end{array}$ & $\begin{array}{c}\text { Error } \\
\text { Spacing }\end{array}$ & $\begin{array}{c}\text { Error } \\
\text { Spacing }\end{array}$ & $\begin{array}{c}C^{\prime} \text { thickness } \\
(\mu \mathrm{m})\end{array}$ \\
\hline & 0 & 4 & & 3 & 13 & 1.41421 & & 127 \\
\hline & 13 & 2 & 13 & & & & & \\
\hline
\end{tabular}

\begin{tabular}{|r|r|r|r|r|r|r|r|c|}
\hline Sample & 25A/90 & & & & & & & \\
\hline Parameter & $\begin{array}{c}C^{\prime} \text { intercept } \\
(\mathrm{mm})\end{array}$ & $\begin{array}{c}C^{\prime} \text { offset } \\
(\mathrm{mm})\end{array}$ & C' spacing $^{\text {Mean } C^{\prime}}$ & $\begin{array}{c}\text { Mean } \\
\text { offset }\end{array}$ & $\begin{array}{c}\text { Error } \\
\text { Spacing }\end{array}$ & $\begin{array}{c}\text { Error } \\
\text { Spacing }\end{array}$ & $\begin{array}{c}C^{\prime} \text { 'hickness } \\
(\mu \mathrm{m})\end{array}$ \\
\hline & 0 & 2 & 3 & 2 & 3 & 0 & 1.22474 & 127 \\
\hline & 3 & 2 & 3 & & & & & \\
\hline & 6 & 2 & 2 & & & & & \\
\hline & 8 & 2 & 2 & & & & & \\
\hline & 10 & 2 & 5 & & & & & \\
\hline & 15 & 2 & & & & & & \\
\hline
\end{tabular}

\begin{tabular}{|r|r|r|r|r|r|r|r|r|}
\hline Sample & 25E/90 & & & & & & & \\
\hline Parameter & $\begin{array}{c}C^{\prime} \text { intercept } \\
(\mathrm{mm})\end{array}$ & $\begin{array}{c}\text { C' }^{\prime} \text { (mfset } \\
(\mathrm{mm})\end{array}$ & C' spacing $^{\text {Mean C' }}$ & $\begin{array}{c}\text { Mean } \\
\text { offset }\end{array}$ & $\begin{array}{c}\text { Error } \\
\text { Spacing }\end{array}$ & $\begin{array}{c}\text { Error } \\
\text { Spacing }\end{array}$ & $\begin{array}{c}C^{\prime} \text { thickness } \\
(\mu \mathrm{m})\end{array}$ \\
\hline & 0 & 3 & 5 & 2 & 6.25 & 1 & 1.5 & 123 \\
\hline & 5 & 1 & 7 & & & & & \\
\hline & 12 & 2 & 5 & & & & & \\
\hline & 17 & 1 & 8 & & & & & \\
\hline & 25 & 3 & & & & & & \\
\hline
\end{tabular}

\begin{tabular}{|r|r|r|r|r|r|r|r|r|}
\hline Sample & 27A/70 & & & & & & & \\
\hline Parameter & $\begin{array}{c}C^{\prime} \text { intercept } \\
(\mathrm{mm})\end{array}$ & $\begin{array}{r}\text { C' }^{\prime} \text { offset } \\
(\mathrm{mm})\end{array}$ & $C^{\prime}$ spacing & $\begin{array}{c}\text { Mean C' } \\
\text { offset }\end{array}$ & $\begin{array}{c}\text { Mean } \\
\text { Spacing }\end{array}$ & $\begin{array}{c}\text { Error } \\
\text { Offset }\end{array}$ & $\begin{array}{c}\text { Error } \\
\text { Spacing }\end{array}$ & $\begin{array}{c}C^{\prime} \text { thickness } \\
(\mu \mathrm{m})\end{array}$ \\
\hline & 0 & 3 & 6 & 2.4 & 6.75 & 1.67332 & 1.70783 & 140 \\
\hline & 6 & 5 & 9 & & & & & \\
\hline & 15 & 2 & 5 & & & & & \\
\hline & 20 & 1 & 7 & & & & & \\
\hline
\end{tabular}

\begin{tabular}{|c|c|c|c|c|c|c|c|c|}
\hline Sample & $32 \mathrm{~B} / 25$ & & & & & & & \\
\hline Parameter & $\begin{array}{c}C^{\prime} \text { intercept } \\
(\mathrm{mm})\end{array}$ & $\begin{array}{c}C^{\prime} \text { offset } \\
(\mathrm{mm})\end{array}$ & $C^{\prime}$ spacing & $\begin{array}{c}\text { Mean } \mathrm{C}^{\prime} \\
\text { offset }\end{array}$ & $\begin{array}{c}\text { Mean } \\
\text { Spacing }\end{array}$ & $\begin{array}{c}\text { Error } \\
\text { Offset }\end{array}$ & $\begin{array}{c}\text { Error } \\
\text { Spacing }\end{array}$ & $\begin{array}{c}C^{\prime} \text { 'thickness } \\
(\mu \mathrm{m})\end{array}$ \\
\hline
\end{tabular}




\begin{tabular}{|r|r|r|r|r|r|r|r|l|}
\hline & 0 & 1 & 1 & 1.2 & 2.5 & 0.27386 & 1.29099 & $\mathrm{~N} / \mathrm{A}$ \\
\hline & 1 & 1 & 2 & & & & & \\
\hline & 3 & 1 & 4 & & & & & \\
\hline & 7 & 1.5 & 3 & & & & & \\
\hline & 10 & 1.5 & & & & & & \\
\hline
\end{tabular}

\begin{tabular}{|r|r|r|r|r|r|r|r|r|}
\hline Sample & 32B/70 & & & & & & & \\
\hline Parameter & $\begin{array}{c}C^{\prime} \text { intercept } \\
(\mathrm{mm})\end{array}$ & $\begin{array}{c}C^{\prime} \text { offset } \\
(\mathrm{mm})\end{array}$ & $C^{\prime}$ spacing & $\begin{array}{c}\text { Mean } \mathrm{C}^{\prime} \\
\text { offset }\end{array}$ & $\begin{array}{c}\text { Mean } \\
\text { Spacing }\end{array}$ & $\begin{array}{c}\text { Error } \\
\text { Offset }\end{array}$ & $\begin{array}{c}\text { Error } \\
\text { Spacing }\end{array}$ & $\begin{array}{c}C^{\prime} \text { thickness } \\
(\mu \mathrm{m})\end{array}$ \\
\hline & 0 & 1 & 2 & 1.25 & 1.666667 & 0.5 & 0.57735 & 93 \\
\hline & 2 & 1 & 1 & & & & & \\
\hline & 3 & 2 & 2 & & & & & \\
\hline & 5 & 1 & & & & & & \\
\hline
\end{tabular}

\begin{tabular}{|r|r|r|r|r|r|r|r|r|}
\hline Sample & $33 \mathrm{~A} / 70$ & & & & & & & \\
\hline Parameter & $\begin{array}{c}C^{\prime} \text { intercept } \\
(\mathrm{mm})\end{array}$ & $\begin{array}{c}C^{\prime} \text { offset } \\
(\mathrm{mm})\end{array}$ & C' 'spacing $^{\text {Mean C' }}$ & $\begin{array}{c}\text { Mean } \\
\text { offset }\end{array}$ & $\begin{array}{c}\text { Error } \\
\text { Spacing }\end{array}$ & $\begin{array}{c}\text { Error } \\
\text { Spacing }\end{array}$ & $\begin{array}{c}C^{\prime} \text { 'thickness } \\
(\mu \mathrm{m})\end{array}$ \\
\hline & 0 & 3 & 1 & 1.928571 & 2.166667 & 0.93223 & 0.75277 & 139 \\
\hline & 1 & 2 & 2 & & & & & \\
\hline & 3 & 2 & 2 & & & & & \\
\hline & 5 & 0.5 & 2 & & & & & \\
\hline & 7 & 2 & 3 & & & & & \\
\hline & 10 & 3 & 3 & & & & & \\
\hline
\end{tabular}

\begin{tabular}{|r|r|r|r|r|r|r|r|r|}
\hline Sample & $34 \mathrm{~A} / 70$ & & & & & & & \\
\hline Parameter & $\begin{array}{c}C^{\prime} \text { intercept } \\
(\mathrm{mm})\end{array}$ & $\begin{array}{c}\text { C' }^{\prime} \text { offset } \\
(\mathrm{mm})\end{array}$ & $C^{\prime}$ spacing & $\begin{array}{c}\text { Mean } C^{\prime} \\
\text { offset }\end{array}$ & $\begin{array}{c}\text { Mean } \\
\text { Spacing }\end{array}$ & $\begin{array}{c}\text { Error } \\
\text { Offset }\end{array}$ & $\begin{array}{c}\text { Error } \\
\text { Spacing }\end{array}$ & $\begin{array}{c}C^{\prime} \text { thickness } \\
(\mu \mathrm{m})\end{array}$ \\
\hline & 0 & 4 & 3 & 1.75 & 1.666667 & 1.5 & 1.1547 & 164 \\
\hline & 3 & 1 & 1 & & & & & \\
\hline & 4 & 1 & 1 & & & & & \\
\hline & 5 & 1 & & & & & & \\
\hline
\end{tabular}

\begin{tabular}{|r|r|r|r|r|r|r|r|r|}
\hline Sample & $36 \mathrm{~A} / 70$ & & & & & & & \\
\hline Parameter & $\begin{array}{c}C^{\prime} \text { intercept } \\
(\mathrm{mm})\end{array}$ & $\begin{array}{c}\text { C' }^{\prime} \text { offset } \\
(\mathrm{mm})\end{array}$ & C'spacing $^{\prime}$ & $\begin{array}{c}\text { Mean C' } \\
\text { offset }\end{array}$ & $\begin{array}{c}\text { Mean } \\
\text { Spacing }\end{array}$ & $\begin{array}{c}\text { Error } \\
\text { Offset }\end{array}$ & $\begin{array}{c}\text { Error } \\
\text { Spacing }\end{array}$ & $\begin{array}{c}C^{\prime} \text { 'thickness } \\
(\mu \mathrm{m})\end{array}$ \\
\hline & 0 & 1 & 4 & 1.5 & 3.666667 & 0.57735 & 1.52753 & 126 \\
\hline & 4 & 2 & 5 & & & & & \\
\hline & 9 & 2 & 2 & & & & & \\
\hline & 11 & 1 & & & & & & \\
\hline
\end{tabular}

\begin{tabular}{|r|c|c|c|c|c|c|c|c|}
\hline Sample & $36 \mathrm{~B} / 70$ & & & & & & & \\
\hline Parameter & $\begin{array}{c}C^{\prime} \text { intercept } \\
(\mathrm{mm})\end{array}$ & $\begin{array}{c}C^{\prime} \text { offset } \\
(\mathrm{mm})\end{array}$ & C' spacing $^{\text {Mean } C^{\prime}}$ & $\begin{array}{c}\text { Mean } \\
\text { offset }\end{array}$ & $\begin{array}{c}\text { Error } \\
\text { Spacing }\end{array}$ & $\begin{array}{c}\text { Error } \\
\text { Spacing }\end{array}$ & $\begin{array}{c}C^{\prime} \text { thickness } \\
(\mu \mathrm{m})\end{array}$ \\
\hline
\end{tabular}




\begin{tabular}{|r|r|r|r|r|r|r|r|r|}
\hline & 0 & 5 & 5 & 2.75 & 5 & 1.70783 & & 1 \\
\hline & 5 & 3 & 6 & & & & & \\
\hline & 11 & 1 & 4 & & & & & \\
\hline & 15 & 2 & & & & & & \\
\hline
\end{tabular}

\begin{tabular}{|r|r|r|r|r|r|r|r|r|}
\hline Sample & $36 \mathrm{C} / 70$ & & & & & & & \\
\hline Parameter & $\begin{array}{c}C^{\prime} \text { intercept } \\
(\mathrm{mm})\end{array}$ & $\begin{array}{c}\text { C'offset }^{\prime}(\mathrm{mm}) \\
\text { C' }^{\prime} \text { spacing }\end{array}$ & $\begin{array}{c}\text { Mean C' } \\
\text { offset }\end{array}$ & $\begin{array}{c}\text { Mean } \\
\text { Spacing }\end{array}$ & $\begin{array}{c}\text { Error } \\
\text { Offset }\end{array}$ & $\begin{array}{c}\text { Error } \\
\text { Spacing }\end{array}$ & $\begin{array}{c}C^{\prime} \text { thickness } \\
(\mu \mathrm{m})\end{array}$ \\
\hline & 0 & 3 & 10 & 2.666667 & 8.5 & 0.57735 & 2.12132 & 139 \\
\hline & 10 & 3 & 7 & & & & & \\
\hline & 17 & 2 & & & & & & \\
\hline
\end{tabular}

\begin{tabular}{|r|r|r|r|r|r|r|r|r|}
\hline Sample & $38 \mathrm{~A} / 70$ & & & & & & & \\
\hline Parameter & $\begin{array}{c}C^{\prime} \text { intercept } \\
(\mathrm{mm})\end{array}$ & $\begin{array}{c}C^{\prime} \text { offset } \\
(\mathrm{mm})\end{array}$ & $C^{\prime}$ spacing & $\begin{array}{c}\text { Mean } C^{\prime} \\
\text { offset }\end{array}$ & $\begin{array}{c}\text { Mean } \\
\text { Spacing }\end{array}$ & $\begin{array}{c}\text { Error } \\
\text { Offset }\end{array}$ & $\begin{array}{c}\text { Error } \\
\text { Spacing }\end{array}$ & $\begin{array}{c}C^{\prime} \text { thickness } \\
(\mu \mathrm{m})\end{array}$ \\
\hline & 0 & 1 & 6 & 1.75 & 6.666667 & 1.5 & 1.1547 & 124 \\
\hline & 6 & 1 & 8 & & & & & \\
\hline & 14 & 4 & 6 & & & & & \\
\hline & 20 & 1 & & & & & & \\
\hline
\end{tabular}

\begin{tabular}{|r|r|r|r|r|r|r|r|c|}
\hline Sample & 37A/70 & & & & & & & \\
\hline Parameter & $\begin{array}{c}C^{\prime} \text { intercept } \\
(\mathrm{mm})\end{array}$ & $\begin{array}{c}C^{\prime} \text { offset } \\
(\mathrm{mm})\end{array}$ & $C^{\prime}$ spacing & $\begin{array}{c}\text { Mean } C^{\prime} \\
\text { offset }\end{array}$ & $\begin{array}{c}\text { Mean } \\
\text { Spacing }\end{array}$ & $\begin{array}{c}\text { Error } \\
\text { Offset }\end{array}$ & $\begin{array}{c}\text { Error } \\
\text { Spacing }\end{array}$ & $\begin{array}{c}C^{\prime} \text { thickness } \\
(\mu \mathrm{m})\end{array}$ \\
\hline & 0 & 4 & 7 & 3.25 & 6.333333 & 1.5 & 2.08167 & $\mathrm{~N} / \mathrm{A}$ \\
\hline & 7 & 4 & 8 & & & & & \\
\hline & 15 & 1 & 4 & & & & & \\
\hline & 19 & 4 & & & & & & \\
\hline
\end{tabular}

\begin{tabular}{|r|r|r|r|r|r|r|r|r|}
\hline Sample & $40 \mathrm{~A} / 70$ & & & & & & & \\
\hline Parameter & $\begin{array}{c}C^{\prime} \text { intercept } \\
(\mathrm{mm})\end{array}$ & $\begin{array}{c}C^{\prime} \text { offset } \\
(\mathrm{mm})\end{array}$ & $C^{\prime}$ spacing & $\begin{array}{c}\text { Mean } C^{\prime} \\
\text { offset }\end{array}$ & $\begin{array}{c}\text { Mean } \\
\text { Spacing }\end{array}$ & $\begin{array}{c}\text { Error } \\
\text { Offset }\end{array}$ & $\begin{array}{c}\text { Error } \\
\text { Spacing }\end{array}$ & $\begin{array}{c}C^{\prime} \text { thickness } \\
(\mu \mathrm{m})\end{array}$ \\
\hline & 0 & 3 & 17 & 2.666667 & 11.5 & 0.57735 & 7.77817 & 154 \\
\hline & 17 & 2 & 6 & & & & & \\
\hline & 23 & 3 & & & & & & \\
\hline
\end{tabular}

\begin{tabular}{|r|r|r|r|r|r|r|r|r|}
\hline Sample & 41A/70 & & & & & & & \\
\hline Parameter & $\begin{array}{c}C^{\prime} \text { intercept } \\
(\mathrm{mm})\end{array}$ & $\begin{array}{c}C^{\prime} \text { offset } \\
(\mathrm{mm})\end{array}$ & C' spacing $^{\text {Mean C' }}$ & $\begin{array}{c}\text { Mean } \\
\text { offset }\end{array}$ & $\begin{array}{c}\text { Error } \\
\text { Spacing }\end{array}$ & $\begin{array}{c}\text { Error } \\
\text { Spacing }\end{array}$ & $\begin{array}{c}C^{\prime} \text { 'thickness } \\
(\mu \mathrm{m})\end{array}$ \\
\hline & 0 & 2 & 1 & 2.555556 & 4.428571 & 1.23603 & 3.04725 & 131 \\
\hline & 1 & 2 & 2 & & & & & \\
\hline & 3 & 4 & 8 & & & & & \\
\hline & 11 & 4 & 9 & & & & & \\
\hline & 20 & 3 & & & & & & \\
\hline & 46 & 4 & 5 & & & & & \\
\hline
\end{tabular}




\begin{tabular}{|l|r|r|r|l|l|l|l|l|}
\hline & 51 & 2 & 3 & & & & & \\
\hline & 54 & 1 & 3 & & & & & \\
\hline & 57 & 1 & & & & & & \\
\hline
\end{tabular}

\begin{tabular}{|r|r|r|r|r|r|r|r|r|}
\hline Sample & 43A/70 & & & & & & & \\
\hline Parameter & $\begin{array}{c}C^{\prime} \text { intercept } \\
(\mathrm{mm})\end{array}$ & \begin{tabular}{c} 
C' offset $_{(\mathrm{mm})}$ \\
\hline
\end{tabular} & $C^{\prime}$ spacing & $\begin{array}{c}\text { Mean } C^{\prime} \\
\text { offset }\end{array}$ & $\begin{array}{c}\text { Mean } \\
\text { Spacing }\end{array}$ & $\begin{array}{c}\text { Error } \\
\text { Offset }\end{array}$ & $\begin{array}{c}\text { Error } \\
\text { Spacing }\end{array}$ & $\begin{array}{c}C^{\prime} \text { thickness } \\
(\mu \mathrm{m})\end{array}$ \\
\hline & 0 & 4 & 5 & 2.25 & 5.333333 & 1.25831 & 2.51661 & 130 \\
\hline & 13 & 2 & 8 & & & & & \\
\hline & 16 & 1 & 3 & & & & & \\
\hline
\end{tabular}

\begin{tabular}{|r|r|r|r|r|r|r|r|r|}
\hline Sample & 45B/70 & & & & & & & \\
\hline Parameter & $\begin{array}{c}C^{\prime} \text { intercept } \\
(\mathrm{mm})\end{array}$ & $\begin{array}{c}\text { C' }^{\prime} \text { offset } \\
(\mathrm{mm})\end{array}$ & $C^{\prime}$ spacing & $\begin{array}{c}\text { Mean C' } \\
\text { offset }\end{array}$ & $\begin{array}{c}\text { Mean } \\
\text { Spacing }\end{array}$ & $\begin{array}{c}\text { Error } \\
\text { Offset }\end{array}$ & $\begin{array}{c}\text { Error } \\
\text { Spacing }\end{array}$ & $\begin{array}{c}C^{\prime} \text { thickness } \\
(\mu \mathrm{m})\end{array}$ \\
\hline & 0 & 1 & 5 & 1.6 & 4.25 & 0.89443 & 1.5 & 112 \\
\hline & 5 & 1 & 5 & & & & & \\
\hline & 10 & 3 & 5 & & & & & \\
\hline & 15 & 2 & 2 & & & & & \\
\hline
\end{tabular}

\begin{tabular}{|r|r|r|r|r|r|r|r|r|}
\hline Sample & 46A/70 & & & & & & & \\
\hline Parameter & $\begin{array}{c}C^{\prime} \text { intercept } \\
(\mathrm{mm})\end{array}$ & $\begin{array}{c}C^{\prime} \text { offset } \\
(\mathrm{mm})\end{array}$ & C' 'spacing $^{\text {Mean C' }}$ & $\begin{array}{c}\text { Mean } \\
\text { offset }\end{array}$ & $\begin{array}{c}\text { Error } \\
\text { Spacing }\end{array}$ & $\begin{array}{c}\text { Error } \\
\text { Spacing }\end{array}$ & $\begin{array}{c}C^{\prime} \text { 'thickness } \\
(\mu \mathrm{m})\end{array}$ \\
\hline & 0 & 2 & 1 & 1.571429 & 3.833333 & 0.7868 & 3.18852 & 100 \\
\hline & 1 & 3 & 4 & & & & & \\
\hline & 5 & 1 & 10 & & & & & \\
\hline & 15 & 2 & 2 & & & & & \\
\hline & 17 & 1 & 3 & & & & & \\
\hline & 20 & 1 & 3 & & & & & \\
\hline
\end{tabular}

\begin{tabular}{|r|r|r|r|r|r|r|r|r|}
\hline Sample & $50 \mathrm{~A} / 70$ & & & & & & & \\
\hline Parameter & $\begin{array}{c}C^{\prime} \text { intercept } \\
(\mathrm{mm})\end{array}$ & $\begin{array}{c}\text { C' }^{\prime}(\mathrm{mm}) \\
(\mathrm{mm})\end{array}$ & $C^{\prime}$ spacing & $\begin{array}{c}\text { Mean } C^{\prime} \\
\text { offset }\end{array}$ & $\begin{array}{c}\text { Mean } \\
\text { Spacing }\end{array}$ & $\begin{array}{c}\text { Error } \\
\text { Offset }\end{array}$ & $\begin{array}{c}\text { Error } \\
\text { Spacing }\end{array}$ & $\begin{array}{c}C^{\prime} \text { thickness } \\
(\mu \mathrm{m})\end{array}$ \\
\hline & 0 & 1 & 1 & 2.166667 & 2.6 & 0.98319 & 1.34164 & 135 \\
\hline & 1 & 1 & 2 & & & & & \\
\hline & 3 & 3 & 4 & & & & & \\
\hline & 11 & 3 & 4 & & & & & \\
\hline & 13 & 3 & 2 & & & & & \\
\hline
\end{tabular}

Sample $51 \mathrm{C} / 70$ 


\begin{tabular}{|r|r|r|r|r|r|r|r|r|}
\hline Parameter & $\begin{array}{c}C^{\prime} \text { intercept } \\
(\mathrm{mm})\end{array}$ & $\begin{array}{c}C^{\prime} \text { offset } \\
(\mathrm{mm})\end{array}$ & C' spacing $^{\text {Mean } C^{\prime}}$ & $\begin{array}{c}\text { Mean } \\
\text { offset }\end{array}$ & $\begin{array}{c}\text { Error } \\
\text { Spacing }\end{array}$ & $\begin{array}{c}\text { Error } \\
\text { Spacing }\end{array}$ & $\begin{array}{c}C^{\prime} \text { thickness } \\
(\mu \mathrm{m})\end{array}$ \\
\hline & 0 & 3 & 10 & 2 & 6.666667 & 0.8165 & 2.88675 & 158 \\
\hline & 10 & 2 & 5 & & & & & \\
\hline & 15 & 2 & 5 & & & & & \\
\hline & 20 & 1 & & & & & & \\
\hline
\end{tabular}

\begin{tabular}{|r|r|r|r|r|r|r|r|r|}
\hline Sample & $52 / 100 / 70$ & & & & & & & \\
\hline Parameter & $\begin{array}{c}C^{\prime} \text { intercept } \\
(\mathrm{mm})\end{array}$ & $\begin{array}{c}\text { C' }^{\prime} \text { (mm) } \\
(\mathrm{mm})\end{array}$ & $C^{\prime}$ spacing & $\begin{array}{c}\text { Mean C' } \\
\text { offset }\end{array}$ & $\begin{array}{c}\text { Mean } \\
\text { Spacing }\end{array}$ & $\begin{array}{c}\text { Error } \\
\text { Offset }\end{array}$ & $\begin{array}{c}\text { Error } \\
\text { Spacing }\end{array}$ & $\begin{array}{c}C^{\prime} \text { thickness } \\
(\mu \mathrm{m})\end{array}$ \\
\hline & 0 & 2 & 10 & 2 & 10 & & & 141 \\
\hline & 10 & 2 & & & & & & \\
\hline
\end{tabular}

\begin{tabular}{|r|r|r|r|r|r|r|r|r|}
\hline Sample & $55 \mathrm{~A} / 70$ & & & & & & & \\
\hline Parameter & $\begin{array}{c}C^{\prime} \text { intercept } \\
(\mathrm{mm})\end{array}$ & $\begin{array}{c}\text { C' }^{\prime} \text { offset } \\
(\mathrm{mm})\end{array}$ & $C^{\prime}$ spacing & $\begin{array}{c}\text { Mean C' } \\
\text { offset }\end{array}$ & $\begin{array}{c}\text { Mean } \\
\text { Spacing }\end{array}$ & $\begin{array}{c}\text { Error } \\
\text { Offset }\end{array}$ & $\begin{array}{c}\text { Error } \\
\text { Spacing }\end{array}$ & $\begin{array}{c}C^{\prime} \text { thickness } \\
(\mu \mathrm{m})\end{array}$ \\
\hline & 0 & 2 & 5 & 2 & 5 & & & 129 \\
\hline & 5 & 2 & & & & & & \\
\hline
\end{tabular}

\begin{tabular}{|r|r|r|r|r|r|r|r|r|}
\hline Sample & $61 \mathrm{~A} / 70$ & & & & & & & \\
\hline Parameter & $\begin{array}{c}C^{\prime} \text { intercept } \\
(\mathrm{mm})\end{array}$ & $\begin{array}{c}\text { C' }^{\prime} \text { offset } \\
(\mathrm{mm})\end{array}$ & $C^{\prime}$ 'spacing & $\begin{array}{c}\text { Mean C' } \\
\text { offset }\end{array}$ & $\begin{array}{c}\text { Mean } \\
\text { Spacing }\end{array}$ & $\begin{array}{c}\text { Error } \\
\text { Offset }\end{array}$ & $\begin{array}{c}\text { Error } \\
\text { Spacing }\end{array}$ & $\begin{array}{c}C^{\prime} \text { thickness } \\
(\mu \mathrm{m})\end{array}$ \\
\hline & 0 & 2 & 3 & 2.25 & 4.333333 & 1.25831 & 1.52753 & 157 \\
\hline & 3 & 2 & 6 & & & & & \\
\hline & 9 & 1 & 4 & & & & & \\
\hline
\end{tabular}

\begin{tabular}{|r|r|r|r|r|r|r|r|r|}
\hline Sample & G01/70/B & & & & & & & \\
\hline Parameter & $\begin{array}{c}C^{\prime} \text { intercept } \\
(\mathrm{mm})\end{array}$ & $\begin{array}{c}\text { C' }^{\prime} \text { (mfset } \\
(\mathrm{mm})\end{array}$ & C' spacing $^{\prime}$ & $\begin{array}{c}\text { Mean C' } \\
\text { offset }\end{array}$ & $\begin{array}{c}\text { Mean } \\
\text { Spacing }\end{array}$ & $\begin{array}{c}\text { Error } \\
\text { Offset }\end{array}$ & $\begin{array}{c}\text { Error } \\
\text { Spacing }\end{array}$ & $\begin{array}{c}C^{\prime} \text { thickness } \\
(\mu \mathrm{m})\end{array}$ \\
\hline & 2 & 0.5 & 1.5 & 0.5 & 1.5 & & & 24 \\
\hline & 3.5 & 0.5 & & & & & & \\
\hline
\end{tabular}

\begin{tabular}{|r|r|r|r|r|r|r|r|r|}
\hline Sample & G05/75 & & & & & & & \\
\hline Parameter & $\begin{array}{c}C^{\prime} \text { intercept } \\
(\mathrm{mm})\end{array}$ & $\begin{array}{c}C^{\prime} \text { offset } \\
(\mathrm{mm})\end{array}$ & $C^{\prime}$ spacing & $\begin{array}{c}\text { Mean } C^{\prime} \\
\text { offset }\end{array}$ & $\begin{array}{c}\text { Mean } \\
\text { Spacing }\end{array}$ & $\begin{array}{c}\text { Error } \\
\text { Offset }\end{array}$ & $\begin{array}{c}\text { Error } \\
\text { Spacing }\end{array}$ & $\begin{array}{c}C^{\prime} \text { thickness } \\
(\mu \mathrm{m})\end{array}$ \\
\hline & 3 & 3 & 4 & 2.5 & 4 & 0.5 & & 105 \\
\hline & 7 & 2 & & & & & & \\
\hline
\end{tabular}

\begin{tabular}{|r|l|r|r|r|r|r|r|r|}
\hline Sample & G06/86 & & & & & & & \\
\hline Parameter & $\begin{array}{c}C^{\prime} \text { intercept } \\
(\mathrm{mm})\end{array}$ & $\begin{array}{c}\text { C' }^{\prime} \text { offset } \\
(\mathrm{mm})\end{array}$ & $C^{\prime}$ spacing & $\begin{array}{c}\text { Mean C' } \\
\text { offset }\end{array}$ & $\begin{array}{c}\text { Mean } \\
\text { Spacing }\end{array}$ & $\begin{array}{c}\text { Error } \\
\text { Offset }\end{array}$ & $\begin{array}{c}\text { Error } \\
\text { Spacing }\end{array}$ & $\begin{array}{c}C^{\prime} \text { thickness } \\
(\mu \mathrm{m})\end{array}$ \\
\hline & 5 & 3 & 2 & 2 & 2 & 1 & & 94.98 \\
\hline
\end{tabular}




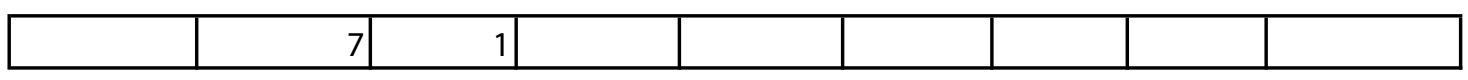

\begin{tabular}{|r|r|r|r|r|r|r|r|r|}
\hline Sample & G07/92 & & & & & & & \\
\hline Parameter & $\begin{array}{c}C^{\prime} \text { intercept } \\
(\mathrm{mm})\end{array}$ & $\begin{array}{c}\text { C' }^{\prime} \text { offset } \\
(\mathrm{mm})\end{array}$ & C' 'spacing $^{\text {Mean C' }}$ & $\begin{array}{c}\text { Mean } \\
\text { offset }\end{array}$ & $\begin{array}{c}\text { Error } \\
\text { Spacing }\end{array}$ & $\begin{array}{c}\text { Error } \\
\text { Spacing }\end{array}$ & $\begin{array}{c}C^{\prime} \text { thickness } \\
(\mu \mathrm{m})\end{array}$ \\
\hline & 0 & 0.5 & 3 & 0.5 & 2.3 & & 0.5164 & 98.64 \\
\hline & 3 & 0.5 & 2 & & & & & \\
\hline & 5 & 0.5 & 2 & & & & & \\
\hline & 7 & 0.5 & 2 & & & & & \\
\hline & 9 & 0.5 & 3 & & & & & \\
\hline & 12 & 0.5 & 2 & & & & & \\
\hline & 14 & 0.5 & & & & & & \\
\hline
\end{tabular}


Garnet Porphyroblast Rotation Data

Geologist: Ben Gillam

Lab: Victoria University of Wellington

Data Collected: 2010

Samples Used: Tatare Stream

Data For: Gillam (Thesis)

Total Garnets:
Colour Key:

Mylonite

Distal-Mylonite

Schist

Transitional

Long Axis Internal inclusion Orientation (LA) orientation (SI)

\begin{tabular}{|c|}
\hline $25 \mathrm{~A} / 0$ \\
\hline $32 \mathrm{~B} / 115$ \\
\hline $31 \mathrm{~A} / 70$ \\
\hline $32 \mathrm{~B} / 25$ \\
\hline $31 \mathrm{~A} / 70$ \\
$31 \mathrm{~A} / 115$ \\
\hline $31 \mathrm{~B} / 25$ \\
\hline $42 \mathrm{~A} / 115$ \\
\hline $31 \mathrm{~B} / 70$ \\
\hline $25 \mathrm{~B} / 45$ \\
\hline $42 \mathrm{~A} / 115$ \\
$41 \mathrm{~A} / 115$ \\
\hline $32 \mathrm{~B} / 25$ \\
$48 \mathrm{C} / 115$ \\
\hline $50 \mathrm{~A} / 70$ \\
\hline $32 \mathrm{~B} / 70$ \\
$32 \mathrm{~B} / 70$ \\
$32 \mathrm{~B} / 70$ \\
\hline $31 \mathrm{~A} / 70$ \\
\hline $33 \mathrm{~A} / 115$ \\
\hline $31 \mathrm{~B} / 70$ \\
\hline $33 \mathrm{~A} / 70$ \\
\hline $31 \mathrm{~B} / 25$ \\
\hline $54 \mathrm{~A} / 70$ \\
\hline $33 \mathrm{~A} / 25$ \\
\hline $32 \mathrm{~B} / 25$ \\
\hline $36 \mathrm{~A} / 115$ \\
$38 \mathrm{~A} / 115$ \\
\hline $45 \mathrm{~B} / 115$ \\
\hline $34 \mathrm{~A} / 25$ \\
$32 \mathrm{~B} / 115$ \\
\hline $31 \mathrm{~A} / 115$ \\
$31 \mathrm{~B} / 25$ \\
\hline $34 \mathrm{~A} / 70$ \\
\hline $53 \mathrm{~B} / 115$ \\
\hline $32 \mathrm{~B} / 70$ \\
\hline \\
\hline
\end{tabular}

90

90

90

90

90

90

90

71

90

115

59

86

60

90

115

90

90

90

90

90

143

90

155

52

64

90

67

125

47

90

28

41

44

90

45

74
Aspect Ratio R

1.000

1.000

1.000

1.000

1.000

1.000

1.000

1.000

1.000

1.000

1.000

1.000

1.000

1.000

1.000

1

1

1

1

1.024

1.033

1.035

1.035714286

1.042

1.043

1.050

1.050

1.058

1.059

1.065

1.067

1.068965517

1.070

1.077

1.077

1.080
Ghosh LA

180

180

180

180

180

180

180

161

180

25

149

176

150

180

25

0

\section{0}

0

0

180

53

180

65

142

154

180

157

35

137

180

118

131

134

180

135

164
Ghosh SI

90

90

108

130

146

150

153

165

169

25

27

36

45

47

60

32

16

73

122

160

130

168

151

135

154

125

157

150

137

148

115

105

134

150

157

153

Gillam, B. G. 


\begin{tabular}{|c|c|c|c|c|c|}
\hline $41 \mathrm{~A} / 115$ & 81 & 68 & 1.080 & 171 & 158 \\
\hline $43 \mathrm{~A} / 70$ & 60 & 68 & 1.083 & 150 & 158 \\
\hline $31 \mathrm{~B} / 70$ & 138 & 44 & 1.086956522 & 48 & 134 \\
\hline $42 \mathrm{~A} / 70$ & 31 & 46 & 1.090 & 121 & 136 \\
\hline $66 \mathrm{~A} / 70$ & 96 & 98 & 1.090 & 6 & 8 \\
\hline $54 \mathrm{~A} / 70$ & 98 & 49 & 1.091 & 8 & 139 \\
\hline $25 \mathrm{~A} / 45$ & 70 & 102 & 1.091 & 160 & 12 \\
\hline $32 \mathrm{~B} / 70$ & 130 & 97 & 1.090909091 & 40 & 7 \\
\hline $36 \mathrm{~A} / 70$ & 89 & 89 & 1.094 & 179 & 179 \\
\hline $48 C / 115$ & 108 & 28 & 1.100 & 18 & 118 \\
\hline $41 \mathrm{~A} / 115$ & 90 & 67 & 1.100 & 180 & 157 \\
\hline $50 \mathrm{~A} / 70$ & 69 & 90 & 1.100 & 159 & 180 \\
\hline $48 C / 115$ & 180 & 121 & 1.100 & 90 & 31 \\
\hline $25 \mathrm{~A} / 0$ & 140 & 140 & 1.103 & 50 & 50 \\
\hline $43 \mathrm{~A} / 115$ & 90 & 50 & 1.104 & 180 & 140 \\
\hline $32 \mathrm{~B} / 70$ & 12 & 22 & 1.110 & 102 & 112 \\
\hline $37 A / 115$ & 7 & 45 & 1.110 & 97 & 135 \\
\hline $37 A / 115$ & 103 & 56 & 1.110 & 13 & 146 \\
\hline $53 \mathrm{~B} / 70$ & 86 & 96 & 1.117 & 176 & 6 \\
\hline $41 \mathrm{~A} / 70$ & 165 & 80 & 1.118 & 75 & 170 \\
\hline $32 \mathrm{~B} / 70$ & 70 & 170 & 1.119 & 160 & 80 \\
\hline $46 \mathrm{~A} / 70$ & 90 & 139 & 1.120 & 180 & 49 \\
\hline $52 / 100 / 70$ & 90 & 82 & 1.120 & 180 & 172 \\
\hline $36 \mathrm{~A} / 115$ & 41 & 41 & 1.125 & 131 & 131 \\
\hline $32 B / 25$ & 162 & 49 & 1.125 & 72 & 139 \\
\hline $55 \mathrm{~A} / 70$ & 143 & 70 & 1.125 & 53 & 160 \\
\hline $42 \mathrm{~A} / 115$ & 107 & 107 & 1.125 & 17 & 17 \\
\hline $32 \mathrm{~B} / 70$ & 180 & 102 & 1.125 & 90 & 12 \\
\hline $27 A / 115$ & 15 & 15 & 1.132 & 105 & 105 \\
\hline $43 \mathrm{~A} / 70$ & 43 & 43 & 1.133 & 133 & 133 \\
\hline $52 / 200 / 115$ & 90 & 49 & 1.133 & 180 & 139 \\
\hline $32 B / 25$ & 70 & 155 & 1.133333333 & 160 & 65 \\
\hline $31 \mathrm{~B} / 70$ & 140 & 33 & 1.142857143 & 50 & 123 \\
\hline $38 \mathrm{~A} / 115$ & 79 & 66 & 1.150 & 169 & 156 \\
\hline $36 \mathrm{~A} / 115$ & 35 & 55 & 1.154 & 125 & 145 \\
\hline $51 C / 70$ & 47 & 36 & 1.161 & 137 & 126 \\
\hline $32 \mathrm{~B} / 70$ & 168 & 128 & 1.164 & 78 & 38 \\
\hline $31 \mathrm{~A} / 70$ & 19 & 19 & 1.166666667 & 109 & 109 \\
\hline $52 / 200 / 115$ & 90 & 60 & 1.169 & 180 & 150 \\
\hline $32 \mathrm{~B} / 70$ & 156 & 54 & 1.170 & 66 & 144 \\
\hline $31 \mathrm{~B} / 25$ & 58 & 31 & 1.174 & 148 & 121 \\
\hline $31 \mathrm{~B} / 70$ & 145 & 52 & 1.173913043 & 55 & 142 \\
\hline $32 B / 25$ & 33 & 138 & 1.176470588 & 123 & 48 \\
\hline A03/A/P & 178 & 150 & 1.179 & 88 & 60 \\
\hline $31 \mathrm{~B} / 70$ & 90 & 49 & 1.181818182 & 0 & 139 \\
\hline $50 \mathrm{~A} / 70$ & 60 & 60 & 1.188 & 150 & 150 \\
\hline
\end{tabular}

Gillam, B. G. 


\begin{tabular}{|c|c|c|c|c|c|}
\hline $25 \mathrm{~A} / 90$ & 135 & 135 & 1.188 & 45 & 45 \\
\hline $55 \mathrm{~A} / 70$ & 106 & 31 & 1.200 & 16 & 121 \\
\hline $31 \mathrm{~A} / 70$ & 46 & 46 & 1.200 & 136 & 136 \\
\hline $38 \mathrm{~A} / 115$ & 109 & 56 & 1.200 & 19 & 146 \\
\hline $41 \mathrm{~A} / 70$ & 65 & 58 & 1.200 & 155 & 148 \\
\hline $45 B / 115$ & 165 & 78 & 1.200 & 75 & 168 \\
\hline $33 \mathrm{~A} / 70$ & 10 & 125 & 1.200 & 100 & 35 \\
\hline $55 A / 115$ & 77 & 126 & 1.200 & 167 & 36 \\
\hline $50 \mathrm{~A} / 70$ & 65 & 138 & 1.200 & 155 & 48 \\
\hline $32 B / 25$ & 166 & 147 & 1.210526316 & 76 & 57 \\
\hline $51 C / 115$ & 58 & 149 & 1.214 & 148 & 59 \\
\hline G05/75 & 147 & 140 & 1.214 & 57 & 50 \\
\hline $32 B / 25$ & 48 & 134 & 1.217 & 138 & 44 \\
\hline $45 B / 70$ & 31 & 84 & 1.220 & 121 & 174 \\
\hline G07/92 & 156 & 156 & 1.222 & 66 & 66 \\
\hline $31 \mathrm{~B} / 70$ & 128 & 8 & 1.231 & 38 & 98 \\
\hline $31 \mathrm{~B} / 70$ & 146 & 62 & 1.231 & 56 & 152 \\
\hline $32 \mathrm{~B} / 70$ & 7 & 99 & 1.230769231 & 97 & 9 \\
\hline $32 \mathrm{~B} / 70$ & 66 & 161 & 1.230769231 & 156 & 71 \\
\hline $32 B / 25$ & 172 & 172 & 1.230769231 & 82 & 82 \\
\hline $27 \mathrm{~A} / 115$ & 55 & 40 & 1.233 & 145 & 130 \\
\hline G05/30 & 13 & 132 & 1.235 & 103 & 42 \\
\hline $32 \mathrm{~B} / 70$ & 140 & 130 & 1.235294118 & 50 & 40 \\
\hline $31 \mathrm{~A} / 25$ & 130 & 9 & 1.250 & 40 & 99 \\
\hline $51 C / 70$ & 125 & 56 & 1.250 & 35 & 146 \\
\hline $34 \mathrm{~B} / 25$ & 114 & 67 & 1.250 & 24 & 157 \\
\hline $53 B / 115$ & 90 & 112 & 1.250 & 180 & 22 \\
\hline $25 B / 45$ & 129 & 143 & 1.250 & 39 & 53 \\
\hline $54 \mathrm{~A} / 115$ & 90 & 178 & 1.250 & 180 & 88 \\
\hline $32 B / 25$ & 43 & 130 & 1.25 & 133 & 40 \\
\hline $31 \mathrm{~B} / 25$ & 60 & 35 & 1.257142857 & 150 & 125 \\
\hline $33 \mathrm{~A} / 70$ & 70 & 65 & 1.267 & 160 & 155 \\
\hline $27 \mathrm{~A} / 25$ & 55 & 3 & 1.269 & 145 & 93 \\
\hline $43 \mathrm{~A} / 115$ & 29 & 29 & 1.270 & 119 & 119 \\
\hline $42 \mathrm{~A} / 70$ & 18 & 98 & 1.272 & 108 & 8 \\
\hline $31 \mathrm{~A} / 70$ & 40 & 40 & 1.272727273 & 130 & 130 \\
\hline $31 \mathrm{~A} / 70$ & 47 & 65 & 1.272727273 & 137 & 155 \\
\hline $26 \mathrm{~A} / 98$ & 120 & 120 & 1.273 & 30 & 30 \\
\hline $26 \mathrm{~A} / 98$ & 124 & 124 & 1.273 & 34 & 34 \\
\hline $66 \mathrm{~A} / 70$ & 148 & 130 & 1.273 & 58 & 40 \\
\hline $41 \mathrm{~A} / 115$ & 53 & 66 & 1.280 & 143 & 156 \\
\hline $26 \mathrm{~A} / 53$ & 110 & 130 & 1.286 & 20 & 40 \\
\hline $54 \mathrm{~A} / 115$ & 90 & 53 & 1.288 & 180 & 143 \\
\hline $37 A / 70$ & 64 & 43 & 1.300 & 154 & 133 \\
\hline $45 B / 115$ & 48 & 48 & 1.300 & 138 & 138 \\
\hline $52 / 100 / 70$ & 125 & 62 & 1.300 & 35 & 152 \\
\hline
\end{tabular}

Gillam, B. G. 


\begin{tabular}{|c|}
\hline $25 \mathrm{~B} / 90$ \\
\hline $32 \mathrm{~B} / 70$ \\
\hline $55 A / 115$ \\
\hline $32 \mathrm{~B} / 70$ \\
\hline $32 B / 25$ \\
\hline $31 \mathrm{~A} / 115$ \\
\hline $53 \mathrm{~A} / 70$ \\
\hline $32 \mathrm{~B} / 70$ \\
\hline $26 \mathrm{~A} / 148$ \\
\hline $32 \mathrm{~B} / 70$ \\
\hline $32 \mathrm{~B} / 70$ \\
\hline $31 \mathrm{~A} / 70$ \\
\hline $55 \mathrm{~A} / 70$ \\
\hline $32 \mathrm{~B} / 70$ \\
\hline $31 \mathrm{~A} / 115$ \\
\hline $51 C / 70$ \\
\hline $26 \mathrm{~A} / 98$ \\
\hline $52 / 200 / 115$ \\
\hline $48 C / 70$ \\
\hline $32 \mathrm{~B} / 25$ \\
\hline $38 \mathrm{~A} / 115$ \\
\hline $42 \mathrm{~A} / 70$ \\
\hline $31 \mathrm{~A} / 70$ \\
\hline $43 A / 115$ \\
\hline $32 B / 115$ \\
\hline $50 \mathrm{~A} / 70$ \\
\hline $43 \mathrm{~A} / 70$ \\
\hline $25 \mathrm{~A} / 90$ \\
\hline $32 \mathrm{~B} / 70$ \\
\hline $31 \mathrm{~B} / 70$ \\
\hline $32 \mathrm{~B} / 70$ \\
\hline $66 \mathrm{~A} / 115$ \\
\hline $43 A / 115$ \\
\hline G05/75 \\
\hline $32 \mathrm{~B} / 25$ \\
\hline $32 \mathrm{~B} / 25$ \\
\hline $34 \mathrm{~A} / 70$ \\
\hline $46 \mathrm{~A} / 115$ \\
\hline $27 A / 115$ \\
\hline $32 \mathrm{~B} / 115$ \\
\hline $26 \mathrm{~A} / 53$ \\
\hline $32 \mathrm{~B} / 115$ \\
\hline G05/75 \\
\hline $41 \mathrm{~A} / 115$ \\
\hline $25 \mathrm{~A} / 0$ \\
\hline $27 \mathrm{~A} / 25$ \\
\hline
\end{tabular}

167

131

41

170

135

28

35

65

178

113

115

37

113

68

33

54

124

130

170

145

25

37

40

57

60

80

105

116

165

46

152

54

94

120

100

124

85

138

38

15

120

132

145

86

154

60

$$
\begin{gathered}
1.308 \\
1.307692308 \\
1.310 \\
1.3125 \\
1.3125 \\
1.329 \\
1.333 \\
1.333 \\
1.333
\end{gathered}
$$

1.333333333

1.333333333

1.333333333

1.346

1.349

1.352941176

1.354

1.364

1.375

1.380

1.384615385

1.400

1.400

1.400

1.400

1.400

1.400

1.400

1.400

1.4

1.4

1.411764706

1.417

1.417

1.429

1.428571429

1.4375

1.438

1.442

1.460

1.462

1.462

1.461538462

1.463

1.467

1.470

1.471
77

115

27

157

145

28

118

110

80

95

70

35

180

90

30

38

34

179

90

122

39

140

130

90

90

170

76

33

75

136

118

180

100

44

127

106

78

138

123

162

30

64

41

74

64

152
77

41

131

80

45

118

125

155

88

23

25

127

23

158

123

144

34

40

80

55

115

127

130

147

150

170

15

26

75

136

62

144

4

30

10

34

175

48

128

105

30

42

55

176

64

150 


\begin{tabular}{|c|ccccc}
\hline $26 \mathrm{~A} / 98$ & 135 & 135 & 1.471 & 45 & 45 \\
\hline $\mathrm{A} 03 / \mathrm{A} / \mathrm{P}$ & 90 & 5 & 1.480 & 180 & 95 \\
\hline $25 \mathrm{~B} / 90$ & 160 & 160 & 1.480 & 70 & 70 \\
$25 \mathrm{~B} / 45$ & 164 & 164 & 1.480 & 74 & 74 \\
\hline $\mathrm{A} 03 / \mathrm{A} / \mathrm{P}$ & 90 & 150 & 1.500 & 180 & 60 \\
\hline $32 \mathrm{~B} / 70$ & 20 & 118 & 1.5 & 110 & 28 \\
$32 \mathrm{~B} / 70$ & 31 & 135 & 1.5 & 121 & 45 \\
$32 \mathrm{~B} / 70$ & 54 & 166 & 1.5 & 144 & 76 \\
\hline $31 \mathrm{~A} / 70$ & 68 & 68 & 1.5 & 158 & 158 \\
\hline $51 \mathrm{C} / 70$ & 168 & 67 & 1.500 & 78 & 157
\end{tabular}

Gillam, B. G. 


\begin{tabular}{|c|c|c|c|c|c|c|c|c|c|c|c|c|c|c|c|c|c|}
\hline 总 & 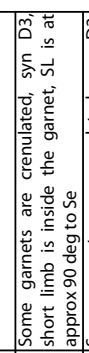 & 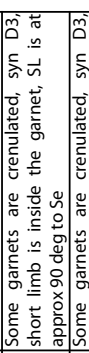 & 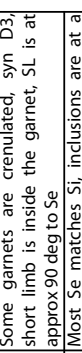 & 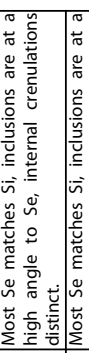 & 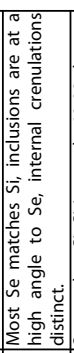 & 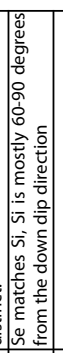 & 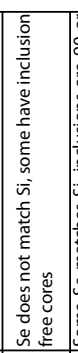 & 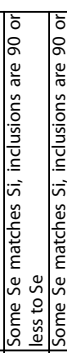 & & 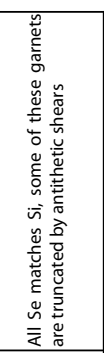 & 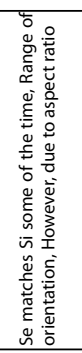 & 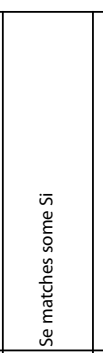 & 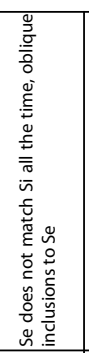 & 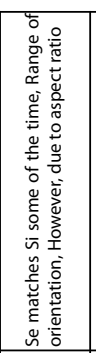 & 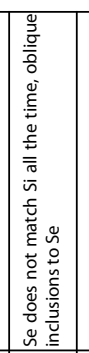 & 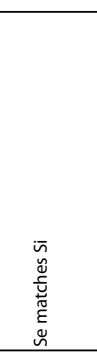 & 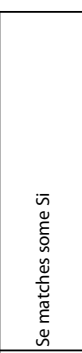 \\
\hline 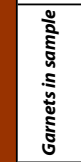 & $\stackrel{\circ}{\circ}$ & $\circ$ & $\infty$ & $\sigma$ & + & $m$ & n & 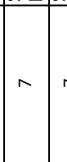 & - & + & n & $=$ & n & 0 & in & $a$ & $\sim$ \\
\hline 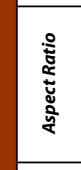 & 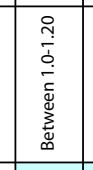 & 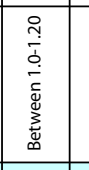 & 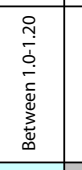 & 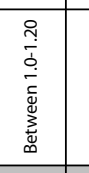 & 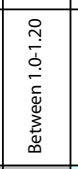 & 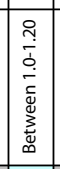 & 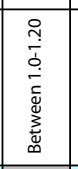 & 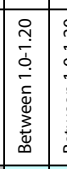 & 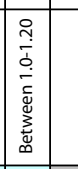 & 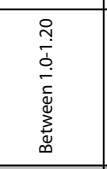 & 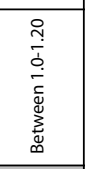 & 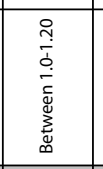 & & 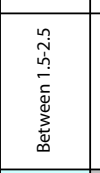 & 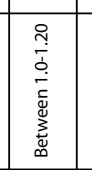 & 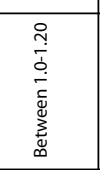 & 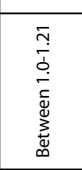 \\
\hline 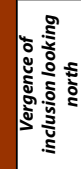 & $\begin{array}{l}\frac{\rho}{\bar{p}} \\
\stackrel{\partial}{\partial}\end{array}$ & \begin{tabular}{|l}
$\frac{2}{\overline{7}}$ \\
$\frac{1}{3}$
\end{tabular} & $\begin{array}{l}\frac{2}{\bar{t}} \\
\stackrel{0}{\partial}\end{array}$ & 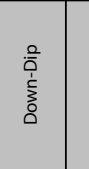 & 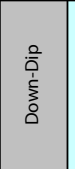 & 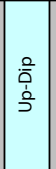 & 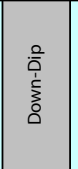 & \begin{tabular}{|l|}
$\frac{2}{\bar{\eta}}$ \\
$\frac{1}{2}$ \\
$=$
\end{tabular} & \begin{tabular}{|l|}
$\frac{2}{7}$ \\
$\frac{1}{3}$ \\
\multirow{2}{*}{}
\end{tabular} & 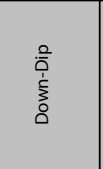 & 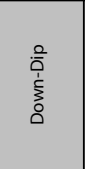 & $\begin{array}{l}\text { o. } \\
\text { ò } \\
\text { ⿳亠二口⿱幺小 }\end{array}$ & 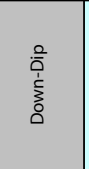 & $\begin{array}{l}\frac{2}{\overline{7}} \\
\frac{\dot{b}}{3}\end{array}$ & $\begin{array}{l}\text { 哀 } \\
\text { 言 }\end{array}$ & $\begin{array}{l}\frac{2}{\bar{y}} \\
\frac{b}{2}\end{array}$ & $\begin{array}{l}\frac{2}{\bar{\eta}} \\
\frac{\dot{b}}{3}\end{array}$ \\
\hline 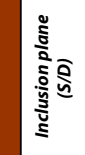 & 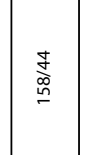 & 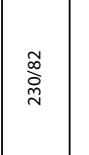 & 表 & 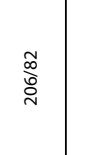 & \begin{tabular}{|c|}
$\tilde{\infty}$ \\
$\stackrel{\infty}{\Delta}$ \\
$\sim$
\end{tabular} & \begin{tabular}{|l|} 
\\
\\
\\
\end{tabular} & 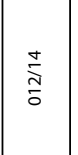 & 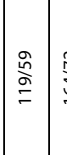 & \begin{tabular}{|l|} 
\\
奀 \\
\end{tabular} & 总 & 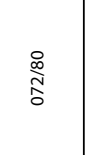 & 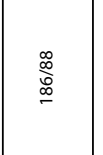 & & & 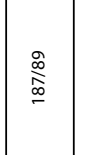 & 荅 & \\
\hline 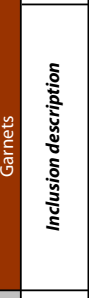 & 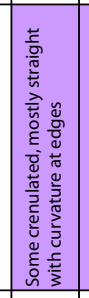 & 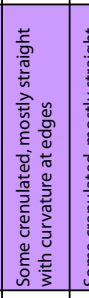 & 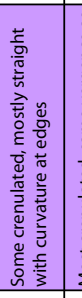 & 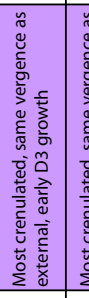 & 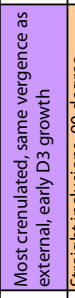 & 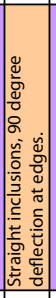 & 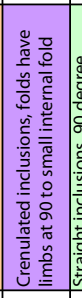 & 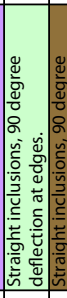 & & 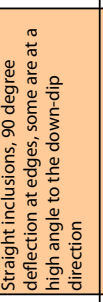 & 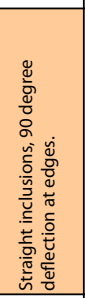 & 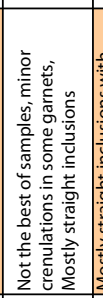 & 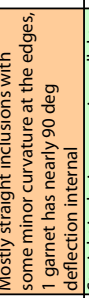 & 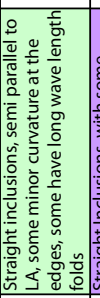 & 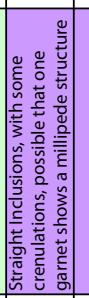 & 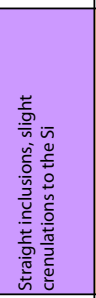 & 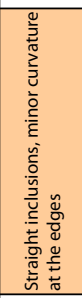 \\
\hline 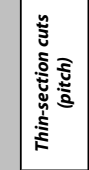 & 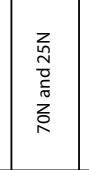 & 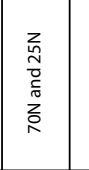 & 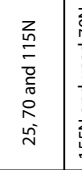 & 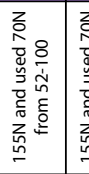 & 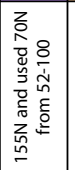 & 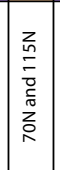 & 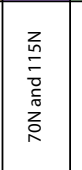 & 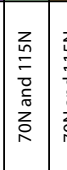 & 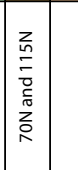 & 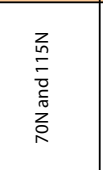 & $\begin{array}{l}\text { zo } \\
\text { o } \\
\text { o } \\
\text { on } \\
0 \\
0\end{array}$ & $\begin{array}{l}z \\
\text { z } \\
\text { o. } \\
\overline{0} \\
\text { y } \\
0\end{array}$ & 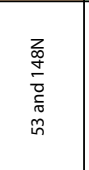 & 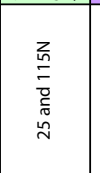 & 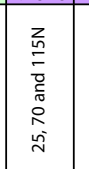 & 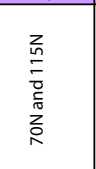 & $\begin{array}{l}\frac{2}{2} \\
\frac{7}{7} \\
\frac{c}{5} \\
\frac{1}{1}\end{array}$ \\
\hline 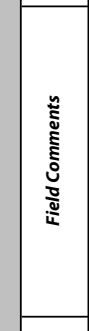 & 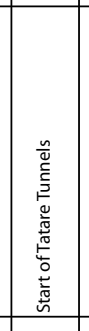 & 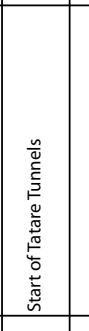 & 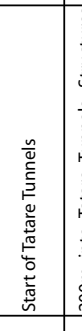 & 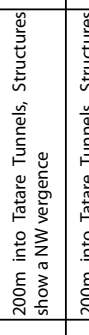 & 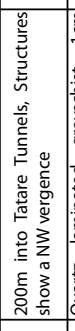 & 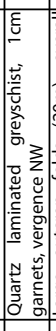 & 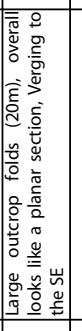 & 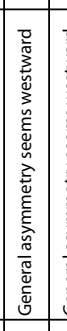 & 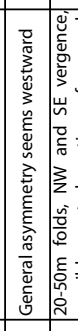 & 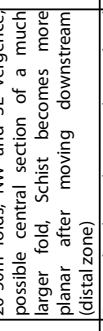 & 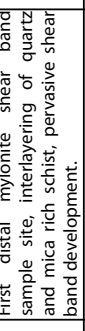 & 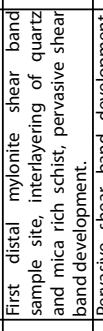 & 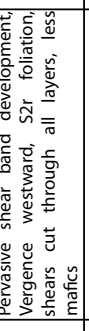 & 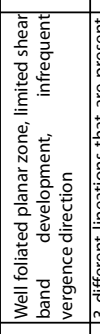 & 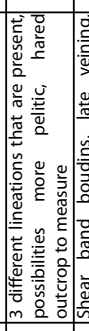 & 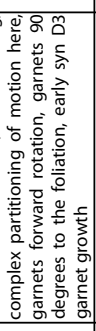 & 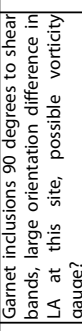 \\
\hline 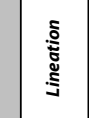 & $\sum_{i}^{m}$ & 岱 & 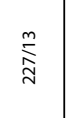 & 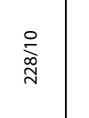 & 品 & 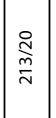 & 䓂 & 弪 & 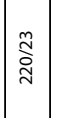 & 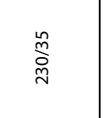 & 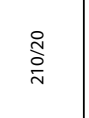 & 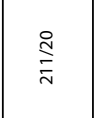 & 誉 & $\frac{\stackrel{2}{n}}{\sqrt[n]{n}}$ & 怘 & $\begin{array}{c}\text { 高 } \\
\text { ळ. }\end{array}$ & \\
\hline 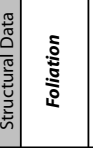 & 㕝 & 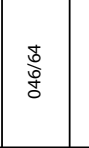 & 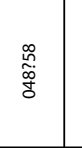 & $\begin{array}{l}\text { 㕝 } \\
\text { ơ }\end{array}$ & $\begin{array}{l}\text { 㕝 } \\
\text { 影 }\end{array}$ & 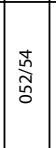 & 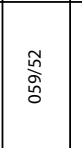 & 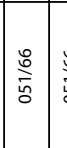 & 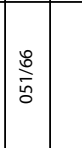 & 莡 & 总 & 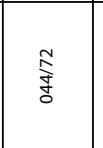 & $\begin{array}{l}\text { on } \\
\text { o }\end{array}$ & 蒿 & $\begin{array}{l}\frac{m}{g} \\
\frac{g}{\delta}\end{array}$ & $\frac{8}{90}$ & $\frac{5}{\partial}$ \\
\hline 产 & $\begin{array}{l}\frac{9}{p^{\circ}} \\
\vdots \\
\frac{1}{\alpha}\end{array}$ & 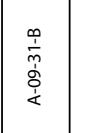 & $\begin{array}{l}\frac{4}{10} \\
0 \\
\vdots \\
⿱ 亠 乂\end{array}$ & 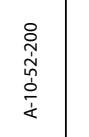 & $\begin{array}{l}\stackrel{8}{1} \\
\text { ஸ̂. } \\
\frac{0}{\dot{\alpha}}\end{array}$ & 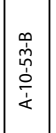 & 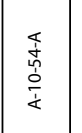 & 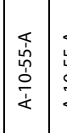 & 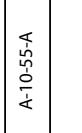 & 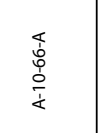 & 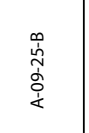 & 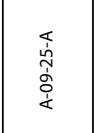 & 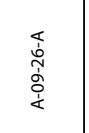 & 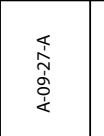 & 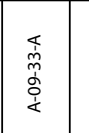 & 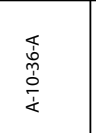 & $\frac{\hat{m}}{\dot{z}}$ \\
\hline 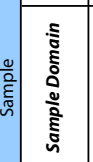 & 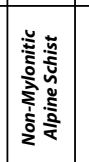 & & & & & & & & & & 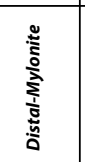 & & & & & & \\
\hline
\end{tabular}




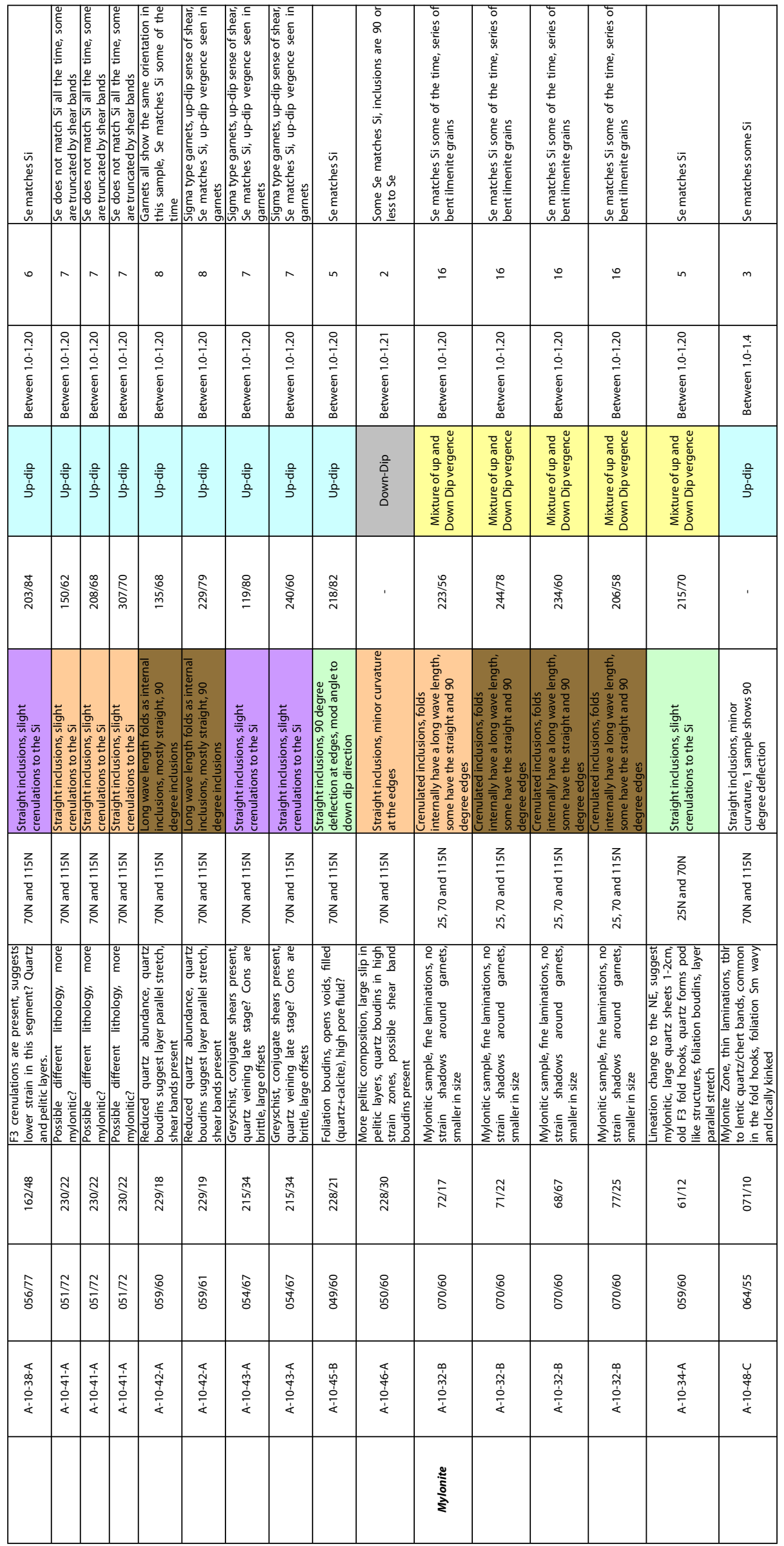




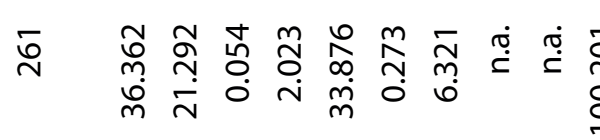

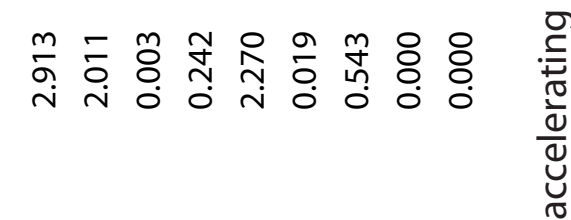

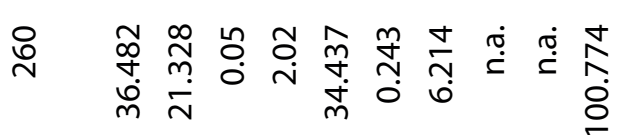

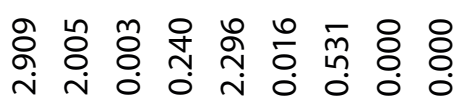
$\frac{\text { 离 }}{\frac{10}{2}}$

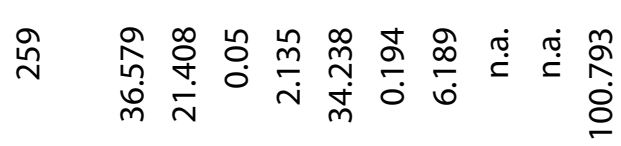

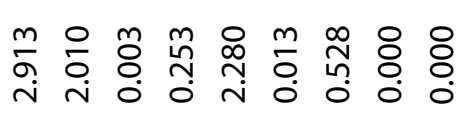

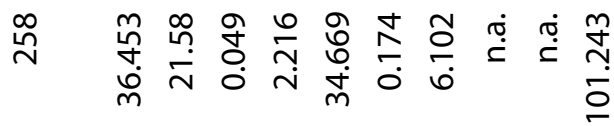

冬

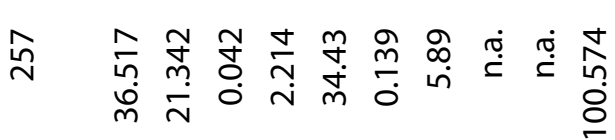

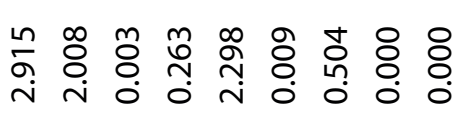

흐

$\frac{5}{\frac{7}{7}}$

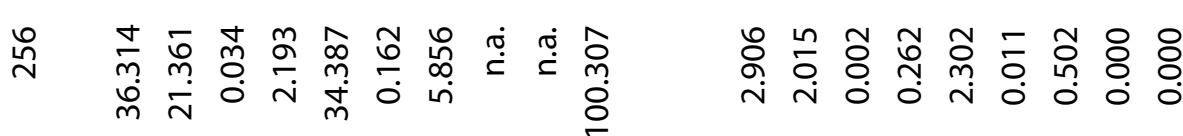

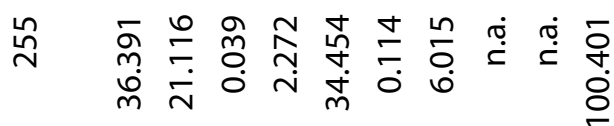

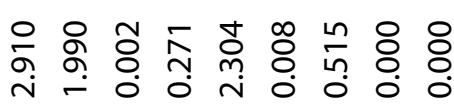

वे

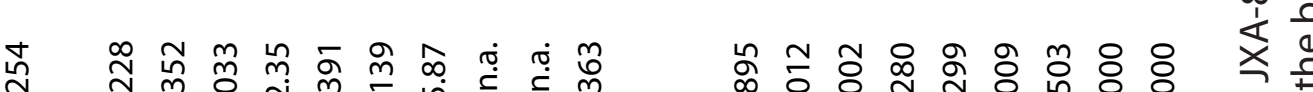

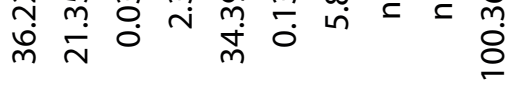

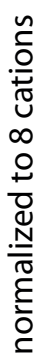

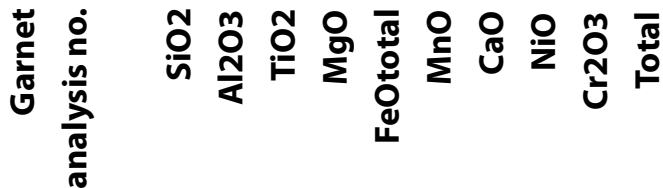

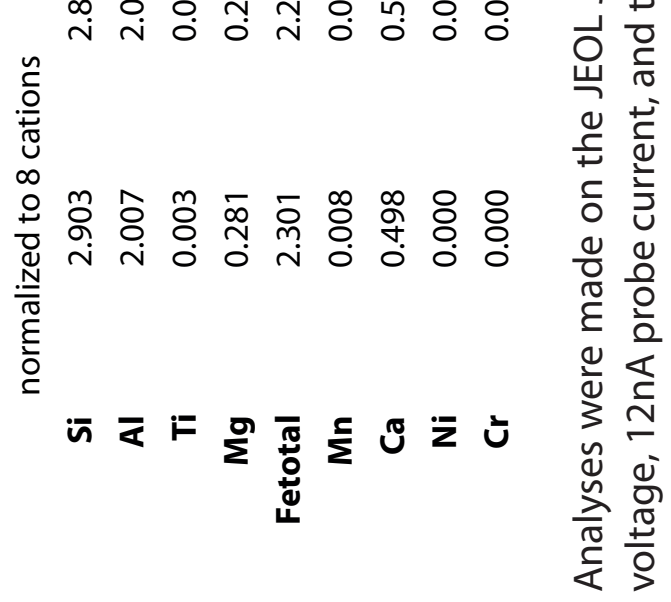




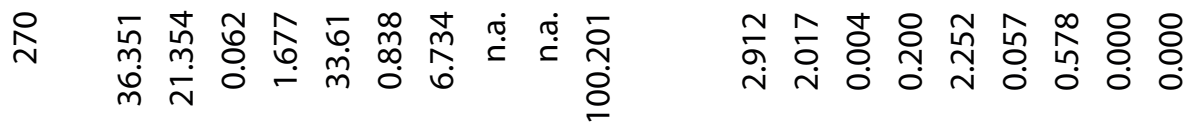

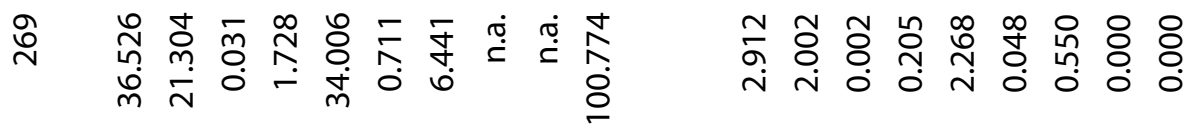

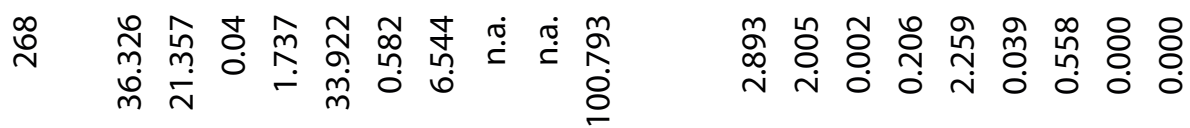

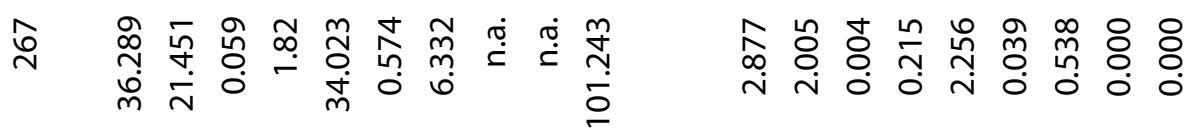

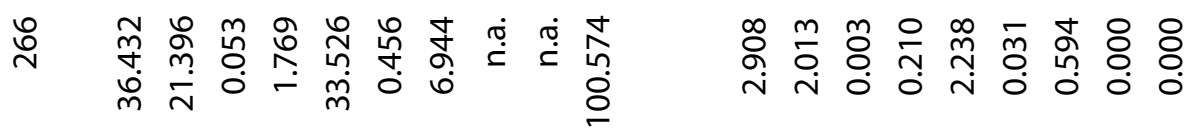

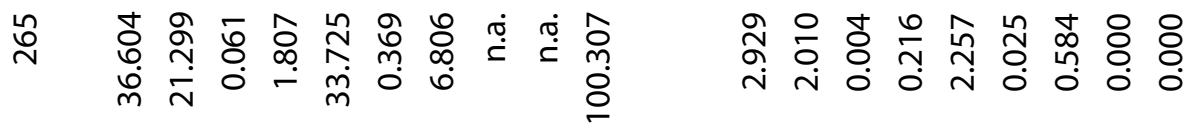

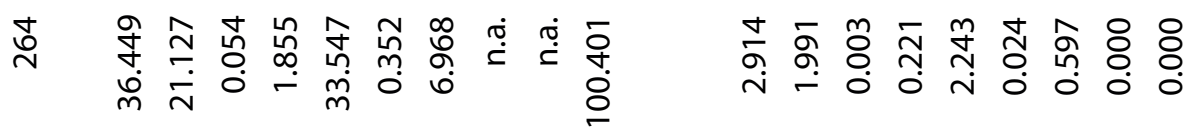

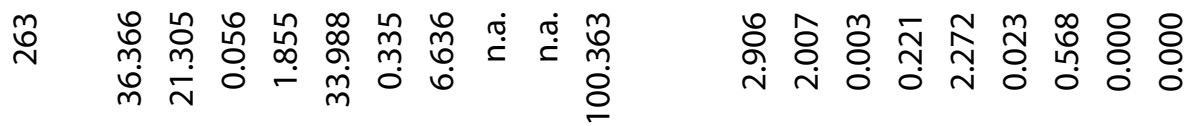

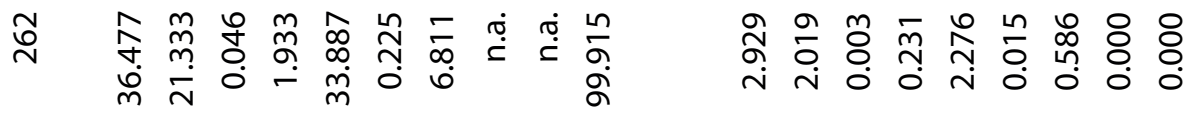

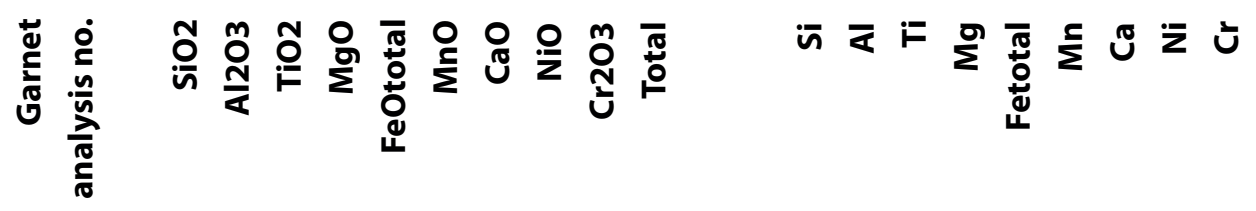


品

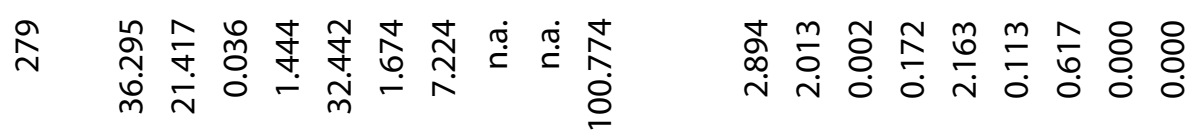

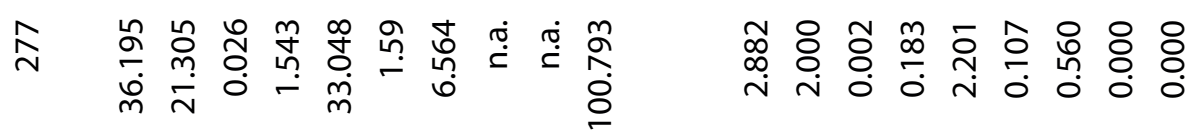

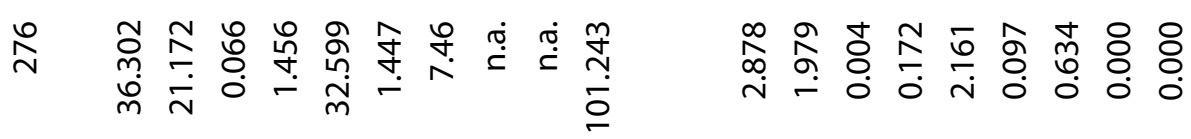

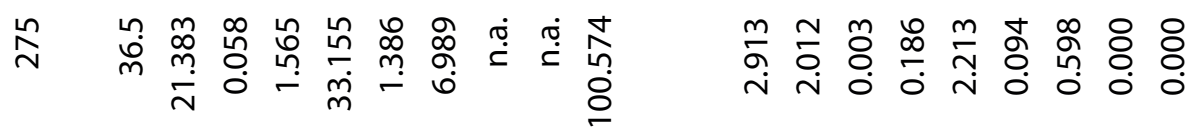

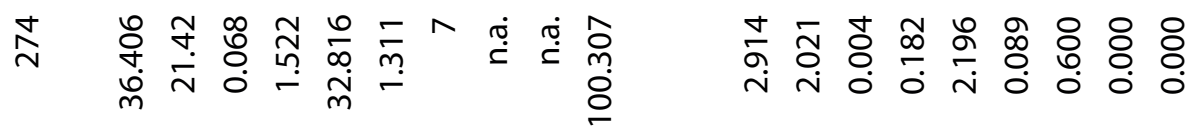

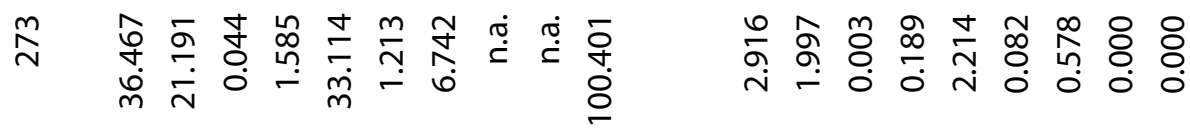

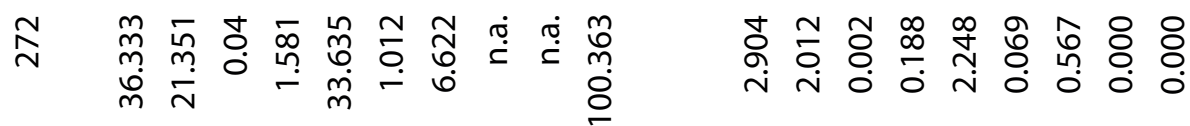

స

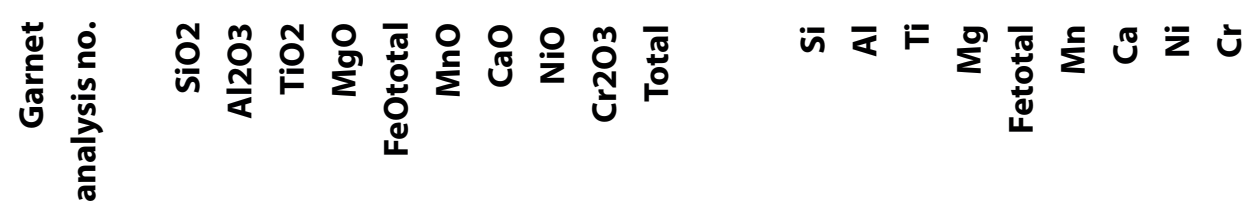




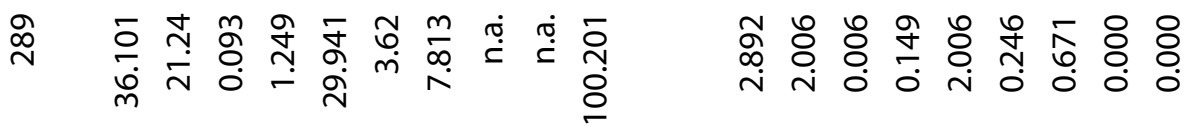

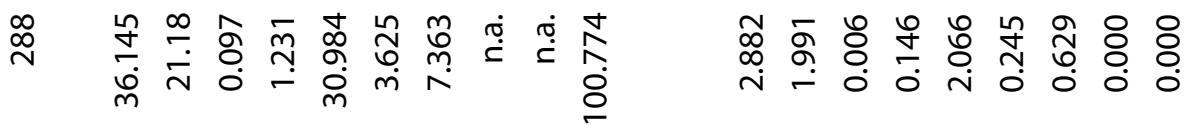

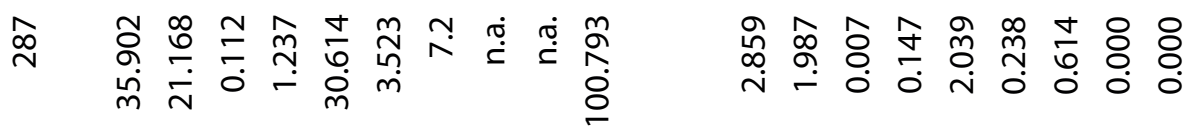

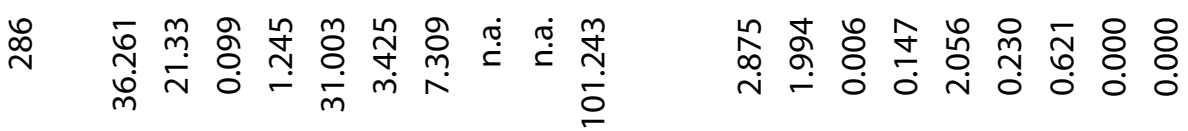

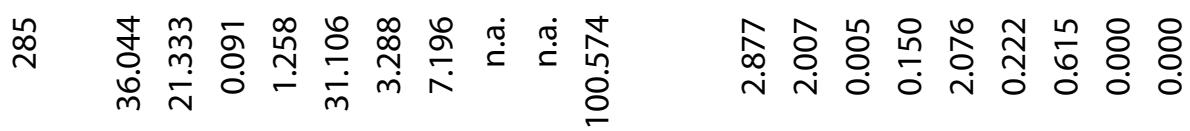

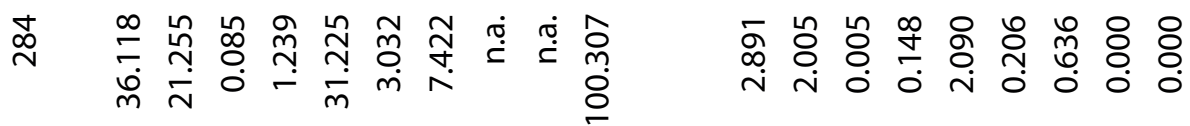

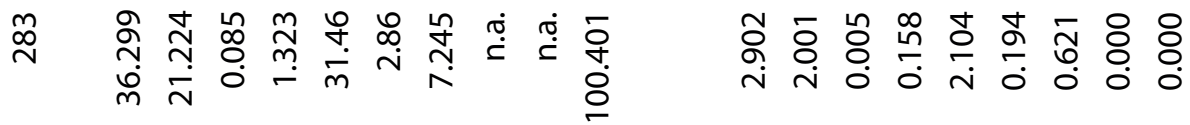

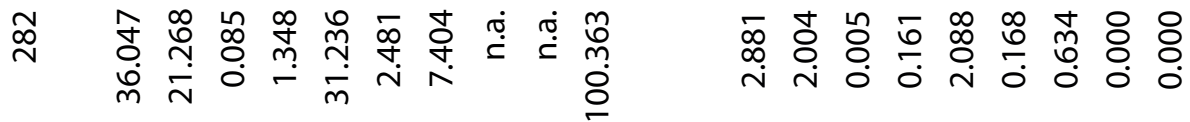

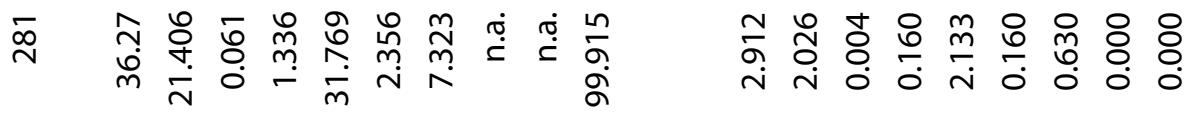

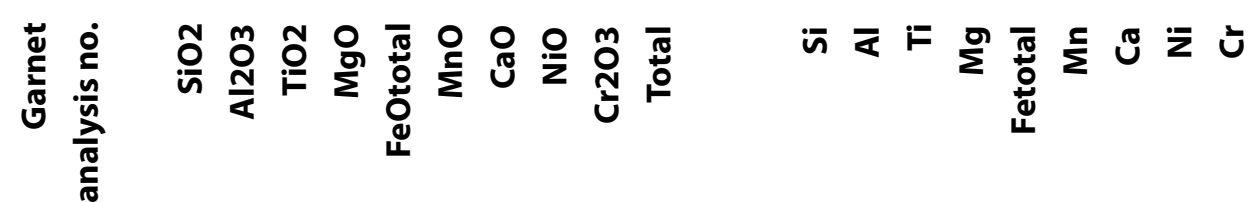




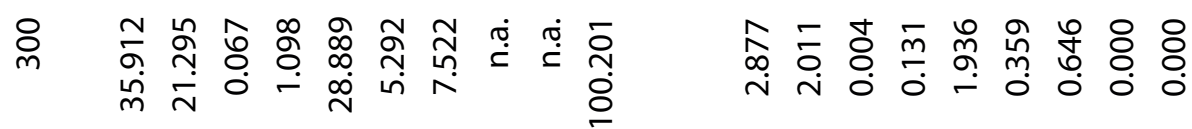

定

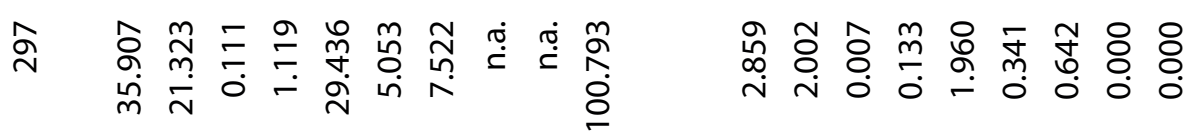

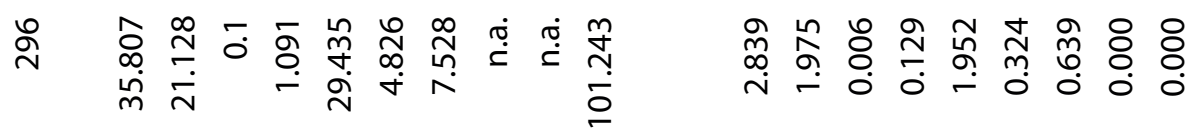

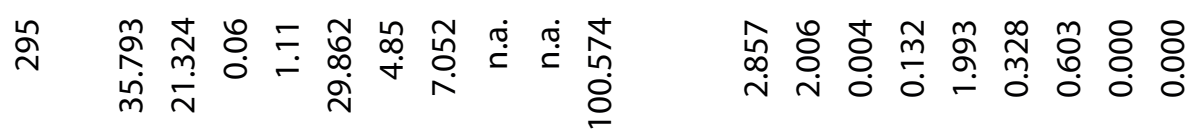

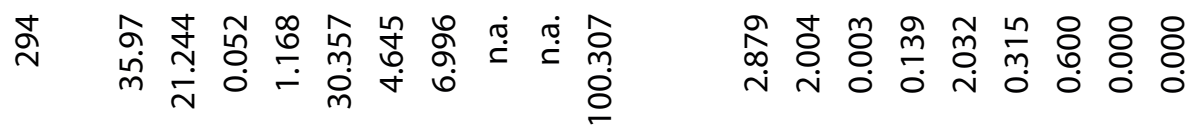

商

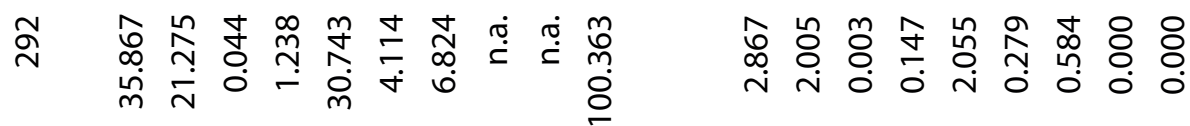

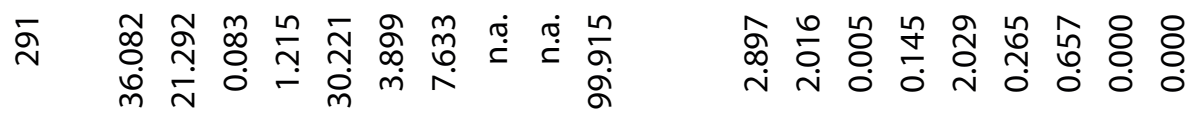

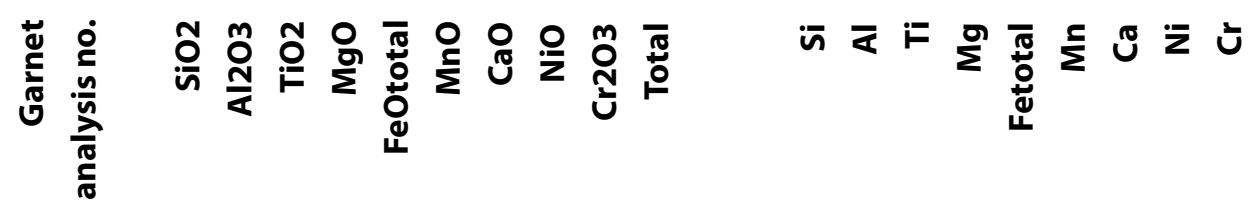




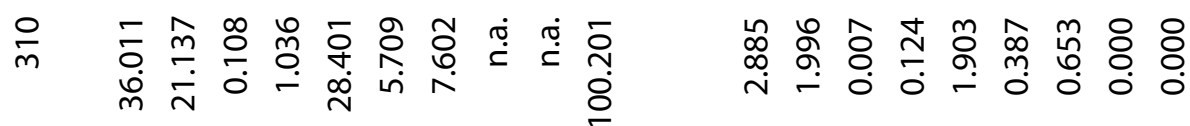

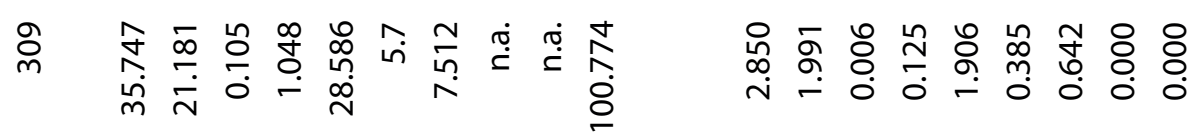

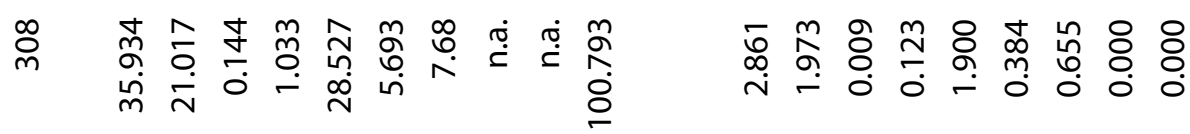

帝

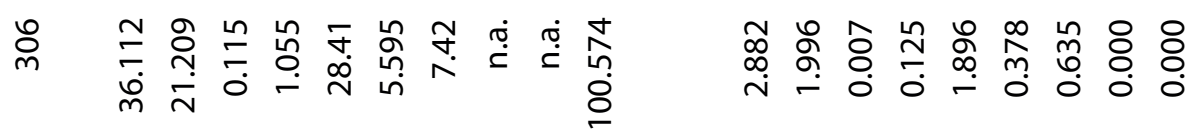

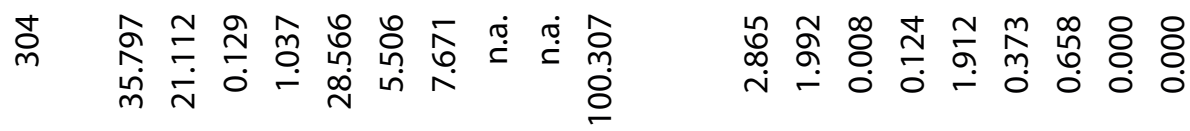

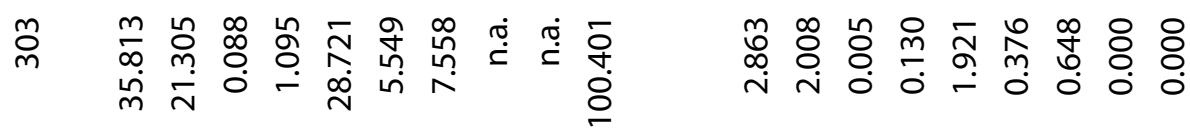

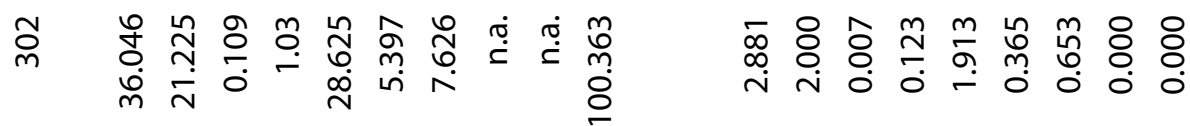

D

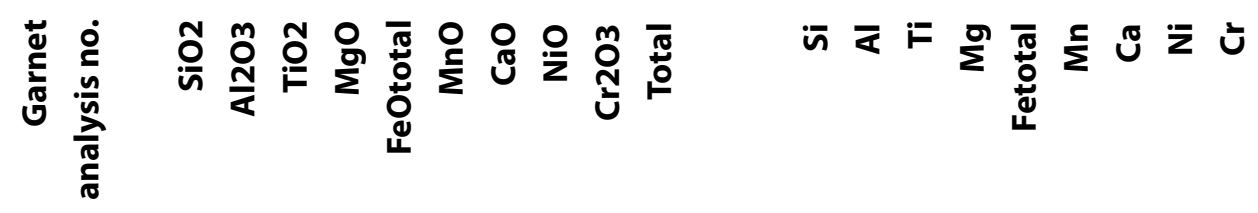




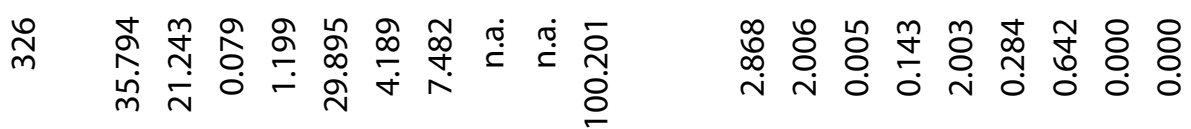

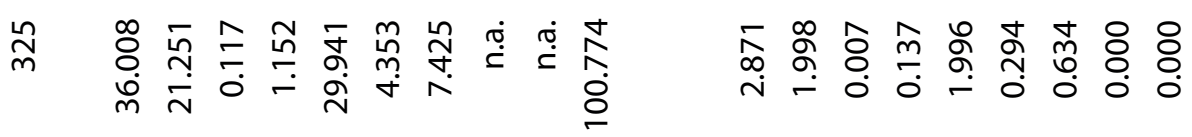

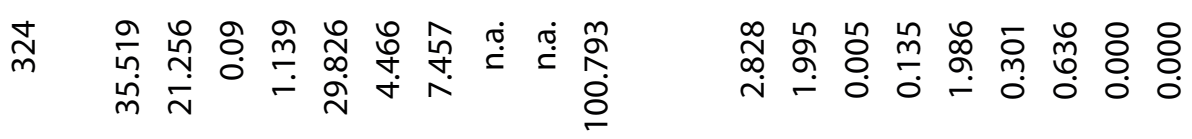

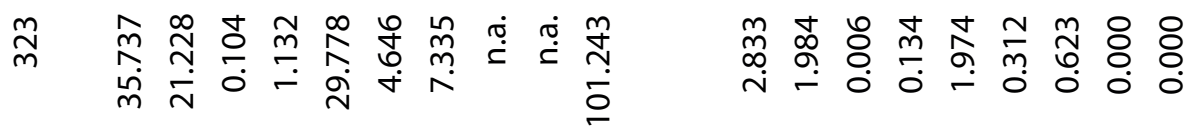

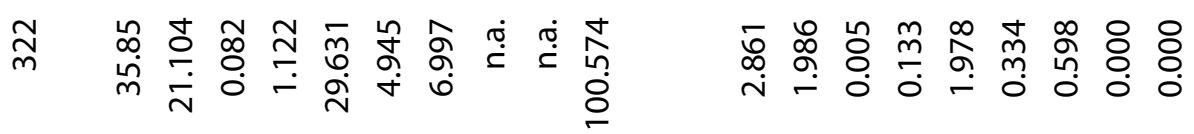

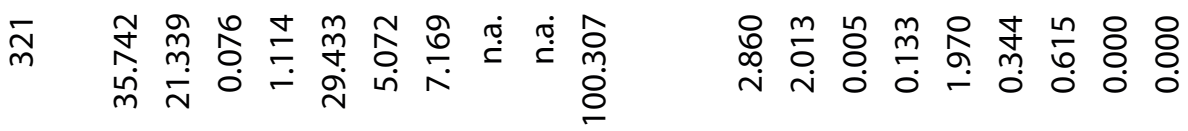

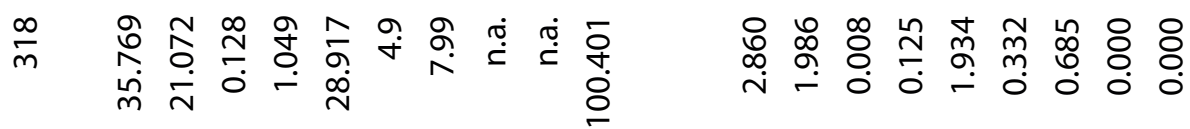

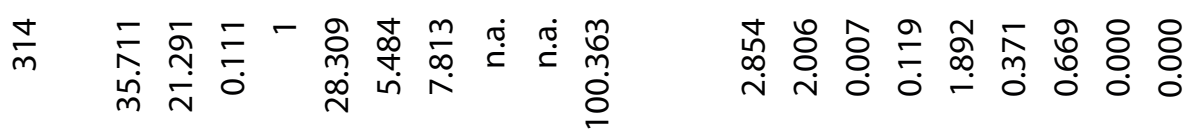

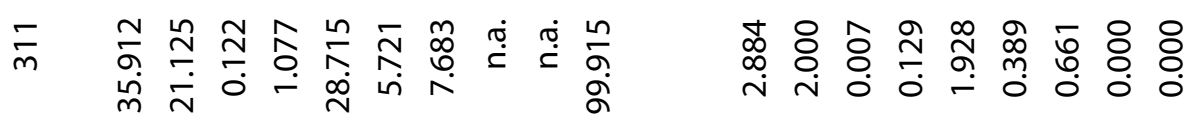

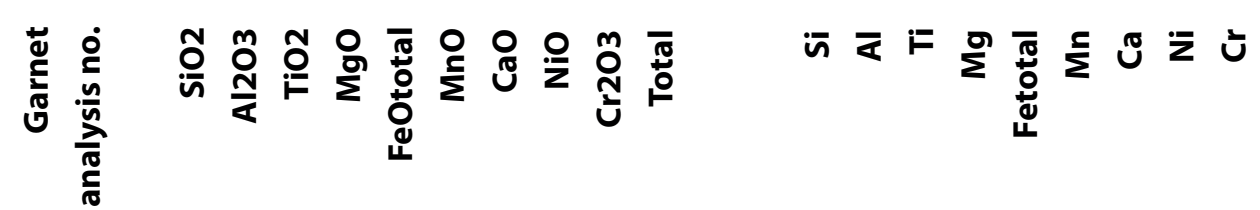




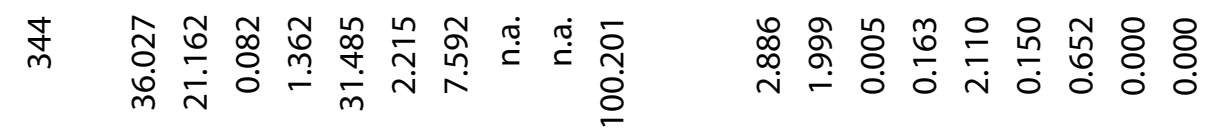

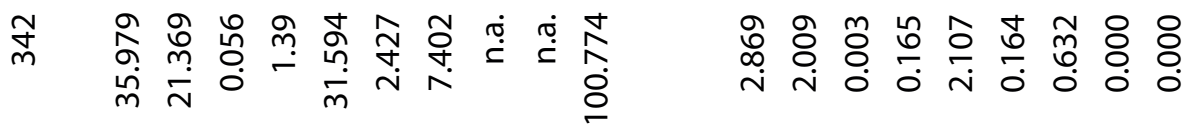

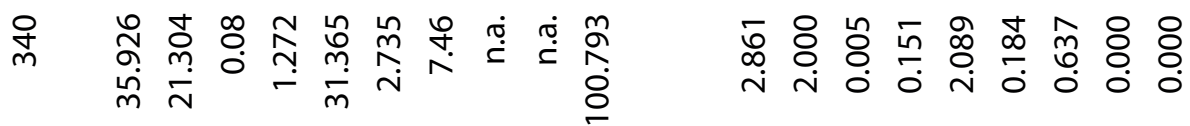

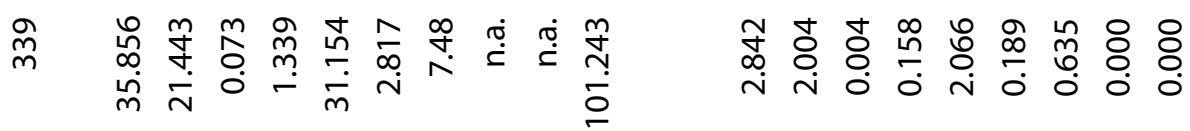

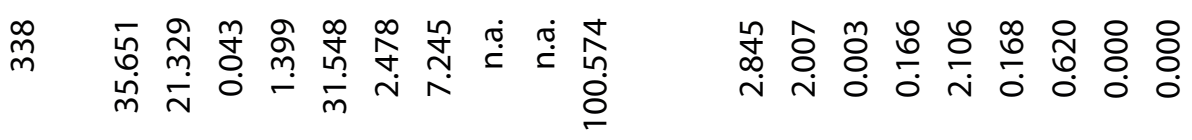

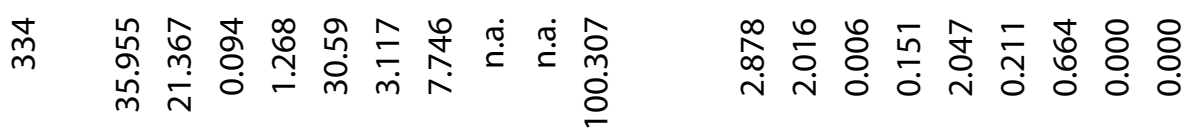

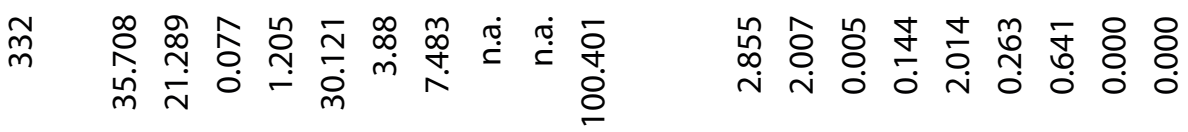

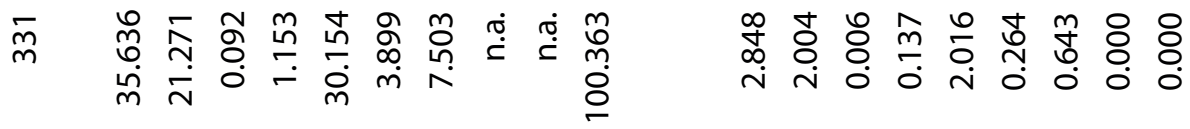

文 总

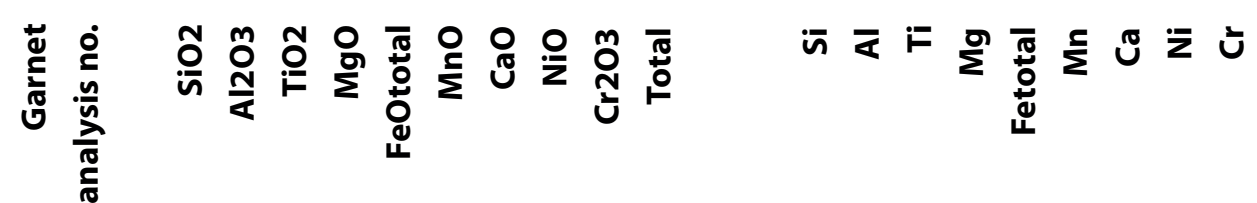




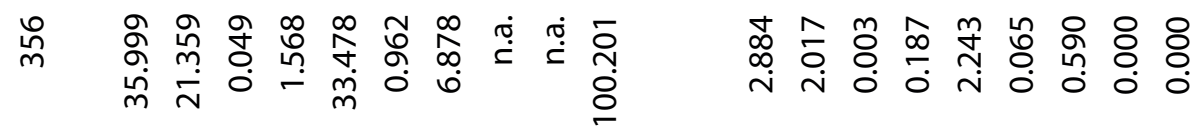

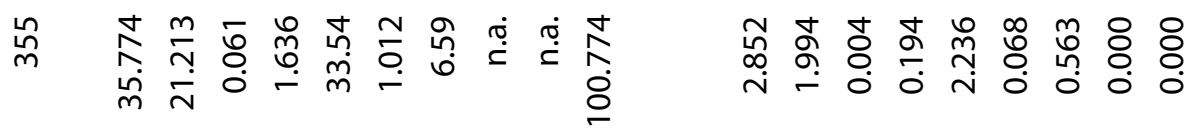

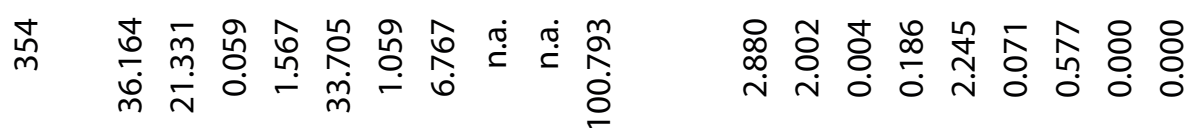

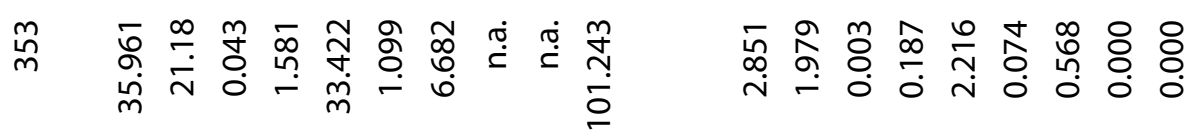

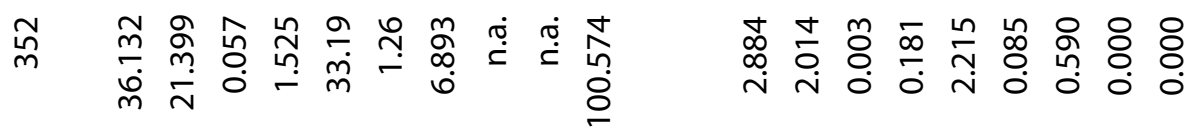

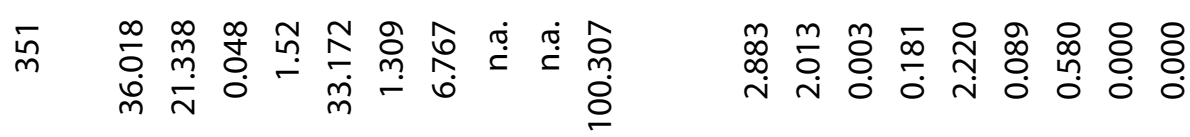

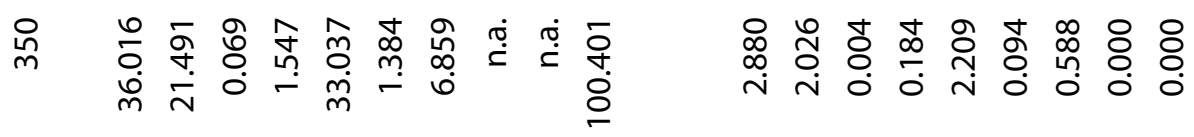

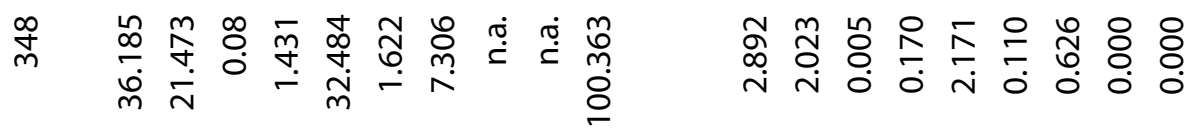

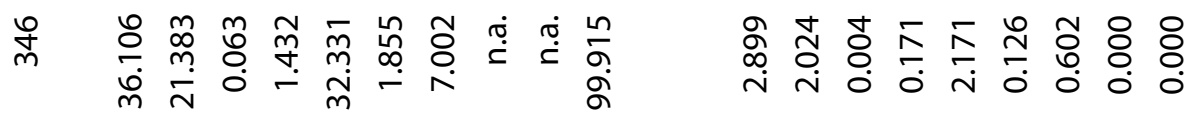

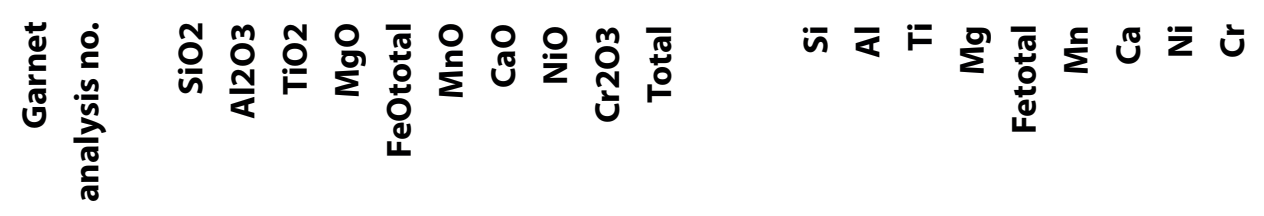




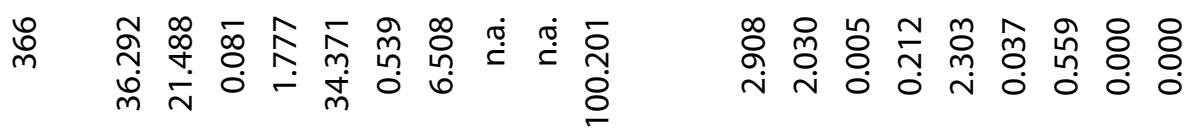

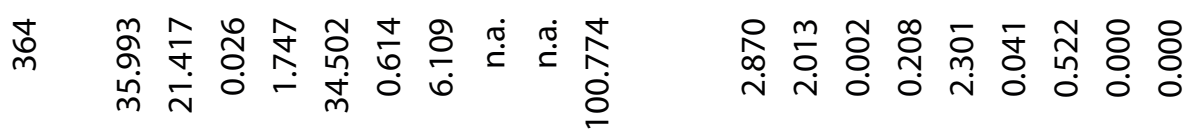

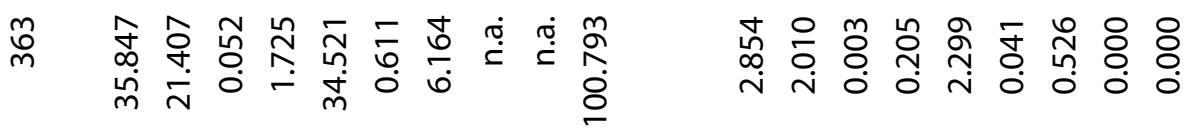

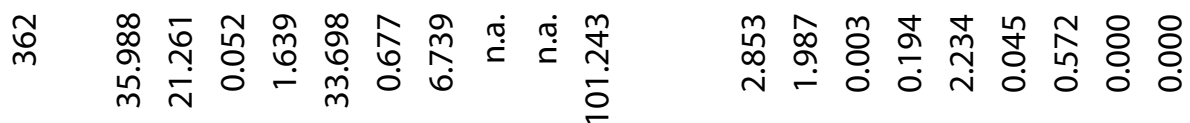

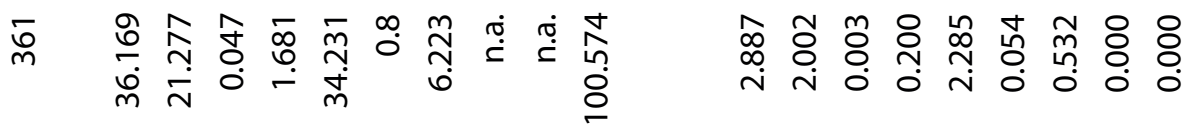

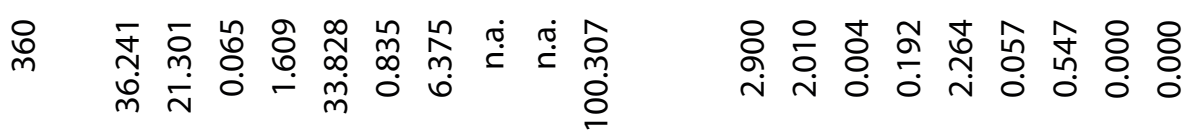

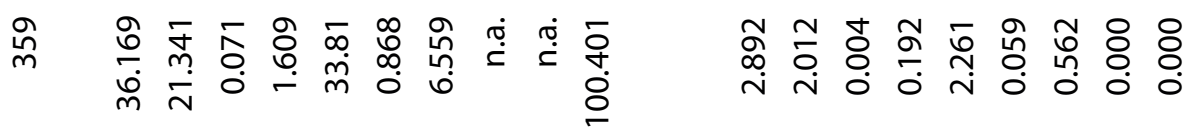

䍚

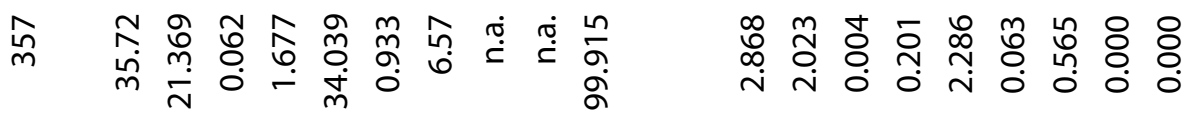

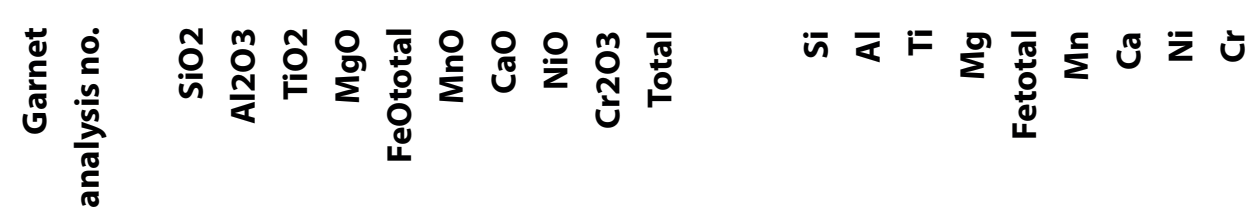




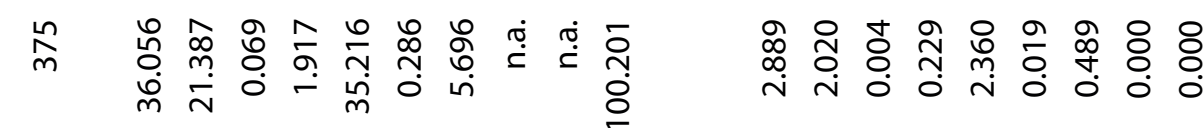

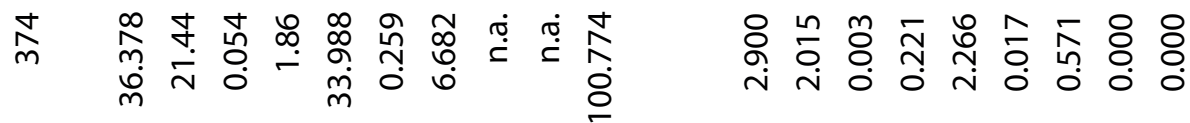

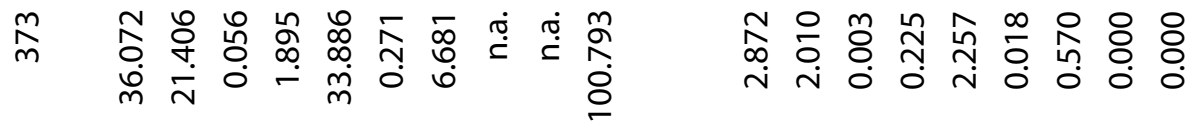

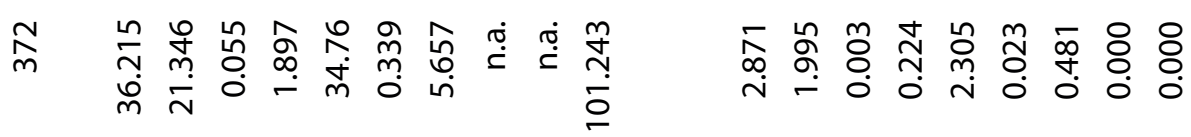

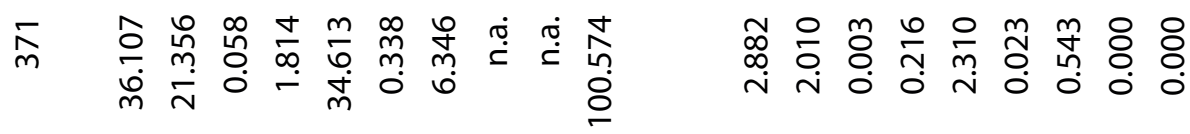

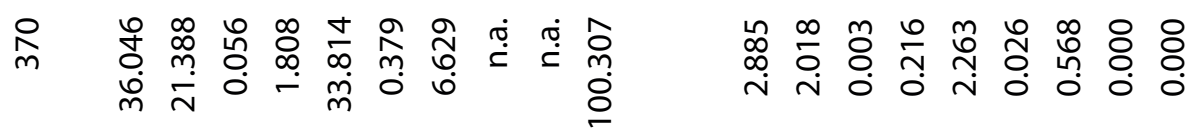

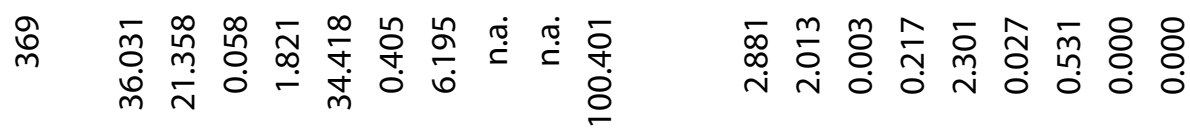

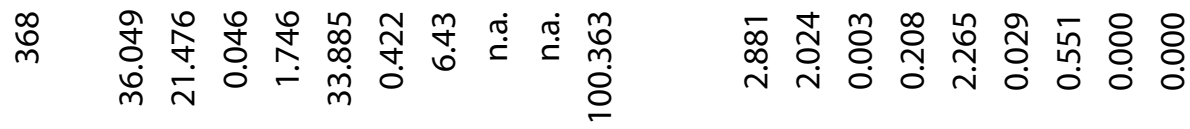

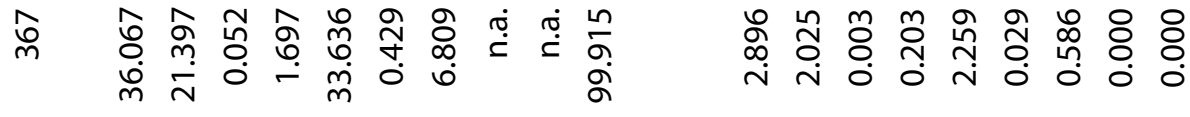

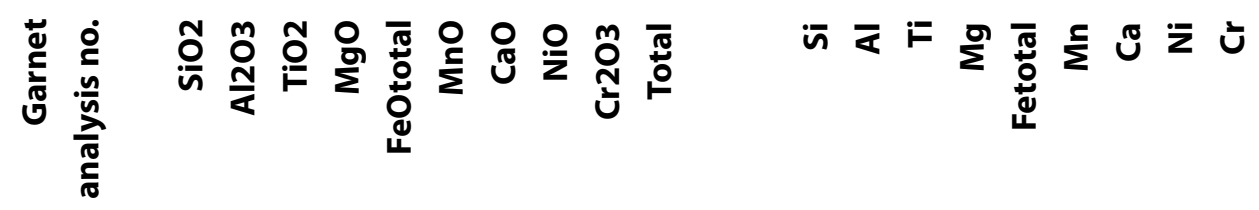




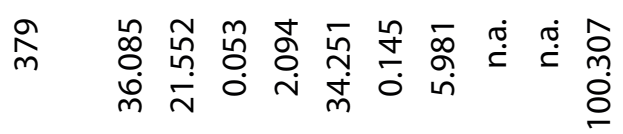

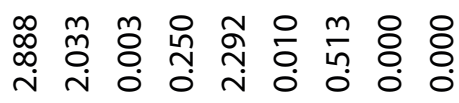

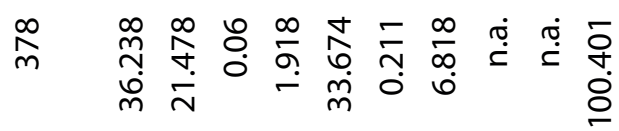

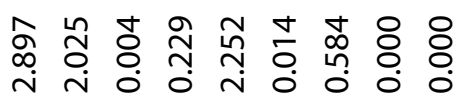

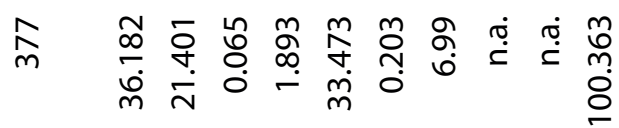

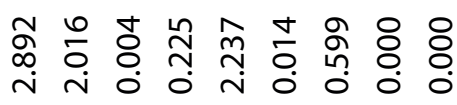

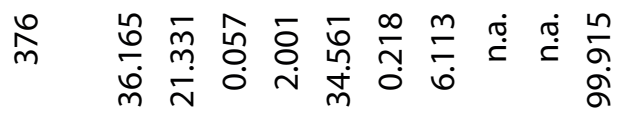

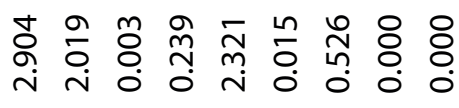

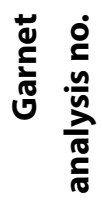

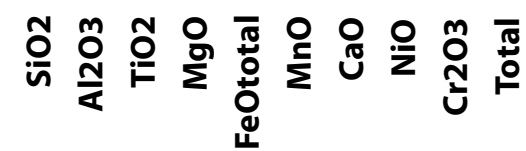

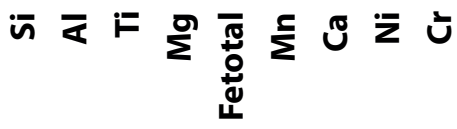




\section{Transitional Zone Tape and Compass}

Tatare Stream True Right

GPS: Start 22833215754105

GPS: Finish 22833655754053

Date: 3/02/06

Time: 9:00 17:00

Geologists: Ben Gillam

Tim Little

Dave Murphy

Layers:

$\begin{array}{lllll}\mathrm{a}=\text { Quartz } & \mathrm{b}=\text { Mica } & \mathrm{c}=\text { Mafic } & \mathrm{d}=\text { Schist } & \text { Tracked } \\ \text { Transect } & \text { Lineation } & \text { Layer Layer Foliation Lineation }\end{array}$

Distance (m) Plunge Direction Type Thick (mm) Strike Dip $T$ P Pitch

\begin{tabular}{|c|c|c|c|c|c|c|c|c|}
\hline 1 & & & & & & & & $15 \mathrm{E}$ \\
\hline 2 & & & & & & & & $13 \mathrm{E}$ \\
\hline 3 & & & & & & & & $17 \mathrm{E}$ \\
\hline 4 & & & & & & & & $12 \mathrm{E}$ \\
\hline 5 & & & & & & & & $18 \mathrm{E}$ \\
\hline 6 & & & & & & & & $10 \mathrm{E}$ \\
\hline 7 & & & & & & & & $17 \mathrm{E}$ \\
\hline 8 & & & & & & & & $11 \mathrm{NE}$ \\
\hline 9 & $3 \mathrm{NE}$ & $a$ & 6 & 54 & 65 & 55 & 3 & $3 E$ \\
\hline 14.1 & $10 \mathrm{NE}$ & $\mathrm{a}$ & 1 & 60 & 62 & 65 & 10 & $11 \mathrm{E}$ \\
\hline 14.3 & $15 \mathrm{NE}$ & $a$ & 6 & & & 68 & 15 & $17 \mathrm{E}$ \\
\hline 14.33 & $12 \mathrm{NE}$ & $\mathrm{a}$ & 5 & & & 66 & 12 & $13 \mathrm{E}$ \\
\hline 14.5 & $13 \mathrm{NE}$ & $a$ & 10 & 60 & 60 & 68 & 13 & $15 \mathrm{E}$ \\
\hline 14.6 & $43 \mathrm{NE}$ & $a$ & 10 & & & 93 & 43 & $52 \mathrm{E}$ \\
\hline 14.61 & $27 \mathrm{NE}$ & $a$ & 10 & & & 77 & 27 & $32 E$ \\
\hline 14.85 & 23 SW & $b$ & 5 & & & 266 & 23 & $9 \mathrm{~W}$ \\
\hline 15.05 & 40 SW & $b$ & & & & 211 & 40 & $48 \mathrm{~W}$ \\
\hline 15.94 & $30 \mathrm{NE}$ & $a$ & 5 & & & 79 & 30 & $35 \mathrm{E}$ \\
\hline 16.25 & $11 \mathrm{NE}$ & $a$ & 10 & & & 66 & 11 & $13 \mathrm{E}$ \\
\hline 17.15 & $22 \mathrm{NE}$ & $a$ & 3 & & & 73 & 22 & $25 \mathrm{E}$ \\
\hline 17.8 & $20 \mathrm{NE}$ & $a$ & 7 & 61 & 65 & 71 & 20 & $22 \mathrm{E}$ \\
\hline 18.03 & $5 \mathrm{SW}$ & $a$ & 4 & 58 & 63 & 235 & 5 & $6 \mathrm{~W}$ \\
\hline 18.05 & 14 NW & $a$ & 1 & & & 231 & 14 & $16 \mathrm{~W}$ \\
\hline 18.08 & $7 \mathrm{NE}$ & $a$ & 5 & & & 62 & 7 & $8 \mathrm{E}$ \\
\hline 19.2 & $11 \mathrm{NE}$ & $a$ & 5 & & & 64 & 11 & $13 \mathrm{E}$ \\
\hline 24.1 & $10 \mathrm{NE}$ & $a$ & 50 & & & 63 & 10 & $11 \mathrm{E}$ \\
\hline 24.9 & & & & 58 & 62 & & & \\
\hline 27.7 & $18 \mathrm{NE}$ & $a$ & 20 & & & 68 & 18 & $21 \mathrm{E}$ \\
\hline 27.75 & $6 \mathrm{NE}$ & & & & & 61 & 6 & $7 E$ \\
\hline 27.75 & $13 \mathrm{NE}$ & $a$ & 3 & & & 65 & 13 & $15 \mathrm{E}$ \\
\hline 28.4 & $13 \mathrm{NE}$ & $a$ & 4 & & & 65 & 13 & \\
\hline
\end{tabular}




\begin{tabular}{|c|c|c|}
\hline & & \\
\hline 28.46 & $2 \mathrm{NE}$ & a \\
\hline 28.46 & $12 \mathrm{NE}$ & \\
\hline 28.56 & $19 \mathrm{NE}$ & a \\
\hline 28.56 & $25 \mathrm{NE}$ & \\
\hline 28.7 & $8 \mathrm{NE}$ & a \\
\hline 28.72 & $18 \mathrm{NE}$ & a \\
\hline 29.15 & $7 \mathrm{SW}$ & a \\
\hline 29.2 & $17 \mathrm{NE}$ & $a$ \\
\hline 29.24 & $18 \mathrm{NE}$ & a \\
\hline 29.25 & $12 \mathrm{NE}$ & $\mathrm{a}$ \\
\hline 29.26 & $13 \mathrm{NE}$ & a \\
\hline 29.27 & $18 \mathrm{NE}$ & a \\
\hline 29.3 & $3 \mathrm{NE}$ & a \\
\hline 29.4 & & \\
\hline 29.45 & $8 \mathrm{NE}$ & $\mathrm{a}$ \\
\hline 29.54 & $5 \mathrm{NE}$ & a \\
\hline 29.55 & $9 \mathrm{NE}$ & a \\
\hline 29.67 & $14 \mathrm{NE}$ & a \\
\hline 29.7 & $1 \mathrm{SW}$ & a \\
\hline 29.8 & $4 \mathrm{NE}$ & a \\
\hline 29.8 & $21 \mathrm{NE}$ & \\
\hline 29.8 & $14 \mathrm{NE}$ & \\
\hline 29.8 & $12 \mathrm{NE}$ & \\
\hline 29.9 & $9 \mathrm{NE}$ & a \\
\hline 29.905 & $1 \mathrm{SW}$ & a \\
\hline 29.915 & $5 \mathrm{NE}$ & \\
\hline 29.915 & $7 \mathrm{SW}$ & \\
\hline 29.915 & $12 \mathrm{NE}$ & a \\
\hline 29.5 & $4 \mathrm{NE}$ & a \\
\hline 29.5 & $47 \mathrm{SW}$ & \\
\hline 29.5 & $2 \mathrm{NE}$ & \\
\hline 29.5 & $47 \mathrm{SW}$ & \\
\hline 30 & $2 \mathrm{SW}$ & C \\
\hline 30.2 & & C \\
\hline 30.25 & $14 \mathrm{NE}$ & d \\
\hline 30.26 & $8 \mathrm{NE}$ & d \\
\hline 30.26 & $18 \mathrm{NE}$ & \\
\hline 31.2 & $18 \mathrm{SW}$ & C \\
\hline 31.2 & $30 \mathrm{SW}$ & \\
\hline 31.2 & 24 SW & \\
\hline 30.21 & $20 \mathrm{NE}$ & a \\
\hline 30.21 & $5 \mathrm{NE}$ & \\
\hline 30.21 & $7 \mathrm{NE}$ & \\
\hline 30.21 & $2 \mathrm{NE}$ & \\
\hline 31.22 & $20 \mathrm{NE}$ & a \\
\hline 31.23 & $16 \mathrm{NE}$ & a \\
\hline
\end{tabular}

\begin{tabular}{|c|c|c|c|c|}
\hline & & 59 & 2 & $2 \mathrm{E}$ \\
\hline & & 64 & 12 & $13 \mathrm{E}$ \\
\hline & & 69 & 19 & $22 \mathrm{E}$ \\
\hline & & 72 & 25 & $28 \mathrm{E}$ \\
\hline 59 & 67 & 62 & 8 & $9 \mathrm{E}$ \\
\hline & & 67 & 18 & $20 \mathrm{E}$ \\
\hline & & 236 & 7 & $8 w$ \\
\hline & & 66 & 17 & $18 \mathrm{E}$ \\
\hline & & 67 & 18 & $20 \mathrm{E}$ \\
\hline & & 64 & 12 & $13 \mathrm{E}$ \\
\hline & & 65 & 13 & $14 \mathrm{E}$ \\
\hline & & 67 & 18 & $20 \mathrm{E}$ \\
\hline 54 & 60 & 60 & 3 & $6 \mathrm{E}$ \\
\hline 52 & 66 & & & \\
\hline & & 59 & 8 & $10 \mathrm{E}$ \\
\hline & & 54 & 5 & $5 \mathrm{E}$ \\
\hline & & 56 & 9 & $10 \mathrm{E}$ \\
\hline & & 58 & 14 & $15 \mathrm{E}$ \\
\hline & & 232 & 1 & $1 \mathrm{~W}$ \\
\hline & & 54 & 4 & $4 \mathrm{E}$ \\
\hline & & 62 & 21 & $23 \mathrm{E}$ \\
\hline & & 58 & 14 & $15 \mathrm{E}$ \\
\hline & & 57 & 12 & $13 \mathrm{E}$ \\
\hline 57 & 56 & 56 & 9 & $7 \mathrm{E}$ \\
\hline & & 232 & 1 & $4 W$ \\
\hline & & 60 & 5 & $6 \mathrm{E}$ \\
\hline & & 232 & 7 & $9 \mathrm{~W}$ \\
\hline & & 65 & 12 & $14 \mathrm{E}$ \\
\hline & & 60 & 4 & $5 \mathrm{E}$ \\
\hline & & 191 & 47 & $62 \mathrm{~W}$ \\
\hline & & 58 & 2 & $2 \mathrm{E}$ \\
\hline & & 191 & 47 & $62 \mathrm{~W}$ \\
\hline & & 236 & 2 & $2 W$ \\
\hline 63 & 62 & 67 & 14 & $14 \mathrm{E}$ \\
\hline & & 62 & 8 & $7 \mathrm{E}$ \\
\hline & & 70 & 18 & $19 \mathrm{E}$ \\
\hline 58 & 57 & 233 & 18 & $18 \mathrm{~W}$ \\
\hline & & 225 & 30 & $32 \mathrm{~W}$ \\
\hline & & 229 & 24 & $25 \mathrm{~W}$ \\
\hline & & 72 & 20 & $24 \mathrm{E}$ \\
\hline & & 61 & 5 & $6 \mathrm{E}$ \\
\hline & & 63 & 7 & $9 \mathrm{E}$ \\
\hline & & 59 & 2 & $2 \mathrm{E}$ \\
\hline & & 72 & 20 & $24 \mathrm{E}$ \\
\hline & & 69 & 16 & $19 \mathrm{E}$ \\
\hline
\end{tabular}

Gillam, B. G. 


\begin{tabular}{|c|c|c|c|c|c|c|c|c|}
\hline 31.26 & $26 \mathrm{NE}$ & a & 2 & & & 76 & 26 & $31 \mathrm{E}$ \\
\hline 31.28 & $78 \mathrm{SW}$ & $\mathrm{a}$ & 2 & & & & 78 & \\
\hline 31.285 & 82 SW & $a$ & & & & & 82 & \\
\hline 31.29 & $71 \mathrm{NE}$ & $a$ & 2 & & & & 71 & \\
\hline 31.29 & $68 \mathrm{NE}$ & & & & & & 68 & \\
\hline 31.29 & $81 \mathrm{NE}$ & & & & & & 81 & \\
\hline 33.8 & $9 \mathrm{NE}$ & $a$ & 1 & & & 64 & 9 & $11 \mathrm{E}$ \\
\hline 33.82 & $15 \mathrm{NE}$ & $a$ & 2 & & & 68 & 15 & $18 \mathrm{E}$ \\
\hline 34.4 & $20 \mathrm{NE}$ & $a$ & 27 & 60 & 62 & 72 & 20 & $23 \mathrm{E}$ \\
\hline 34.4 & $5 \mathrm{NE}$ & & & & & 61 & 5 & $5 \mathrm{E}$ \\
\hline 34.45 & $36 \mathrm{NE}$ & a & 3 & & & 86 & 36 & $43 \mathrm{E}$ \\
\hline 34.45 & $11 \mathrm{NE}$ & & & & & 61 & 11 & $10 \mathrm{E}$ \\
\hline 34.8 & 0 & $a$ & 1 & & & 86 & 0 & $13 \mathrm{E}$ \\
\hline 34.8 & $16 \mathrm{NE}$ & & & & & 66 & 16 & $17 \mathrm{E}$ \\
\hline 34.81 & $5 \mathrm{NE}$ & $\mathrm{a}$ & 2 & & & 60 & 5 & $4 \mathrm{E}$ \\
\hline 34.81 & $7 \mathrm{SW}$ & & & & & 236 & 7 & $8 \mathrm{~W}$ \\
\hline 34.83 & $18 \mathrm{NE}$ & $a$ & & & & 63 & 18 & $17 \mathrm{E}$ \\
\hline 34.83 & $16 \mathrm{NE}$ & & & & & 69 & 16 & $18 \mathrm{E}$ \\
\hline 35.4 & $20 \mathrm{NE}$ & $a$ & 2 & & & 70 & 20 & $22 \mathrm{E}$ \\
\hline 35.4 & $25 \mathrm{NE}$ & & & & & 69 & 25 & $26 \mathrm{E}$ \\
\hline 35.58 & $15 \mathrm{NE}$ & $a$ & 1 & & & 71 & 15 & $18 \mathrm{E}$ \\
\hline 35.59 & $14 \mathrm{NE}$ & $a$ & 2 & & & 74 & 14 & $19 \mathrm{E}$ \\
\hline 35.595 & $9 \mathrm{NE}$ & $a$ & 5 & & & 68 & 9 & $12 \mathrm{E}$ \\
\hline 35.65 & $15 \mathrm{NE}$ & $a$ & 3 & & & 68 & 15 & $17 \mathrm{E}$ \\
\hline 35.75 & $6 \mathrm{NE}$ & $a$ & 2 & & & 65 & 6 & $8 \mathrm{E}$ \\
\hline 35.78 & $10 \mathrm{NE}$ & $a$ & 5 & & & 68 & 10 & $13 \mathrm{E}$ \\
\hline 35.8 & $16 \mathrm{NE}$ & $a$ & 1 & & & 63 & 16 & $16 \mathrm{E}$ \\
\hline 36.1 & $12 \mathrm{NE}$ & $a$ & 2 & & & 65 & 12 & $13 \mathrm{E}$ \\
\hline 36.12 & $19 \mathrm{NE}$ & $a$ & 3 & 58 & 64 & 69 & 19 & $22 \mathrm{E}$ \\
\hline 36.16 & $11 \mathrm{NE}$ & $\mathrm{a}$ & 1 & & & 66 & 11 & $13 \mathrm{E}$ \\
\hline 36.23 & $5 \mathrm{NE}$ & $a$ & 5 & & & 71 & 5 & $10 \mathrm{E}$ \\
\hline 37.47 & $44 \mathrm{SW}$ & $\mathrm{b}$ & 2 & & & 210 & 44 & $51 \mathrm{~W}$ \\
\hline 37.5 & $3 \mathrm{NW}$ & $a$ & 2 & & & 63 & 3 & $5 \mathrm{E}$ \\
\hline 37.53 & $13 \mathrm{NE}$ & $a$ & 4 & & & 66 & 13 & $15 \mathrm{E}$ \\
\hline 37.53 & $2 \mathrm{SW}$ & & & & & 237 & 2 & $2 W$ \\
\hline 37.53 & $7 \mathrm{NE}$ & & & & & 64 & 7 & $9 \mathrm{E}$ \\
\hline 33.555 & $12 \mathrm{NE}$ & $a$ & 2 & 58 & 64 & 66 & 12 & $14 \mathrm{E}$ \\
\hline 33.555 & $15 \mathrm{NE}$ & & & & & 61 & 15 & $15 \mathrm{E}$ \\
\hline 37.62 & $10 \mathrm{SW}$ & $a$ & 2 & & & 233 & 10 & $11 \mathrm{~W}$ \\
\hline 37.62 & $10 \mathrm{NE}$ & & & & & 66 & 10 & $12 \mathrm{E}$ \\
\hline 37.62 & $2 \mathrm{NE}$ & & & & & 63 & 2 & $4 \mathrm{E}$ \\
\hline 38.7 & $16 \mathrm{NE}$ & $a$ & 2 & & & 59 & 16 & $15 \mathrm{E}$ \\
\hline 38.82 & $21 \mathrm{NE}$ & $a$ & 1 & & & 66 & 21 & $22 \mathrm{E}$ \\
\hline 38.821 & $23 \mathrm{NE}$ & $a$ & 1 & & & 69 & 23 & $25 \mathrm{E}$ \\
\hline 38.822 & $22 \mathrm{NE}$ & $a$ & 1 & & & 69 & 22 & $24 \mathrm{E}$ \\
\hline 38.823 & $10 \mathrm{NE}$ & $a$ & 1 & & & 63 & 10 & $11 \mathrm{E}$ \\
\hline
\end{tabular}

Gillam, B. G. 


\begin{tabular}{|c|c|c|c|c|c|c|c|c|}
\hline 38.828 & $15 \mathrm{NE}$ & $a$ & 5 & & & 66 & 15 & $17 \mathrm{E}$ \\
\hline 38.829 & $28 \mathrm{NE}$ & $\mathrm{a}$ & 1 & 59 & 69 & 73 & 28 & $31 \mathrm{E}$ \\
\hline 38.83 & $10 \mathrm{NE}$ & $\mathrm{a}$ & 1 & & & 66 & 10 & $12 \mathrm{E}$ \\
\hline 38.84 & $15 \mathrm{NE}$ & $\mathrm{a}$ & 5 & & & 66 & 15 & $16 \mathrm{E}$ \\
\hline 38.84 & $6 \mathrm{SW}$ & & & & & 237 & 6 & $6 \mathrm{~W}$ \\
\hline 38.84 & $18 \mathrm{NE}$ & & & & & 66 & 18 & $19 \mathrm{E}$ \\
\hline 38.842 & $15 \mathrm{NE}$ & $a$ & 2 & & & 65 & 15 & $16 \mathrm{E}$ \\
\hline 40.5 & $5 \mathrm{NE}$ & $\mathrm{a}$ & 5 & & & 61 & 5 & $5 \mathrm{E}$ \\
\hline 46.6 & $25 \mathrm{NE}$ & $a$ & 10 & & & 69 & 25 & $27 \mathrm{E}$ \\
\hline 46.6 & $36 \mathrm{NE}$ & & & & & 75 & 36 & $39 \mathrm{E}$ \\
\hline 46.6 & $50 \mathrm{NE}$ & & & & & 86 & 50 & $55 \mathrm{E}$ \\
\hline 47.87 & $2 \mathrm{NE}$ & $a$ & 2 & & & 60 & 2 & $2 \mathrm{E}$ \\
\hline 47.87 & $3 \mathrm{NE}$ & & & & & 60 & 3 & $3 E$ \\
\hline 47.9 & 19 SW & $a$ & 6 & 55 & 60 & 231 & 19 & $18 \mathrm{~W}$ \\
\hline 47.915 & $12 \mathrm{SW}$ & $a$ & 15 & & & 234 & 12 & $11 \mathrm{~W}$ \\
\hline 48.06 & $13 \mathrm{SW}$ & $a$ & 4 & 59 & 68 & 234 & 13 & $14 \mathrm{~W}$ \\
\hline 48.063 & $6 \mathrm{NE}$ & $\mathrm{a}$ & 1 & & & 58 & 6 & $5 \mathrm{E}$ \\
\hline 52.7 & $15 \mathrm{NE}$ & $a$ & 1 & 87 & 70 & 64 & 15 & $7 \mathrm{E}$ \\
\hline 52.72 & $11 \mathrm{NE}$ & $a$ & 3 & & & 64 & 11 & $3 E$ \\
\hline 53.4 & $26 \mathrm{NE}$ & $a$ & 5 & & & 70 & 26 & $21 \mathrm{E}$ \\
\hline 53.4 & $45 \mathrm{NE}$ & & & & & 108 & 45 & $49 \mathrm{E}$ \\
\hline 53.9 & $32 \mathrm{sW}$ & $a$ & 5 & 54 & 70 & 254 & 32 & $27 \mathrm{~W}$ \\
\hline 53.9 & $15 \mathrm{SW}$ & & & & & 261 & 15 & $6 \mathrm{~W}$ \\
\hline 53.901 & $21 \mathrm{NE}$ & $a$ & 3 & & & 95 & 21 & $38 \mathrm{E}$ \\
\hline 53.901 & $10 \mathrm{NE}$ & & & & & 58 & 10 & $11 \mathrm{E}$ \\
\hline 53.903 & $21 \mathrm{NE}$ & $a$ & 1 & & & 62 & 21 & $22 \mathrm{E}$ \\
\hline 53.903 & $10 \mathrm{NE}$ & & & & & 58 & 10 & $11 \mathrm{E}$ \\
\hline 53.97 & $20 \mathrm{NE}$ & $a$ & 2 & & & 62 & 20 & $21 \mathrm{E}$ \\
\hline 55.8 & $2 \mathrm{NE}$ & $a$ & 2 & & & 55 & 2 & $2 \mathrm{E}$ \\
\hline 55.8 & $2 \mathrm{SW}$ & & & & & 233 & 2 & $2 W$ \\
\hline 55.8 & $16 \mathrm{SW}$ & & & & & 228 & 16 & $17 \mathrm{~W}$ \\
\hline 55.805 & 19 SW & $a$ & 3 & & & 227 & 19 & $20 \mathrm{~W}$ \\
\hline 55.808 & $4 \mathrm{SW}$ & $a$ & 2 & & & 233 & 4 & $4 W$ \\
\hline 55.83 & $19 \mathrm{NE}$ & & & & & 61 & 19 & $20 \mathrm{E}$ \\
\hline 55.83 & $5 \mathrm{NE}$ & $a$ & 4 & & & 56 & 5 & $5 \mathrm{E}$ \\
\hline 55.9 & $12 \mathrm{NE}$ & $a$ & 1 & & & 58 & 12 & $13 \mathrm{E}$ \\
\hline 55.9 & $9 \mathrm{NE}$ & & & & & 57 & 9 & $9 \mathrm{E}$ \\
\hline 56.35 & $8 \mathrm{NE}$ & $a$ & 1 & 57 & 70 & 57 & 8 & $8 \mathrm{E}$ \\
\hline 56.35 & $12 \mathrm{NE}$ & & & & & 58 & 12 & $12 \mathrm{E}$ \\
\hline 56.36 & $10 \mathrm{NE}$ & $a$ & 2 & & & 58 & 10 & $10 \mathrm{E}$ \\
\hline 56.363 & $2 \mathrm{NE}$ & $a$ & 5 & & & 58 & 2 & $2 E$ \\
\hline 56.368 & $10 \mathrm{NE}$ & $a$ & 3 & & & 61 & 10 & $11 \mathrm{E}$ \\
\hline 56.368 & $17 \mathrm{NE}$ & & & & & 63 & 17 & $18 \mathrm{E}$ \\
\hline 56.368 & $41 \mathrm{NE}$ & & & & & 75 & 41 & $44 \mathrm{E}$ \\
\hline 56.368 & $47 \mathrm{NE}$ & & & & & 80 & 47 & $51 \mathrm{E}$ \\
\hline 56.368 & $46 \mathrm{NE}$ & & & & & 79 & 46 & $50 \mathrm{E}$ \\
\hline
\end{tabular}




\begin{tabular}{|c|c|c|}
\hline 56.368 & $44 \mathrm{NE}$ & \\
\hline 56.39 & $14 \mathrm{NE}$ & $b$ \\
\hline 56.4 & $31 \mathrm{NE}$ & $b$ \\
\hline 56.45 & $8 \mathrm{NE}$ & a \\
\hline 56.53 & $55 \mathrm{SW}$ & a \\
\hline 56.53 & $45 \mathrm{SW}$ & \\
\hline 56.53 & $36 \mathrm{SW}$ & \\
\hline 56.61 & $41 \mathrm{SW}$ & a \\
\hline 56.61 & $40 \mathrm{SW}$ & \\
\hline 56.63 & $45 \mathrm{NE}$ & a \\
\hline 56.63 & $40 \mathrm{NE}$ & \\
\hline 57 & & \\
\hline 58 & & \\
\hline 59 & & \\
\hline 60 & & \\
\hline 61 & & \\
\hline 62 & & \\
\hline 63 & & \\
\hline 64 & & \\
\hline 65 & & \\
\hline
\end{tabular}

$\begin{array}{rrrr}78 & 44 & 48 \mathrm{E} \\ 62 & 14 & 15 \mathrm{E} \\ 70 & 31 & 33 \mathrm{E} \\ 60 & 8 & 9 \mathrm{E} \\ 206 & 55 & 61 \mathrm{~W} \\ 216 & 45 & 49 \mathrm{~W} \\ 222 & 36 & 39 \mathrm{~W} \\ 219 & 41 & 44 \mathrm{~W} \\ 219 & 40 & 43 \mathrm{~W} \\ 78 & 45 & 49 \mathrm{E} \\ 75 & 40 & 43 \mathrm{E} \\ & & 24 \mathrm{SW} \\ & & 21 \mathrm{~W} \\ & & 21 \mathrm{~W} \\ & & 27 \mathrm{~W} \\ & & 27 \mathrm{~W} \\ & & 29 \mathrm{~W} \\ & & 33 \mathrm{~W} \\ & & 30 \mathrm{~W}\end{array}$

Gillam, B. G. 
Modelling the stretching of the schist lineations. Matlab code can be avaliable on request.

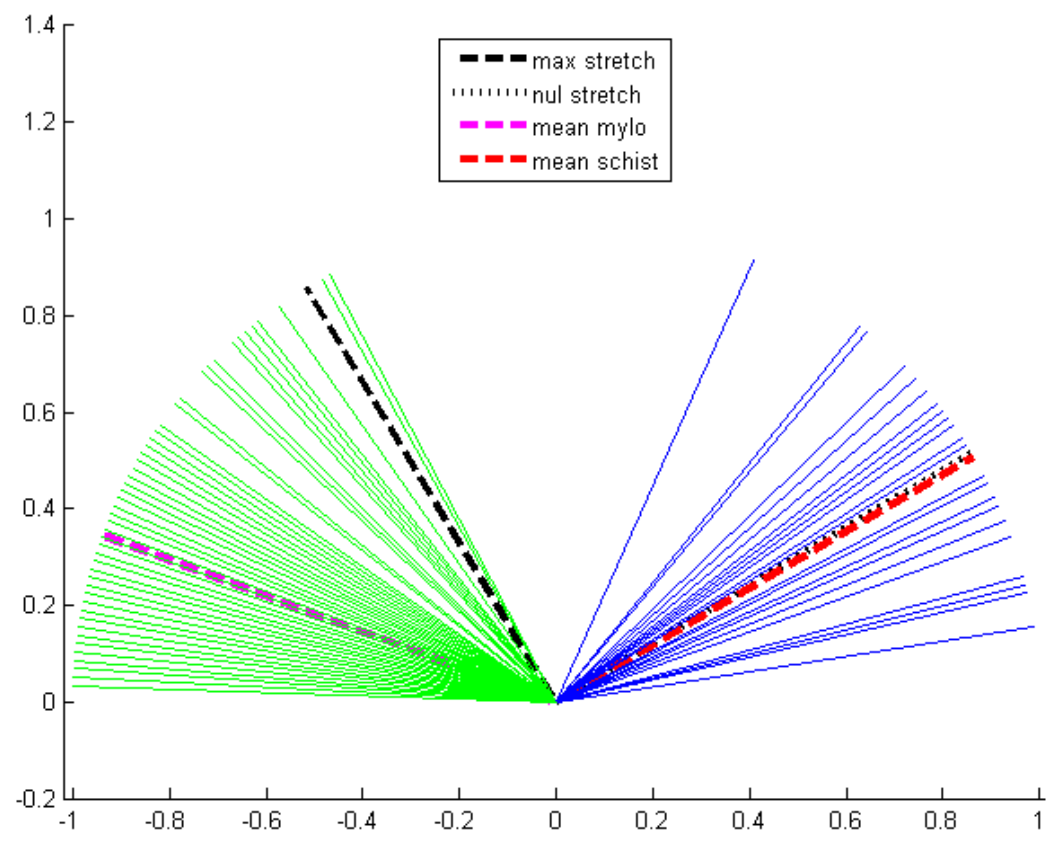

Fig 1. Distribution of schist (blue) and mylonite (green) data, together with their mean directions and the direction of maximum stretch, assuming a null stretch direction of 59 degrees. 


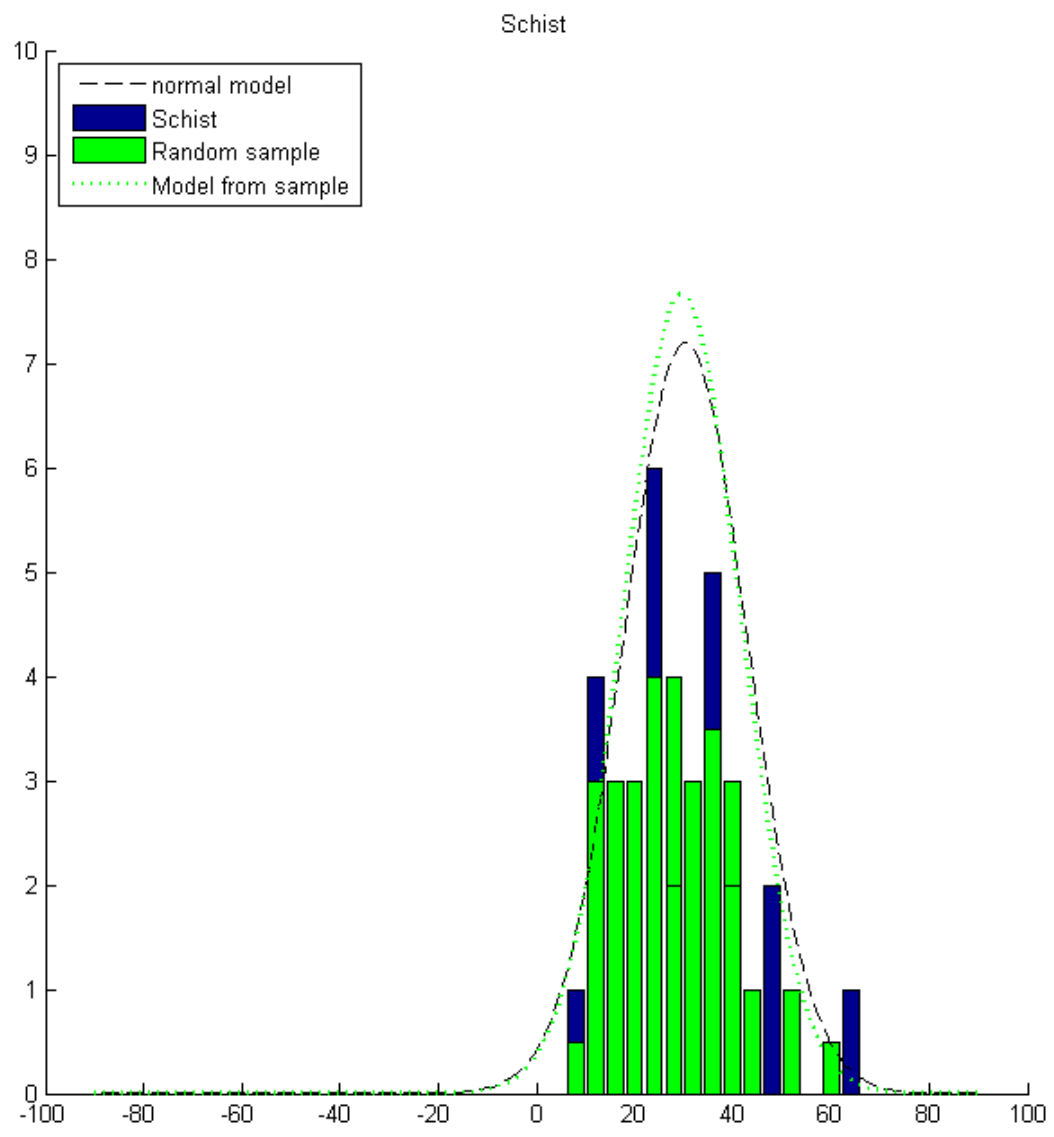

Fig. 2. Histogram of schist directions (blue; $\mathrm{N}=30$ ) and representation by a Von Mises distribution (e.g. Wikipedia http://en.wikipedia.org/wiki/Von_Mises_distribution ) with the same mean as the data and a best-fitting width parameter $\mathrm{K}=20.66$ (blue dashed; standard deviation approximately $1 / \sqrt{ } \mathrm{K})$. The green histogram is a random sample $(\mathrm{N}=60)$ drawn from a Normal approximation to the Von Mieses distribution (green dashed; $\mathrm{K}=$ 23.33). 


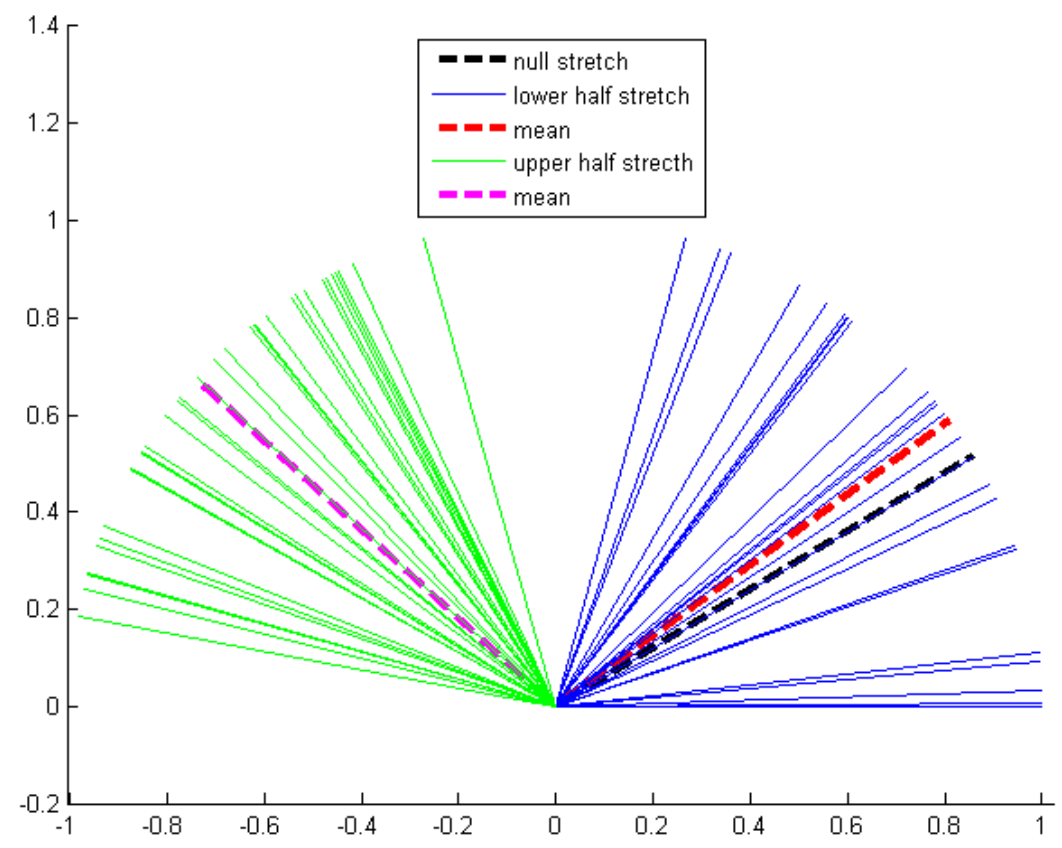

Fig. 3. The results of stretching, 6-fold, the random sample from Fig. 2. The stretched sample is divided into those in the first quadrant (blue; mean red) and those stretched into the fourth quadrant, which are plotted in the second quadrant (green; mean magenta). The distributions are qualitatively similar to those in Fig. 1. 


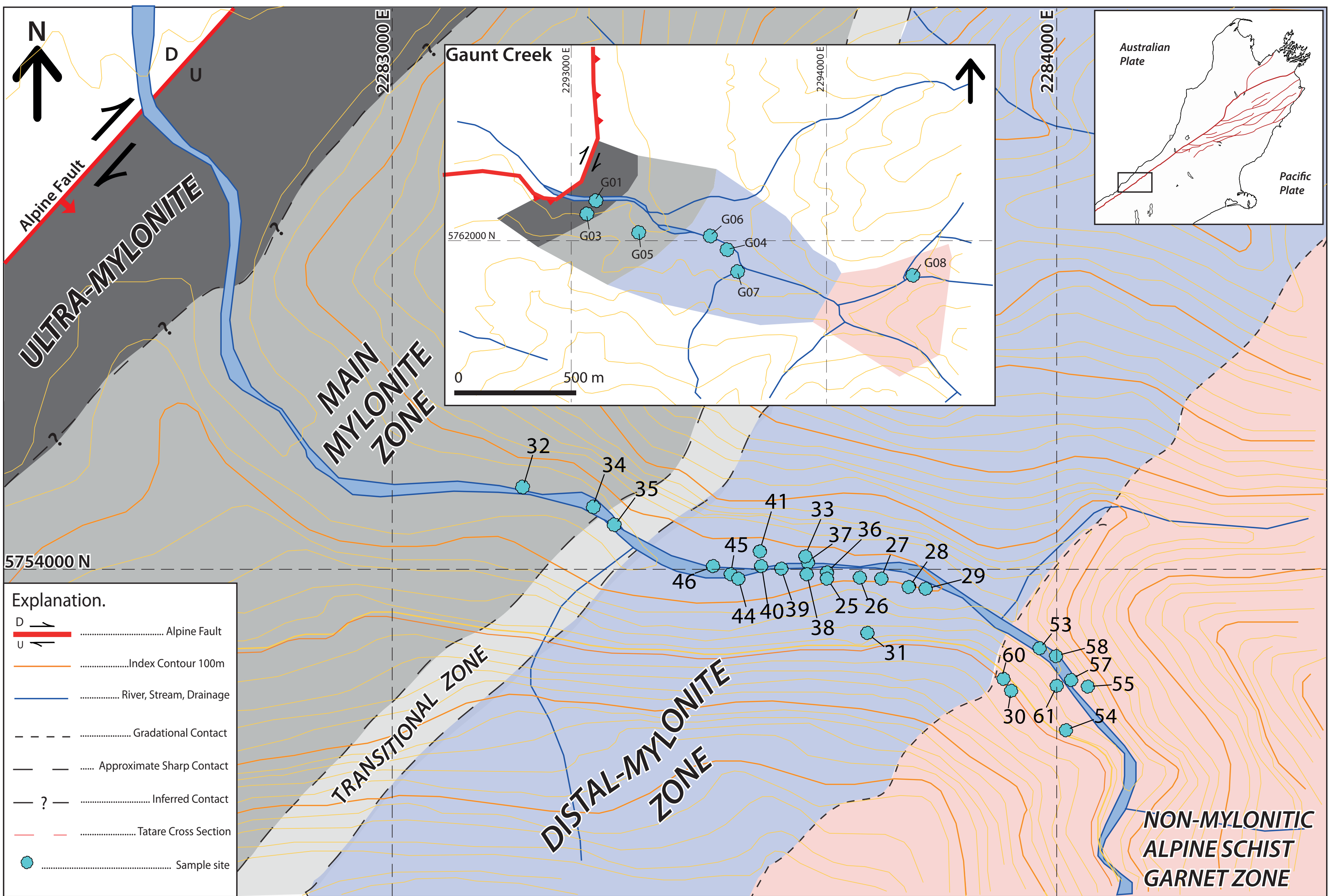

Plate 1: Geological map of Tatare Stream: Sample locations.

Plate 1. Location of Alpine Fault from Norris \& Cooper (1995). Sample locations from both the 2009 and 2010 field seasons. Gaunt Creek geol- 


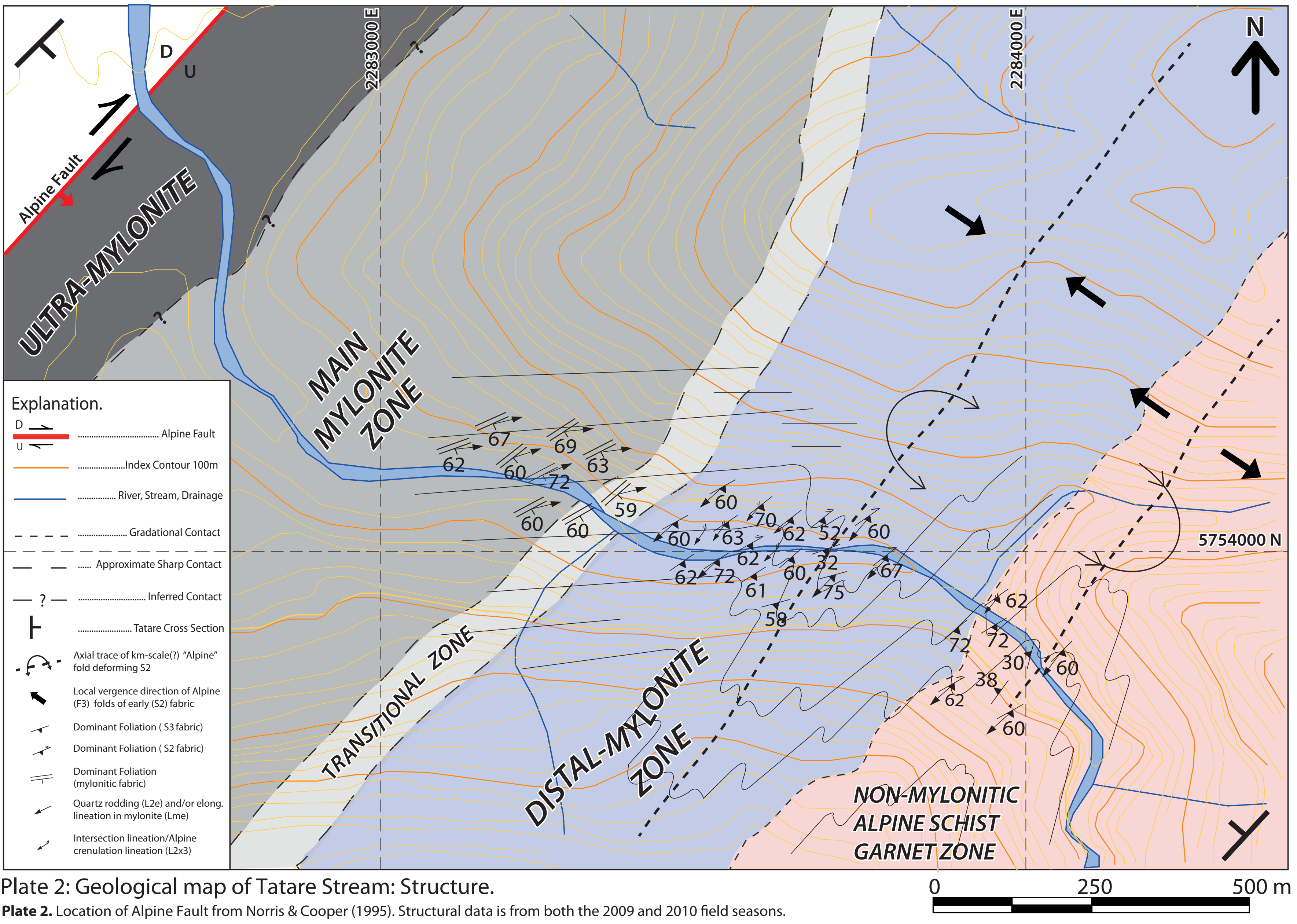

Plate 2. Location of Alpine Fault from Norris \& Cooper (1995). Structural data is from both the 2009 and 2010 field seasons. 


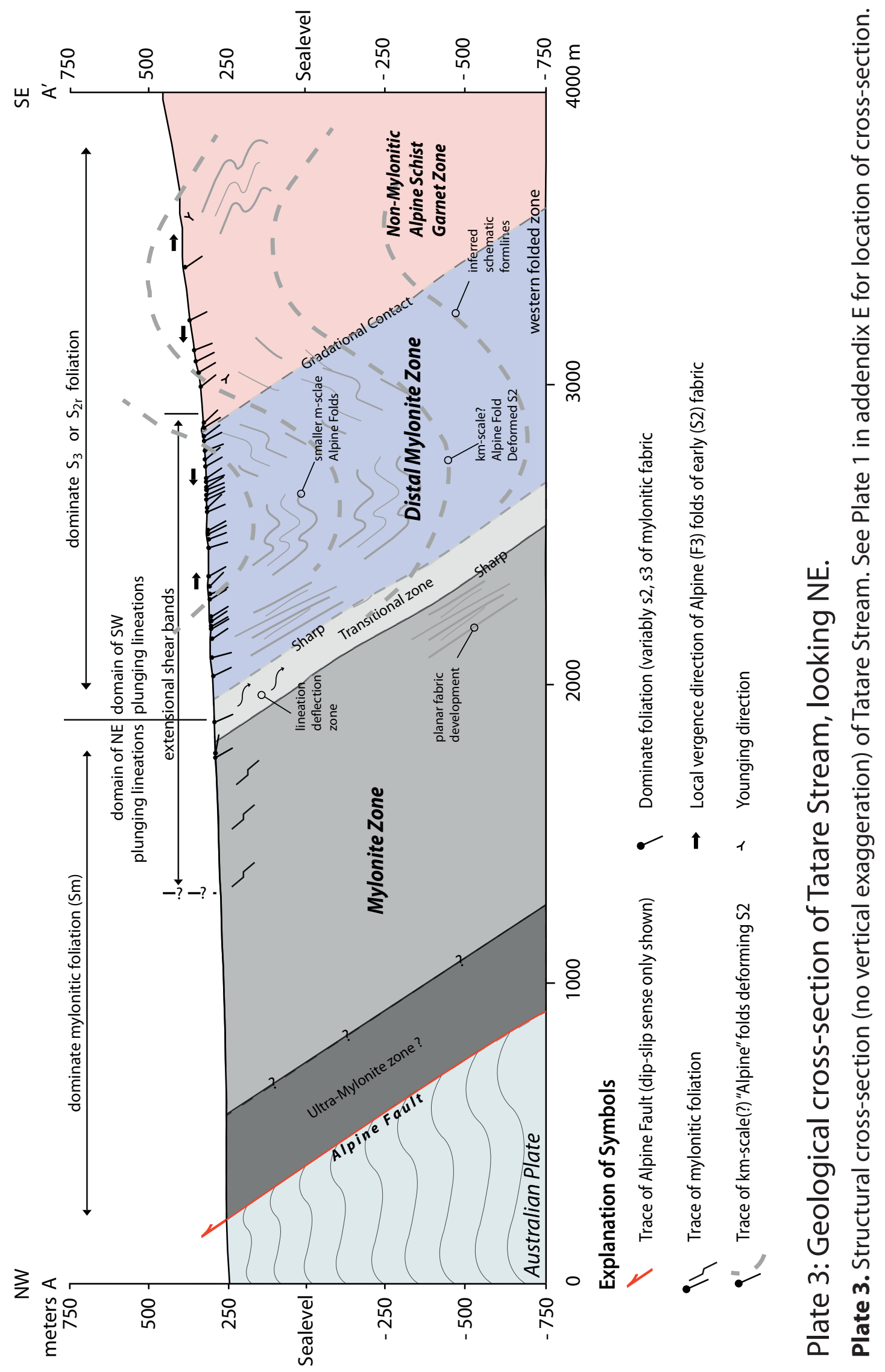

